Portland State University

PDXScholar

$5-24-2019$

\title{
Isoprene Emission in Polytrichaceae Mosses
}

Timea Deakova

Portland State University

Follow this and additional works at: https://pdxscholar.library.pdx.edu/open_access_etds

Part of the Biology Commons, and the Botany Commons Let us know how access to this document benefits you.

\section{Recommended Citation}

Deakova, Timea, "Isoprene Emission in Polytrichaceae Mosses" (2019). Dissertations and Theses. Paper 4984.

https://doi.org/10.15760/etd.6860

This Dissertation is brought to you for free and open access. It has been accepted for inclusion in Dissertations and Theses by an authorized administrator of PDXScholar. Please contact us if we can make this document more accessible: pdxscholar@pdx.edu. 
Isoprene Emission in Polytrichaceae Mosses

by

Timea Deakova

A dissertation submitted in partial fulfillment of the requirements for the degree of

Doctor of Philosophy

in

Biology

Dissertation Committee:

Sarah Eppley, Chair

Todd Rosenstiel, Co-Chair

Daniel Ballhorn

Andrew Rice

Erin Shortlidge

Portland State University

2019 
(C) 2019 Timea Deakova 


\begin{abstract}
Our first aim was to identify and quantify Biological Volatile Organic Compound (BVOC) emissions, specifically emissions of isoprene, from the moss Polytrichum juniperinum during its earliest stage of life. Isoprene emission from mosses could be a significant component of the total global budget of BVOC emissions. Data concerning the spatial and temporal variability of these emissions are lacking due to poor characterization of the physical and biological factors controlling isoprene synthesis in both vascular and non-vascular plants. We found that $P$. juniperinum in its early life stage (protonema) can emit isoprene at detectable levels at day five after spore germination. These results suggest that protonema is capable of isoprene emission, shown here for the first time, and media affects emission rates. We saw a negative trend with leaf emergence and protonema growth. Chlorophyll fluorescence ratio had a positive correlation with isoprene emission, and isoprene emission was both temperature and light dependent in early protonema.
\end{abstract}

Our second aim was to determine the effects of sex and sexual expression on isoprene emission in mosses. Sex is a biologically costly, but it can result in genetic adaptability and variety for resulting offspring. Using three Polytrichaceae species, we measured isoprene emission between plants sexually expressing and non-expressing and between male and female moss plants. We found that non-sexually expressing gametophytes had significantly higher isoprene emission than gametophytes expressing sex, suggesting that sex expression may be costly and that additional resources are 
allocated to isoprene emission when plants are not reproducing. Males emitted higher levels of isoprene than females, but surprisingly this difference occurred only when plants were not expressing sex. We found species and sex-specific differences in chlorophyll fluorescence ratio (CFR) and relative electron transport rate (RETR).

Our third aim was to investigate and categorize the effect of nitrogen addition on isoprene emission of $P$. juniperinum by creating an artificial nitrogen gradient with ammonium nitrate addition $\left(\mathrm{NH}_{4} \mathrm{NO}_{3}\right)$. Current rates of anthropogenic $\mathrm{N}$ deposition are altering many biogeochemical processes. In these changing environments, increased nitrogen availability alters plant phenology, physiology, and the allocation of resources, but no information is available on whether additional $\mathrm{N}$ increases isoprene emissions in mosses. We used a manipulative experiment to measure the effects of nitrogen addition on moss isoprene emission, as well as on moss morphology and reproductive effort. We found site-specific differences in our morphological and physiological measurements. Isoprene emission was site, sex, and $\mathrm{N}$ addition specific, with the highest isoprene emission seen from our mid-level $\mathrm{N}$ addition, in both female- and male-majority pots. We found significant treatment and sex-specific interactions among our sites and within sites. We saw the highest reproductive effort counts from non-sexual expressive gametophytes, followed by high sporophyte count from female-majority pots. We also saw chlorophyll fluorescence ratio (CFR) differences between sites and treatments, but not between sexes. 


\section{Acknowledgements}

I am extremely grateful for the advice, assistance, and encouragement I received from all my friends and colleagues during my graduate work. I was able to accomplish far more than I could have on my own. Undertaking this $\mathrm{PhD}$ has been a great life experience for me, and it would have been impossible to accomplish without the support and advice I received from many people. I would like first to thank my supervisor Dr. Sarah Eppley for her patience, mentorship for lending an ear to the many concerns and for the support, she provided me during this period. Her understanding and positive attitude was an important motivation for me to pursue my doctoral degree and I feel very fortunate to have had the opportunity to work with her support. I am also thankful to Dr. Rosenstiel; he introduced me to the wonderful world of mosses and gave me the opportunity to join his lab to explore them. I am grateful that he provided the insight I needed to explore isoprene emission in mosses. I also extend my thanks to my committee members, who have helped me reach the completion of this stage in my journey through academia with support and advice.

Special thanks also to my friends and fellow lab mates and collaborators especially for their advice and friendship and support inside and outside the lab. They created a pleasant working environment that kept me motivated during my $\mathrm{PhD}$ while lending an ear to the inevitable gripes about the difficulties always experienced in the search for knowledge. I am especially thankful for Scott Kiel and his expertise in showing me the ropes in running the reduced gas analyzer. Thank you for sharing a passion of science with me. Thank you Scott! 
I would like to say heartfelt thanks to my family especially my children Annika and Mika, who have understood the long hours I have been working during their young lives. I am very thankful for my mother-in-law supported me taking care of my children when I was attending school. I would also like to thank my mother who has both supported me financially and emotionally through having children and going to school.

I would like to thank my husband who was the first to show me how exciting science really is, how beautiful and elegant it can be, for sharing his sense of wonder at discovery a feeling that inspired hope, a hope that allowed me to summon my own strength to see this through. He was the first to believe in me, the first to recognize my abilities. I am thankful for his endless support in achieving my academic goals in his unflagging ability to convince me that all of this was possible even when I was not sure it was. Thank you, Doug, for your vision, energy, enthusiasm support in all the steps of my $\mathrm{PhD}$.

This work was funded by the National Science Foundation (NSF GRFP) Biological Science Grant 2015. Proposal Title: Moss Volatile Emissions: The role of BVOC in non-flowering sexual systems. I am extremely grateful to be awarded the NSF GRFP fund and without this award I would not have been able to complete my work. I want to thank additional funding from Sigma Xi, the American Association for the Advancement of Science Pacific Division. Lastly, I would also like to thank the ForbesLea research award and the Botanical Society Award that helped me get started on my initial data collection. 


\section{Table of Contents}

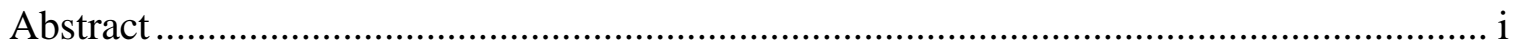

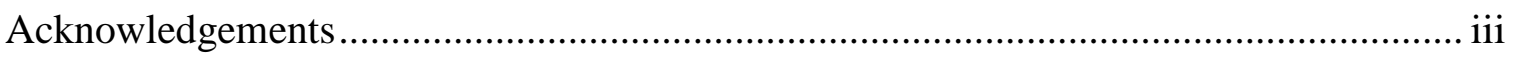

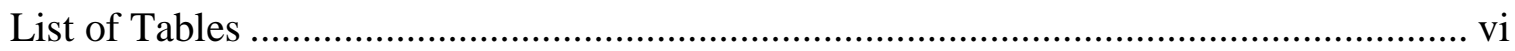

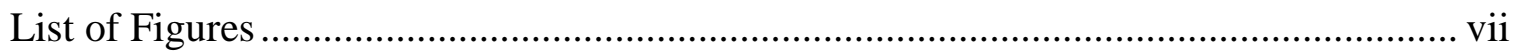

\section{Chapter 1}

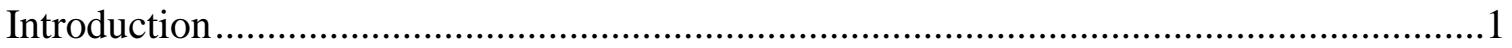

\section{Chapter 2}

Isoprene emission from Polytrichum juniperinum protonema.

\section{Chapter 3}

The role of isoprene in Polytrichaceae sexual systems

\section{Chapter 4}

The effect of nitrogen addition on moss morphology, sexual reproduction, and isoprene production.

\section{Chapter 5}

Conclusion

References 


\section{List of Tables}

Table 2.1 Summary table of Polytrichum juniperinum populations used for protonema single spore and mixed spore experiments.

Table 3.1 Summary table of $P$. juniperinum populations used for non-sexually expressing isoprene emission $(\mathrm{n}=45)$.

Table 3.2 Summary table of $P$. juniperinum populations used for sexually expressing isoprene emission $(\mathrm{n}=25)$.

Table 3.3 Summary table of Atrichum undulatum, Polytrichum juniperinum and Pogonatum urnigerum populations used for sexually expressing isoprene emission $(\mathrm{n}=167)$.

Table 3.4 Summary table for aboveground morphological trait measurements from $P$. juniperinum gametophytes to assess discernable characteristics and contributions to isoprene emission $(n=45)$. .104

Table 3.5 Summary table for belowground morphological trait measurements from P. juniperinum gametophytes to assess discernable characteristics and contributions to isoprene emission $(n=45)$.

Table 4.1 Summary table of Polytrichum juniperinum from six populations $(n=60) \ldots . .165$

Table 4.2 Site characteristics of Polytrichum moss collected in the winter of 2015...... 166

Table 4.3 Age classification rubric of $P$. juniperinum.populations 167

Table 4.4 Summary of all morphological measurements taken from $P$. juniperinum populations .168

Table 4.5 Experimental design set up showing three nitrogen additions. 170 


\section{List of Figures}

Figure 1.1 Conceptual model for exploring isoprene emission in moss

Figure 2.1 (a) Depiction of $P$. juniperinum spores before capsule sterilization from two sites. .44

Figure 2.2 Isoprene emission (nmol m-2 s-1) versus $P$. juniperinum spore germinated protonema $(n=21)$.

Figure 2.3 Isoprene emission (nmol m-2 s-1) versus media (agar versus $\mathrm{BCD}$ ) in $P$. juniperinum protonema $(\mathrm{n}=52)$.

Figure 2.4 Image depicting $P$. juniperinum protonema growth

versus day number $(\mathrm{n}=21)$.

Figure 2.5 Isoprene emission (nmol m-2 s-1) versus P. juniperinum protonema and leaf number $(\mathrm{n}=81)$.

Figure 2.6 Isoprene emission (nmol m-2 s-1)/growth versus protonema growth ( $\mathrm{n}=246)$.

Figure 2.7 P. juniperinum \% change in protonema growth versus leaf emergence for three individual dates $(\mathrm{n}=246)$.

Figure 2.8 Isoprene emission (nmol m-2 s-1) versus Chlorophyll Fluorescence Ratio (CFR) in P. juniperinum protonema on agar and BCD media $(\mathrm{n}=52)$.

Figure 2.9 Chlorophyll Fluorescence Ratio (CFR) versus $P$. juniperinum protonema on agar and BCD media $(n=52)$.

Figure 2.10 Relative Electron Transport Rate (RETR) ( $\mu \mathrm{mol} \mathrm{m-2} \mathrm{s-1)} \mathrm{from} P$. juniperinum protonema versus agar and $\mathrm{BCD}$ media under low-light setting $(0-820 \mu \mathrm{mol} \mathrm{m}-2 \mathrm{~s}-1)$ PPFD ( $\mathrm{n}=20)$.

Figure 2.11 Relative Electron Transport Rate (RETR) ( $\mu \mathrm{mol} \mathrm{m-2} \mathrm{s-1)} \mathrm{from} P$. juniperinum protonema versus agar and $\mathrm{BCD}$ media under high-light setting (0-1150 $\mu \mathrm{mol} \mathrm{m-2} \mathrm{s-1)} \mathrm{PPFD} \mathrm{(n=20).}$

Figure 2.12 Relative Electron Transport Rate (RETR) ( $\mu \mathrm{mol} \mathrm{m-2} \mathrm{s-1)} \mathrm{from} P$. juniperinum protonema versus combined agar and $\mathrm{BCD}$ media under low-light 
setting $(0-820 \mu \mathrm{mol} \mathrm{m}-2 \mathrm{~s}-1)$ and high-light setting $(0-1150 \mu \mathrm{mol} \mathrm{m}-2 \mathrm{~s}-1)(\mathrm{n}=40) \ldots . . .55$

Figure 2.13 Isoprene emission (nmol m-2 s-1) in P. juniperinum protonema versus temperature $\left({ }^{\circ} \mathrm{C} ; \mathrm{n}=38\right)$.

Figure 2.14 Isoprene emission (nmol m-2 s-1) in $P$. juniperinum protonema versus Photosynthetic Photon Flux Density (PPFD) (n=53).

Figure 3.1 Illustration of $P$. juniperinum costa cross section with number of lamellae counts (LN) measurement at the widest part of the costa cross section 106 Figure 3.2 Illustration on $P$. juniperinum costa cross section with five lamellae height (CLH) measurement at the widest part of the costa cross section.

Figure 3.3 Illustration on $P$. juniperinum costa cross section of gametophyte stem after leaf removal.

Figure 3.4 Setup for isoprene emission assessment for individual gametophyte emission using Dracast LED1000 Pro Daylight light panel, with light-emitting diode array (Photon Systems Instruments).....

Figure 3.5 Logged isoprene emission $\left(\mathrm{nmol} \mathrm{m} \mathrm{m}^{-2} \mathrm{~s}^{-1}\right)$ versus above and belowground morphological variables in non-sexually expressing $P$. juniperinum gametophytes $(\mathrm{n}=45)$.

Figure 3.6 Isoprene emission $\left(\mathrm{nmol} \mathrm{m}^{-2} \mathrm{~s}^{-1}\right)$ best fit regression line versus stem area dry $(\mathrm{SAD}) \mathrm{mm}^{2}$ in $P$. juniperinum gametophytes $(\mathrm{n}=45)$.

Figure 3.7 Isoprene emission $\left(\mathrm{nmol} \mathrm{m}^{-2} \mathrm{~s}^{-1}\right)$ versus plant sex in $P$. juniperinum gametophytes that were not expressing sex during the experiment $(n=300)$.

Figure 3.8 Isoprene emission ( $\mathrm{nmol} \mathrm{m}^{-2} \mathrm{~s}^{-1}$ ) versus species: Atrichum undulatum, Pogonatum urnigerum and Polytrichum juniperinum gametophytes $(\mathrm{n}=167)$.

Figure 3.9 Logged isoprene emission $\left(\mathrm{nmol} \mathrm{m}^{-2} \mathrm{~s}^{-1}\right)$ versus sex between species of A. undulatum, $P$. urnigerum and $P$. juniperinum gametophytes $(\mathrm{n}=167)$.

Figure 3.10 Isoprene emission $\left(\mathrm{nmol} \mathrm{m}^{-2} \mathrm{~s}^{-1}\right)$ versus sexes in Polytrichaceae gametophytes $(\mathrm{n}=167)$.

Figure 3.11 Isoprene emission $\left(\mathrm{nmol} \mathrm{m}^{-2} \mathrm{~s}^{-1}\right)$ versus site in A. undulatum gametophytes $(\mathrm{n}=70)$ 


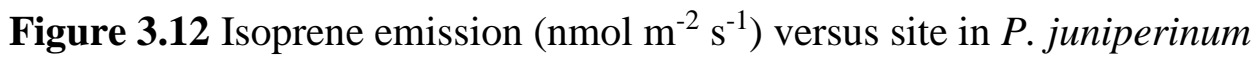
gametophytes $(\mathrm{n}=56)$

Figure 3.13 Isoprene emission $\left(\mathrm{nmol} \mathrm{m} \mathrm{m}^{-2} \mathrm{~s}^{-1}\right)$ versus site in P. urnigerum gametophytes $(\mathrm{n}=41)$..

Figure 3.14 Isoprene emission $\left(\mathrm{nmol} \mathrm{m} \mathrm{m}^{-2} \mathrm{~s}^{-1}\right)$ best fit regression line versus

Chlorophyll Fluorescence Ratio (CFR) in P. juniperinum gametophytes $(\mathrm{n}=45)$

Figure 3.15 Logged isoprene emission $\left(\mathrm{nmol} \mathrm{m} \mathrm{m}^{-2} \mathrm{~s}^{-1}\right)$ best fit regression line versus

Chlorophyll Fluorescence Ratio (CFR) in P. juniperinum gametophytes $(\mathrm{n}=28)$

Figure 3.16 Chlorophyll Fluorescence Ratio (CFR) versus sex

in $P$. juniperinum $(\mathrm{n}=25)$

Figure 3.17 Relative Electron Transport Rate (RETR) ( $\mu$ mols $\mathrm{m}^{-2} \mathrm{~s}^{-1}$ ) versus sex on BCD media in P. juniperinum and A. undulatum gametophytes $(\mathrm{n}=28)$

Figure 3.18 Isoprene emission $\left(\mathrm{nmol} \mathrm{m} \mathrm{m}^{-2} \mathrm{~s}^{-1}\right)$ best fit regression line versus

Chlorophyll Fluorescence Ratio (CFR) in P. juniperinum gametophytes $(\mathrm{n}=28)$

Figure 3.19 Chlorophyll Fluorescence Ratio (CFR) versus species:

$P$. juniperinum and $A$. undulatum gametophytes $(\mathrm{n}=28)$

Figure 3.20 Relative Electron Transport Rate (RETR) ( $\mu$ mols $\mathrm{m}^{-2} \mathrm{~s}^{-1}$ ) versus Photosynthetic Photon Flux Density (PPFD) ( $\mu$ mols $\left.\mathrm{m}^{-2} \mathrm{~s}^{-1}\right)$ in $P$. juniperinum and A. undulatum gametophytes $(\mathrm{n}=28)$.

Figure 3.21 Relative Electron Transport Rate (RETR) ( $\mu$ mols $\mathrm{m}^{-2} \mathrm{~s}^{-1}$ ) versus sex in $P$. juniperinum and A. undulatum gametophytes $(\mathrm{n}=28)$.

Figure 4.1 Ammonium nitrate addition to $P$. juniperinum moss via 1 Liter (L) hand held pump mister sprayer (Solo INC., Model 418, Newport News, VA)

Figure 4.2 Small $77 \mathrm{~mm} \times 77 \mathrm{~mm} \times 97 \mathrm{~mm}$ static chamber (magenta jar) created for headspace analyses using (Magenta vessel ${ }^{\mathrm{TM}}$ ).

Figure 4.3 Magenta vessel ${ }^{\mathrm{TM}}$ used to collect isoprene emission data from $P$. juniperinum populations before and after nitrogen addition.

Figure 4.4 Gametophyte length (GL) cm versus sites (1-6) in P. juniperinum $(n=3596)$. .174 
Figure 4.5 Gametophyte length (GL) cm versus sex and nitrogen treatment in $P$. juniperinum $(\mathrm{n}=3596)$.

Figure 4.6 Gametophyte width (GW) cm versus sites (1-6) in

$P$. juniperinum $(\mathrm{n}=3596)$.

Figure 4.7 Gametophyte width $(\mathrm{GW}) \mathrm{cm}$ versus sex and nitrogen treatment in $P$.

juniperinum $(\mathrm{n}=3596)$.

Figure 4.8 Reproductive effort versus sexual expression in

P. juniperinum $(\mathrm{n}=1440)$.

Figure 4.9 Isoprene emission $\left(\mathrm{nmol} \mathrm{m} \mathrm{m}^{-2} \mathrm{~s}^{-1}\right)$ in the winter of 2015 versus

site-specific differences in $P$. juniperinum gametophytes $(\mathrm{n}=244)$.

Figure 4.10 Isoprene emission $\left(\mathrm{nmol} \mathrm{m}^{-2} \mathrm{~s}^{-1}\right)$ before $\mathrm{N}$ treatment versus

within site-specific differences in $P$. juniperinum gametophytes $(\mathrm{n}=244)$.

Figure 4.11 Isoprene emission $\left(\mathrm{nmol} \mathrm{m} \mathrm{m}^{-2} \mathrm{~s}^{-1}\right)$ before $\mathrm{N}$ treatment versus sex in

$P$. juniperinum gametophytes $(\mathrm{n}=244) \ldots$

Figure 4.12 Isoprene emission $\left(\mathrm{nmol} \mathrm{m} \mathrm{m}^{-2} \mathrm{~s}^{-1}\right)$ after $\mathrm{N}$ treatment versus site-specific

differences in $P$. juniperinum gametophytes $(\mathrm{n}=244)$.

Figure 4.13 Isoprene emission $\left(\mathrm{nmol} \mathrm{m}^{-2} \mathrm{~s}^{-1}\right)$ after $\mathrm{N}$ treatment versus

within site-specific differences in $P$. juniperinum gametophytes $(\mathrm{n}=244)$

Figure 4.14 Isoprene emission $\left(\mathrm{nmol} \mathrm{m} \mathrm{m}^{-2} \mathrm{~s}^{-1}\right)$ after $\mathrm{N}$ treatment versus sex in $P$.

juniperinum gametophytes $(\mathrm{n}=244)$.

Figure 4.15 Isoprene emission $\left(\mathrm{nmol} \mathrm{m}^{-2} \mathrm{~s}^{-1}\right)$ versus nitrogen treatment in

$P$. juniperinum gametophytes $(\mathrm{n}=244)$

Figure 4.16 Chlorophyll Fluorescence Ratio (CFR) measures versus site in $P$. juniperinum gametophytes $(\mathrm{n}=244)$.

Figure 4.17 Chlorophyll Fluorescence Ratio (CFR) measures versus N treatment in $P$. juniperinum gametophytes $(\mathrm{n}=244)$. 


\section{Chapter 1}

\section{Introduction}

Global emissions of non-methane Biogenic Volatile Organic Compounds (BVOCs) produced by plants are estimated to be between 700 and $1150 \mathrm{Tg} \mathrm{C} \mathrm{yr}^{1}$ (Guenther et al. 1995, 2006, 2012) and have significant effects on tropospheric chemistry at regional and global scales (Zimmerman et al. 1978; Fehsenfeld et al. 1992). Isoprene is highly reactive and in the presence of $\mathrm{OH}$ has a short atmospheric lifetime (Guenther et al. 1991, 1993; Funk et al. 2003; Fowler et al. 2009; Matsunaga et al. 2012; Seinfeld et al. 2012; Harrison et al. 2013). We must understand these emissions if we are to properly model regional atmospheric processes and chemistry transport models (CTMS).

Isoprene (2-methyl-1,3-butadiene; $\mathrm{CH} 2=\mathrm{C}(\mathrm{CH} 3) \mathrm{CH}=\mathrm{CH} 2)$, an unsaturated pentahydrocarbon, is the dominant non methane BVOC by mass, contributing about half of the global non methane BVOC flux (Stotzky et al. 1976; Guenther et al. 1995, 2006, 2012; Müller et al. 2008; Atkinson et al. 2003; Ashworth et al. 2013; Marmulla et al. 2014). In many ecosystems and even some urban areas, isoprene plays a significant, often dominant role, in photochemical reactions in the atmospheric boundary layer (Chameides et al. 1988; Goldstein et al. 1998). Modeled isoprene emission from urban areas with high nitrous oxides $\left(\mathrm{NO}_{\mathrm{X}}\right)$ (Curci et al. 2009; Calfapietra et al. 2013) can be as significant as anthropogenic hydrocarbons input (Geron et al. 1994; Guenther et al. 1994; Biesenthal et al. 1997). High levels of NOx, particularly in major cities where atmospheric photochemical reactivity and ozone production are high (Ling et al. 2014) are of global 
concern (Fares et al. 2011; Dieleman et al. 2012; Lahr et al. 2015). In these environments a single isoprene molecule can lead to the production of multiple ozone $\left(\mathrm{O}_{3}\right)$ molecules (Zeng et al. 2008; Fini et al. 2017) through Secondary Organic Aerosol (SOA) production (Cai et al. 2006; Ng et al. 2008; Goldstein et al. 2009; Hallquist et al. 2009; Makkonen et al. 2012; Pratt et al. 2013; Rap et al. 2018; Tegen et al. 2018).

Daytime atmospheric chemistry of BVOCs, such as isoprene, is dominated by $\mathrm{OH} /$ isoprene reactions that result in SOA's and precursors to tropospheric ozone (Chameides et al. 1988; Goldan et al. 1995; Lerdau et al. 1997; Duane et al. 2002), and thus can contribute to a localized feedback on radiative forcing (Peñuelas et al. 2010; Bonan et al. 2011). Oxidation capacity of the boundary layer is therefore reduced with a positive feedback on climate change by increasing the lifetime of tropospheric methane (Lelieveld et al. 1998; Bell et al. 2003, 2007; Peñuelas et al. 2003, 2009, 2010). Under increased BVOC production due to warming, commiserate increases in SOA production is expected. Given that the atmospheric chemistry interactions of isoprene with $\mathrm{OH}$ and the reactive nitrogen species reactions are implicated in creating atmospheric ozone, with increased climate change we expect to see increased BVOC production, including increased isoprene, resulting in increased SOA (Ng et al. 2008; Bison et al. 2018; Jambert et al. 2017; Fiore et al. 2005) and boundary layer ozone production.

Persistent BVOCs can serve as a viable carbon source. For example, methane can account for $15 \%$ of the carbon source for Sphagnum mosses (Raghoebarsing et al. 2005; Larmola et al. 2010). Active consumption of isoprene in soil is performed by microbes that consume isoprene as a source of energy and carbon (Van Ginkel et al. 1987; 
Pegoraro et al. 2006; Gray et al. 2015; McGenity et al. 2018). Rain or precipitation can transport BVOCs to soils, where microorganisms encounter BVOCs while living in or on plants (Atkinson et al. 2003; Fu et al. 2009; Ziemann et al. 2012). Specific bacteria that can degrade isoprene in soil, marine sediments, and on the leaves of plants have recently sparked interest in new areas of investigation (Crombie et al. 2019). These interactions regulate a considerable amount of soil communities carbon and energy budgets and affects chemical ecology both aboveground and belowground.

Organic molecules like isoprene are extremely costly for plants to produce (Sharkey et al. 2001), and the ability has been lost and gained multiple times during plant evolution (Sharkey et al. 2007, 2013; Fineschi et al. 2013; Monson et al. 2013; Dani et al. 2014; Loreto et al. 2015). Normal levels of isoprene production are greatly influenced by many abiotic and biotic factors, such as temperature, water stress, $\mathrm{CO}_{2}$ and drought, and have been measured using a wide range of techniques in a number of higher plants (Zimmerman, 1979; Khalil et al. 1992; Fares et al. 2006; Tiiva et al. 2007a,b; Duncan et al. 2009; Pétron et al. 2001; Peñuelas et al. 2001, 2003, 2010; Rasulov et al. 2010, 2018; review Loreto et al. 2015; review Sharkey et al. 2014, 2017; Yu et al. 2017; Bamberger et al. 2017).

Speculation as to why plants spend so much of their resources on isoprene production and the functional role of isoprene emission continues (Saxena et al. 2019). Isoprene has mainly been investigated and explored in vascular plants, but its biological and environmental significance is still poorly understood (Sharkey et al. 2017). There is a complicated and poorly understood calculous between isoprene emission and biomass 
accumulation in vascular plants (Hong et al. 2012). Understanding the reasons for the observed resource allocation will require a better understanding of the benefits to fitness of isoprene production and emission.

Isoprene emission has been observed in nonvascular plants (Hanson et al. 1999; Janson et al. 1999; Trapp et al. 2001; Haapanala et al. 2006; Tiiva et al. 2007a,b), in freshwater green algae (Disch et al. 1998), marine phytoplankton, cyanobacteria (Meskhidze et al. 2015; Dani et al. 2017), and macroalgae (seaweed) (Broadgate et al. 2004). Isoprene emission has roles in a wide array of interactions including evolutionary roles (Hanson et al. 1999; Harley et al. 1999; Sharkey et al. 2005b), biological roles (Fall et al. 1998; Logan et al. 2000; Loreto et al. 2001; Sharkey et al. 2001; Brilli et al. 2009; Tattini et al. 2014; Velikova et al. 2004, 2005, 2016; Sanadze et al. 2017; Wilson et al. 2018), and atmospheric roles (Lim et al. 2005; Zhang et al. 2007; Gerken et al. 2016). Isoprene is considered a true "building block in nature" (Barton et al. 1999; Morrison et al. 2002); however, our understanding of the role of isoprene emission in vascular plants is limited and in non-vascular plants it is extremely limited.

\section{Purpose of Study}

Bryophytes have been shown to be more responsive than vascular plants to nitrogen deposition and climate warming, and in a changing environment, they can serve as model systems in exploring biodiversity and ecosystem functioning (Becker Scarpitta et al. 2017). Bryophytes diverged from vascular plants with many unique morphological and biochemical adaptations (Roberts et al. 2012). Mosses contain a number of unique metabolites (Asakawa et al. 1981, 1995, 2007, 2011; Xie et al. 2009; Erxleben et al. 
2012; Ruiz-Molina et al. 2015). Over 300 BVOC chemical compounds have been recorded in bryophytes (Rosenstiel et al. 2012), but a lack of mechanistic understanding of these compounds hinders our ability to interpret and predict the responses of mosses to anthropogenic drivers such as climate change and anthropogenic nitrogen addition (Vitousek et al. 1997; Royles et al. 2015; Patiño et al. 2016; Gavazov et al. 2018; Delgado-Baquerizo et al. 2018). This is particularly important today as researcher are trying to decode the moss genome to understand how climate change will affect plants (Ludwig et al. 2017) and what mechanisms enable moss to survive extremely unfavorable environments (Hartley et al. 2014; Machteld et al. 2017).

Data concerning the spatial and temporal variability of BVOC emissions are lacking due to poor characterization of the physical and biological factors controlling isoprene synthesis in non-vascular plants as most research has been focused on vascular plants (Sharkey et al. 2017). There is also scarce research into sex expression in bryophytes regarding BVOC emissions and cost benefit analyses for reproductive effort. Previous research in bryophytes suggests that some BVOC emissions are sex-specific and can influence fertilization in mosses by microarthropods (Rosenstiel et al. 2012). There exists modest evidence that physiological factors affect sex expression in bryophytes, and sex can be modified by these external physiological factors (Bowker et al. 2000; Rosenstiel et al. 2012; Shortlidge et al. 2014; Slate et al. 2017).

To test hypotheses concerning the biosynthetic, metabolic and functional processes relating to isoprene emission, we investigated isoprene emission in the Polytrichaceae. Polytrichaceae are morphologically diverse (Mishler et al. 2009), 
perennial and evergreen, and are able to colonize a wide range of habitats on every continent (Bazzaz et al. 1970, Shortlidge et al. 2016) and are a significant pioneer species.

- In Chapter 1, I introduce isoprene emission as it relates to plant BVOC production in vascular and non-vascular plants. I explain the background for my dissertation, explaining the potential roles of nitrogen deposition and sexual allocation in influencing BVOC emissions.

- In Chapter 2, I describe isoprene emission in early P. juniperinum protonema by assessing and quantifying isoprene emission. Further, I explore effects on protonema growth and how physiological factors contribute to and are affected by these emissions.

- In Chapter 3, I assess and quantify how isoprene emission varies between species and sexes within the Polytrichaceae family. In addition, I measure morphological and physiological traits from the cell to population level to investigate how these traits can contribute to isoprene emission.

- In Chapter 4, I conduct a four-year nitrogen addition experiment with $P$. juniperinum and explore abiotic and biotic factors that influenced isoprene emission, sexual expression, reproductive effort, morphology and physiological diversity along an artificial nitrogen gradient.

A conceptual model of isoprene production by plants can be seen in Figure 1.1, where production is considered a result of morphological and physiological characteristics, though it can also be positively or negatively be influenced by genetics, 
environmental factors, and atmospheric chemistry. This may shed light on community wide emission characteristics from different populations and site categories, both as snapshots and over time for spatial location of the colony within the population of both sexes, and time during ontogeny. This work will examine for the first time the hypothesis that isoprene-BVOC emission capabilities are present in early protonema in $P$. juniperinum. This work will also examine for the first time the hypothesis that sexual expression affects isoprene emission in Polytrichaceae species. Lastly, this work will examine for the first time the hypothesis that isoprene emission under nitrogen addition influences isoprene emission in P. juniperinum.

Isoprene emissions from mosses and their response to climate change could lead to an increase in landscape level BVOC emissions with profound implications for possible uncharacterized climate change feedback mechanisms. Currently, non-vascular plants are not included in atmospheric chemistry modeling, and after 60 years of research into isoprene emission with vascular plants, the reason why some plants emit and what provides the evolutionary pressure to do so remains poorly understood (Sharkey et al. 2017). With uncertainty in the capacity of largely overlooked non-vascular plants to emit isoprene it is hard to predict how these emissions will be affected by and in turn affect climate change in possible positive or negative feedback loops.

In Chapters 1-4, as outlined above, I discuss how I have conducted research to understand my research topic and explain what steps I have taken to complete this dissertation. In Chapter 5, I discuss the broader implications of this work for future studies of the role of moss isoprene emissions on Earth's early land plant evolution. The 
results from this work will allow a preliminary parameterization of the emission of BVOC's, specifically isoprene, from this often overlooked but ubiquitous flora. I further give explanation for the work I did, which supports a role for bulk isoprene emission in the development of water stress management in mosses possibly going all the way back to the emergence of life onto land. The implications of mosses isoprene emissions driving local atmospheric hydrological processes are explored but their parameterizations are beyond the scope of this study and require further research. 


\title{
Chapter 2
}

\section{Isoprene emission from Polytrichum juniperinum protonema}

\begin{abstract}
Isoprene (2-methyl-1, 3-butadiene) accounts for > 90\% of non-methane Biogenic Volatile Organic Compounds (BVOCs) emissions from vegetation. In this study, working with the moss Polytrichum juniperinum (Polytrichaceae), we (1) determine when isoprene emission begins after spore germination, (2) quantify isoprene emission in single-spore isolated protonema (the earliest life stage after spore germination), (3) investigate physiological effects through laboratory gas exchange measurements, and (4) investigate light and temperature curves that influence and affect isoprene emission.

Here, we show for the first time that protonema from $P$. juniperinum emits isoprene, and a time lag after germination exists before isoprene production. We recorded an increase in isoprene emission with young protonema and measured emission at detectable levels between days 5-6, which declined over time with leaf expression. The emission is the first ever reported for $P$. juniperinum, or any moss protonema. We show that physiological measurements, such as relative electron transport rate, are comparable to what is known for macro algae. Isoprene emission is temperature and light dependent and these curves correspond to what is has been observed in vascular plant isoprene emissions. We think moss may provide a novel model system suited to assess further questions as to why early land plants emitted isoprene, why plants continue to emit isoprene and what factors contribute to these emissions.
\end{abstract}


Keywords: bryophyte, isoprene emission, life stage, Polytrichum juniperinum, protonema, relative electron transport rate 


\section{Introduction}

Annually, plants assimilate 120 Picogram $(\mathrm{Pg})$ of carbon dioxide through photosynthesis. Carbon dioxide has increased in the Earth's atmosphere due to anthropogenic emission factors (Bala et al. 2007; Pongratz et al. 2009; Reichstein et al. 2013; Ussiri et al. 2017; Doetterl et al. 2018; Mau et al. 2018). Atmospheric $\mathrm{CO}_{2}$ is warming the planet, will alter carbon cycles, and is already intensifying shifts in ecosystem processes (Gorham et al. 1991; Heimann et al. 2008; Allison et al. 2010; Jiang et al. 2013; Pold et al. 2017; Unda et al. 2017; Yvon-Durocher et al. 2017; Quesada et al. 2018; Pellegrini et al. 2018). Plants use carbon dioxide for photosynthesis, but in the process can transform it into chemically complex molecules, some of which are reemitted back into the atmosphere in the form of isoprene (Sharkey et al. 1993, 1995, 1996; Harley et al. 1994; Magel et al. 2006; Kuhn et al. 2007; Ghirardo et al. 2011, 2014). Isoprene, a terpenoid, is significantly more chemically reactive than $\mathrm{CO}_{2}$ and may have a larger than suspected impact on atmospheric temperature through albedo effects via the formation of SOA (Mooney et al. 1987; Scholefield et al. 2004; Lohmann et al. 2005, Arneth et al. 2007; Heald et al. 2009; Bauwens et al. 2018).

We need to understand why and at what rate plants produce isoprene to fully understand the global carbon cycle and the effects of vegetative shifts on climate change. However, as of yet, our limited understanding of isoprene emission does not include a definitive reason as to why some plants emit isoprene and others do not. This is all the more remarkable given that isoprene production is so metabolically costly (Loreto et al. 2010; Behnke et al. 2007, 2009, 2012). Despite decades of work on this topic, the 
physiological role and the evolutionary origins of isoprene emission is a matter of debate. Even within plant groups (e.g., flowering plants) isoprene emission is inconsistent (Hanson et al. 1999; Monson et al. 2013). Without an understanding of the fundamental motivations for isoprene production and emission, we have a limited ability to predict emissions with increasing climate change (Sharkey et al. 2017).

The process of isoprene synthesis and emission are biochemically expensive and energy dependent (Vickers et al. 2009; Loreto et al 2010; Sharkey et al. 2001; Behnke et al. 2012). Isoprene is produced from its five-carbon precursor, isopentenyl diphosphate (IPP) to its isomer, dimethylallyl diphosphate (DMAPP) (Lichtenthaler et al. 1997) by isoprene synthase enzyme (Kuzma et al. 1993; Schnitzler et al. 1996; Miller et al. 2001; Sharkey et al. 2005a,b). Two pathways are known for isoprene synthesis: the eukaryotic mevalonic acid pathway (MVA) in cytosol and the methylerythritol phosphate (MEP) pathway in plastids (Kuzuyama et al. 2002), with little crosstalk between the pathways (Eisenreich et al. 2001; Laule et al. 2003; Schuhr et al. 2003; Loreto et al. 2004; Peñuelas et al. 2005). Isoprene is not a general plant trait (Ekberg et al. 2011), but all plants possess the MEP pathway.

Isoprene emission is more common in mosses and ferns than in other major plant groups (Hanson et al. 1999), making bryophytes (liverworts, mosses, and hornworts) an important focus of research in isoprene emissions. Bryophytes were the earliest land plants observed in the fossil record and date back 475 million years (Wellman et al. 2003; Nickrent et al. 2000; Morris et al. 2018; Rensing et al. 2018a). Isoprene emission has been hypothesized as a thermo-tolerance mechanism beneficial for the radiation of early 
plants on land (Hanson et al. 1999) through resistance to damage due to increased temperature variations that are part of an aerial existence. Later plants evolved other protective mechanism such as heat shock proteins (Waters et al. 1996; Heckathorn et al. 1998) to cope with these temperature swings. Isoprene emitted by these early plants should be accounted for in models of early climate and biological environmental engineering. Under current climate conditions, mosses occur on every continent, dominating observed biomass in the high arctic and can tolerate a wide array of temperature and water stresses (Ward 1960; Collins 1976; Corradini et al. 1999; Van der Velde et al. 2001, 2005; review Mishler et al. 2001; Wilson et al. 2003; Shafigullina et al. 2018; Ojiodu et al. 2018). Global warming may lead to the expansion of isoprene emitting moss communities in some regions such as Antarctica and an increase in landscape level isoprene emissions with profound implications for climate change.

Isoprene emitting mosses have been found in the Sphagnum (Sphagnaceae) and Warnstorfia (Amblystegiaceae) genera, and several species from the Polytrichaceae family (Hanson et al. 1999). Research suggests that these mosses can emit substantial amounts of isoprene to the atmosphere with an annual emissions peak observed in the relative heat and high solar insolation days of both the northern and southern summers. Temperature, light level and time of day all contribute to diurnal and annual variation in isoprene emissions. Enhanced UV-B radiation leads to higher observed emissions which were explained by higher carbon assimilation (Sharkey et al. 1996, 1999; Singsaas et al. 1997, 1998; Rinne et al. 2002; Centritto et al. 2011; Fares et al. 2011; Ryan et al. 2014; Nogues et al. 2018; Niinemets et al. 2018). This research suggests that peatlands are 
likely to be more important sources of isoprene than forests in the subarctic (Janson et al. 1998, 1999; Haapanala et al. 2006; Hellén et al. 2006; Tiiva et al. 2007a,b, 2009).

A time lag that exists between the onset of photosynthesis and isoprene emission has been observed in young vascular plants (Grinspoon et al. 1991; Rasulov et al. 2014, 2015). However, it is unknown when during development mosses start to emit isoprene, and whether the emission rates are similar to mature plants. Understanding how emission rates change during moss development will help us better estimate moss isoprene emissions on larger scales.

The objective of this study was to quantify moss isoprene emission across the earliest life history stages. After testing more than 90 species of moss for isoprene emissions including ten members of the Polytrichaceae family, all of which emitted isoprene, we chose the moss Polytrichum juniperinum as our test species because of its' high rate of emission, global distribution (Conard 1956; Cremer et al. 1965; Callaghan et al. 1978; Crum et al, 1981; Van der Velde 2000, 2003; Ryömä et al. 2005; Newton et al. 2000; Nickrent et al. 2000; Bell et al. 2010a,b; Yumol 2016) and status as a one of the planets most successful pioneer species (Scotter 1964; Sims et al. 1981; Foster 1985; Kim et al. 2014; Shortlidge et al. 2016). Comparable rates of emission are found coming from oak leaves $32.8 \pm 2.9 \mathrm{nmol} \mathrm{m}^{-2} \mathrm{~s}^{-1}$ at $30^{\circ} \mathrm{C}$ and $900 \mu \mathrm{mol} \mathrm{m} \mathrm{m}^{-2} \mathrm{~s}^{-1}$ (Sharkey et al. 1991) a widely distributed vascular counterpart. In this study, we investigated: 1) whether isoprene emission is present and quantifiable in $P$. juniperinum protonema and 2) how isoprene emission changes during gametophytic development. Additionally, we attained 1) repeated protonema growth measurements, 2) gas exchange measurements and 
electron transport rates, and 3) light and temperature curves with respect to isoprene emissions. These data allow us to assess both the production of isoprene during the early life stages in this moss species, but also allows the first look at how this production may vary with environmental and growth parameters.

\section{Materials and Methods}

\section{Study species}

We used Polytrichum juniperinum (Hedw.) (Polytrichaceae), a cosmopolitan species, for the experiments described in this study (Smith 1972; Forrest et al. 1995; Zouhair et al. 2000; Magombo et al. 2003; Hyvönen et al. 2004; Bell et al. 2010 a,b). P. juniperinum grows on every continent (Conard 1956; Cremer et al. 1965; Callaghan et al. 1978; Crum et al, 1981; Van der Velde 2000, 2003; Ryömä et al. 2005; Newton et al. 2000; Nickrent et al. 2000; Bell et al. 2010a,b; Yumol 2016) and is a pioneer moss species (Scotter 1964; Sims et al. 1981; Foster 1985; Kim et al. 2014). It is often found in disturbed habitats and on recently burned soil (Rundel et al. 1977; Rencz, et al. 1978; Fryer 2008; Depante et al. 2018; Maslov et al. 2018; Shafigullina et al. 2018) where it can rapidly outcompete non-colonizing species (Duncan et al. 1982; Delach et al. 2002; Gonzáles et al. 2013; Juutinen et al. 2015). This moss has been observed to vary in physiology and morphology to adapt to fluctuating environments (Bazzaz et al. 1970; Sarafis 1971; Collins 1976; Potter et al. 1995; Callaghan et al. 1997; Shafigullina et al. 2018), can sustain high light level fluctuations (Lloyd et al. 2003; Marschall et al. 2004; Proctor et al. 2018), and withstand increased summer temperatures (Potter et al. 1995; 
Richter et al. 2000; O’Neill et al. 2006; Oishi 2018). This observed resilience and strategy for broad temperature tolerance and make it of particular interest as a model species for observing potential plant physiological changes in the face of a warming environment.

\section{Protonema from mixed spore samples}

To assess detectable levels of isoprene emission from $P$. juniperinum, ten intact adult mature sporophytes were collected randomly from three locations in and around Portland, OR during the summer of 2015 (Table 2.1). Mature spores were inspected under a Leica DME compound microscope (Figure 2.1a) to ensure sporophytes had intact protective cover (calyptra) over sporophytes and were not damaged. Calyptra and seta were detached using forceps before sterilization. Using sterile techniques, the calyptra was removed from each sporophyte $(n=7)$, and sterilization of mature sporophytes was achieved by using sodium hypochlorite following (McDaniel et al. 2007). We sterilized the capsules in $1.0 \%$ solution of sodium hypochlorite for 60 seconds and subsequently washed them in tap water for 60 seconds repeating this three times in three Eppendorf tubes inside a laminar flow hood. The fourth Eppendorf tube contained $1 \mathrm{ml}$ water in which the sporophyte was ruptured using sterilized forceps and spores released.

Agar and nutritive BCD media were prepared following protocol outlined by Wang et al. (2015). Sixty milliliters of prepared media was poured into base of $9.5 \mathrm{~cm} \mathrm{x}$ $9.5 \mathrm{~cm} \times 3.5 \mathrm{~cm}$ PlantCon ${ }^{\mathrm{TM}}$ containers (MP Biomedicals, 2017) and sterilized before the addition of spore mixtures under UV light. The container lid was placed atop the base 
which measured $9.5 \mathrm{~cm}$ x $9.5 \mathrm{~cm}$ x $7.0 \mathrm{~cm}$. PlantCon ${ }^{\mathrm{TM}}$ containers are made of clear polyvinyl chloride (PVC) and are designed for plant culture applications because they allow light transmission and produce optimal growth. The PlantCon ${ }^{\mathrm{TM}}$ container eliminated bacterial growth and allowed for easy sampling (Figure 2.1b).

Three sporophytes from the same location were chosen at random and the capsule of the three sporophytes were excavated and vortexed together to ensure enough spores would be viable to achieve detectable levels of isoprene emission. Once thoroughly blended, the mix was plated in PlantCon container on agar or BCD media. Spores emissions were assessed daily until detectable isoprene emission was observed. The $P$. juniperinum protonema samples were grouped into a binary system of emitting and nonemitting samples for analyses.

\section{Protonema from single spores}

To assess isoprene emission from single-spores of $P$. juniperinum, a single capsule was obtained from a rural site outside of Portland, Oregon (Table 2.1). Using the protocol described above and using standard microbiological procedures, the single healthy sporophyte was opened using sterile forceps and $~ 100$ spores per 90 -mmdiameter Petri dish were spread on agar following Cove et al. (2009). This allowed dilution of the spores from the plate and made it possible to transfer individual spores under a Leica microscope (Leitz DME, Leica, Wetzlar, Germany) with a AxioCam 105 Color camera and Zen Blue software (version 1.1.2.0; Carl Zeiss Microscopy). Using sterile forceps single spore isolates were transferred onto individual 90-mm Petri dishes 
with agar media which then were sealed with Parafilm wax film (Pechiney Plastic Packaging, Menasha, WI). Eighty one single-spore isolates were allowed to grow for 2 months under standardized growth conditions of $\left(55-70 \mu \mathrm{mol} \mathrm{m}^{-2} \mathrm{~s}^{-1}\right)$ light intensity and a photoperiod of $16 \mathrm{~h}$ light to $8 \mathrm{~h}$ dark at $22^{\circ} \mathrm{C} \pm 2 \mathrm{SEM}$ using Adaptis1000 Conviron growth chambers (Pembina, ND).

P. juniperinum moss spores germinate on agar in $\sim 2$ days, and protonema develops in 7 days (Nehlsen 1979; Duncan et al. 1982). Every two week, we tested the single-spore germinated protonema for isoprene emission under controlled light level and basal rate (maintained at $1000 \mu \mathrm{mol} \mathrm{m} \mathrm{m}^{-2} \mathrm{~s}^{1}, \pm 100 \mathrm{SEM}$ ) and $30 \pm 2^{\circ} \mathrm{C}$ using a Reduced Gas Detector (RGD2, Trace Analytical, Menlo Park, CA). Light intensity was assessed every other day to maintain consistency and samples were rotated clockwise each day to avoid edge effects and allow light optimum to penetrate each Petri dish.

Two isoprene emission sampling events occurred for single-spore isolated protonema. First, isoprene emission was assessed at from day 1 after spore plating and germination until day 45 , and second after 75 days. P. juniperinum spores need 20-40 days for complete protonema formation (de Carvalho et al. 2011). In the first set of isoprene emission at day 45, we sampled isoprene from three sites in two growth media and performed physiological measurements. In the second set, our assessment consisted of single-spore isolated protonema, where we investigated whether protonemal growth had an effect on isoprene emission. We used 81 half-siblings from one capsule to eliminate environmental variability and variance in maternal effects (Shaw 1985; Vanderpoorten et al. 2002; Budke et al. 2012, 2013). These spores were assessed in two- 
week intervals, starting from assessment one on day 75 on September 2, 2016. The second isoprene assessment on day 89 occurred on September 15. The last isoprene assessment on day 103 occurred on September 28, 2016. During the last two isoprene assessments (assessments 2 and 3), protonema began to sprout phyllids (leaves), and plants were now considered to be in the gametophytic stage. Therefore, the last two isoprene emission quantifications included leaves. Quantitative analyses using Reduced Gas Detector (RGD2, Trace Analytical, Menlo Park, CA) picked up detectable levels of isoprene emission.

Using a Leica microscope (Leitz DME, Leica, Wetzlar, Germany), single-spore grown protonema were quantified with a bright-field microscope and inspected for health. Differential interference contrast images were captured using automatic exposure when taking images of the protonema; the drawing tool was used to manually circle the area of moss protonema growth using Leica Application Suite software. A $2 \mathrm{~mm}$ stage micrometer (Ward's Science, cat. \#949910) was used to calibrate the camera drawing tool, and we used calibrated images from Zen software version 1.1.2.0 (Carl Zeiss Microscopy).

\section{Isoprene measurement method of $P$. juniperinum protonema}

To measure isoprene emission in $P$. juniperinum protonema, we used a nondestructive method, headspace sampling, which gives a spatially realistic profile of emission for sampling volatiles in an ecological context. Headspace gas chromatography using gas extraction was used after a specified time interval, and a small headspace 
sample was injected with a syringe directly into packed columns in the Gas

Chromatograph with a reduction gas detector (GC/RGD2). Each sample was allowed an acclimation period before the headspace was sampled under the standard conditions of controlled light level (maintained at $1000 \mu \mathrm{mol} \mathrm{m}^{-2} \mathrm{~s}^{-1} \pm 100 \mathrm{SEM}$ ), also known as the basal rate of isoprene emission. We tested isoprene emission during timed intervals with 3 samples of protonema and 3 replicates and found that most of the isoprene was emitted within the first five minutes of incubation. The moss protonema were photographed under a Leica microscope (Leitz DME, Leica, Wetzlar, Germany), to establish the area of each sample allowing us to use area in the equation for isoprene emission (Equation 1.). All protonema level isoprene emission samples were collected in $2 \mathrm{ml}$ PressureLok® Precision Analytical Syringe (VICI Precision Sampling Inc., Baton Rouge, LA, USA) for laboratory analyses. These samples were injected into $1 \mathrm{ml}$ sample loop within 10 minutes. Prior to use, $20 \mathrm{ml}$ round bottom vials were cleaned by rinsing with $3 \mathrm{ml}$ methanol and then baked at $60{ }^{\circ} \mathrm{C}$ for a minimum of 2 hours on a MaxQ 4000 ventilated shaker (Barnstead Lab-Line, Thermo Scientific; Logan, UT). Vials were removed from heat and immediately capped with clean septa and caps that had been washed using DI water and baked at $60^{\circ} \mathrm{C}$ alongside the vials. Each moss protonema clump was placed in a clean $20 \mathrm{ml}$ vial with Teflon backed 6mm silicone septa (Supelco, Sigma-Aldrich; Bellefonte, PA). After 10 minutes, $1 \mathrm{ml}$ of air was removed via Pressure-Lok® precision analytical syringe (VICI Precision Sampling Inc., Baton Rouge, LA) and injected into a reduction gas detector (RGD2, Trace Analytical, Menlo Park, CA). Isoprene was separated isothermally $\left(100^{\circ} \mathrm{C}\right)$ in a stainless-steel column $(1.3 \mathrm{~m}$ long x $2 \mathrm{~mm}$ inner 
diameter i.d.) packed with UNI 8 Beads 3S 60/80 6' x 1/8”, 0.085 SS (Alicat Scientific, Inc; Tucson, AZ).

Peak times and areas were recorded using a commercial integrator (Model 3396, Hewlett-Packard, Avondale, Pennsylvania) and transformed to parts per million of isoprene. The GC-RGD2 was calibrated each day using a standard cylinder containing 71 $\mathrm{ppb}(\mathrm{v} / \mathrm{v})$ isoprene, referenced to a National Institute of Standard and Technology (NIST) and helium (He) standard (SRM 1660a; 1 ppm He in $\mathrm{N}_{2}$, Rochester, NY; Praxair Inc., Specialty Gases, Portland, OR) with a ten point standard dilution of isoprene and Helium as a carrier gas. Blanks were run every five samples to ensure quality assessment and to detect contamination within the column. Isoprene gas was mixed with high purity helium using a mass flow controller calibrated to a flow rate of $21 \mathrm{ml} / \mathrm{min}$ (Alicat Scientific, Inc; Tucson, AZ). One $\mathrm{ml}$ of the calibration gas mixture was removed with a syringe from a mixing chamber and injected into the GC-RGD2 to create the calibration curve and obtain slope of the equation see (Equation 1.).

\section{Isoprene GC-analyses of $\boldsymbol{P}$. juniperinum protonema}

Two types of isoprene measurements were performed to determine isoprene emission from $P$. juniperinum protonema. First, we tested whether isoprene emission occurs in early protonema. We found no previous reports on isoprene emission from moss protonema. To test for isoprene emission in protonema, we used protonema derived from spores grown from several sporophytes (see above "Protonema from mixed spore samples"). Second, we wanted to assess quantity of isoprene emission from single-spore 
isolates grown into protonema after a period of adjustment (see above "Protonema from single spores"). Variation in isoprene emission during three separate time intervals was assessed and labeled; assessment 1 (September 2, 2016), assessment 2 (September 15, 2016), and assessment 3 (September 28, 2016).

Isoprene emission measurement was calculated as follows, using Peak Area Units (PAU) from the standard calibration curve $y=m x+b$, at GC temperature of 298 Kelvin (K), and Atmospheric Pressure (P) of 760 Torr.

$$
\begin{aligned}
= & \left(\frac{\mathrm{PAU}+20.69}{2.4703}\right) \times\left(\frac{1 \mathrm{nmol} / \mathrm{L}}{\mathrm{ppb}}\right) \times(.0005) \times\left(\frac{\text { std } \mathrm{nl}}{\mathrm{nl}}\right) \times\left(\frac{760 \mathrm{Torr}}{298 \mathrm{~K}}\right) \times\left(\frac{378 \mathrm{~K}}{771.8 \mathrm{Torr}}\right) \\
& x\left(\frac{1 \mathrm{nmol}}{22.4 \mathrm{std} \mathrm{nl}}\right) \times\left(\frac{\text { volume vial }(\mathrm{ml})}{.5 \mathrm{ml}}\right) \times 1 \text { (factor for loop recovery) } \\
& x\left(\frac{1}{\text { area } / \mathrm{m} 2}\right)=\left(\text { nmol } \mathrm{m}^{2} \mathrm{~s}^{-1}\right)
\end{aligned}
$$

Equation 1. Formula used to convert isoprene from calibration curve, $y=m x+b$, and PAU to isoprene $\left(\mathrm{nmol} \mathrm{m} \mathrm{m}^{-2} \mathrm{~s}^{-1}\right)$.

We obtained the volume-mixing ratio of isoprene (ppb) using Equation 1 to determine protonema isoprene emission flux. We determined the area of the protonema using AxioCam 105 Color camera, and Zen Blue software, version 1.1.2.0 (Carl Zeiss Microscopy).

Peak identification was performed with the PEAK software (Stein 1999) that integrates raw peak area units and retention times. To identify isoprene, a custom calibration curve was created from isoprene standard (Sigma, Deisenhofen, Germany). For quantification, peak areas of isoprene were determined after baseline correction. Levels of background contamination were determined from blanks. Analytical quality was analyzed by using Standard Reference Material of isoprene (NIST SRM 1515, 
National Institute of Standards and Technology, Gaithersburg, MD). The standard material was used in the analyses to create calibration curves for quality assurance and quality control purposes.

\section{Laboratory gas exchange measurements of $P$. juniperinum protonema}

To investigate physiological factors affecting isoprene emission from $P$. juniperinum, we conducted measurements of photosynthetic parameters of mature photosynthetic green protonema tissue using Junior Pulse-amplitude modulated (JUNIOR-PAM) chlorophyll fluorometer and WinControl Software (Walz, Effeltrich, Germany). All gas exchange measurements in the lab were conducted using the protocol outlined by JR-PAM, with a single $100 \mathrm{~cm}$ plastic fiber, $1.5 \mathrm{~mm}$ in diameter. The JuniorPAM (Walz, Germany, http://www.walz.com/) was used according to the manufacturer's instructions with the following parameters: light - saturation pulse intensity 6 , pulse

frequency $20 \mathrm{sec}$, actinic light intensity 8 . The effective photochemical quantum yield of photosystem II [Y (II)] was calculated as described by Genty et al. (1989).

Our second physiology measure was chlorophyll fluorescence ratio (CFR), as a non-intrusive tool in using it as a proxy to establish plant stress and gain information on photosynthetic reactions in the chloroplast (Schreiber et al. 1987). The fluorescenceemission spectra read out two maxima in the $690 \mathrm{~nm}$ and the $735 \mathrm{~nm}$ region. The fluorescence ratio F690/F735 for green leaves is higher (values of 0.8 to 1.1), than in the yellow to red wavelength region $(525$ to $633 \mathrm{~nm})$, which only yields values for F690/F735 of 0.5 to 0.7 (Rinderle et al. 1988). Chlorophyll fluorescence ratio 
(CFR) was measured with a chlorophyll content meter (OPTI-Sciences model CCM-300, Hudson, USA).

Relative Electron Transport Rate (RETR) was calculated with JUNIOR-PAM chlorophyll fluorometer and WinControl Software (Walz, Effeltrich, Germany). Modulated excitation energy and the fluorescence signal were transmitted through a bifurcated fiber-optic cable. $P$. juniperinum protonema samples were placed in a cuvette containing moist cotton ball to provide adequate moisture through the assessment. Measurements with the Junior-PAM were conducted under constant fluorescent lighting in the laboratory at mean photosynthetically active radiation (PAR) value of $250 \mu \mathrm{mol} \mathrm{m}$ ${ }^{2} \mathrm{~s}^{-1} \pm 50$ SEM. Relative electron transport rate (RETR) can be obtained as PFD x $(\Phi)$ PSII (Bilger et al. 1995). Junior-PAM recorded electron transport rate, photosynthetic yield

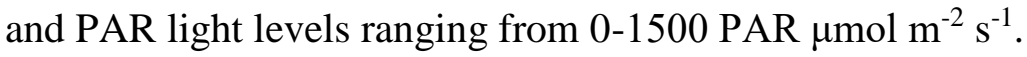

\section{Light and temperature response curves of $P$. juniperinum protonema}

Isoprene emission rates were quantified at different levels of incident light of photosynthetic photon flux density (PPFD). Temperature curve measurements were controlled by a water bath. Sample container leaf temperatures were monitored with thermocouples and adjusted as needed. Experiments were carried out under standard

conditions $\left(30^{\circ} \mathrm{C}\right.$ and $1,000 \mu \mathrm{mol} \mathrm{m} \mathrm{m}^{-2} \mathrm{~s}^{-1}$ photosynthetic photon flux density at leaf level (PPFD)), unless otherwise noted. Light was provided with a Dracast LED1000 Pro Daylight light panel, with a light-emitting diode array (Photon Systems Instruments, Albuquerque, NM). 
Light and temperature curve measurements were made using JUNIOR-PAM chlorophyll fluorometer and WinControl Software (Walz, Effeltrich, Germany). For temperature response curves, we subjected $P$. juniperinum protonema $(\mathrm{n}=17)$, with 3 replicates for each sample with temperature increasing from $0-35.5^{\circ} \mathrm{C}$ under constant irradiance of $1000 \mu \mathrm{mol} \mathrm{m} \mathrm{m}^{-2} \mathrm{~s}^{-1}$ to establish basal emission rates. The temperature at the time of the measurement correlated to inside temperature of the PlantCon ${ }^{\mathrm{TM}}$ containers (MP Biomedicals, 2017), which was $0.5 \mathrm{~cm}$ away from the sample. For light measurements we used $(n=28)$ with three replicates per protonema under constant temperature of $30^{\circ} \mathrm{C}$ and increasing light from $0-2250 \mu \mathrm{mol} \mathrm{m} \mathrm{m}^{-2}$ photosynthetic photon flux density (PPFD).

\section{Statistical analyses}

Statistical analyses of the data were performed using R version 3.4.2 (R Studio 2017) and JMP Pro 14.0 (SAS Institute, Cary, North Carolina, USA). To determine the effects of day number, site, and media on isoprene emission in protonema, we used Chisquare Goodness of Fit with a statistical significance level of $p=0.05$. Day number, site and media using binary code of isoprene emitters (1), and non-isoprene emitters (0) was used to analyze the dataset. The chi-square statistic quantified how much of the observed distribution of isoprene emitter counts varied from a hypothesized uniform distribution.

To determine the effects of media and site on protonema isoprene emission up until day forty-five, we used an ANOVA to compare means of protonema emission from each site and each media to assess whether the means of emission by media and site 
stayed consistent. We ran a second ANOVA to test the effects of leaf number on isoprene emission from our half sibling isoprene emission experiment. For our continuous halfsibling experiment early $P$. juniperinum protonema, we ran repeated measure ANOVA (RM ANOVA) to test the effects of media and time on isoprene emission during our three assessments. Data met the assumptions of the model.

We used regression analysis to examine the relationship between isoprene emission and protonemal growth along with percentage change in protonema growth. Logged isoprene emission was classified as the response variable, and protonemal growth was classified as the continuous predictor.

To determine the effect of media on CFR, we used an ANOVA. We used regression analysis to examine the relationship between CFR and isoprene emission. To determine the effect of media on Relative Electron Transport Rate (RETR), we used an ANOVA. We also used regression to examine the relationship between RETR and isoprene emission. Similarly, we used regression analysis to examine the relationship between isoprene emission and light, as well as isoprene and temperature.

\section{Results}

\section{Early isoprene emission in Polytrichum juniperinum protonema}

Day number and initial collection site contributed significantly to our model fit in predicting isoprene emission in early $P$. juniperinum protonema. There was a significant difference between effect of day $\left(\mathrm{DF}=7 ; \mathrm{X}^{2}=149.6 ; \mathrm{P}<0.0001\right)$ for total isoprene emitting samples of $P$. juniperinum and site-specific effects $\left(\mathrm{DF}=2 ; \mathrm{X}^{2}=6.015 ; \mathrm{P} \leq 0.0009\right)$. Not 
all samples emitted isoprene at the same time, and we saw site-specific differences in emission ability and timing. Overall, day contributed to $78 \%$ of variation in emission, while site contributed only $2 \%$ of variation in isoprene emission, with the rest of the contribution coming from residual effects (Figure 2.2). On day five, $14 \%$ of the samples ( 3 of 21) emitted isoprene, and plants from two of the three sites were emitting at detectable levels. The last site started emitting the following day. By day six $62 \%$ of the samples (13 of 21) were emitting, and plants from all three sites were emitting at different rates. This increased to $95 \%$ (20 of 21 samples) emitting isoprene by day eight, and we saw emissions from all samples and sites on day ten. From three sites, site 6 vs. site 8 , and site 8 vs. site 9 were statistically significant from each other, while site 6 vs. site 9 had no statistical significance. We found no effect of media on isoprene emission at this early stage $(\mathrm{P}=0.44)$.

\section{The effects of media and time on isoprene emission in early Polytrichum juniperinum protonema}

Isoprene emission was greatly influenced by the media on which it was grown by day forty-five (ANOVA; $\mathrm{DF}=1 ; \mathrm{F}=7.4082 ; \mathrm{P}<0.0001$; Figure 2.3). Isoprene emission from single spore isolated protonema showed higher levels of emissions on BCD media than agar. Mean isoprene emission on agar media was lower than BCD media. On agar isoprene emission mean value was $26.2 \mathrm{nmol} \mathrm{m}^{-2} \mathrm{~s}^{-1} \pm 8.093 \mathrm{SEM}(\mathrm{n}=9)$, on BCD media mean isoprene emission value was $62.56 \mathrm{nmol} \mathrm{m}^{-2} \mathrm{~s}^{-1} \pm 9.887 \mathrm{SEM}(\mathrm{n}=9)$. All surviving protonema in its resting phase has increased in growth, but none of the samples 
differentiated into gametophytic tissue in the first assessment (Figure 2.4). Protonema by day 45 was embedded into the agar and separation was not possible without breaking the integrated protonemal network. Overall, media contributed $58 \%$ of the total variation in isoprene emission, protonema on agar had $42 \%$ less isoprene emission than protonema on $\mathrm{BCD}$, while we have found no statistical significance between sites $(\mathrm{P}=0.1325)$.

In our second assessment, we found that isoprene emission was significantly affected by leaf number for single spore isolates of eighty-one siblings (ANOVA; $D F=4$; $\mathrm{F}=4.01 ; \mathrm{P}=0.0036$; Figure 2.5), with isoprene emission decreasing as leaf number increased. Total leaf count was 35 by our second assessment $(n=81)$, and 51 on our third assessment. Mean isoprene emission was significantly different between days tested and leaf number (RM ANOVA; $\mathrm{DF}=1 ; \mathrm{X}^{2}=4.83 ; P \leq 0.0001$ ). Mean isoprene emission from the three individual time assessments was $9.76 \mathrm{nmol} \mathrm{m}^{-2} \mathrm{~s}^{-1} \pm 0.55 \mathrm{SEM}(\mathrm{n}=243)$, and ranged from 7.23 to $11.41 \mathrm{nmol} \mathrm{m}^{-2} \mathrm{~s}^{-1}(\mathrm{n}=243)$, with the lowest isoprene emission seen on our last assessment.

\section{Isoprene emission and growth in Polytrichum juniperinum protonema}

We found a significant correlation between isoprene emission and protonema growth. Protonema growth showed a negative trend against isoprene emission with larger diameter protonema emitting less isoprene than protonema with smaller diameter. Logarithmic line equation for first assessment was $\mathrm{Y}=-1.15 \ln (\mathrm{x})+3.02$; and for the second assessment was $\mathrm{Y}=-1.02 \ln (\mathrm{x})+2.72\left(\right.$ Regression; $\mathrm{r}^{2}=66.18 ; \mathrm{P}<0.0001 ;$ Figure 2.6). Isoprene emission increased in the beginning, plateaued midway and as soon as leaf 
emergence took place isoprene emission dropped significantly. Collectively, mean isoprene emission from single spore isolates from all dates were $27.4 \mathrm{nmol} \mathrm{m}^{-2} \mathrm{~s}^{-1} \pm$ 4.378 SEM $(n=243)$, which were higher than from protonema grown from $\sim 100$ spores. Isoprene emission ranges during September 2, 2016, September 15, 2016 and September 28, 2016 were from $13.92 \mathrm{nmol} \mathrm{m}^{-2} \mathrm{~s}^{-1} \pm 1.217$ SEM to $40.89 \mathrm{nmol} \mathrm{m}^{-2} \mathrm{~s}^{-1} \pm 8.434$ SEM $(n=162)$.

Mean protonema growth for the three time intervals (September 2, 2016; September 15, 2016; September 28, 2016) was $1.456 \mathrm{~mm}^{2} \pm 0.0657 \mathrm{SEM}(\mathrm{n}=243)$. Protonema growth ranges were from $1.04 \mathrm{~mm}^{2} \pm 0.089 \mathrm{SEM}$ to $1.872 \mathrm{~mm}^{2} \pm 0.072$ SEM $(n=162)$. Overall protonema growth contributed to $52 \%$ of total variation in isoprene emission in the first assessment from September 2, 2016 to September 15, 2016 and contributed to $23 \%$ of total variation in isoprene in the second assessment from September 15, 2016 to September 28, 2016.

We found significant differences in percentage change in protonema growth versus leaf emergence (ANOVA; $\mathrm{DF}=2 ; \mathrm{F}=67.23 ; \mathrm{P}=<0.0001 ;$ Figure 2.7). In the first assessment we saw an increase in the percentage change in protonema growth up until leaf emergence, but with leaves $\%$ change in protonema growth declined with more horizontal, rather than vertical growth development.

\section{Laboratory gas exchange measurements}

We have found that media significantly affects isoprene emission $\left(\mathrm{DF}=1 ; \mathrm{X}^{2}=\right.$ 21.25; $\mathrm{P}<0.0001)$, as well as isoprene emission and $\mathrm{CFR}\left(\mathrm{DF}=1 ; \mathrm{X}^{2}=5.85 ; \mathrm{P}<0.0156\right)$. 
The line slopes between media for CFR vs. isoprene emission are statistically significantly different with a regression line equation for agar $\mathrm{Y}=3.2774 * \mathrm{x}+0.5941$, and for $\mathrm{BCD} Y=0.7023^{*} \mathrm{x}+2.641(\mathrm{~F}=37.96 ; \mathrm{P}<0.0001 ;$ Figure 2.8). We found media significantly affects CFR measures (ANOVA; DF=1; F=11.6593; $\mathrm{P}<0.0013$; Figure 2.9).

Mean isoprene emission values overall were $16.18 \mathrm{nmol} \mathrm{m}^{-2} \mathrm{~s}^{-1} \pm 1.614 \mathrm{SEM}$ $(\mathrm{n}=52)$. While on agar media mean isoprene emission were $9.267 \mathrm{nmol} \mathrm{m}^{-2} \mathrm{~s}^{-1} \pm 1.137$ SEM ( $n=26)$, and ranged from 3.021 to $22.901 \mathrm{nmol} \mathrm{m}^{-2} \mathrm{~s}^{-1}(\mathrm{n}=26)$. Mean isoprene emission values on BCD were $23.140 \mathrm{nmol} \mathrm{m}^{-2} \mathrm{~s}^{-1} \pm 2.348 \mathrm{SEM}(\mathrm{n}=26)$, and ranged from 4.274 to $57.680 \mathrm{nmol} \mathrm{m}^{-2} \mathrm{~s}^{-1}(\mathrm{n}=26)$. On agar media, we saw a reduction of isoprene emission and on BCD isoprene emission was $40 \%$ higher than on agar media. CFR measures together explained 60\% variability in isoprene emission seen from $P$. juniperinum protonema.

Mean CFR values collectively were $0.489 \pm 0.015$ SEM $(n=52)$. On agar and BCD media CFR values ranged from 0.33 to $0.74(n=26)$, but mean CFR values on BCD media was higher $(0.5377 \pm 0.012 \mathrm{SEM}, \mathrm{n}=26)$, than on agar media $(0.442 \pm 0.010 \mathrm{SEM}$, $\mathrm{n}=26$ ). On agar media, CFR contributed $39 \%$ of variation in isoprene emission, and on BCD media, CFR contributed $21 \%$ of variation in isoprene emission.

We also took two light setting measurements for Relative Electron Transport Rate (RETR) curves for plants on two media (agar and BCD). Under low light setting (0-820 $\mu \mathrm{mol} \mathrm{m} \mathrm{m}^{-2} \mathrm{~s}^{-1}$, we found no statistical differences in RETR curves between media $(\mathrm{P}=$ 0.81; Figure 2.10). Mean RETR values were $33.06 \mu \mathrm{mol} \mathrm{m}^{-2} \mathrm{~s}^{-1} \pm 3.367 \mathrm{SEM}(\mathrm{n}=40)$. 
While on agar media under low light setting $(0,66,90,125,190,285,420,625,820$

$\left.\mu \mathrm{mol} \mathrm{m} \mathrm{m}^{-2}\right)$, RETR mean values were $32.18 \mu \mathrm{mol} \mathrm{m}^{-2} \mathrm{~s}^{-1} \pm 3.328 \mathrm{SEM}(\mathrm{n}=20)$ on agar; and on BCD media mean RETR were $33.94 \pm 3.406 \mathrm{SEM}(\mathrm{n}=20)$. Our regression line equation under agar was $\mathrm{Y}=0.1067 *+1.812$, and under $\mathrm{BCD}$ was $\mathrm{Y}=0.1102 * \mathrm{x}+0.8975$.

Under high light setting, we found statistical difference in media (RM ANOVA; $\mathrm{DF}=1 ; \mathrm{F}=3.9027 ; \mathrm{P}<0.05$; Figure 2.11). Regression line equation for RETR measures on agar being $\mathrm{Y}=0.1116^{*}+0.9509$, and under $\mathrm{BCD}$ were $\mathrm{Y}=0.1486 * \mathrm{x}+2.885(\mathrm{RM}$ ANOVA; $\mathrm{DF}=1 ; \mathrm{x} 2=3.65 ; \mathrm{P}=0.056)$. Under higher light settings $(236,302,325,361$, $\left.425,520,655,860,1055 \mu \mathrm{mol} \mathrm{m}^{-2} \mathrm{~s}^{-1}\right)$, mean RETR values were $74.06 \mu \mathrm{mol} \mathrm{m}^{-2} \mathrm{~s}^{-1} \pm$ 4.746 SEM ( $\mathrm{n}=40)$. Mean RETR values on agar were $68.06 \mu \mathrm{mol} \mathrm{m}^{-2} \mathrm{~s}^{-1} \pm 4.28$ SEM $(\mathrm{n}=20)$ and on BCD media were $81.14 \mu \mathrm{mol} \mathrm{m}^{-2} \mathrm{~s}^{-1} \pm 5.212$ SEM $(\mathrm{n}=20)$. RETR values contributed to $78.5 \%$ variation under low light setting $\left(0-820 \mu \mathrm{mol} \mathrm{m}^{-2} \mathrm{~s}^{-1}\right)$ on agar media, and RETR values contributed 51\% variation under high light setting (0-1150 $\mu \mathrm{mol} \mathrm{m} \mathrm{m}^{-2} \mathrm{~s}^{-1}$ on agar media with PAR levels selected as random effects. Our combined low agar and low BCD media RETR values were $26.2 \mu \mathrm{mol} \mathrm{m}^{-2} \mathrm{~s}^{-1} \pm 8.093$ SEM ( $\left.\mathrm{n}=20\right)$; whereas the combined high agar and BCD values were $62.56 \mu \mathrm{mol} \mathrm{m}^{-2} \mathrm{~s}^{-1} \pm 9.887 \mathrm{SEM}$ $(\mathrm{n}=20)$, with a regression line equation for low agar and BCD; Low $\mathrm{Y}=.01087^{*} \mathrm{x}+1.355$, and for high agar and BCD; High $\mathrm{Y}=0.13012 * \mathrm{x}+6.197$ (Figure 2.12).

\section{Light and temperature response curves of $P$. juniperinum protonema}

We found that isoprene emission and light in $P$. juniperinum were statistically correlated across temperature. Our regression line equation for isoprene emission and 
temperature was $\mathrm{Y}=0.4798 * \mathrm{x}-4.791$ (Regression; $\mathrm{r}^{2}=0.56 ; \mathrm{P}<0.0027$; Figure 2.13).

Light correlated logarithmically to PPFD with a nonlinear lognormal line equation of Y=$49.69 \ln (\mathrm{x})+34.2\left(\right.$ Regression; $\mathrm{r}^{2}=0.62 ; \mathrm{P}<0.0004 ;$ Figure 2.14). Under varying temperature and constant light (PPFD) P. juniperinum mean isoprene emission were 11.7 $n m o l m^{-2} s^{-1} \pm 0.8862$ SEM ( $\left.n=38\right)$. Under varying light (PPFD) and constant temperature mean isoprene emission were $7.267 \mathrm{nmol} \mathrm{m}^{-2} \mathrm{~s}^{-1} \pm 0.421 \mathrm{SEM}(\mathrm{n}=53)$.

\section{Discussion}

\section{Isoprene emission in Polytrichum juniperinum protonema}

Sampling detectable levels of isoprene emission from $P$. juniperinum protonema was accomplished here for the first time. We demonstrate that protonema from mature sporophytes (Figure 2.1) can be successfully assessed for isoprene emission in both as single spore isolates from half siblings and from mixed spores. In the earliest life stage in the moss life cycle, $P$. juniperinum can emit detectable levels of isoprene (Figure 2.2). Our aim was to assess and quantify isoprene emission in moss protonema. We have found that mosses can emit isoprene as early as five days after spore germination, and we demonstrate that a time lag exists from the beginning of protonemal development to isoprene emission. In vascular plants, it is already established that a time lag exists between onset of photosynthesis and isoprene emission (Rasulov et al. 2014). Vascular leaves will take days to weeks to be able to produce isoprene depending on photosynthetic adequacy (Sharkey et al. 1993; Monson et al. 1994; Goldstein et al. 1998; Kuhn et al. 2004; Mayrhofer et al. 2005; Wiberley et al. 2005; Sharkey et al. 2007). We 
can confirm that we observed moss protonema isoprene emission time lag that is comparable to the time lag observed in vascular plants where isoprene emission develops by day six after new leaf emergence (Velikova et al. 2008; Rasulov et al. 2014). Our results indicate that isoprene emission initiates during the first moss protonemal stage, a stage which can last indefinitely in many mosses (Rensing et al. 2007, 2018a,b; Reski et al. 2018a,b; Ryo et al. 2018).

Additionally, our results suggest that isoprene emission capacity is higher for young moss tissue compared with older tissue. We found average isoprene emission for protonema to be $45.85 \mathrm{nmol} \mathrm{m} \mathrm{m}^{-2}$ (at $1000 \mu \mathrm{mol} \mathrm{m}^{-2} \mathrm{~s}^{-1}$ and $30^{\circ} \mathrm{C}$ ). This range is higher than what is reported for $P$. juniperinum gametophytes of $37 \mathrm{nmol} \mathrm{m}^{-2} \mathrm{~s}^{-1}$ (at $1600 \mu \mathrm{mol}$ $\mathrm{m}^{-2} \mathrm{~s}^{-1}$ and $30^{\circ} \mathrm{C}$ ) (Hanson et al. 1999). Isoprene emission from protonema was highly variable, in both mixed sporophytes and half sibling surveys, suggesting genetic differences within moss capsules. Our data suggest that isoprene production in $P$. juniperinum is influenced by site-specific effects suggesting both genetic control and environmental effects in isoprene emission. These results are similar to those found in vascular plants, where large genetic differences between plants have been recorded (Loreto et al. 1998, 2009; Velikova et al. 2014). In addition, in vascular plants, isoprene emission has been seen to be highly developmentally variable within the same plant when sampled between the lower branches and top branches of a single tree, with emissions higher in the top of the tree (Harley et al. 1997).

For our spore mixtures from multiple sporophyte assessment, isoprene emission increased on nutritive BCD media as opposed to non-nutritive agar. This suggests that the 
young protonema on nutrient rich media was able to utilize the resources available for secondary metabolite production rather than expend the resource on growth (Figure 2.4). We observed more isoprene emission from spores plated on BCD suggesting that the protonema can utilize environmental sources of nutrients to fix carbon for isoprene emission. On agar media, observed isoprene emission was lower as demand for resources to expand and grow initiated a higher demand than available supply allowed (Lambers 1993; Kuhn et al. 2004; Owen et al. 2005; Rosenstiel et al. 2004; Brilli et al. 2007; Loreto et al. 2007a,b; Sharkey et al. 2007; Morfopoulos et al. 2014). Moss protonema development provides useful insight into what factors control life cycle phases of mosses (Niklas et al. 2010; Hackenberg et al. 2016; Silva-e-Costa et al. 2017).

Light and temperature are closely linked to protonema development (Cove et al. 1978), as is bioavailable nitrogen (Alcade et al. 1996). Other factors that can contribute to protonema development include macronutrient availability (Basile et al. 1975), cell growth by osmotic cell properties (George et al. 2008), and the effects of moisture conditions (Pakarinen et al. 1977; Chopra et al. 1981; Chaban et al. 1999; Silva et al. 2010; Sabovljević et al. 2014; Nishihama et al. 2015; Liu et al. 2016). However, no other study has looked at isoprene emission and protonema development and considered this as a factor when assessing growth and resources allocation, as well as carbon allocation between growth and isoprene emission.

For our half sibling experiment, using single-spore isolates, we saw high isoprene values initially. We observed a decrease in isoprene emissions by our second assessment when leaves had first emerged from the young protonema. For the third and final 
isoprene assessment, we saw more leaves and the lowest amount of isoprene collectively (Figure 2.5), suggesting a metabolic cost to isoprene emission. The 81 half siblings reached peaked protonema growth just as leaves emerged and dropped significantly as more leaves grew perhaps as a result of exhausted resources and accumulation of stress factors within the PlantCon ${ }^{\mathrm{TM}}$ container.

Isoprene synthase enzyme is developmentally regulated and for mature vascular leaves, emission rates depend on DMADP (dimethylallyl diphosphate) availability, whereas in young leaves emission is also influenced by isoprene synthase protein availability (Vickers et al. 2010). Differences have been observed in vascular plant isoprene emission, where its capacity was $124 \%$ higher in young leaves than in older mature leaves (Alves et al. 2014). We suspect that we could also find young to mature gametophyte $P$. juniperinum isoprene emission differences as we saw protonema age and leaf development with decreased isoprene emission.

\section{Isoprene emission and growth in Polytrichum juniperinum protonema}

In vascular plants, each isoprene molecule costs carbon and energy. The energy and carbon cost have been summarized by Sharkey et al (2001), with each isoprene molecule costing nine carbon atoms, 24 molecules of ATP, and 14 molecules of NADPH when using the MVA isoprene production pathway (Sharkey et al. 2001; Niinemets et al. 1999; Sanadze 2010; Sanadze et al. 2016; Fini et al. 2017). Whether the cost in nonvascular plants is the same as it is in vascular plants is yet to be determined. However, to be able to emit isoprene in mosses, photosynthetic capability must be adequate as it is in 
vascular plants (Schnitzler et al. 2005), and carbon that is used for isoprene emission may not be available for growth. Isoprene emission rate and photosynthetic rate generally correlates, but both processes can have independent responses to plant growth (Monson et al. 1994).

In vascular plants under increased $\mathrm{CO}_{2}$ growth of biomass can be enhanced, but isoprene emission is reduced, suggesting leaf level suppression of isoprene emission given increased $\mathrm{CO}_{2}$ (Rosenstiel et al. 2003). We explored protonema growth as one of the costs to isoprene emission and found that plants with small protonema growth had higher isoprene emission than plants with higher rates of growth (Figure 2.6) suggesting a trade-off between growth and isoprene emission for carbon resource allocation in early protonema development. It was very interesting to find that some moss protonema allocated enough resources to isoprene production that growth was significantly delayed indicating that isoprene production and emission can play a role in early development whose importance is on par with the imperative of early growth.

Similar trade-offs have been reported in vascular plants. In overexpressed Populus canescens isoprene synthase gene in non-isoprene emitter Camelina sativa lead to alterations in its growth and metabolism. This resulted in shorter and smaller leaves than wild types, suggesting a trade-off between biomass production and isoprene emission (Rossi et al. 2017).

We observed a significant trade off associated with growth and isoprene emission when we assessed the percentage change in protonema growth compared to isoprene emission as new leaves began to emerge. Then with increased growth as evidenced by 
more leaves emerging, and P. juniperinum spent resources on horizontal, rather than vertical growth (Figure 2.7) isoprene emissions leveled off and then fell. The advantages that plants receive must outweigh the cost to keep isoprene emission as an evolutionary trait present in many species. This observation makes studies showing that North American oaks all emit isoprene, but many of the European oaks do not (Loreto et al. 1998; Kesselmeier et al. 1999) that much more confounding in our search to understand a mechanistic model that provides a cost benefit analysis between isoprene emission and growth.

Mosses can serve as an ideal system to study isoprene emission, as many of the necessary traits such as isoprene emission were established in early land plants. Isoprene emission was conserved in some mosses and vascular plants, but not all plants emit isoprene. Since plants, including mosses have lost and gained this trait multiple times, it is possible to trace evolutionary linkages with gene targeting to understand what the evolutionary advantage is that repeatedly selected for this mechanism (Reski 1998; Wood et al. 2000; Stenøien et al. 2001, 2005; Fattash et al. 2007; Cove et al. 2009; Reski 2018b; Lang et al. 2018; Zhao et al. 2018).

\section{Laboratory gas exchange measurements}

We wanted to find out whether isoprene-emitting protonema are able to maintain typical levels of photosynthesis as stress levels change and if we could observe a relationship between isoprene emission and either chlorophyll fluorescence ratio (CFR) or Relative Electron Transport Rate measures (RETR). Polytrichaceae gametophytes 
have been found to have a good negative exponential saturation curve in high irradiances, and this moss light saturation curve approaches and can exceed full midday sun (Proctor et al. 2005, 2006). However, no protonema electron transport curves have been published to our knowledge. We know that there is a strong positive correlation between photosynthetic electron transport rate and isoprene emission (Warren et al. 2000; Dani et al 2015). Even under moderate stress, electron transport rate values can be maintained (Genard et al. 2014). In vascular plants, mild stress can decrease stomata opening and affect carbon assimilation, while isoprene emission and electron transport rate maintenance is not affected (Niinemets et al. 2010).

Desiccation tolerant bryophytes and desiccation tolerant dicots conserve chlorophyll during desiccation (Tuba et al. 1996; Porembski et al. 2000), suggesting chlorophyll loss is an acceptable cost associated with desiccation tolerance (Hinshiri et al. 1971; Alpert 2000; Oliver et al. 2005). We have seen in our protonema that the low values we obtained for chlorophyll fluorescence ratio (CFR) was due to phenotypic plasticity to desiccation. Chlorophyll fluorescence is sensitive to moss water content and during desiccation, mosses suffer low capacity to maintain photosynthetic efficiency (Robinson et al. 2000). Mosses are $\mathrm{C} 3$ plants and the relationship between $\mathrm{CO}_{2}$ gas exchange and ETR are complex and different from what has been found in higher plants (Green et al. 1998). We found a statistically significant relationship between chlorophyll fluorescence ratio on agar versus BCD media, and we saw a statistically significant relationship between media and CFR values affecting isoprene emission (Figure 2.8; Figure 2.9). 
Relative electron transport rate measures stress and enables dissipation through photorespiration or photochemical quenching. Changes in isoprene emission have been strongly correlated with changes in leaf ATP content suggesting that the rate of photosynthetic electron transport (ETR) may exert control over isoprene production and emission (Loreto et al. 1990; Niinemets et al. 1999). RETR was measured independently using fluorescence and was not coupled with LiCor measurements and should only be taken as indicative and not as absolute measures (Dani et al. 2014). The values presented here for low light RETR, high RETR and combined low and high RETR curves were assessed for stress. Our results correspond under both high and low light conditions to what has been documented for macroalgae RETR ranges (Franklin et al. 2001; Figueroa et al. 2003), where a good correlation can be found between RETR and $\mathrm{O}_{2}$ evolution (Beer et al. 2000; Longstaff et al. 2002). Our ranges are considered to be under low stress, neither of our low or high RETR curves reached saturation, meaning that protonema is capable of exceeding our values once saturation is reached (Figure 2.10, $2.11,2.12)$.

\section{Light and temperature response curves of $P$. juniperinum protonema}

Isoprene emission saturation values for light (PPFD) and temperature in $P$. juniperinum are much lower than reported for mature vascular plants, where isoprene emission can increase with photosynthetic photon flux density of up to $3000 \mu \mathrm{mol} \mathrm{m} \mathrm{m}^{-2} \mathrm{~s}^{-1}$ (at $30^{\circ} \mathrm{C}$ ) and can continue to increase after photosynthesis is saturated at $1000 \mu \mathrm{mol} \mathrm{m} \mathrm{m}^{-2}$ $\mathrm{s}^{-1}$ (Sharkey et al. 1993). We found a strong effect on isoprene emission of both 
temperature and light, indicating that isoprene emission can increase with photon flux up to $2250 \mu \mathrm{mol} \mathrm{m} \mathrm{m}^{-2} \mathrm{~s}^{-1}$ and temperature for up to $35^{\circ} \mathrm{C}$. Our ranges for emission maxima were between $40-45^{\circ} \mathrm{C}$ and $800-1200 \mu \mathrm{mol} \mathrm{m} \mathrm{m}^{-2}$, which is close to saturation level of young leaves in vascular plants (Alves et al. 2014). Isoprene saturation in moss protonema occurred at $1500 \mathrm{PPFD} \mu \mathrm{mol} \mathrm{m} \mathrm{m}^{-2} \mathrm{~s}^{-1}$, and isoprene emission did not saturate for our temperature curves. This suggests that $P$. juniperinum protonema is sensitive to changes in light, but whether it is able to tolerate higher temperature values to reach saturation remains to be seen. Others have shown that at $40^{\circ} \mathrm{C}$ and 1000 PPFD $\mu \mathrm{mol} \mathrm{m}{ }^{-2}$ $\mathrm{s}^{-1}$ isoprene emission reaches maximum level and can produce over $200 \mathrm{nmol} \mathrm{m} \mathrm{s}^{-2}$ in kudzu leaves (Sharkey et al. 1993). Water stress plays a large role in emission as was shown by Sharkey where at $35^{\circ} \mathrm{C}$ and $1000 \mu \mathrm{mol} \mathrm{m} \mathrm{m}^{-2} \mathrm{~s}^{-1}$ isoprene emission in proportion to photosynthesis increased from $24 \%$ to $67 \%$ (Sharkey et al. 1993).

The positive correlation in this study between isoprene emission and temperature (Figure 2.13) as well as between isoprene emission and light (Figure 2.14) confirm temperature dependency and light dependency in moss protonema, as has been reported from vascular plants (Sanadze et al. 1966, 1969; Tingey et al. 1979; Monson et al. 1989, 1992; Sanadze 2004; Sasaki et al. 2005). Many protonemal samples did not respond to either light or temperature and remained flat lined through the trials, while higher temperatures caused the chloroplast to be released from the protonema membrane at $40^{\circ} \mathrm{C}$. This resulted in complete chloroplast loss as evident the next day with protonema that turned translucent. High variability in isoprene emission seen in our light and temperature trials indicates that there is a close relationship between photosynthesis and 
isoprene emission (Kuhn et al. 2002). We need to understand how much carbon taken up by photosynthesis is released as isoprene in mosses. In vascular plants, the loss of carbon that is fixed by photosynthesis can vary, and it can be as high as $20 \%$ (Sharkey et al. 1991, 1993). It has been shown in vascular plants that carbon fixed by photosynthesis and re-emitted as isoprene is 53\% higher in sun leaves than in shade leaves (Harley et al. 1996). Further investigation is required to understand isoprene emission in moss species such as the Polytrichaceae, which ecologically occupy a wide range of habitats from xerophytes capable of withstanding high light to species which thrive in deep shaded wet habitat. 


\section{Tables and Figures}

Table 2.1 Summary table of Polytrichum juniperinum populations used for protonema single spore and mixed spore experiments.

\begin{tabular}{|c|l|l|l|}
\hline Experiment & Latitude & Longitude & $\begin{array}{l}\text { Elevation } \\
\text { (meters) }\end{array}$ \\
\hline $\begin{array}{l}\text { Protonema from single } \\
\text { spore samples }\end{array}$ & $45^{\circ} 41^{\prime} 38.34^{\prime \prime} \mathrm{N}$ & $122^{\circ} 52^{\prime} 14.23^{\prime \prime} \mathrm{W}$ & 15 \\
\hline $\begin{array}{l}\text { Location 1 } \\
\text { spore samples }\end{array}$ & $45^{\circ} 47^{\prime} 17^{\prime \prime} \mathrm{N}$ & $122^{\circ} 56^{\prime} 16.00^{\prime \prime} \mathrm{W}$ & 241 \\
\hline $\begin{array}{l}\text { Protonema from mixed } \\
\text { spore samples } \\
\text { Location 2 }\end{array}$ & $45^{\circ} 41^{\prime} 50.54 " \mathrm{~N}$ & $122^{\circ} 52^{\prime} 40.83^{\prime \prime} \mathrm{W}$ & 145 \\
\hline $\begin{array}{l}\text { Protonema from mixed } \\
\text { spore samples } \\
\text { Location 3 }\end{array}$ & $45^{\circ} 46^{\prime} 58.78^{\prime \prime} \mathrm{N}$ & $123^{\circ} 22^{\prime} 14.14^{\prime \prime} \mathrm{W}$ & 315 \\
\hline
\end{tabular}


Figure 1.1 Conceptual model for exploring isoprene emission in moss. Factors in this study excluded from analyses were Environmental factors and Atmospheric Chemistry differences associated with isoprene emission.

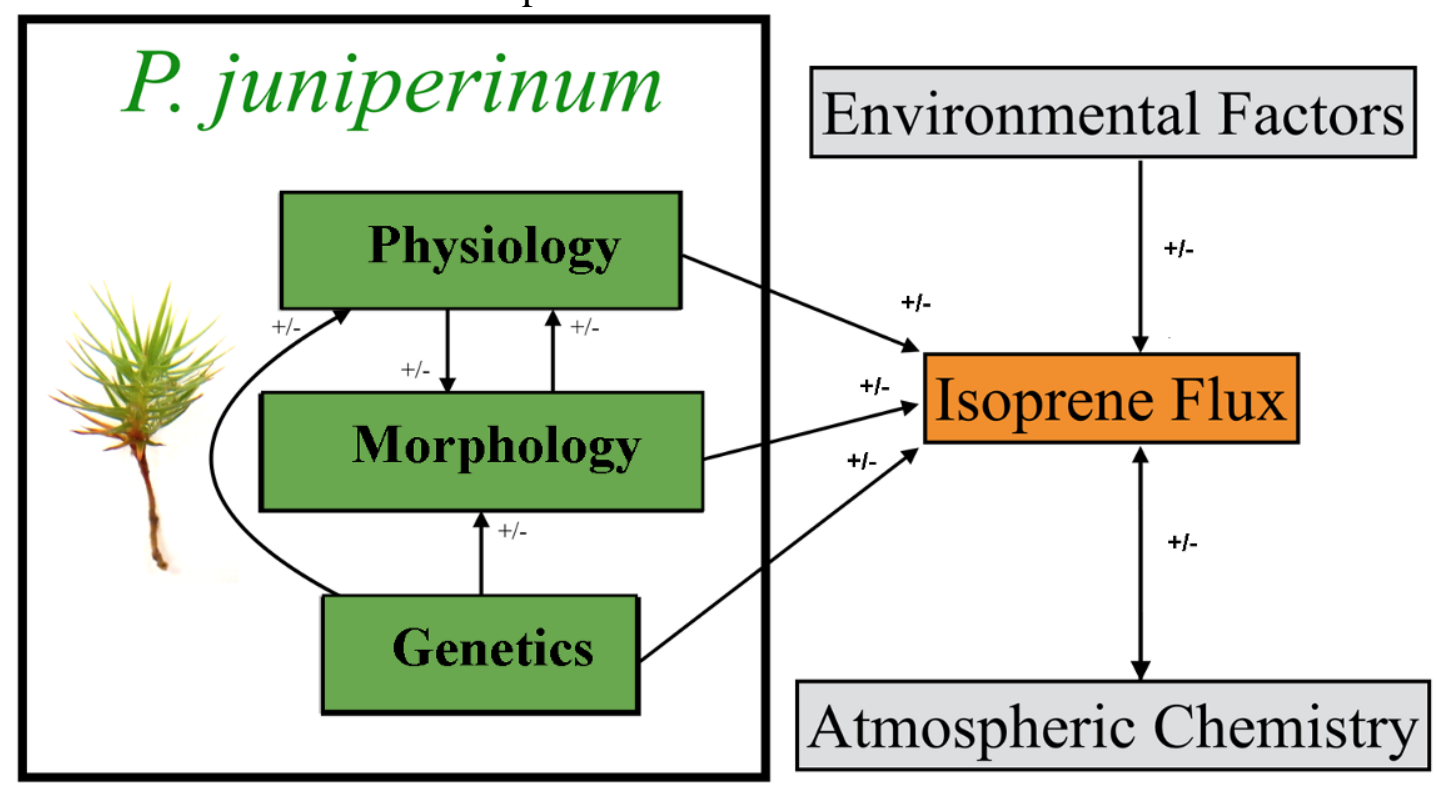


Figure 2.1 (a) Depiction of $P$. juniperinum spores before capsule sterilization from two sites (upper right rural forest site), and (lower left high elevation mountain site); (b) fortyfive day old $P$. juniperinum protonema growing in $\mathrm{BCD}$ media in PlantCon ${ }^{\mathrm{TM}}$ containers.

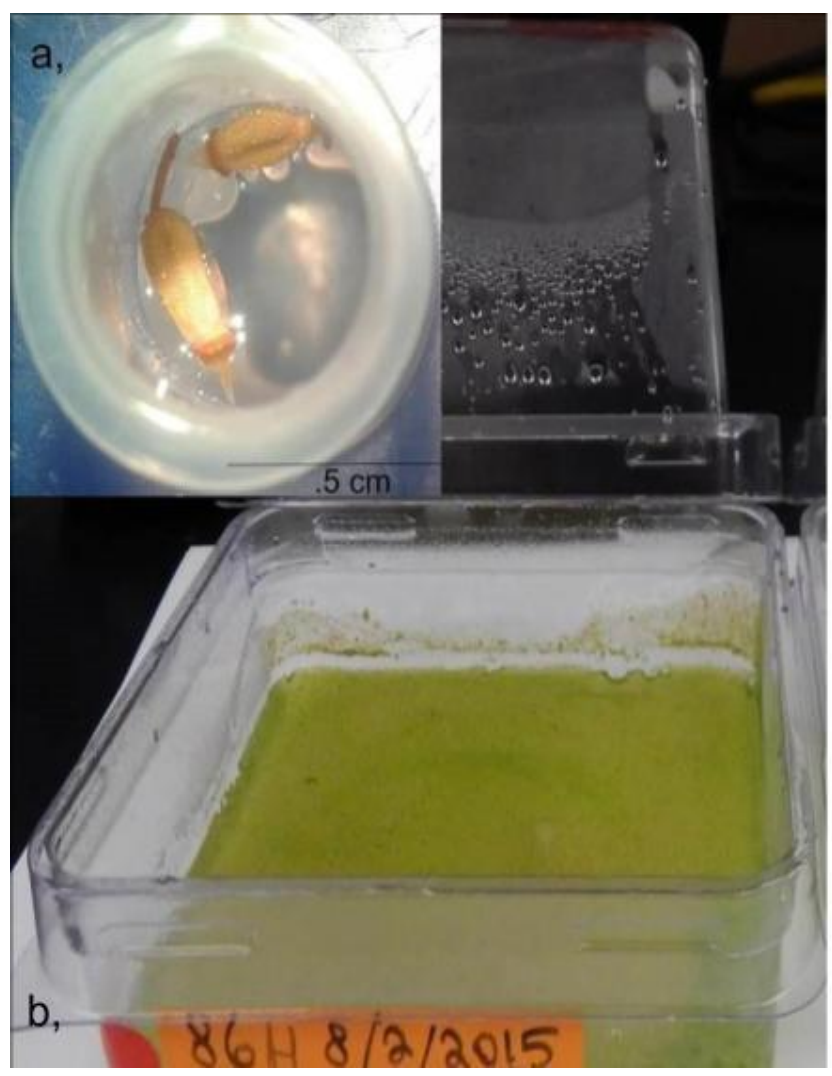


Figure 2.2 Isoprene emission (nmol $\mathrm{m}^{-2} \mathrm{~s}^{-1}$ ) versus $P$. juniperinum spore germinated protonema $(\mathrm{n}=21)$. Isoprene emission $\left(\mathrm{nmol} \mathrm{m} \mathrm{m}^{-2} \mathrm{~s}^{-1}\right)$ by day is plotted on the $\mathrm{x}$-axis from day 1 to day 10. Nominal Tukey-Kramer HSD Multiple Comparisons Test shows areas of significant difference between isoprene emitting samples among days. Letters show statistical significance between means. Means with the same letter are not significantly different. A * indicates significant difference, ** indicates a highly significant difference, *** indicates high statistical significance, NS indicates no significance.

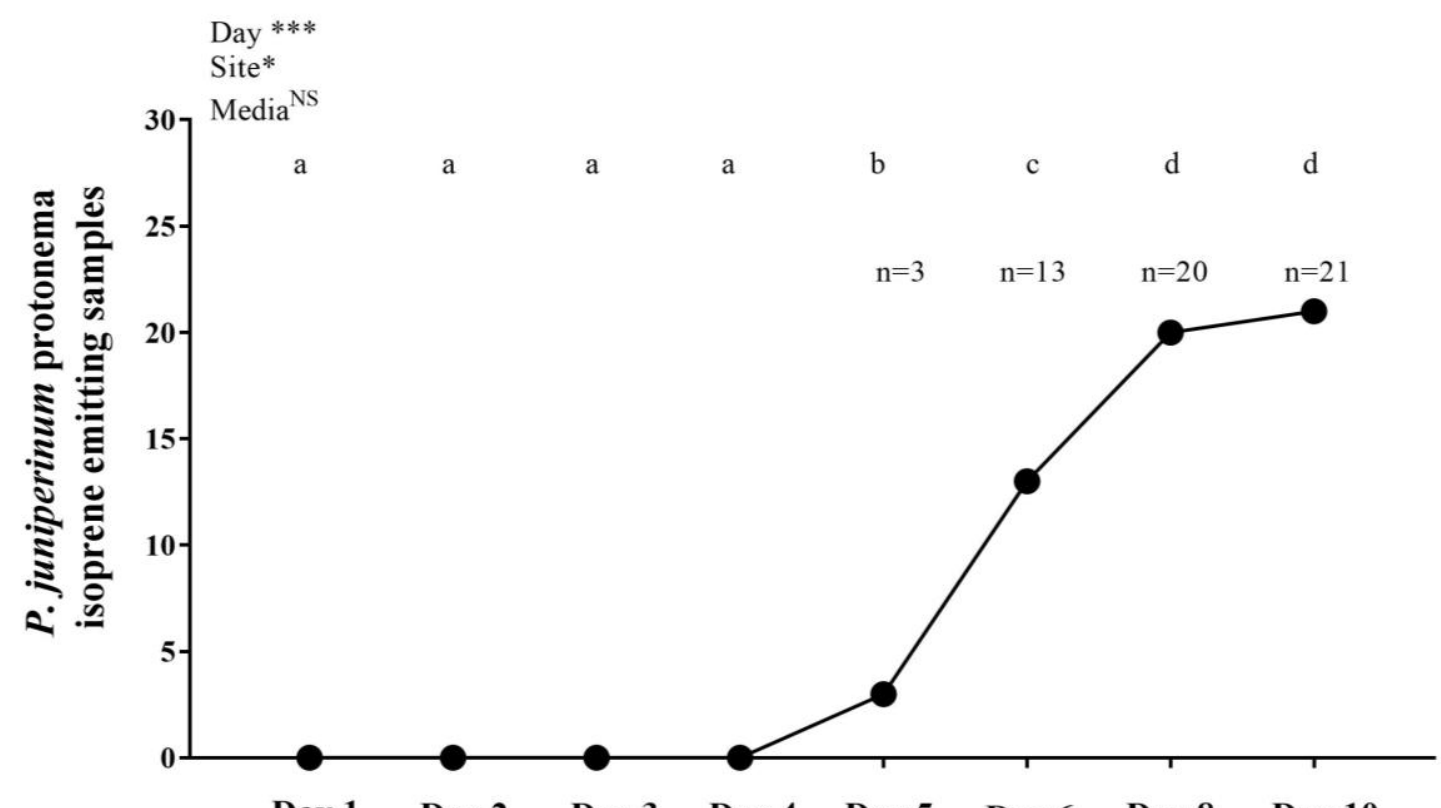

Day 1 Day 2 Day 3 Day 4 Day 5 Day 6 Day 8 Day 10 
Figure 2.3 Isoprene emission $\left(\mathrm{nmol} \mathrm{m} \mathrm{m}^{-2} \mathrm{~s}^{-1}\right.$ ) versus media (agar versus BCD) in $P$. juniperinum protonema $(\mathrm{n}=52)$. Media source is plotted on the $\mathrm{x}$-axis. Error bars represent $\pm 1 \sigma$ (standard deviation). Letters show statistical significance between means. Means with the same letter are not significantly different. A * indicates significant difference, $* *$ indicates a highly significant difference, $* * *$ indicates high statistical significance, NS indicates no significance.

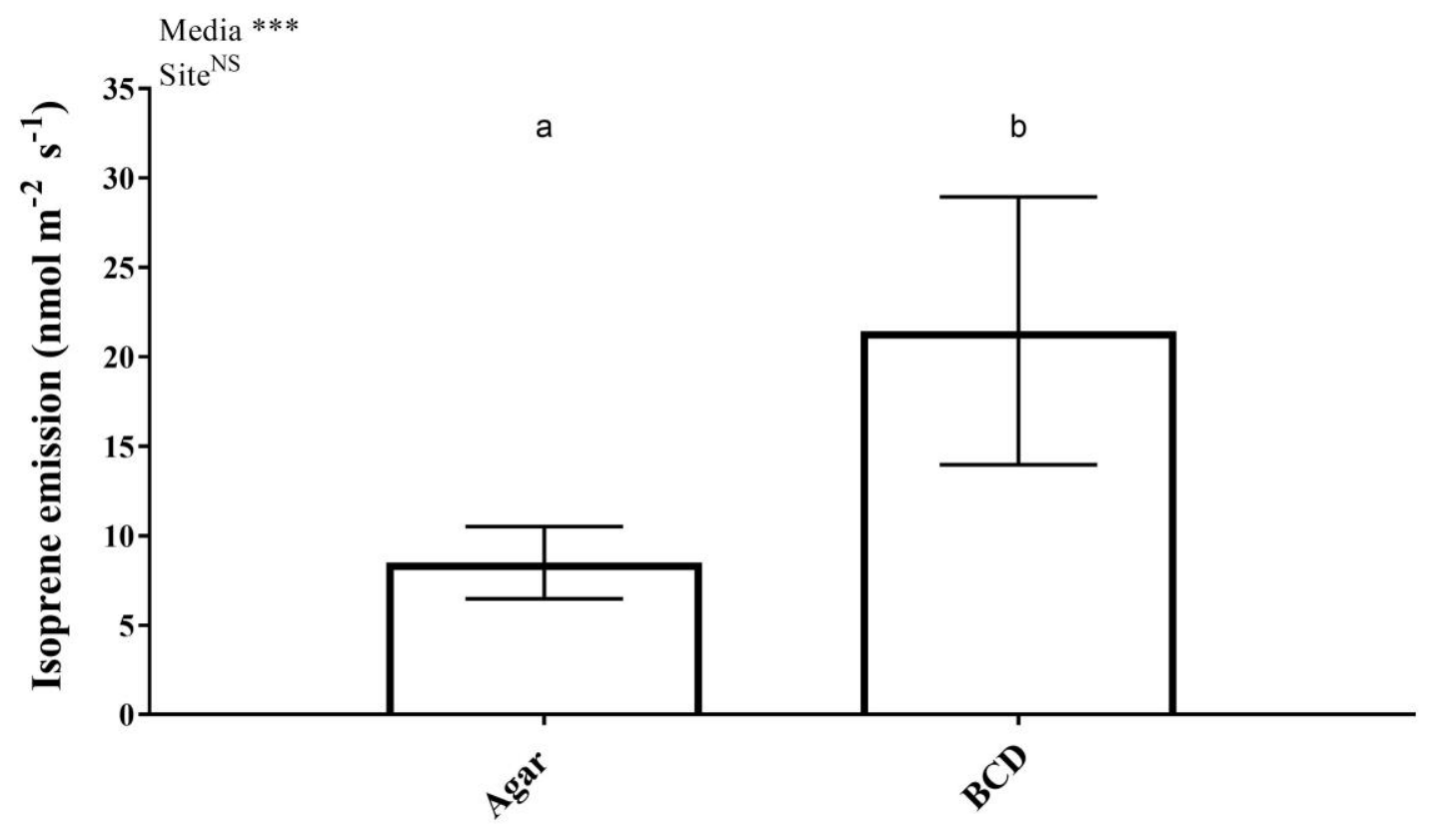


Figure 2.4 Image depicting $P$. juniperinum protonema growth versus day number $(\mathrm{n}=21)$. Detail is shown for average protonema growth for each day. Growth of protonema was measured using upright bright-field microscopy (Leitz DME, Leica, Wetzlar, Germany) equipped with AxioCam 105 Color camera and Zen Blue software (version 1.1.2.0; Carl Zeiss Microscopy).

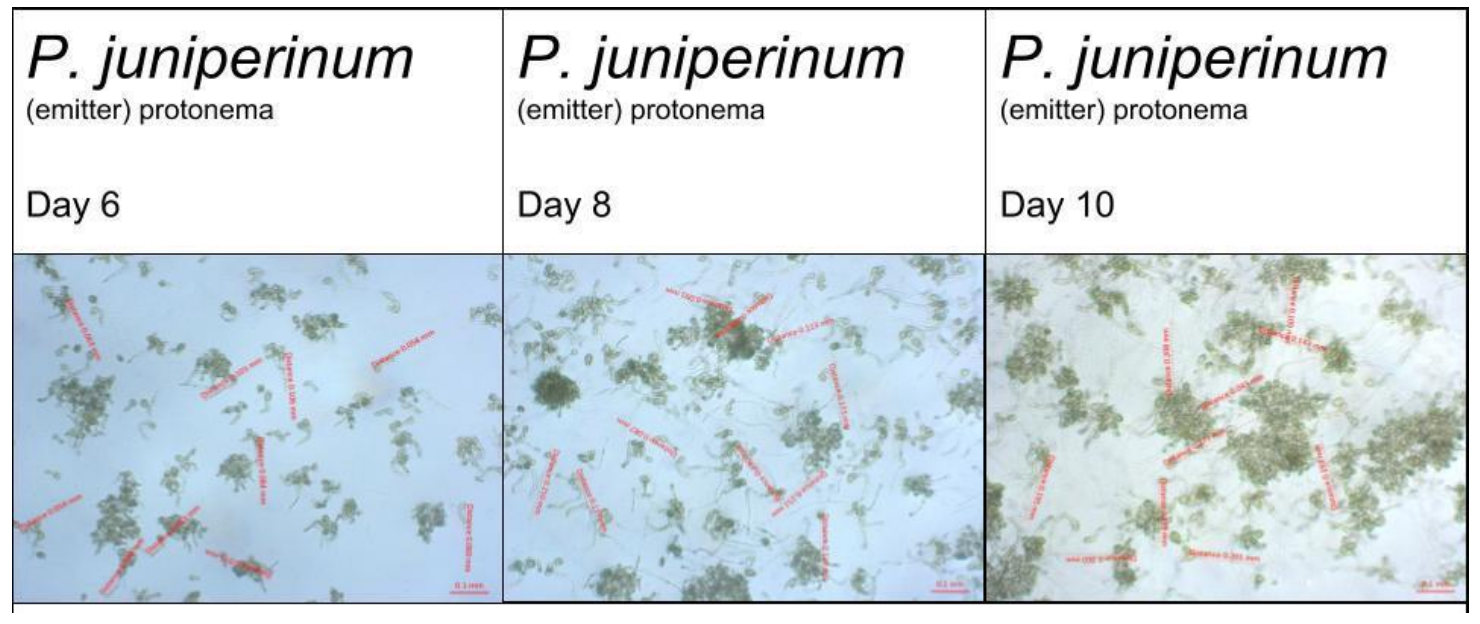




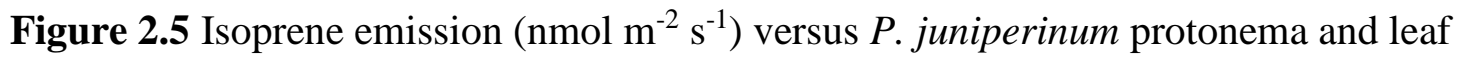
number $(\mathrm{n}=81)$. Assessment date is plotted on the $\mathrm{x}$-axis. Tukey-Kramer HSD Multiple Comparisons Test shows areas of significant difference between isoprene emission (nmol $\mathrm{m}^{-2} \mathrm{~s}^{-1}$ ) vs. leaf number. Error bars represent $\pm 1 \sigma$ (standard deviation). Letters show statistical significance between means. Means with the same letter are not significantly different. A * indicates significant difference, ** indicates a highly significant difference, *** indicates high statistical significance, NS indicates no significance.

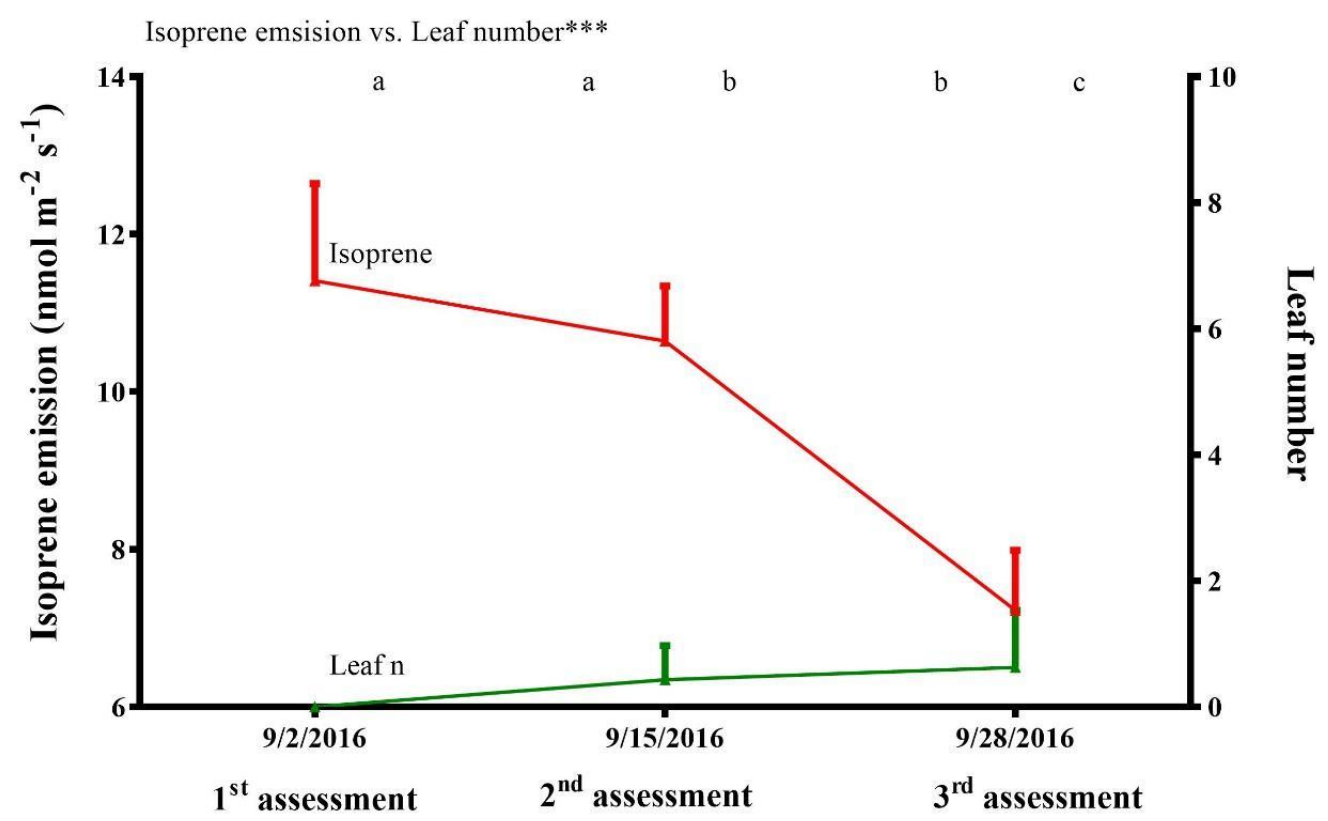


Figure 2.6 Isoprene emission $\left(\mathrm{nmol} \mathrm{m} \mathrm{m}^{-2} \mathrm{~s}^{-1}\right)$ /growth versus protonema growth $(\mathrm{n}=246)$. Protonema growth is plotted on the $\mathrm{x}$-axis. The line slopes between two assessments are not significantly different. A * indicates significant difference, ** indicates a highly significant difference, $* * *$ indicates high statistical significance, NS indicates no significance. Logarithmic line equations are shown for both time intervals.

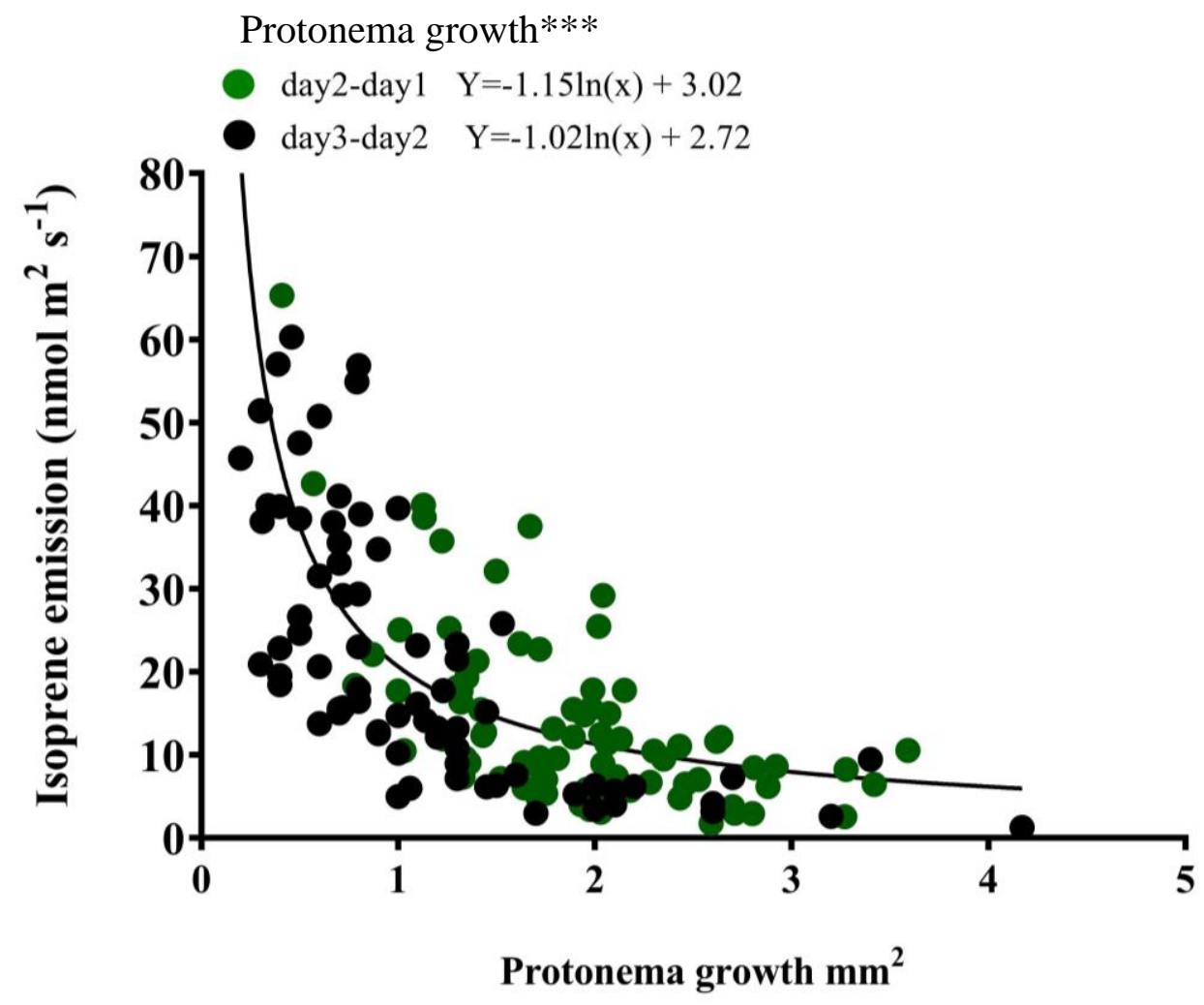


Figure 2.7 $P$. juniperinum $\%$ change in protonema growth versus leaf emergence for three individual dates $(n=246)$. Date is plotted on the $x$-axis. Lines represent $\%$ change in protonema growth with leaves present for individual dates. Tukey-Kramer HSD Multiple Comparisons Test shows areas of significant difference between $\%$ change in protonema growth vs. leaf emergence. Error bars represent $\pm 1 \sigma$ (standard deviation). Letters show statistical significance between means. Means with the same letter are not significantly different. A* indicates significant difference, $* *$ indicates a highly significant difference, *** indicates high statistical significance, NS indicates no significance.

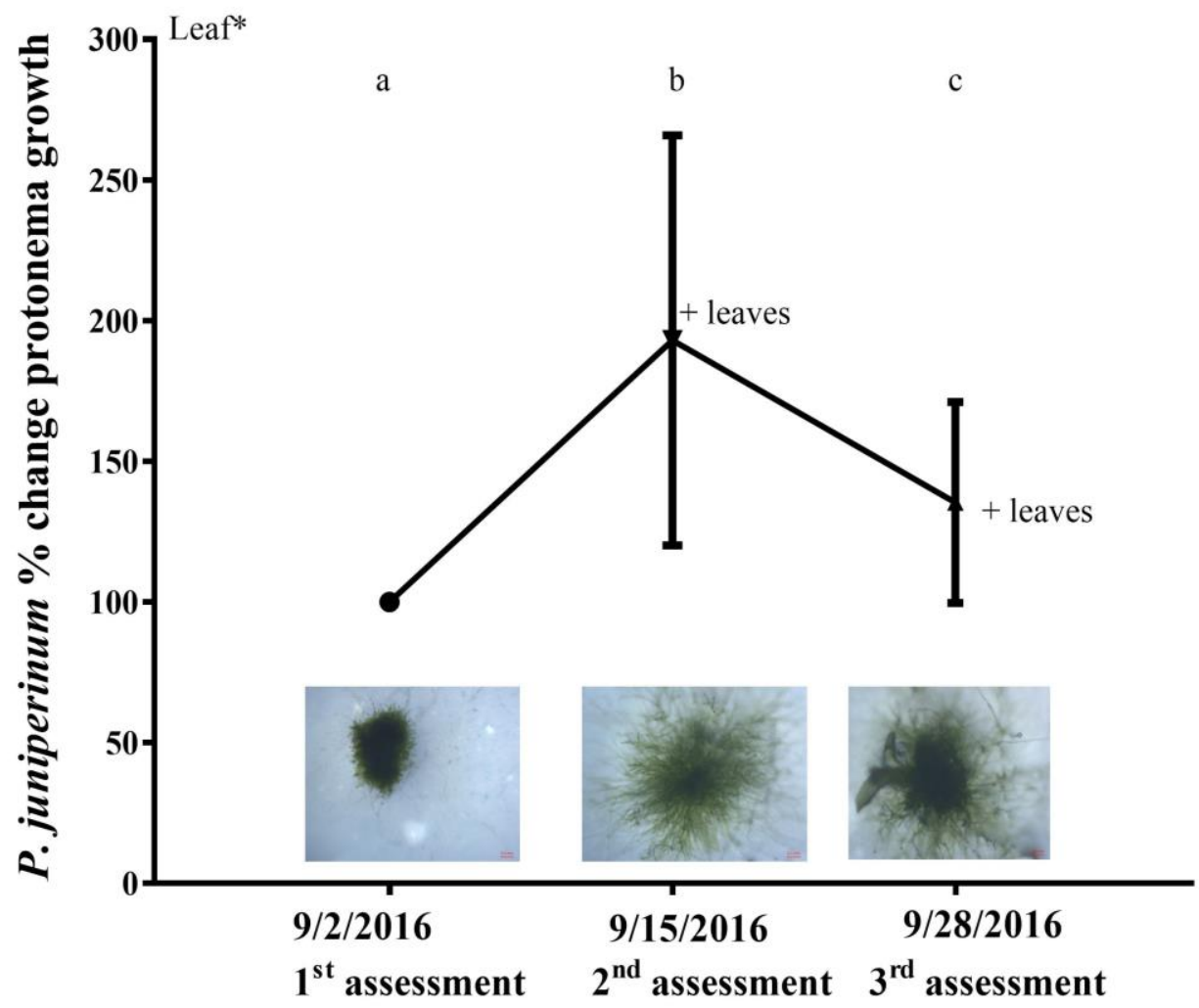


Figure 2.8 Isoprene emission ( $\mathrm{nmol} \mathrm{m} \mathrm{m}^{-2} \mathrm{~s}^{-1}$ ) versus Chlorophyll Fluorescence Ratio (CFR) in P. juniperinum protonema on agar and BCD media $(\mathrm{n}=52)$. Chlorophyll Fluorescence Ratio (CFR) is plotted on the $\mathrm{x}$-axis. The line slopes between the two media are statistically significant. $\mathrm{A} *$ indicates significant difference, $* *$ indicates a highly significant difference, $* * *$ indicates high statistical significance, NS indicates no significance. Regression line equations are shown for both media source.

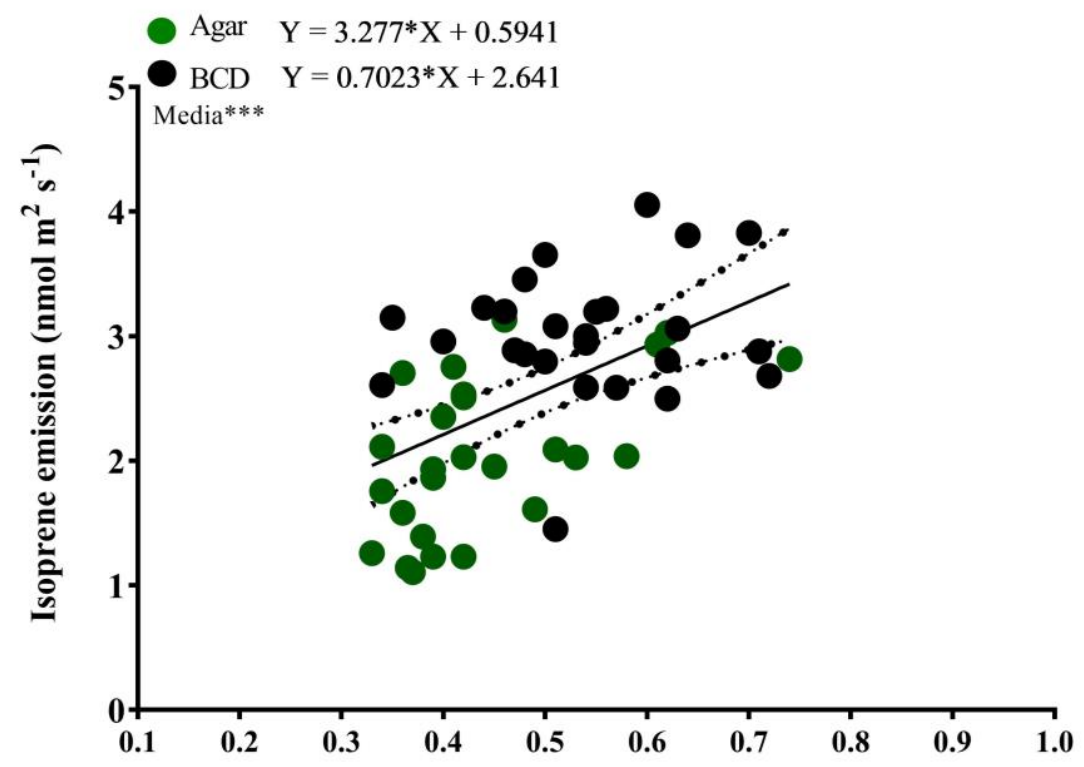

Chlorophyll fluorescence ratio (CFR) 
Figure 2.9 Chlorophyll Fluorescence Ratio (CFR) versus P. juniperinum protonema on agar and BCD media $(n=52)$. Media is plotted on the $x$-axis. Error bars represent $\pm 1 \sigma$ (standard deviation). Letters show statistical significance between means. Means with the same letter are not significantly different. A * indicates significant difference, ** indicates a highly significant difference, $* * *$ indicates high statistical significance, NS indicates no significance.

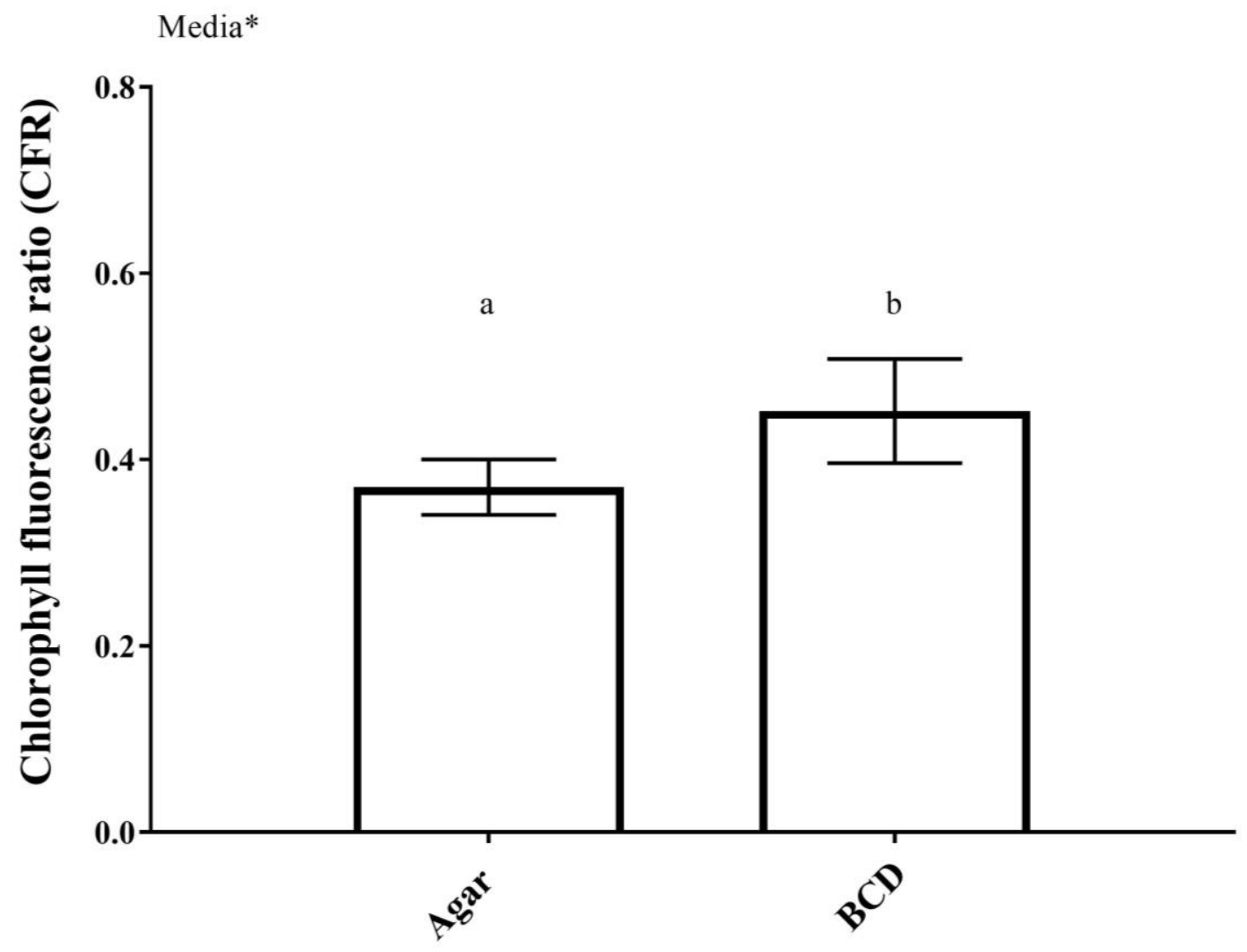


Figure 2.10 Relative Electron Transport Rate (RETR) $\left(\mu \mathrm{mol} \mathrm{m}^{-2} \mathrm{~s}^{-1}\right)$ from $P$. juniperinum protonema versus agar and BCD media under low-light setting $(0-820 \mu \mathrm{mol}$ $\left.\mathrm{m}^{-2} \mathrm{~s}^{-1}\right)$ PPFD $(\mathrm{n}=20)$. Photosynthetic Photon Flux Density (PPFD) is plotted on the $\mathrm{x}$ axis. No statistical differences were found between media and RETR. The line slopes between media are not significantly different. Error bars represent $\pm 1 \sigma$ (standard deviation). Letters show statistical significance between means. Means with the same letter are not significantly different. A * indicates significant difference, ** indicates a highly significant difference, $* * *$ indicates high statistical significance, NS indicates no significance. Regression line equation shown below for media under RETR versus lowlight (PPFD).

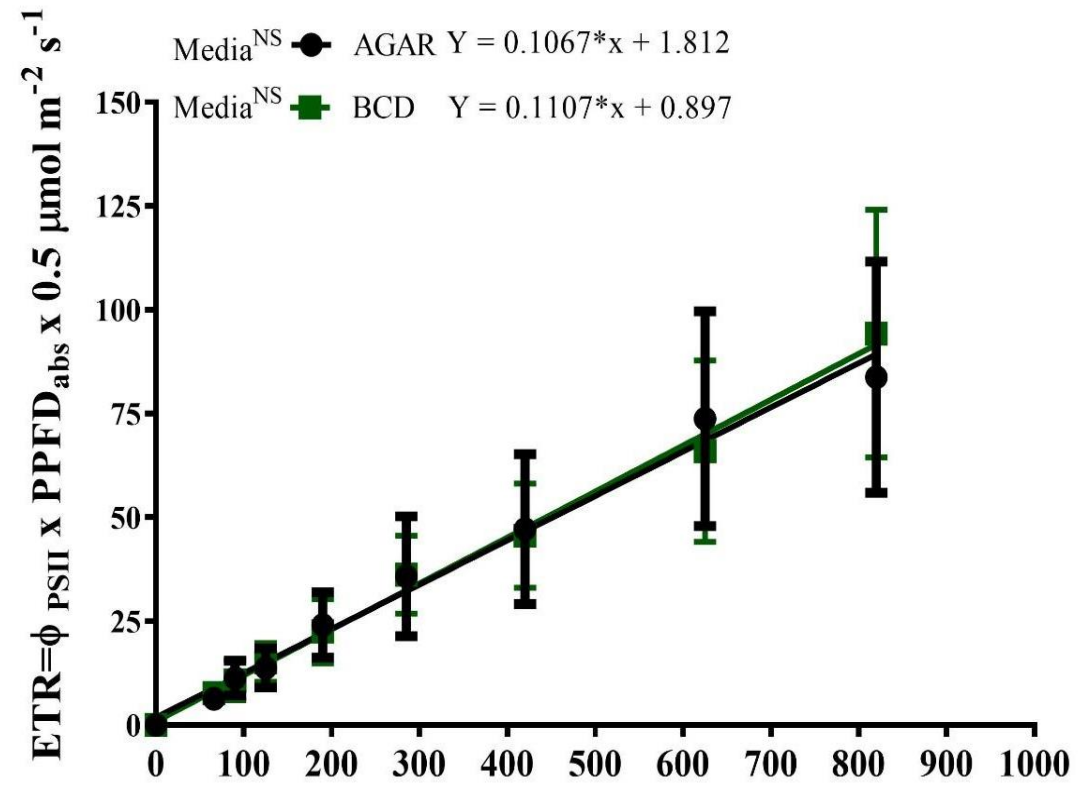

PPFD $\left(\mu \mathrm{mol} \mathrm{m} \mathrm{m}^{-2} \mathrm{~s}^{-1}\right)$ 
Figure 2.11 Relative Electron Transport Rate (RETR) $\left(\mu \mathrm{mol} \mathrm{m} \mathrm{m}^{-2} \mathrm{~s}^{-1}\right)$ from $P$. juniperinum protonema versus agar and BCD media under high-light setting (0-1150 $\mu \mathrm{mol} \mathrm{m} \mathrm{m}^{-2}$ ) PPFD ( $\left.=20\right)$. Photosynthetic Photon Flux Density (PPFD) is plotted on the $\mathrm{X}$-axis. The line slopes between media are significantly different. Error bars represent $\pm 1 \sigma$ (standard deviation). Letters show statistical significance between means. Means with the same letter are not significantly different. A * indicates significant difference, ** indicates a highly significant difference, $* * *$ indicates high statistical significance, NS indicates no significance. Regression line equation shown below for media under RETR versus high-light (PPFD).

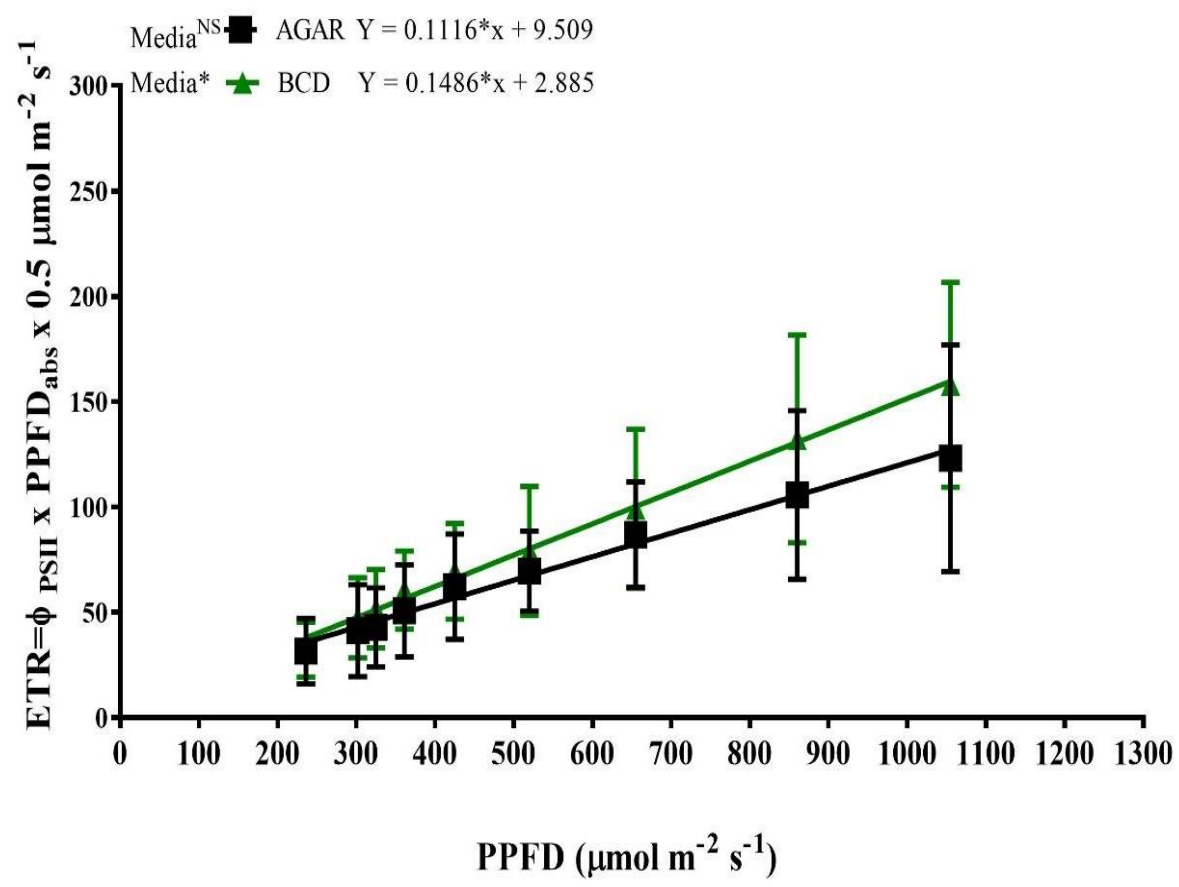


Figure 2.12 Relative Electron Transport Rate (RETR) $\left(\mu \mathrm{mol} \mathrm{m} \mathrm{m}^{-2} \mathrm{~s}^{-1}\right)$ from $P$.

juniperinum protonema versus combined agar and BCD media under low-light setting (0$\left.820 \mu \mathrm{mol} \mathrm{m}^{-2} \mathrm{~s}^{-1}\right)$ and high-light setting $\left(0-1150 \mu \mathrm{mol} \mathrm{m}^{-2} \mathrm{~s}^{-1}\right)$ PPFD $(\mathrm{n}=40)$.

Photosynthetic Photon Flux Density (PPFD) is plotted on the x-axis. The line slopes

between media are significantly different. Error bars represent $\pm 1 \sigma$ (standard deviation).

Letters show statistical significance between means. Means with the same letter are not significantly different. A * indicates significant difference, ** indicates a highly significant difference, $* * *$ indicates high statistical significance, NS indicates no significance. Regression line equation shown below for media under RETR versus light (PPFD).

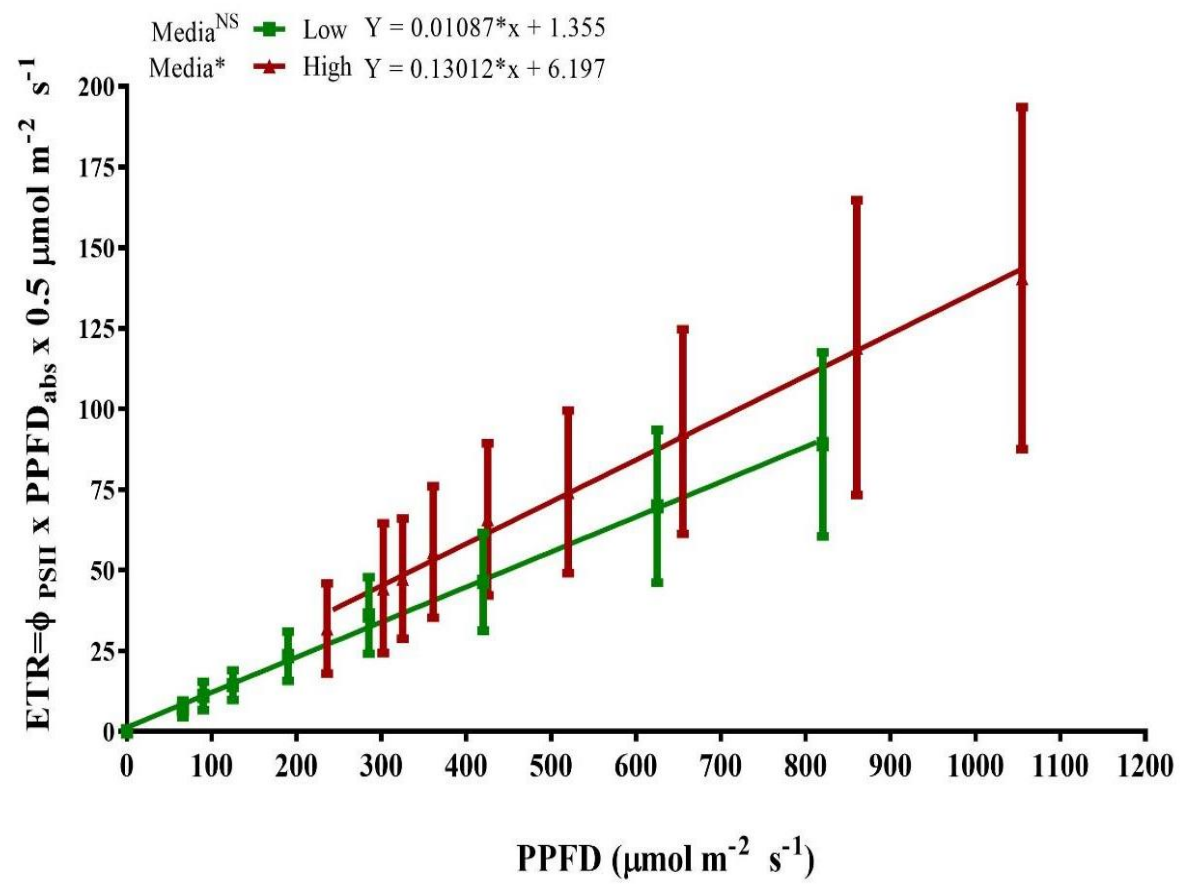


Figure 2.13 Isoprene emission (nmol m $\mathrm{m}^{-2} \mathrm{~s}^{-1}$ ) in $P$. juniperinum protonema versus temperature $\left({ }^{\circ} \mathrm{C} ; \mathrm{n}=38\right)$. Temperature is plotted on the $\mathrm{x}$-axis. Regression line is statistically significant. Error bars represent $\pm 1 \sigma$ (standard deviation). A * indicates significant difference, $* *$ indicates a highly significant difference, $* * *$ indicates high statistical significance, NS indicates no significance. Regression line equation shown below for isoprene emission versus temperature.

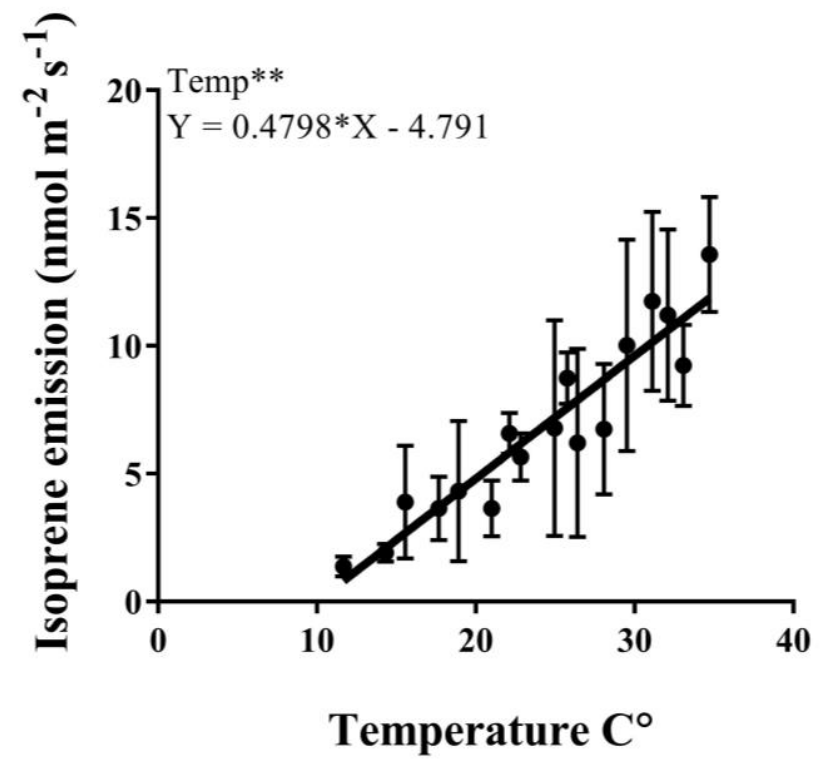


Figure 2.14 Isoprene emission (nmol $\mathrm{m}^{-2} \mathrm{~s}^{-1}$ ) in $P$. juniperinum protonema versus Photosynthetic Photon Flux Density (PPFD) $(n=53)$. Photosynthetic Photon Flux Density $\left(\mu \mathrm{mol} \mathrm{m} \mathrm{m}^{-2} \mathrm{~s}^{-1}\right)$ is plotted on the $\mathrm{x}$-axis. Error bars represent $\pm 1 \sigma$ (standard deviation). A * indicates significant difference, $* *$ indicates a highly significant difference, $* * *$ indicates high statistical significance, NS indicates no significance. Regression line equation shown below for isoprene emission versus light (PPFD).

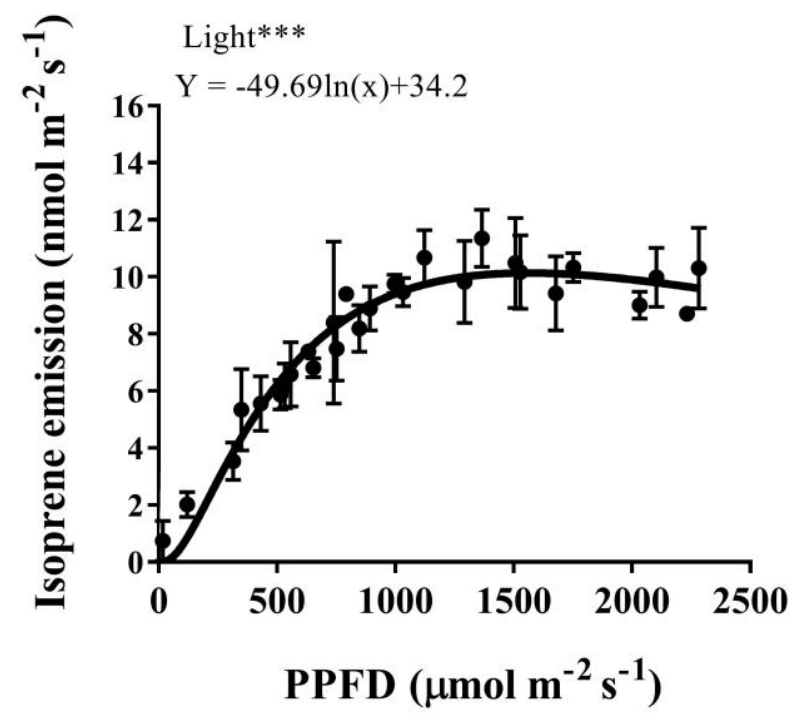




\title{
Chapter 3
}

\section{The role of isoprene in Polytrichaceae sexual systems}

\begin{abstract}
Mosses are some of Earth's most species-rich, ancient, and stress-tolerant ecosystem engineers. They play key roles in carbon and nitrogen cycling. Emission by mosses of Biological Volatile Organic Compounds (BVOCs), including isoprene, may locally engineer the atmosphere causing changes in the atmospheric hydrological cycle. Isoprene emission is poorly understood in bryophytes, and little is known about variation in emission across species and sexes. In this study, working with mosses in the Polytrichaceae family we (1) investigate the effects of morphological and physiological traits on isoprene emission in P. juniperinum, (2) explore the effects of gametangia expression or lack thereof on isoprene emission in P. juniperinum, and (3) assess variation in isoprene emission among mosses within the family.

Isoprene emission rate is significantly higher in sexually non-expressing gametophytes than female or male gametophytes. The cosmopolitan Polytrichum juniperinum had higher isoprene emission than shade adapted Atrichum undulatum and montane Pogonatum urnigerum. The highest emission rates were seen from non-sexually expressing gametophytes with significant canopy traits affecting isoprene emission; such as total leaves (TL) per gametophyte, gametophyte width (GW), wet weight (WW) and leaf tip redness (LTR). We are the first to report sexual expression affecting isoprene emission in Polytrichaceae species. We hypothesize that gametophytes with no sexual
\end{abstract}


expression are the least expensive to maintain as they have a higher investment after sexual organ formation takes place. We also saw great variation in above and belowground traits, along with isoprene emission and physiological measures between species and within sexes. This research uses a combination of physiological and comparative approaches to develop the first comprehensive view of the relationship between isoprene emissions and sexual systems in the mosses.

Keywords: bryophyte, gametophyte, isoprene, life stage, sexual systems 


\section{Introduction}

\section{Background}

Large fractions of atmospheric hydrocarbons are emitted by plants in the form of Biogenic Volatile Organic Compounds (BVOCs). These represent a larger fraction than is emitted by human activities (Purves et al. 2004; Sharkey et al. 2007). Recent data suggest that these emissions have a complex link to climate and contribute to global warming (Peñuelas et al. 2003, 2010; Feng et al. 2019; Guidolotti et al. 2019; Mäki et al. 2019). Increase in temperature can disrupt these chemical signals leading to significant increases in landscape level BVOC emissions with profound implications for both vascular and nonvascular plants (Kivimäenpää et al. 2016). Isoprene, a BVOC, has been shown to increase thermotolerance of photosynthesis in vascular plants (Sharkey et al. 1995) and in nonvascular plants such as mosses (Hanson et al. 1999). As a result, isoprene emission may have been beneficial for the radiation of early plants on land (Hanson et al. 1999). The capacity to emit isoprene was gained and lost multiple times during bryophyte evolution; in addition, it was lost in later divergent plants that have evolved other protective mechanism from light such as heat shock proteins (Waters et al. 1996, Heckathorn et al. 1998). More systematic observations are needed; currently, there are not enough measurements of enzyme activity, substrate pools, costs of alternate protection strategies between emitting and non-emitting species in vascular plants to better understand isoprene and its place in plant evolution (Harrison et al. 2013). No data exists, to our knowledge, concerning the tradeoffs made in the divergence of isoprene emitting species and non-emitting species within families in non-vascular plants. 
Isoprene represents a loss of fixed carbon and a significant metabolic cost to plants (Behnke et al. 2012; Ryan et al. 2014). In isoprene emitting plants, emission is controlled through light-dependent regulation of the isoprene synthase enzyme (IspS), which uses dimethylallyl diphosphate (DMADP) as a substrate for isoprene biosynthesis (Potosnak et al. 2014). We know that some of the emitted isoprene can be locally deposited where a number of bacterial and fungal taxa are capable of breaking down and utilizing isoprene as their energy and carbon source (Gray et al. 2015; McGenity et al. 2018; Crombie et al. 2019; Singh et al. 2019). These interactions help regulate soil microbe and fungal communities and affect soil chemical ecology and biogeochemistry. Isoprene emission fluxes from bryophyte fens have been shown to be comparable to boreal forests (Janson et al. 1998, 1999; Tiiva et al. 2007a,b). Biogenic isoprene has been observed in monitoring stations as early as March and it is speculated to be of bryophytes in origin given that broadleaf trees in these latitudes at this time are bare and unable to produce or emit isoprene (Reimann et al. 2000). Isoprene emissions are highest in the summer influenced primarily by temperature (Tingey et al. 1979; Monson et al. 1994; Schnitzler et al. 1997; Nogues et al. 2018; Meehl et al. 2018). Mosses can emit significant quantities of BVOCs and experience microclimates that can greatly deviate from and broader local conditions (Busby et al. 1978; Hinshiri et al. 1971, Bates, 1979; Bisang et al. 2006; Zotz et al. 2007).

Approximately $60 \%$ of mosses have separate male and female individuals (dioecious sexual system) (Villarreal et al. 2013), rather than being hermaphroditic as is more common in vascular plants. In mosses, females generally outnumber males 3:2 
(Shaw et al. 1993), even up to 4:1 (Newton 1972; Stark et al. 2001; Baughman et al. 2017). These skewed sex ratios have been hypothesized to be a result of competitive and facilitative interactions among relatives (Hamilton 1967; Clark 1978; Gowaty 1993; McLetchie et al. 2001; Bisang et al. 2008; Korpelainen et al. 2008; Baughman et al. 2017). Most often, it has been found that sterile or undifferentiated moss gametophytes outnumber males and females (Longton et al. 1990), and in mosses such as Ceratodon purpureus, the non-reproductive gametophytes make up high percentages of the population (Shaw et al. 1993; Rydgren et al. 2002a,b; Cronberg et al. 2003). Sexual reproduction can be rare for many dioecious mosses; one study found that out of 380 species of dioecious mosses 262 (69\%) have been found to have rare sporophytes, which suggests that they are rarely sexually reproductive. Often, this is apparently due to individual females and males living in different patches and not in close proximity (Gemmell 1950; Haig 2016; de Jong et al. 2018).

Isoprene research in mosses has been gaining a foothold in the literature (Hanson et al. 1999, 2001; Tiiva et al. 2007, 2009; Ekberg et al. 2011; Lantz et al. 2015), but studies looking for sex-specific BVOCs in mosses have been rare and more recent (Rosenstiel et al. 2012; McCuaig et al. 2015). Mosses have effective defense in the form of chemical barriers and can serve as model systems for studying land plant evolution, and early chemical defense evolution, as they are sophisticated in ontogeny and have a host of defenses against both abiotic and biotic stress factors. Through isoprene emission, not only do mosses regulate their own system but they appear to exert influence on their surrounding environment. Other local influences exerted by moss emitted BVOC's may 
include sex-specific volatile compounds that influence microarthropods mediated fertilization in mosses (Rosenstiel et al. 2012). Further, there are sex-specific fungal communities that affect their ecology (Sharkey et al. 2001; Devika et al. 2012; Kandi et al. 2015, Balkan 2016).

Mosses can influence nearby atmospheric process by emitting isoprene which is reduced by hydroxyl radical $(\mathrm{OH})$ into water droplet nucleation. Secondary Organic Aerosol (SOA) acts as a local form of cloud or fog seeding allowing plants to exert influence on the atmospheric hydrological conditions of its local microclimate. The prospect of microclimate engineering among some mosses is an exciting prospect and bears further study. Bryophytes are key component of many forest landscapes where they serve as components of many diverse ecosystems (Jonsson et al. 1993; Longton et al. 1997; Sedia et al. 2003; Gornall et al. 2011). Mosses also uptake nutrients from the surrounding environment (Wilkinson et al. 2005; Ayres et al. 2006; Gundale et al. 2011), and they provide habitat for micro-invertebrates (Gerson 1982; Sohlberg et al. 1987; Nakamura et al. 1992; Andrew et al. 2003; Korsu et al. 2004; Heino et al. 2005; Jakub et al. 2018). Mosses possess two different terpene synthase genes, unlike vascular plants, which only possess one type of terpene synthase gene. In bryophytes in addition to the plant terpene synthase gene another class called microbial-terpene synthase like genes are also present (Chen et al. 2018). Terpenoids, including isoprene, have important function in biological, ecological and atmospheric processes.

The maintenance of sex is one of great interest in evolutionary biology (Smith 1978; Burt 2000; Vamosi et al. 2003). It has been hypothesized that when sex in a 
dioecious species is mate-limited the non-limiting sex will produce the greatest abundance of floral scents (Case et al. 2009), and a similar pattern has seen by found in bryophytes (Rosenstiel et al. 2012). Mosses have been investigated for their sex-specific interactions (Eppley et al. 2011; Koncz et al. 2012; Balkan, 2015; Bisang et al. 2017; Slate et al. 2017; Maraist et al. 2018), but moss sexual systems and emission profiles are rarely studied together so as to understand these processes.

\section{Purpose of Study}

Mosses are some of Earth's most species-rich, ancient, and stress-tolerant “ecosystem engineers” (Jones et al. 1994; Eckstein et al. 2000; Keuper et al. 2011; Jassey et al. 2013). Unfortunately, only $2 \%$ of the 20,000 species of mosses have been chemically investigated (Turetsky et al. 2012). Despite their potential evolutionary and ecological significance, sex-specific BVOC emissions are extremely poorly characterized in mosses, creating a fundamental gap in our understanding of the chemical ecology of these ubiquitous plants. The lack of mechanistic understanding of the emission profiles of over $\sim 300$ chemical compounds (Rosenstiel et al. 2012) hinders our ability to interpret and predict the responses of mosses will have to anthropogenic drivers such as climate change (Vitousek et al. 1997; Aerts et al. 1999; Bell et al. 2007; Christensen et al. 2007; Erwin 2009; de Vries et al. 2011; Feng et al. 2019).

In this study, we will use a combination of physiological and comparative approaches to develop the first comprehensive view of the relationship between isoprene emissions and sex in mosses. This work will examine the hypothesis that isoprene-BVOC 
emissions are related and perhaps contribute to the evolution of sexual systems in the mosses. We aimed to measure the rate of change in sexually expressing individuals in emission capacity within and across species in the Polytrichaceae family. By understanding emission capacity of individual sexes and species-specific profiles we will gain a comprehensive understanding of the variation in isoprene emission within the sexes and enable us to address future hypotheses aimed at addressing fitness costs and benefits associated with sexual reproduction in mosses.

\section{Methods}

\section{Study species}

We have used three species from the Polytrichaceae family in this study: 1) Polytrichum juniperinum (Hedw.), 2) Atrichum undulatum (Hedw.), and 3) Pogonatum urnigerum (Hedw.). The polytrichaceous mosses reside in the base of the phylogenetic tree, having no close living relatives (Bippus et al. 2018) and contain approximately 200 accepted species (Hyvönen et al. 1998; Bell et al. 2010a,b). The family Polytrichaceae forms a monophyletic group (Hyvönen et al. 2004) and possesses the highest degree of specialization, able to move photosynthate through conducting cells called leptoids, in both the haploid gametophyte and diploid sporophyte. Leptoids acts like protophloem sieve cells in vascular plants (Ligrone et al. 2000). The structure of leaves in Polytrichaceae is, among bryophytes, closest to the function of the leaves of vascular plants with thick cuticularized leaves having differentiated photosynthetic tissue anatomy (Clayton- Greene et al. 1985). 
Mosses experience strong limitation of photosynthesis because of the high resistance to $\mathrm{CO}_{2}$ diffusion through liquid water into the leaf surface and in the cell wall. The evolution of rows of chlorophyll-rich specialized lamellae cells are critical in this moss family for providing increased leaf surface area capable of 6-fold rates of $\mathrm{CO}_{2}$ uptake per unit area (Proctor 1990, 2005; Marschall et al. 2004). This is a faster rate of diffusion of $\mathrm{CO}_{2}$ into the plant when compared to other mosses (Krupa 1984). Lamellae also facilitate the absorption of $\mathrm{CO}_{2}$ by repelling water with the presence of wax coated cells that prevent surface water retention. Air trapped in these lamellae cells minimize water loss (Bayfield 1973) while still allowing free gas exchange. The folding of leaves against the stem, followed by lateral closure appears to minimize water loss from the lamellar space and loss during the progression from leaf arrangements, resembling stomatal closure in vascular plants (Thomas et al. 1996). Poikilohydric plants, such as bryophytes, rely on soil water supply and atmospheric humidity for water uptake and retention (Stuber 2013, Yumol 2016); therefore, growth and weather are closely tied to productivity of the plant. This is a condition left over from the ancestral state (Raven et al. 2002, 2014). Polytrichum mosses are able to utilize water vapor in the air (Proctor 2005), giving them an advantage over other mosses. We hypothesize that isoprene emission plays a role in this.

Endohydric Polytrichum mosses differ from typical bryophytes in that they have a network of underground rhizomes and efficient internal water and carbohydrate conducting systems with apoplastic sugar loading (Thomas 1990). They are able to translocate photoassimilates to sister shoots suggesting capacity for physiological 
integration between connected moss stems (Thomas 1988). This family of mosses also stores starches in their rhizoids, which act as sites for overwinter storage for carbohydrates (Skre et al. 1983). It has been suggested that the inflexed achlorophyllous leaf margins enclosing the photosynthetic lamellae in $P$. juniperinum serve to increase the relative humidity and temperature of the air surrounding the lamellae, and this adaptation can increase the length of the effective growing season (Thomas et al. 1996; Proctor 2005).

P. juniperinum has great desiccation tolerance that is owed to drought evasion strategy enabled by its highly specialized photosynthetic lamellae. It has been hypothesized that early land plants had to be desiccation tolerant in both gametophyte and reproductive states (Renzaglia et al. 2000; Oliver et al. 2000, 2005). New research highlights that a key biochemical pathway to aid moss on land was the development of moss cuticle, wax covered epidermal cells, which predate lignin in vascular plants (Renault et al. 2017).

\section{Polytrichaceae moss collection method}

In our first experiment, we wanted to investigate isoprene emission from nonsexually expressing gametophytes to avoid sex-specific differences or maternal effects (Shaw et al. 1999, 2000). In February 2016 we collected $P$. juniperinum $(\mathrm{n}=45)$ moss from a single large population in Oregon (Table 3.1). Moss was collected from a forested area with substratum and rhizoidal connections intact and brought to the lab in enclosed containers. From this a number of $5 \mathrm{~cm}$ by $5 \mathrm{~cm}$ sectors were selected and were cleaned of 
debris and detritus. We identified the moss species using costa cross sections and moss field guides for the Pacific Northwest using Leica microscope (Leitz DME, Leica, Wetzlar, Germany) with an AxioCam 105 Color camera and Zen Blue software (version 1.1.2.0; Carl Zeiss Microscopy). We randomly selected 45 healthy individuals within the containers and immediately made physiological measurements (see below). Once physiological testing concluded gametophytes were labeled and placed individually in PlantCon ${ }^{\mathrm{TM}}$ containers (MP Biomedicals, 2017). We proceeded to take both aboveground and belowground morphological measurements (see below).

In our second experiment, we wanted to explore effects of sexual organ (gametangia) expression or lack thereof in isoprene emission under agar a non-nutritive media and BCD a nutritive media. In March of 2016 we collected sexually expressing $P$. juniperinum $(\mathrm{n}=25)$ female, male, and undifferentiated (non-sex expressing) gametophytes from six individual locations and grouped them accordingly (Table 3.2). Moss was brought in from the field as described above and was kept together with the rhizoidal connections intact. Gametophytes were selected and randomly distributed between media. Agar and nutritive BCD media was prepared following protocol outlined by Wang et al. (2015). Four females, four males and four non-sexually expressing gametophytes were cleaned of debris and soil and placed in agar media. Five females, four males and four non-sexually expressing gametophytes were cleaned of debris and soil and placed in BCD media. Sixty milliliters of prepared agar media was poured into base of $9.5 \mathrm{~cm}$ x $9.5 \mathrm{~cm} \times 3.5 \mathrm{~cm}$ PlantCon ${ }^{\mathrm{TM}}$ containers (MP Biomedicals, 2017) and sterilized under UV light before each gametophyte was randomly placed in the middle of 
a container. The gametophytes were allowed a two-week acclimation period before isoprene emission sampling began.

In our third experiment, we wanted to assess variation in isoprene emission and sexual expression among moss species within Polytrichaceae family. In April 2015, we selected shade adapted Atrichum undulatum $(\mathrm{n}=70)$ from four locations. We collected cosmopolitan Polytrichum juniperinum $(\mathrm{n}=56)$ from seven locations, and montane Pogonatum urnigerum $(\mathrm{n}=41$ ) from six locations (Table 3.3). We selected several sites for each moss species as we were investigating species and site-specific differences between related mosses. Mosses were brought in as described from above and immediate testing of isoprene emission began, following morphological assessment of sex.

\section{Aboveground morphological data collection from $P$. juniperinum gametophytes}

Our aboveground measurements of $P$. juniperinum gametophytes included twelve canopy structure traits including leaf length (LL, mm) and leaf width (LW, mm) by using a digital caliper (Fowler, Lux Scientific Instrument Corp., Tucson, AZ, USA). Leaf tip redness or the apex of non-photosynthetic tissue (LTR, mm) was measured by examining five leaves from each gametophyte and determining leaf tip redness using a Leica microscope (Leitz DME, Leica, Wetzlar, Germany) with an AxioCam 105 Color camera and Zen Blue software (version 1.1.2.0; Carl Zeiss Microscopy). Lastly, we determined canopy height $(\mathrm{CH}, \mathrm{mm})$ of each gametophyte by taking total gametophyte length (GL, $\mathrm{mm}$ ) measurement and subtracting the rhizoid length (RL, mm). 
To count the total number of leaves (TL), gametophytes were viewed under a dissection microscope and individual leaves were counted on each gametophyte (Leica L2, Leica Microsystems Inc.). We obtained leaf mass area (LMA, $\mathrm{mg} \mathrm{cm}^{-2}$ ), which is the ratio between leaf dry weight after 48 hours and leaf area (Villar et al. 2013). We have also calculated plant biomass (B) by dividing dry weight by total leaf area from the moss gametophyte (TLA, $\mathrm{mg} \mathrm{cm}^{-2}$ ).

Water holding capacity measures were estimated using Pypker et al. (2006). Adult P. juniperinum gametophytes were saturated with water in a plastic sealed container for 12 hours, after which they were blotted dry, and maximum wet mass was measured using an analytical microbalance (AB104-S/FACT, manufactured by Mettler Toledo Corporation, Tualatin, Oregon). Shoots were air-dried and weighed again at 24 hours, and oven dried at $60^{\circ} \mathrm{C}$ for 48 hours and then weighed again for dry mass. We determined loss of water weight in gametophyte (LWC, mg) by using dry weight of each gametophyte and subtracting it from the final wet weight of the gametophyte.

We have calculated leaf moisture (LM, mg); in which we took the final dry weight of the gametophyte subtracted final wet weight and divided by wet weight (Xiao et al. 2015; Wang et al. 2006). To measure water content of the gametophyte (WC, mg), we have calculated $\mathrm{WC}=($ fresh weight-dry weight $) /$ fresh weight $* 100$. Values are represented in milligrams $\left(\mathrm{mg} \mathrm{cm}^{-2}\right)$ and expressed as percentage dry mass (Michel et al. 2013). After all other measurements were completed, we weighed each gametophyte while wet and oven dried each gametophyte at $60^{\circ} \mathrm{C}$ for 48 hours for the purpose of dry 
weight (DW, mg) and wet weight $\mathrm{mg}(\mathrm{WW}, \mathrm{mg})$ using an analytical microbalance (AB104-S/FACT, manufactured by Mettler Toledo Corporation, Tualatin, Oregon).

In all, we measured seven leaf dimension traits. We placed the gametophyte intact and deconstructed between two transparency sheets and scanned at 1600 dpi to determine leaf area $\left(\mathrm{LA}, \mathrm{mm}^{-2}\right)$ and total leaf area by multiplying leaf area with number of leaves (TLA). Once the leaves were removed from each gametophyte, we were able to take five leaves from each gametophyte, use a wet mount each leaf and measure costa length (CL, $\mathrm{mm})$, costa width $(\mathrm{CW}, \mathrm{mm})$, costa cross sectional area $\left(\mathrm{CCA}, \mathrm{mm}^{-2}\right)$ and lamina thickness, which was measured midway between costa and leaf margin (LT, $\mu \mathrm{m})$ from all five replicates. We also calculated leaf density $\left(\mathrm{LD}, \mathrm{mg} \mathrm{m}^{-3}\right)$, by taking the width of cross section of the leaf dividing it by area of the cross section of the leaf, and multiplying it by leaf mass area (LMA, $\mathrm{mg} \mathrm{cm}^{-2}$ ) from our canopy trait measurements (Xiong et al. 2016).

To measure two leaf shape traits, we followed protocol from Waite et al. (2000); and calculated perimeter ${ }^{2} /$ leaf area $\left(\mathrm{P} 2 / \mathrm{A}, \mathrm{cm}^{-3}\right)$ and length/width of individual gametophytes $(\mathrm{L} / \mathrm{W}, \mathrm{cm})$. We went a step further and calculated two other measures appropriate for leaf shape traits. To account for total perimeter, we first measured perimeter $(\mathrm{P}, \mathrm{cm})$ with the formula $\mathrm{P}=2$ (width of gametophyte) +2 (height of gametophyte). We then took perimeter and divided it by area $\left(\mathrm{P} 2 / \mathrm{A}, \mathrm{cm}^{-3}\right)$ from measuring the leaf surface area. To determine total perimeter/area (TP2/A), we took perimeter we have calculated earlier, and divided it by leaf surface area multiplied by total leaves on each gametophyte. This was calculated from the photograph of each leaf sample under a Leica microscope (Leitz DME, Leica, Wetzlar, Germany) with an 
AxioCam 105 Color camera and Zen Blue software (version 1.1.2.0; Carl Zeiss Microscopy).

In addition, we measured ten cell-specific traits where we used enhanced and magnified images of the leaves and mid-lamina cross sections. The average area of an individual cell lumen, cell lumen area $\left(\mathrm{CLA}, \mu \mathrm{m}^{-2}\right)$ was measured. These were averaged from the five individual leaves from the same gametophyte. To measure, interior cell wall thickness (IWT, $\mu \mathrm{m}^{-2}$ ), we followed methods outlined in Waite paper, and measured the lamina cross section centrally between margin and costa (Waite et al. 2010).

Lastly, we supplemented further cell trait measures of our own, such as lamellae number (LN) by counting the number of lamellae cells at five locations within the widest part of the costa cross section from five individual leaves on the same gametophyte $(\mathrm{n}=25)$ (Figure 3.1). We also measured lamellae height (CLH, mm) by measuring the widest part of five lamellae stacks within same costa cross section from five individual leaves $(n=25)$ (Figure 3.2). We measured the number of rows of lamellae (NRL) that each costa cross section contained from the five leaves and five costa cross sectional cuts, by measuring how far within each costa cross section the lamellae extends from one end to the other side of the lamina. We also took the number of rows of lamellae (NRL) and multiplied it by lamellae cells we counted (LN) to get an area estimate of lamellae space (LANR) within each leaf costa cross section. Lastly, we quantified how much area was taken up by chloroplast $\left(\mathrm{CHA}, \mu \mathrm{m}^{-2}\right)$ within lamellae cells from a perpendicular thin layer of leaf section. We used one or two layers of lamellae that was visible and individual cell 
size could be measured (ICS, $\mu \mathrm{m})$, as well as the space that surrounded or was next to the chloroplast (CS, $\mu \mathrm{m})$ within each cell (Table 3.4).

\section{Belowground morphological data collection from $P$. juniperinum gametophytes}

We collected data on belowground rhizoidal function and stem structure to shed light on possible roles of these structures in non-vascular plants and the role they might play in isoprene emission. P. juniperinum has been found to have extensive penetrating underground network of rhizoids, which aids in resource acquisition and storage in harsh environments and allows recolonization after fires (Duncan et al. 1982; Viereck et al. 1983). Polytrichum mosses are able to inhibit large areas with the aid of a thick tomentum of rhizoidal network as far reaching as 1-2 meters in depth (Smith et al. 2008). We wanted to determine how the rhizoidal network assists in retaining water in $P$. juniperinum, as it is highly variable in some moss species. Some mosses have been reported to have water content potential of up to 20 times the dry weight (Clymo et al. 1982), or the water holding capacity of up to $1400 \%$ of their dry mass (Glime 2007; Proctor 2008; Michel et al. 2013).

For our belowground measurements of $P$. juniperinum gametophytes $(\mathrm{n}=45)$, we measured fifteen stem related measurements and water related traits. All water related trials were started using 72 hour air dried material that was then soaked until full saturation was achieved after about 24 hours. We measured rhizoidal length (RL, mm) of each gametophyte using a digital caliper (Fowler, Lux Scientific Instrument Corp., Tucson, AZ, USA). We obtained measurements of dry stem area (SAD, $\mathrm{mm}^{-2}$ ), and dry 
diameter of the stem $\left(\mathrm{SSD}, \mathrm{mm}^{-2}\right)$ by first capturing the image under a microscope slide with a Leica microscope (Leitz DME, Leica, Wetzlar, Germany) with an AxioCam 105 Color camera and then tracing the area of the stem or the diameter of costa cross section of the stem (Zen Blue software (version 1.1.2.0; Carl Zeiss Microscopy).

We placed dry gametophytes in water for 12 hours (WSA12), and 24 hours (WSA24) to measure how much water stems alone absorb without any leaves on the gametophytes. We measured the diameter of the stem at same time intervals. This way we could measure water content in steam area at 12 (SAWC12) and 24 hours (SAWC24) and measured water content within stem diameter at 12 (SDWC12) and 24 hours (SDWC24) (Figure 3.3). We took the final value we obtained from our water measures, as follows; ((24 hour wet measures - initial dry measures)/initial dry measures) and multiplied by a 100 . We calculated total dry stem area $\left(\mathrm{TDSA}, \mathrm{mm}^{-2}\right)$, by taking the dry stem area and multiplying it by the gametophyte length. We proceeded to do the same for wet stem area at 12 hours (TWSA12) and at 24 hours (TWSA24). We also estimated root shoot ratio (RSR, $\mathrm{mm}^{-2}$ ) by taking the dry area of the root and dividing by dry area of the aboveground gametophyte length (Table 3.5).

\section{Sex determination among mosses within the family of Polytrichaceae}

Each gametophyte sexual expression was assessed using forceps and Leica microscope (Leitz DME, Leica, Wetzlar, Germany) with an AxioCam 105 Color camera and Zen Blue software (version 1.1.2.0; Carl Zeiss Microscopy). Species within the Polytrichaceae family were cataloged as either female if sporophyte development was 
visible (Hughes 1962) or archegonia was found, in which case the number of archegonia present was documented. Males were categorized based on splash cup presence (Brodie 1951), and all splash cups were examined for viable antheridia containing male sperm. In these species, male splash cups serves as innate markers (Bu 2005); while for females reproduction in terms of fertilization and sporophyte production is fatalistic (Greene 1960; Sarafis 1971; Watson 1975; Callaghan et al. 1978).

Gametophytes were categorized as non-sexually expressing if only sterile paraphyses were found, and no sexual organs were present along the body of the gametophyte (Frederick et al. 1968). Paraphyses are multicellular hair-like structures that can conserve moisture, secrete mucilage and aid in sperm discharge (Goebel 1905). Paraphyses can regenerate into protonema and rhizoids (Brown 1919); hence, they serve an important function in moss life strategy. Sexual expression was assessed for the current year and recorded if previous year sexual expression was visible. Identification and key to each species was accomplished following McCune et al. (2018), with herbarium samples deposited at the Portland State University herbarium.

\section{Isoprene emission among mosses within the family of Polytrichaceae}

Polytrichaceae gametophytes were sampled in a randomized fashion on a GC/RGD2 Gas Chromatograph with a RGD2 reduction gas detector (RGD-2, Trace Analytical Instruments, Menlo Park, CA) to avoid species bias. An individual gametophyte was separated from the clump and analyzed for isoprene emission. After moss collection from the field, identification and debris removal, we placed each 
gametophytes into a $40 \mathrm{ml}$ glass vial. We proceeded to collect isoprene by closing the vials and placing them under basal conditions of $1,000 \mu \mathrm{mol}$ photons $\mathrm{m}^{-2} \mathrm{~s}^{-1}$ using Dracast LED1000 Pro Daylight light panel, with light-emitting diode array (Photon Systems Instruments) and using a water bath at $\left(30^{\circ} \mathrm{C}\right)$. This gives a better spatially realistic profile of emission for sampling volatiles in an ecological context (Geron et al. 2000).

The isoprene collection lasted for a five-minute period, after which a $1 \mathrm{ml}$ Pressure-Lok® Precision Analytical Syringe (VICI Precision Sampling Inc., Baton Rouge, LA, USA) was used to pull the headspace gas from the vial and inject it into a reduction gas detector (GC/RGD2). One $\mathrm{ml}$ of the calibration gas mixture was removed with a syringe from a mixing chamber and injected into the GC-RGD2 to create the calibration curve and obtain slope of the equation see (Equation 1) as described in the previous chapter. Isoprene was separated on a stainless steel column $(1.3 \mathrm{~m}$ long $\mathrm{x} 2 \mathrm{~mm}$ inner diameter i.d.). The column was packed with UNI 8 Beads 3 S 60/80 6' x 1/8”, 0.085 SS (Alicat Scientific, Inc; Tucson, AZ). The GC-RGD2 was calibrated each day using a standard cylinder containing $71 \mathrm{ppb}(\mathrm{v} / \mathrm{v})$ isoprene, references to a National Institute of Standard and Technology (NIST) and helium (He) standard (SRM 1660a; 1 ppm He in $\mathrm{N}_{2}$, Rochester, NY).

Isoprene gas was mixed with high purity helium using a mass flow controller calibrated to a flow rate of $21 \mathrm{ml} / \mathrm{min}$ (Alicat Scientific, Inc; Tucson, AZ). Blanks were run every five samples to ensure quality check and to detect contamination within the column. Isoprene emission measurement was calculated as follows, using Peak Area 
Units (PAU) from the standard calibration curve $y=m x+b$, at $\mathrm{GC}$ temperature of 298

Kelvin (K), and Atmospheric Pressure (P) of 760 Torr.

$$
\begin{aligned}
= & \left(\frac{\mathrm{PAU}+20.69}{2.4703}\right) \times\left(\frac{1 \mathrm{nmol} / \mathrm{L}}{\mathrm{ppb}}\right) \times(.0005) \times\left(\frac{\text { std } \mathrm{nl}}{\mathrm{nl}}\right) \times\left(\frac{760 \mathrm{Torr}}{298 \mathrm{~K}}\right) \times\left(\frac{378 \mathrm{~K}}{771.8 \mathrm{Torr}}\right) \\
& x\left(\frac{1 \mathrm{nmol}}{22.4 \mathrm{std} \mathrm{nl}}\right) \times\left(\frac{\text { volume vial }(\mathrm{ml})}{.5 \mathrm{ml}}\right) \times 1 \text { (factor for loop recovery) } \\
& x\left(\frac{1}{\text { area } / \mathrm{m} 2}\right)=\left(\mathrm{nmol} \mathrm{\textrm {m } ^ { 2 } \mathrm { s } ^ { - 1 } )}\right.
\end{aligned}
$$

Equation 1. Formula used to convert isoprene from calibration curve, $y=m x+b$, and PAU to isoprene $\left(\mathrm{nmol} \mathrm{m} \mathrm{m}^{-2} \mathrm{~s}^{-1}\right)$.

We obtained the volume-mixing ratio of isoprene ( $\mathrm{ppb}$ ) to determine gametophyte emission flux. We determined the area of the gametophyte using AxioCam 105 Color camera, and Zen Blue software, version 1.1.2.0 (Carl Zeiss Microscopy).

Peak identification was performed with the PEAK software (Stein 1999) that integrates raw peak area units and retention times. To identify isoprene, a custom calibration curve was created from isoprene standard (Sigma, Deisenhofen, Germany). For quantification, peak areas of isoprene were determined after baseline correction. Levels of background contamination were determined from blanks. Analytical quality was analyzed by using Standard Reference Material of isoprene (NIST SRM 1515, National Institute of Standards and Technology, Gaithersburg, MD). The standard material was used in the analyses to create calibration curves for quality assurance and quality control purposes.

Both Experiment 1 and Experiment 3 isoprene emission testing involved a snapshot view of emission for non-sexually expressing $P$. juniperinum gametophytes 
(n=45), and sexually expressing $A$. undulatum, $P$. juniperinum, and $P$. urnigerum gametophytes (n=167) (Figure 3.4).

Experiment 2 involved repeated measure isoprene emission testing of $P$. juniperinum sexually expressing gametophytes from different locations and under nonnutritive agar and nutritive BCD media $(n=25)$. Isoprene emission was checked three times a month, beginning May of 2016, through August of 2016 totaling eighteen isoprene observations. $P$. juniperinum was kept in PlantCon ${ }^{\mathrm{TM}}$ containers under the light source of standardized growth conditions of $\left(150-200 \mu \mathrm{mol} \mathrm{m} \mathrm{m}^{-2} \mathrm{~s}^{-1}\right)$ light intensity and a photoperiod of $16 \mathrm{~h}$ light to $8 \mathrm{~h}$ dark at $20 \pm 3^{\circ} \mathrm{C}$ using Adaptis 1000 Conviron growth chambers (Pembina, ND). The PlantCon ${ }^{\mathrm{TM}}$ containers were allowed to sit in the growth chambers until isoprene emission testing occurred under basal conditions of $30^{\circ} \mathrm{C}$ and $1000 \mu \mathrm{mol} \mathrm{m} \mathrm{m}^{-2} \mathrm{~s}^{-1}$. Each sample was opened daily, and after isoprene emission testing was completed, the individual gametophyte was sprayed with $5 \mathrm{ml}$ tap water to ensure proper hydration. Visual inspection followed, where bacterial growth, brown tissue was recorded and noted if the sample has completely turned brown and showed no visible sign of green leaf tissue. We did have high mortality and out of 70 samples, 25 samples remained to test for continuous isoprene emission. This allowed us to gain basal isoprene emission (Monson et al. 1994) from non-sexually expressing gametophytes, and sexually expressing male gametophytes and female gametophytes from multiple sites.

\section{Laboratory gas exchange measurements of $P$. juniperinum gametophytes}


To assess and compare differences between physiological measurements we have subjected gametophytes to the same protocol as was outlined in the previous chapter for gas exchange measurements (see Chapter 2 methods). We have conducted three separate laboratory gas exchange measurements. After isoprene emission testing, gametophyte samples were placed in a glass cuvette containing a moist cotton ball to provide adequate moisture through the trial. All gas exchange measurements in the lab were conducted using protocol outlined by Junior Pulse-amplitude modulated (JUNIOR-PAM) chlorophyll fluorometer and WinControl Software (Walz, Effeltrich, Germany), with a single $100 \mathrm{~cm}$ plastic fiber, $1.5 \mathrm{~mm}$ in diameter. We measured chlorophyll fluorescence ratio (CFR), as a non-intrusive tool in using it as a proxy to establish information on photosynthetic reactions in the chloroplast (Schreiber et al. 1987). The fluorescenceemission spectra read out two maxima in the $690 \mathrm{~nm}$ and the $735 \mathrm{~nm}$ region. The fluorescence ratio F690/F735 for green leaves is higher (values of 0.8 to 1.1), than in the yellow to red wavelength region ( 525 to $633 \mathrm{~nm}$ ), which only yields values for F690/F735 of 0.5 to 0.7 (Rinderle et al. 1988). Chlorophyll fluorescence ratio (CFR) was measured with a chlorophyll content meter (OPTI-Sciences model CCM-300, Hudson, USA).

The Junior-PAM (Walz, Germany, http://www.walz.com/) was used according to the manufacturer's instructions with the following parameters: light saturation pulse intensity 6 , pulse frequency $20 \mathrm{sec}$, actinic light intensity 8 . The effective photochemical quantum yield of photosystem II [Y (II)] was calculated as described by Genty et al. (1989). Relative Electron Transport Rate (RETR) was calculated with JUNIOR-PAM 
chlorophyll fluorometer and WinControl software. Modulated excitation energy and the fluorescence signal were transmitted through a bifurcated fiber-optic cable.

Measurements with the Junior-PAM were conducted under constant fluorescent lighting in the laboratory at mean Photosynthetically Active Radiation (PAR) value of $250 \pm 50$ $\mu \mathrm{mol} \mathrm{m} \mathrm{m}^{-2} \mathrm{~s}^{-1}$. Relative electron transport rate (RETR) can be obtained as PFD x (Ф) PSII (Bilger et al. 1995). Junior-PAM recorded electron transport rate, photosynthetic yield and PAR light levels ranging from $0-1500 \mu \mathrm{mol} \mathrm{m} \mathrm{m}^{-2} \mathrm{~s}^{-1}$.

\section{Statistical analyses}

Graphical and statistical analyses of the data were performed using Prism 7.0 software (GraphPad), R version 3.4.2 (R Studio 2017) and JMP Pro 14.1 (SAS Institute, Cary, North Carolina, USA); with significance determined at $\alpha=0.05$. We were interested in which independent variables influenced isoprene emission and used TukeyKramer HSD Multiple Comparison test (Ellison et al. 2004) to find sources of significant differences between Polytrichaceae species and within sexual expression and non-sexual expression. Violations of normality were diagnosed using distribution plots and normal quantile plots and assessed using Shapiro-Wilk test for normality. Violations of homoscedasticity were assessed using residuals versus predicted values. Violations of independence were assessed using a table or plot of residual autocorrelations. Violations of linearity or additivity were assessed using residuals versus individual independent variables using Tukey 1-df Tests for Nonadditivity (Hair et al. 2009). Violations of unequal variances were estimated using Welch Tests (Rusticus et al. 2014). Violation of 
multicollinearity was assessed using nonparametric correlation matrix to determine if any of the variables are highly correlated. As well as we have determined variance inflation factor (VIF), and found low VIFS indicating that our variables did not have multicollinearity (Craney et al. 2002).

For our morphological data for aboveground and belowground, we log transformed our dependent variable, which was isoprene emission because it did not fit a normal distribution and we observed heteroscedasticity after testing for unequal variances with Levene's test using the statistical software JMP Pro 14.1 (SAS Institute, Cary, North Carolina, USA). We wanted to answer if isoprene emission, our dependent variable had significant effects on our independent variables of aboveground and belowground measurements, and what interactions were present among them. To determine the effects of isoprene emission on our aboveground variables, we analyzed the data using the generalized linear models (GLM) procedure in JMP Pro 14.1 (SAS Institute, Cary, North Carolina, USA). To determine the effects of isoprene emission on our belowground variables, we used multiple regression procedure in JMP Pro 14.1 (SAS Institute, Cary, North Carolina, USA). We choose AIC (Akaike's Information Criteria) to evaluate the contribution of subsets of explanatory variables to our response variable. The GLM model assessed variance and bias by controlling for factors causing variability in multiple independent variables (Armstrong 1985). This way we acquired greater statistical power by controlling for differences and correlations between and within groups (Field et al. 2012). We used a multiple regression to determine the influence of our belowground variables on isoprene emissions. 
For our species and sex data set within $P$. juniperinum, we ran repeated measure ANOVA (RM ANOVA) to test the effects of sex, media, site, and time on isoprene emission. Isoprene emission was log transformed to meet assumption for analyses. We also used this method to compare data points over time between groups, such as isoprene emission in May 2016, June 2016, July 2016 and August 2016 between and within groups. For data looking at the factors affecting isoprene emission across categorical variables, including leaf number, shoot number, and species, we used ANOVA. Additionally, we used regression analysis to determine how isoprene emission correlated with gas exchange measures.

\section{Results}

\section{Experiment 1a:}

\section{The effects of aboveground morphological variables on isoprene emission in $P$. juniperinum gametophytes}

We found that six variables explain $50 \%$ of variability in isoprene emission (GLM; DF=6; x2=27.325; $\mathrm{P}<0.0001 ;$ Figure 3.5). Isoprene emission among $P$. juniperinum gametophytes was highly variable, with a mean isoprene emission of 16.917 $\mathrm{nmol} \mathrm{m} \mathrm{m}^{-2} \mathrm{~s}^{-1} \pm 1.4183 \mathrm{SEM}(\mathrm{n}=45)$. We found minimum isoprene emission value of 2.917 $\mathrm{nmol} \mathrm{m} \mathrm{s}^{-2}$ and a maximum value of $53.460 \mathrm{nmol} \mathrm{m}^{-2} \mathrm{~s}^{-1}$. Four aboveground variables explained $39 \%$ of the variability in isoprene emission, and two belowground variables explained $11 \%$ of the variability in isoprene emission. The aboveground canopy traits 
included: total number of leaves (TL) on a gametophyte, gametophyte width (GW), wet weight (WW), and leaf tip redness (LTR).

Total leaves (TL) mean values were $55.98 \pm 2.944$ SEM $(n=45)$, with minimum leaves counted as 11, and maximum leaves counted as 103 per gametophyte. We did not see an increase in isoprene emission with increase number of leaves $(\mathrm{P}=0.06)$.

Gametophyte width $(\mathrm{GW})$ mean ranges were $10.98 \mathrm{~mm} \pm 0.2494$ SEM $(\mathrm{n}=45)$, with minimum gametophyte width of $4.18 \mathrm{~mm}$ and maximum value of $13.79 \mathrm{~mm}$. Gametophyte width was shown to be statistically significant when it came to isoprene emission, as it contributed to $19 \%$ variability in isoprene emission between gametophytes (ANOVA; $\mathrm{DF}=1 ; \mathrm{F}=10.4395 ; \mathrm{P}=0.0024)$. As gametophyte width increased, isoprene emission increased.

We also found that gametophyte leaf length (LL) scaled geometrically with leaf area (LA) resulting in 27\% variability due to gametophyte leaf length (LL) among samples (ANOVA; DF=1; F=15.8299; $\mathrm{P}<0.0003$ ). Unlike Waite and Sack et al. (2010), who found that gametophyte leaf width (LW) scaled geometrically with leaf area (LA), we found that for $P$. juniperinum gametophyte leaf width (LW) did not scale with leaf $\operatorname{area}(\mathrm{LA})(\mathrm{P}=0.081)$.

Wet weight $(\mathrm{WW})$ mean values were $62.29 \mathrm{mg} \pm 4.932 \mathrm{SEM}(\mathrm{n}=45)$, with minimum wet weight of $19.6 \mathrm{mg}$ and maximum of $169 \mathrm{mg}$. As wet weight (WW) increased isoprene emission decreased. Lastly, leaf tip redness (LTR) mean values were $1.004 \mathrm{~mm} \pm 0.03291 \mathrm{SEM}(\mathrm{n}=45)$, with a minimum value of $0.582 \mathrm{~mm}$ and a maximum value of $1.58 \mathrm{~mm}$. The more leaf tip redness was present (LTR) the more isoprene 
emission decreased. We found no statistical effects for leaf dimension, leaf shape or cell traits on isoprene emission.

\section{Experiment 1b:}

\section{The effects of belowground morphological variables on isoprene emission in $P$. juniperinum gametophytes}

Two belowground traits contributed to $11 \%$ variability in isoprene emission in our final model; stem area dry (SAD), and wet stem area at 24 hours (WSA24). When we logged isoprene emission against stem area dry, we saw that the relationship was statistically significant and as dry stem area increased isoprene emission followed (Regression; $\mathrm{r}^{2}=0.11 ; \mathrm{P}=0.0293$; Figure 3.6). Our regression line equation with logged isoprene emission and stem area dry $(\mathrm{SAD})$ was $\mathrm{Y}=5.851185^{*} \mathrm{x}+2.2250985$. For our belowground morphological measures, stem area dry (SAD) mean values were 0.0782 $\mathrm{mm}^{2} \pm 0.00465 \operatorname{SEM}(\mathrm{n}=45)$. For wet steam area at 24 hours (WSA24) mean values were $0.1609 \mathrm{~mm}^{2} \pm 0.00626 \mathrm{SEM}(\mathrm{n}=45)$.

We also significant correlation between shoot to root ratio (RSR) and logged isoprene emission (Regression; $\mathrm{r}^{2}=0.09 ; \mathrm{F}=4.2174 ; \mathrm{P}=0.0461$ ). We were able to establish that as dry stem area (SAD) increased isoprene emission increased. As wet stem area (WSA24) increased isoprene emission decreased. We also saw a strong positive linear correlation between dry stem area (SAD) and wet stem area (WSA24).

\section{Experiment 2:}




\section{P. juniperinum isoprene emission, sex and morphological variables}

Sex had a significant effect on isoprene emission (RM ANOVA; DF=1,9; $F=7.11$; $\mathrm{P}=0.026$; Figure 3.7), with males producing higher isoprene emission levels than females. These plants had been previously sexed, but they were not expressing sex when isoprene emission was measured. Female mean isoprene emission value was $8.032 \mathrm{nmol} \mathrm{m}^{-2} \mathrm{~s}^{-1} \pm$ $0.642 \operatorname{SEM}(\mathrm{n}=27)$, male mean values were $8.946 \mathrm{nmol} \mathrm{m}^{-2} \mathrm{~s}^{-1} \pm 0.662$ SEM $(\mathrm{n}=24)$. Media did not have a significant effect on isoprene emission ( $\mathrm{F}=0.90 ; \mathrm{P}=0.37)$, and site also did not have a significant effect on isoprene emission ( $\mathrm{F}=1.42 ; \mathrm{P}=0.30)$.

The number of leaves on sexually expressing gametophytes was statistically significant and explained 20\% variability in isoprene emission (ANOVA; DF=2; $\mathrm{F}=4.675 ; \mathrm{P}=0.0098)$. We have found that for females the number of shoots and gametophyte width explained 45\% variability in isoprene emission (ANOVA; DF=7; $\mathrm{F}=5.485 ; \mathrm{P}<0.0001)$. For males, we found that $49 \%$ of variability in isoprene emission could be explained by number of shoots and gametophyte width (ANOVA; DF=12; $\mathrm{F}=2.790 ; \mathrm{P}=0.0089)$.

We saw several morphological variables that were influenced by sex of the gametophyte, and invariably affected our isoprene emission measurements. Gametophyte width had statistical significance when it came to the three sexes in our continuous isoprene emission and explained $16 \%$ variability between the sexes in gametophyte width (ANOVA; $\mathrm{DF}=2 ; \mathrm{F}=4.5190 ; \mathrm{P}=0.0160)$. 


\section{Experiment 3:}

\section{A. undulatum, P. juniperinum and $P$. urnigerum isoprene emission, sexual expression and site-specific differences}

Isoprene emission among Polytrichaceae species was statistically significant explaining $42 \%$ variability in isoprene emission between species (ANOVA; DF=2; $\mathrm{F}=59.010 ; \mathrm{P}<0.0001 ;$ Figure 3.8). The highest isoprene emission was seen from cosmopolitan P. juniperinum, where we saw our maximum value at $59 \mathrm{nmol} \mathrm{m}^{-2} \mathrm{~s}^{-1}$, the highest recorded value for this moss species. P. juniperinum mean isoprene emission values were $16.3885 \mathrm{nmol} \mathrm{m}^{-2} \mathrm{~s}^{-1} \pm 1.902 \mathrm{SEM}(\mathrm{n}=56)$. Montane $P$. urnigerum mean isoprene emission were $4.496 \mathrm{nmol} \mathrm{m}^{-2} \mathrm{~s}^{-1} \pm 0.5981 \mathrm{SEM}(\mathrm{n}=41)$. Lastly, our shade adapted $A$. undulatum mean isoprene emission value were $2.4183 \mathrm{nmol} \mathrm{m}^{-2} \mathrm{~s}^{-1} \pm 0.196$ $\operatorname{SEM}(n=70)$.

In all three species sexual expression was statistically significant, from our data we can explain $48 \%$ variability in isoprene emission by sexual expression nested within species (ANOVA; DF=6; F=24.25; $\mathrm{P}<0.0001 ;$ Figure 3.9). The highest isoprene emission was seen from $P$. juniperinum non-sexually expressing gametophytes. In all three species of Polytrichaceae, species that did not have sexual expression were found to have higher isoprene emission than those that were sexually expressing. We found that sexual expression nested within species contributed $50 \%$ variability in isoprene emission between species and sex (ANOVA; DF=2; F=7.334; $\mathrm{P}=0.0009$; Figure 3.10).

We also saw site-specific variation in all three species that explained high variation in isoprene emission. In A. undulatum site-specific differences can be attributed 
to $18 \%$ of variability in isoprene emission (ANOVA; $\mathrm{DF}=3 ; \mathrm{F}=4.97 ; \mathrm{P}=0.0036$; Figure

3.11). In P. juniperinum, $27 \%$ of variability in isoprene emission can be attributed to sitespecific differences (ANOVA; DF=6; F=3.0792; $\mathrm{P}=0.0123$; Figure 3.12). Lastly, in $P$. urnigerum, $30 \%$ of variability in isoprene emission can be attributed to site-specific differences (ANOVA; DF=5; F=3.082; $\mathrm{P}=0.0208$; Figure 3.13).

\section{Laboratory gas exchange measurements}

\section{Experiment 1}

We found isoprene emission positively correlated with CFR across species (Regression, $\mathrm{r}^{2}=0.85 ; \mathrm{P}<0.0001$; Figure 3.14). Our regression line equation with $\mathrm{CFR}$ was $Y=36.22 * x-16.12$. Mean CFR values were $0.9264 \pm 0.011$ SEM $(n=45)$, with minimum value of 0.698 and maximum value of 1.074 .

We found statistical differences between the forty-five non-sexually expressing gametophytes we tested for RETR in low photosynthetic photon flux density (PPFD) $\mu \mathrm{mol} \mathrm{m} \mathrm{m}^{-2} \mathrm{~s}^{-1}$ and high photosynthetic photon flux density (PPFD) $\mu \mathrm{mol} \mathrm{m} \mathrm{m}^{-2} \mathrm{~s}^{-1}$ (ANOVA; $\mathrm{DF}=1 ; \mathrm{F}=18.343 ; \mathrm{P}<0.0001)$. Our low PPFD $\mu \mathrm{mol} \mathrm{m}^{-2} \mathrm{~s}^{-1}$ setting values between the 45 non-sexually expressing gametophytes explained $16 \%$ variation between samples, and under high PPFD setting we saw 24\% variation in RETR values.

\section{Experiment 2}

We found a significant positive correlation between CFR and isoprene emission (Regression; $\mathrm{r}^{2}=0.07 ; \mathrm{P}<0.0001$; Figure 3.15). Our regression line equation for isoprene 
emission vs. CFR measures were $\mathrm{Y}=2.820 * \mathrm{x}+0.1808$. Mean CFR values were 0.703 \pm 0.0094 SEM ( $n=25)$. Also, we saw sex-specific differences in CFR values, with the highest $\mathrm{CFR}$ values in males (ANOVA; $\mathrm{DF}=2 ; \mathrm{F}=5.446 ; \mathrm{P}=0.0046$; Figure 3.16). Under female sexual expression, mean CFR value were 0.678 \pm 0.0105 SEM $(n=15)$. Under male sexual expression, mean CFR value were 0.723 \pm 0.008 SEM $(n=12)$. Lastly, under non-sexually expressing gametophytes, mean CFR value were 0.693 \pm 0.010 SEM $(n=12)$.

The sexes were significantly different in (RETR); however, these effects depended on light conditions and the type of media the plants were growing on. Under low PPFD $\mu \mathrm{mol} \mathrm{m} \mathrm{m}^{-2} \mathrm{~s}^{-1}$ we found significant differences in RETR curves between sexes for plants growing on $\mathrm{BCD}$ media. Our regression line equation for males on BCD media was $\mathrm{Y}=0.0447^{*} \mathrm{x}+4.912$ (Figure 3.17). Male RETR values were higher than female or non-sexually expressing gametophyte values. At neither low nor high PPFD $\mu \mathrm{mol} \mathrm{m} \mathrm{m}^{-2} \mathrm{~s}^{-1}$ we found no statistical differences in RETR curves between sexes for plants growing on

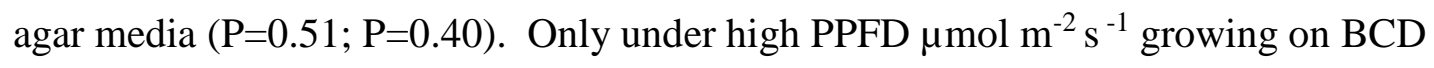
media did we find significant differences in RETR curves between sexes (ANOVA; $\mathrm{DF}=1 ; \mathrm{F}=9.0432 \mathrm{P}<0.0001)$.

\section{Experiment 3}

Isoprene emission had a positive correlation with CFR, and was statistically significant in A. undulatum (Regression; $\mathrm{r}^{2}=0.41 ; \mathrm{P}=0.0123$; Figure 3.18). Our regression 
line equation with CFR was $\mathrm{Y}=9.9136 * \mathrm{x}-17.1921$. We found no statistical significance for isoprene emission vs. CFR values in P. juniperinum $(\mathrm{P}=0.445)$.

CFR values explained $24 \%$ of variability among species in the Polytrichaceae family (ANOVA; DF=1; F=8.4475; $\mathrm{P}<0.0074$; Figure 3.19). P. juniperinum had higher CFR values than A. undulatum. Mean CFR value for $A$. undulatum was $0.73 \pm 0.015$ SEM (n=15). Mean CFR value for P. juniperinum was 0.79 \pm 0.026 SEM ( $n=13)$.

Species differences among RETR values were high, explaining $45 \%$ of variability in RETR values among species (ANOVA; DF=1; F=21.2391; $\mathrm{P}<0.0001$; Figure 3.20). Cosmopolitan $P$. juniperinum had five fold higher values in RETR measures than did shade adapted $A$. undulatum.

We accounted for nested sex within species, and used RETR as our response variable and found statistical significance between sexes (ANOVA; DF=1; F=4.4601; $\mathrm{P}$ $=0.0357$; Figure 3.21). A. undulatum under PPFD $\mu \mathrm{mol} \mathrm{m} \mathrm{m}^{-2} \mathrm{~s}^{-1}$ mean values were 18.6 $\mu \mathrm{mol} \mathrm{m} \mathrm{m}^{-2} \pm 0.72$ SEM $(\mathrm{n}=15) . P$. juniperinum under low PPFD $\mu \mathrm{mol} \mathrm{m} \mathrm{m}^{-2} \mathrm{~s}^{-1}$ mean values were $29.2 \mu \mathrm{mol} \mathrm{m} \mathrm{m}^{-2} \pm 1.32 \mathrm{SEM}(\mathrm{n}=13)$. We could not analyze isoprene emission versus RETR, as each sample contained eight RETR measures, and we have sampled one isoprene emission value at basal isoprene emission $\left(1000 \mu \mathrm{mol} \mathrm{m}^{-2} \mathrm{~s}^{-1}\right.$ and $\left.30^{\circ} \mathrm{C}\right)$.

\section{Discussion}

\section{Aboveground morphological variables and isoprene emission}


A single moss gametophyte is made up of many leaves and each leaf contributes to isoprene emission (Wildermuth et al. 1996; Velikova et al. 2011, 2012; Schnitzler et al. 2005). Even within the same population of $P$. juniperinum, we saw a high degree of variation of isoprene emission all within the range of what has already been previously reported (Hanson et al. 1999) and even exceeding previously reported values. We found that the four most significant variables, canopy traits, contributed $39 \%$ of variation in isoprene emission. We saw high variation in isoprene emission from the forty-five $P$. juniperinum gametophytes of a single population. Within the canopy, multivariate traits were found to have a positive correlation between total leaves (TL), dry weight (DW), and canopy height $(\mathrm{CH})$, and negative statistical significance was found between leaf tip redness (LTR) and total leaves (TL) (Figure 3.5). Leaf number contributed to $11 \%$ variation in isoprene emission among gametophytes and gametophyte width contributed to $19 \%$ variation in isoprene emission revealing that a larger area will contribute to more isoprene emission and chloroplast area.

Like Waite and Sack (2010), we have found high correlation between leaf length (LL) and gametophyte length/gametophyte width (GL/GW) which support taller gametophyte structure. High allocation to structural support with longer gametophytes need more support for more leaves. We found gametophyte leaf length (GL) scaled geometrically with leaf area (LA), as it has been shown in mosses by Waite (2010). We also show that non-sexually expressing gametophytes had significantly higher dry weight compared with males and females. This suggests that nutrient requirement and allocation 
pattern of resources differ in investment strategies between gametophytes that are sexually reproducing versus gametophytes that are non-sexual.

\section{Belowground morphological variables and isoprene emission}

Many internal factors (genetics and biochemical) and external factors (abiotic and biotic influences) control BVOC emissions (Lehning et al. 1999; Peñuelas et al. 2001, Geron et al. 2001; Sasaki et al. 2005; Sharkey et al. 2007; Monson et al. 2012; Sharkey et al. 2017). We were able to show a high rate of variation in isoprene emission out of which two belowground morphological variables were extracted for use in our final emissions model. These were stem area dry (SAD) and wet stem area at 24 hours (WSA24). These together contributed to $11 \%$ variation in isoprene emission in our model (Figure 3.6).

Isoprene synthesis requires energy and photosynthetic carbon (Grinspoon et al. 1991; Rasulov et al. 2009; Melis et al. 2013; Unger et al. 2013; Jiang et al. 2013). When conditions limit photosynthesis, alternate carbon sources have been found to be used in vascular plants. Besides recently photosynthetically fixed $\mathrm{CO}_{2}$, alternate carbon sources include xylem transported carbohydrates, and leaf internal carbon pools which can be used for isoprene production (Schnitzler et al. 2004). Given vascular plants can utilize alternate source of carbon for isoprene production, such as starch from xylem transported carbon, we hypothesize that our model moss $P$. juniperinum might also use alternate carbon sources, as we know that starch is stored in its underground rhizoids and these acts as sites for overwinter storage of carbohydrates (Skre et al. 1983). 


\section{Species and isoprene emission}

In this study, we tested isoprene emission from three species of the Polytrichaceae family, which we collected from a range of altitude from 4 meters to 88 meters above sea level and from a variety of substrates (Table 3.3). The phenological stage of the mosses at the time of collection could have played a part in the high degree of variation we saw in isoprene emission rates between and within species. We saw low isoprene emission values for our deep shade adapted $A$. undulatum which is always found in forest understory and does not live in direct sunlight. While, our sun loving $P$. juniperinum was able to emit high amounts of isoprene which can be comparable to levels found in isoprene emitting vascular plants. This is not entirely surprising as this moss has the ability to survive in insolation values exceeding equatorial noon sunlight (Marschall et al. 2004; Proctor et al. 2005), and it is accustomed to high temperature regimes (Monson et al. 1994; Geron et al. 2001).

In vascular plants, it has been noted that isoprene emission rates vary greatly among species and isoprene emission ability may or may not be shared by member of the same family or genus with no clear evolutionary link between emitters (Harley et al. 1999; Sharkey et al. 2001, 2007; Dani et al. 2014; Loreto et al. 2015). Given basal emission rates of the three species tested, we saw varying isoprene emission rates due to environmental and genetic factors. Further work is required to evaluate independently how these factors affect the instantaneous isoprene emission rate against basal isoprene emission rate. 


\section{Sex and isoprene emission}

Over 60\% of moss species have separate sexes (Wyatt et al. 1984; Hedenäs et al. 2011), while sexual differentiation only occurs in 5\% of seed plants (Richards 1997). Sexual reproduction in mosses is an energy and resource intensive process (Glime 1984). Sex is costly and is subject to resource limitations in the Polytrichaceae family (Koncz et al. 2012). The "cost of sex hypothesis" predicts that the most expensive sex should be the rarest sex (Stark et al. 2000) and suggests that the costly sex would have few resources to allocate elsewhere, including isoprene production. In P. juniperinum, we found that male and female plants, that are not currently expressing sexual organs, differ in isoprene emission, with males emitting more isoprene than female counterparts (Figure 3.7). However, in our experiment using all three species, in which the males and females were expressing sex organs, males and females did not differ in isoprene emission (Figure 3.9, 3.10). Our results indicate that there are sex-specific differences in isoprene emission between non-sexually expressing male and female moss plants, but these may lessen when plants are paying the cost of producing sexual organs. Further study is required, as sexual organ formation takes up considerable resources and space in moss gametophytes. The difference we saw in male and female isoprene emission could be due to a number of both environmental and genetic factors.

Also, in our study, we found that non-sexually expressing gametophytes of all three species had significantly higher isoprene emission rates compared to sexually expressing moss, suggesting resource limitation does exist in mosses. Previously, reproductive effort has been investigated in mosses by assessing sporophyte abortion 
rates, morphological differences between the sexes in terms of size, growth, branching and number of sexual organs in each sex (Glime 1984; Bowker et al. 2000). We are the first to report that sexual expression affects isoprene emission in moss, and presents a reproductive cost as sexually expressing females and males had much lower isoprene emission rates than non-sexually expressing gametophytes. Isoprene emission in each sex is a resource that is limited, perhaps affects reproductive performance, and contributes to reproductive cost in these species. To our knowledge, this study is the first to examine potential trade-offs in resource allocation among female, male and non-sexually expressing gametophytes. Future investigation should differentiate between trade-offs associated with isoprene emission in sexually expressing and non-sexually expressing gametophytes and consider the cost and benefit associated with these emissions in conjunction with biomass and nutrient content. We propose that further study of these isoprene-emitting mosses should help resolve some fundamental unanswered questions in resource allocation between species and between sexes, and even fundamental questions such as land plant evolution of the sexes. Much more work is needed to understand the evolutionary pressures and environmental factors that influence isoprene emission from mosses and all major group of land plants.

Changes in resource allocation associated with isoprene production might play a role in directing and constraining sexual reproduction in mosses under stress (Eppley et al. 2011, Huttunen 2003; Kis-Papo et al. 2003; Stark et al. 2005). Changing stressors associated with global warming, particularly in high latitude environments may exacerbate these effects. The factors influencing maintenance of sex are of great interest 
in evolutionary biology (Vamosi et al. 2003). While sex-specific BVOC emissions are poorly characterized in mosses, we do know they are sex-specific and mediate microarthropod fertilization in mosses (Rosenstiel et al. 2012). Sexual expression explained $38 \%$ variability in isoprene emission.

In many bryophytes, a large part of the population is made up of sterile plants, with males and females absent (Stark 2002; Rydgren et al. 2002a,b) and many interdependent factors affect reproductive success (Longton et al. 1983, 1990; Mishler et al. 1988; Shaw 1991a,b; Bisang et al. 2004; McLetchie 2001; Silva et al. 2012). We saw the highest isoprene emission from all three species in non-sexually expressing gametophytes (Figure 3.9). In turn, A. undulatum explained 14\% variability in isoprene emission within its sexes while $P$. urnigerum explained $18 \%$ variability in isoprene emission in sexes. In $P$. juniperinum, we saw the least amounts of variability, accounting for only $11 \%$ variation within sexes. We had a total of 65 gametophytes that did not express sex, and 35 gametophytes that expressed sexual female and male characteristic, with males emitting higher isoprene values than females (Figure 3.10). Large moss populations contain non-sexual gametophytes, and the key to understanding isoprene fluxes from moss populations will be to understand the control on the development of sex organs in mosses (Zaugol'nova 1971; Watson 1974; Callaghan et al. 1978; Glime 2017). Life history for male and female gametophytes must be assessed independently, as the sexes are dimorphic in size, maturation rates, and reproductive output (Shaw et al. 1999).

\section{Laboratory gas exchange measurements}


Most mosses have saturating light curve levels that are close to $600 \mu \mathrm{mol} \mathrm{m} \mathrm{m}^{-2} \mathrm{~s}^{-1}$ Photosynthetic Photon Flux Density (PPFD), while species in the Polytrichaceae family attain the highest light saturating curves. For A. undulatum light saturation have been found to be $\sim 648 \mu \mathrm{mol} \mathrm{m} \mathrm{m}^{-2} \mathrm{~s}^{-1}$ PPFD (Marschall et al. 2004). This low light level saturation helps explain the low isoprene emission we saw from this species typically found in deep shade near water sources. $P$. urnigerum light saturation have been found to be $\sim 957 \mu \mathrm{mol} \mathrm{m} \mathrm{m}^{-2} \mathrm{~s}^{-1}$ PPFD (Marschall et al. 2004). This is a high elevation montane species that is often exposed to more sunlight than shade adapted $A$. undulatum and has a thicker leaf composition than the one-cell layer leaves of A. undulatum. Lastly, the cosmopolitan $P$. juniperinum, the highest isoprene emitter we have documented, has been shown to have light saturation curves comparable to vascular 'sun plants' reaching values as high as $2175 \mu \mathrm{mol} \mathrm{m} \mathrm{m}^{-2} \mathrm{~s}^{-1}$ PPFD (Proctor et al. 2002; Marschall et al. 2004; Proctor 2005). We saw this species emit the highest amount of isoprene, but further study is needed to look at how habitat and environment influences isoprene emission. In general, we saw high within species variation in isoprene emission as well, which was potentially due to the fact that we had a wide range of environmental variation including altitude and substrate differences.

We measured the basal isoprene emission under controlled condition as a function of temperature of $30^{\circ} \mathrm{C}$ and as a function of light at $1000 \mu \mathrm{mol} \mathrm{m} \mathrm{m}^{-2} \mathrm{~s}^{-1} \mathrm{PPFD}$. This measure depends on substrate availability and photosynthetic machinery from the plant; this measure is often taken as the inherent capacity of isoprene emission (Monson et al. 1994; Sharkey et al. 1999; Geron et al. 2000). A second level of isoprene emission rate 
called the "instantaneous emission rate' needs further investigation in non-vascular plants. This measure is set against environmental condition on basal emissions (Monson et al. 1994). Future work should focus on understanding how environmental drivers affect isoprene emission in mosses.

Isoprene production rate and chlorophyll content in marine phytoplankton shows a "simple and robust" relationship (Shaw et al. 2003; Palmer et al. 2005), with peak isoprene emission correlating strongly to chlorophyll fluorescence (Bonsang et al. 1992, 2010; Baker et al. 2000). We used chlorophyll fluorescence ratio (CFR) as a nonintrusive tool as a proxy to establish information on photosynthetic reactions in the chloroplast and stress level in plants (Schreiber et al. 1987). We saw chlorophyll fluorescence ratio highly correlating to isoprene emission. We found a positive correlation between CFR and isoprene emission (Figure 3.14; Figure 3.15). We also saw sex-specific CFR value differences between species, owing to cost of sexual reproduction, with males having higher CFR values than females or non-sexually expressing gametophytes (Figure 3.16). High light dwelling $P$. juniperinum had higher CFR values than shade adapted $A$. undulatum with species difference explaining $24 \%$ variability in CFR measures (Figure 3.19).

Since the light dependent isoprene emission is related to electron transport rate in vascular plants (Dani et al. 2014; Niinemets et al. 1999, 2015), we looked at electron transport rates within our samples to determine if we can establish a relationship between the two. RETR was measured independently using fluorescence and was not coupled 
with LiCor measurements and should only be taken as indicative and not as absolute measures (Dani et al. 2014).

We have observed species and sex-specific RETR curves (Figure 3.17). We analyzed if we could find species differences in RETR values, and showed that sun tolerant $P$. juniperinum had five fold higher RETR values than shade adapted $A$. undulatum (Figure 3.20). Lastly, we showed sexual differences in RETR between the species (Figure 3.21), with non-sexual gametophyte having higher values of RETR than sexually expressing gametophytes.

Mosses vary widely in their photosynthetic light response, but Polytrichum species were shown to have the highest light saturating curves of 39 species of mosses tested (Marschall et al. 2004). This moss species is unique given their lamellae that forms a ventilated photosynthetic tissue (Marschall et al. 2004). The photosynthetic lamellae aids in lowering leaf resistance to $\mathrm{CO}_{2}$ uptake, allowing the utilization of direct sunlight (Proctor 2005). With our RETR curves, we did not reach full saturation, as some Polytrichaceae species reach saturation at $2549 \mu \mathrm{mol} \mathrm{m} \mathrm{m}^{-2} \mathrm{~s}^{-1}$ (Marschall et al. 2004). Our highest value was measured consistently at $1500 \mu \mathrm{mol} \mathrm{m}^{-2} \mathrm{~s}^{-1}$ and in further experiments; a higher saturation PPFD would allow us to measure RETR saturation curves for this species in conjunction with isoprene emission. We aim to create electron transport rate curves by taking isoprene emission values at each level of a full light saturation curve. This will allow us to confer what has been found with vascular plants and determine if electron transport rate is positively correlated with isoprene emission in mosses as it is in vascular plants (Niinemets et al. 1999). 
Under drought conditions, it has been shown that while electron transport values are still favorable, isoprene emission can decrease which highly suggest carbon limitation (Dreyer et al. 2001; Dani et al. 2014; Darbah et al. 2008). It is hypothesized that leaf temperature determines the amount of isoprene in the membrane, when the temperature goes up isoprene emission ameliorate the stresses on the membrane, but once cooling it can dissipate as a safety valve (Rosenstiel et al. 2004; Singsaas et al. 1998).

Lower isoprene emission was shown to exist with young leaves compared to mature leaves. Isoprene emission from young leaves was twice what was observed in older leaves. The saturating light for isoprene emission could positively correlate with photosynthetic electron transport rate in mosses as it has been observed in vascular plants (Niinemets et al. 1999; Rasulov et al. 2009; Morfopoulos et al. 2014). We can speculate that, as with vascular plants, we would see electron transport rate scale with isoprene emission. Further research and methodological development is necessary. Our experimental setup and data collection would have had to take an isoprene emission sample at each light interval to determine if this holds true. From preliminary data collection we were able to confirm that this is the case at least in what we were able to observe. RETR values we observed are less than half the values we have seen in our previous experiments, possibly due to the fact that the gametophytes were planted in March and checked for RETR measures at the end of the experiment as they were embedded in media by this time, with many shoots sprouting out. We believe that these values reflect a low photosynthetic rate given exposure to low light levels throughout the trial. 


\section{Tables and Figures}

Table 3.1 Summary table of $P$. juniperinum populations used for non-sexually expressing isoprene emission $(n=45)$.

\begin{tabular}{|l|l|l|l|}
\hline $\begin{array}{l}\text { Altitude } \\
\text { (meters) }\end{array}$ & Latitude & Longitude & Substrate \\
\hline 241 & $45^{\circ} 47^{\prime} 17^{\prime \prime} \mathrm{N}$ & $122^{\circ} 56^{\prime} 16.00^{\prime \prime} \mathrm{W}$ & $\begin{array}{l}\text { Clay soil, hillside road } \\
\text { cut in forest }\end{array}$ \\
\hline
\end{tabular}


Table 3.2 Summary table of $P$. juniperinum populations used for sexually expressing isoprene emission $(n=25)$.

\begin{tabular}{|r|l|l|l|l|}
\hline Site & $\begin{array}{l}\text { Altitude } \\
\text { (meters })\end{array}$ & Latitude & Longitude & Substrate \\
\hline 1 & 15 & $45^{\circ} 41^{\prime} 38.34^{\prime \prime N}$ & $122^{\circ} 52^{\prime} 14.23^{\prime \prime} \mathrm{W}$ & $\begin{array}{l}\text { Gravelly soil, on } \\
\text { hillside near } \\
\text { highway }\end{array}$ \\
\hline 2 & 21 & $45^{\circ} 38^{\prime} 7.45^{\prime \prime} \mathrm{N}$ & $122^{\circ} 49^{\prime} 45.09^{\prime \prime} \mathrm{W}$ & $\begin{array}{l}\text { Gravelly soil, steep } \\
\text { hillside next to road }\end{array}$ \\
\hline 3 & 145 & $45^{\circ} 41^{\prime} 50.54^{\prime \prime} \mathrm{N}$ & $122^{\circ} 52^{\prime} 40.83^{\prime \prime} \mathrm{W}$ & $\begin{array}{l}\text { Gravelly soil, steep } \\
\text { hillside next to road }\end{array}$ \\
\hline 4 & 315 & $45^{\circ} 46^{\prime} 58.78^{\prime \prime} \mathrm{N}$ & $123^{\circ} 22^{\prime} 14.14^{\prime \prime} \mathrm{W}$ & $\begin{array}{l}\text { Clay soil, hillside } \\
\text { road cut }\end{array}$ \\
\hline 5 & 412 & $45^{\circ} 44^{\prime} 6.80^{\prime \prime} \mathrm{N}$ & $122^{\circ} 59^{\prime} 30.62^{\prime \prime} \mathrm{W}$ & $\begin{array}{l}\text { Clay soil, hillside } \\
\text { road cut in forest }\end{array}$ \\
\hline 6 & 241 & $45^{\circ} 47^{\prime} 17^{\prime \prime} \mathrm{N}$ & $122^{\circ} 56^{\prime} 16.00^{\prime \prime} \mathrm{W}$ & $\begin{array}{l}\text { Clay soil, hillside } \\
\text { road cut in forest }\end{array}$ \\
\hline
\end{tabular}


Table 3.3 Summary table of Atrichum undulatum, Polytrichum juniperinum and Pogonatum urnigerum populations used for sexually expressing isoprene emission (n=167). Abbreviations: MC-Multnomah county, CC-Columbia county, CL-Clatsop county MC-Marion country, COC-Cowlitz county, WC-Washington county, TCTillamook county.

\begin{tabular}{|c|c|c|c|c|c|c|}
\hline Moss & ID & $\begin{array}{l}\text { Alt. } \\
(\mathrm{m})\end{array}$ & Latitude & Longitude & County & Substrate \\
\hline $\begin{array}{l}\text { A. undulatum } \\
(\mathrm{n}=9)\end{array}$ & U1 & 8 & $45^{\circ} 8^{\prime} 1.55^{\prime \prime} \mathrm{N}$ & $122^{\circ} 0 ' 57.57^{\prime \prime} \mathrm{W}$ & MC & $\begin{array}{l}\text { gravelly } \\
\text { soil }\end{array}$ \\
\hline $\begin{array}{l}\text { A.undulatum } \\
(\mathrm{n}=24)\end{array}$ & U2 & 20 & $45^{\circ} 44^{\prime} 43.95^{\prime \prime} \mathrm{N}$ & $122^{\circ} 57^{\prime} 32.99^{\prime \prime} \mathrm{W}$ & $\mathrm{CC}$ & $\begin{array}{l}\text { loamy } \\
\text { soil }\end{array}$ \\
\hline $\begin{array}{l}\text { A.undulatum } \\
(\mathrm{n}=22)\end{array}$ & U3 & 76 & $45^{\circ} 43^{\prime} 34.68^{\prime \prime} \mathrm{N}$ & $122^{\circ} 59^{\prime} 3.91^{\prime \prime} \mathrm{W}$ & $\mathrm{CC}$ & $\begin{array}{l}\text { decayed } \\
\text { tree } \\
\text { stump }\end{array}$ \\
\hline $\begin{array}{l}\text { A.undulatum } \\
(\mathrm{n}=15)\end{array}$ & U4 & 31 & $45^{\circ} 44^{\prime} 24.32^{\prime \prime} \mathrm{N}$ & $122^{\circ} 57^{\prime} 37.19^{\prime \prime} \mathrm{W}$ & $\mathrm{CC}$ & clay soil \\
\hline $\begin{array}{l}P . \\
\text { juniperinum } \\
(\mathrm{n}=3)\end{array}$ & $\mathrm{J} 1$ & 21 & $45^{\circ} 44^{\prime} 46.89^{\prime \prime} \mathrm{N}$ & $122^{\circ} 57^{\prime} 37.54^{\prime \prime} \mathrm{W}$ & $\mathrm{CC}$ & $\begin{array}{l}\text { loamy } \\
\text { soil }\end{array}$ \\
\hline $\begin{array}{l}P . \\
\text { juniperinum } \\
(\mathrm{n}=5)\end{array}$ & $\mathrm{J} 2$ & 9 & $45^{\circ} 13^{\prime} 38.97 " \mathrm{~N}$ & $122^{\circ} 52^{\prime} 5.00^{\prime \prime} \mathrm{W}$ & $\mathrm{MC}$ & $\begin{array}{l}\text { gravelly } \\
\text { soil }\end{array}$ \\
\hline $\begin{array}{l}P . \\
\text { juniperinum } \\
(\mathrm{n}=5)\end{array}$ & $\mathrm{J} 3$ & 56 & $46^{\circ} 20^{\prime} 37.13^{\prime \prime} \mathrm{N}$ & $122^{\circ} 43^{\prime} 41.10^{\prime \prime} \mathrm{W}$ & $\mathrm{COC}$ & $\begin{array}{l}\text { gravelly } \\
\text { soil }\end{array}$ \\
\hline $\begin{array}{l}P . \\
\text { juniperinum } \\
(\mathrm{n}=13)\end{array}$ & $\mathrm{J} 4$ & 39 & $45^{\circ} 45^{\prime} 40.19^{\prime \prime} \mathrm{N}$ & $123^{\circ} 18^{\prime} 25.48^{\prime \prime} \mathrm{W}$ & WC & gravel \\
\hline $\begin{array}{l}P . \\
\text { juniperinum } \\
(\mathrm{n}=14)\end{array}$ & J5 & 4 & $45^{\circ} 38^{\prime} 7.44^{\prime \prime} \mathrm{N}$ & $122^{\circ} 49^{\prime} 44.95^{\prime \prime} \mathrm{W}$ & $\mathrm{MC}$ & gravel \\
\hline $\begin{array}{l}P . \\
\text { juniperinum } \\
(\mathrm{n}=12)\end{array}$ & J6 & 9 & $45^{\circ} 41^{\prime} 38.75^{\prime \prime} \mathrm{N}$ & $122^{\circ} 52^{\prime} 14.18^{\prime \prime} \mathrm{W}$ & $\mathrm{MC}$ & $\begin{array}{l}\text { gravelly } \\
\text { soil }\end{array}$ \\
\hline $\begin{array}{l}P . \\
\text { juniperinum } \\
(\mathrm{n}=4)\end{array}$ & J7 & 83 & $45^{\circ} 57^{\prime} 55.06^{\prime \prime} \mathrm{N}$ & $123^{\circ} 40^{\prime} 46.24^{\prime \prime} \mathrm{W}$ & $\mathrm{CL}$ & $\begin{array}{l}\text { loamy } \\
\text { soil }\end{array}$ \\
\hline $\begin{array}{l}\text { P. urnigerum } \\
(\mathrm{n}=4)\end{array}$ & PU1 & 83 & $45^{\circ} 57^{\prime} 55.06^{\prime \prime} \mathrm{N}$ & $123^{\circ} 40^{\prime} 46.24^{\prime \prime} \mathrm{W}$ & $\mathrm{CL}$ & $\begin{array}{l}\text { loamy } \\
\text { soil }\end{array}$ \\
\hline $\begin{array}{l}\text { P. urnigerum } \\
(\mathrm{n}=11)\end{array}$ & $\mathrm{U} 2$ & 72 & $45^{\circ} 43^{\prime} 47.10^{\prime \prime} \mathrm{N}$ & $122^{\circ} 59^{\prime} 22.03^{\prime \prime} \mathrm{W}$ & $\mathrm{CC}$ & $\begin{array}{l}\text { loamy } \\
\text { soil }\end{array}$ \\
\hline $\begin{array}{l}\text { P. urnigeium } \\
(\mathrm{n}=4)\end{array}$ & U3 & 71 & $45^{\circ} 57^{\prime} 37.98^{\prime \prime} \mathrm{N}$ & $123^{\circ} 41^{\prime} 6.02^{\prime \prime W}$ & $\mathrm{CL}$ & $\begin{array}{l}\text { loamy } \\
\text { soil }\end{array}$ \\
\hline
\end{tabular}




\begin{tabular}{|l|l|l|l|l|l|l|}
\hline $\begin{array}{l}\text { P. urnigerum } \\
(\mathrm{n}=9)\end{array}$ & $\mathrm{U} 4$ & 88 & $45^{\circ} 57^{\prime} 44.30^{\prime \prime} \mathrm{N}$ & $123^{\circ} 41^{\prime} 1.16^{\prime \prime} \mathrm{W}$ & $\mathrm{CL}$ & $\begin{array}{l}\text { loamy } \\
\text { soil }\end{array}$ \\
\hline $\begin{array}{l}\text { P. urnigerum } \\
(\mathrm{n}=7)\end{array}$ & $\mathrm{U} 5$ & 21 & $45^{\circ} 57^{\prime} 39.31^{\prime \prime} \mathrm{N}$ & $123^{\circ} 40^{\prime} 58.62^{\prime \prime} \mathrm{W}$ & $\mathrm{TC}$ & $\begin{array}{l}\text { loamy } \\
\text { soil }\end{array}$ \\
\hline $\begin{array}{l}P . \text { urnigerum } \\
(\mathrm{n}=6)\end{array}$ & $\mathrm{U} 6$ & 37 & $45^{\circ} 57^{\prime} 46.89^{\prime \prime} \mathrm{N}$ & $123^{\circ} 41^{\prime} 1.49^{\prime \prime} \mathrm{W}$ & $\mathrm{TC}$ & $\begin{array}{l}\text { loamy } \\
\text { soil }\end{array}$ \\
\hline
\end{tabular}


Table 3.4 Summary table for aboveground morphological trait measurements from $P$. juniperinum gametophytes to assess discernable characteristics and contributions to isoprene emission $(\mathrm{n}=45)$.

\begin{tabular}{|c|c|}
\hline Canopy structure & 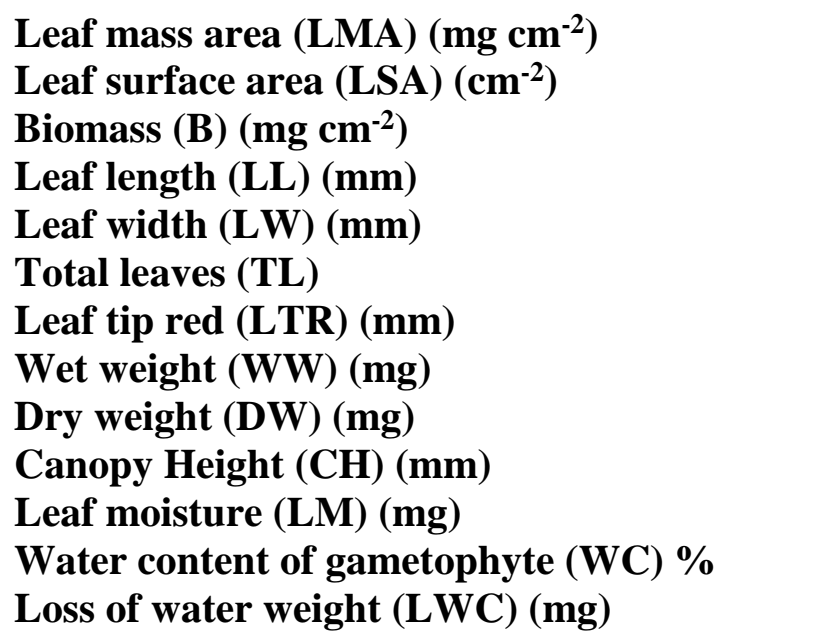 \\
\hline Cell traits & $\begin{array}{l}\text { Cell lumen area }(\mathrm{CLA})\left(\mathrm{mm}^{-2}\right) \\
\text { Cell lumen length }(\mathrm{CLL})(\mu \mathrm{m}) \\
\text { Interior cell wall thickness }(\mathrm{IWT})(\mu \mathrm{m}) \\
\text { Cell lamellae height }(\mathrm{CLH})(\mu \mathrm{m}) \\
\text { Lamellae number }(\mathrm{LN}) \\
\text { Number of rows of lamellae (NRL) } \\
\text { Lamellae number* rows of lamellae (LANR) } \\
\text { Chloroplast area }(\mathrm{CHA})\left(\mu \mathrm{m}^{-2}\right) \\
\text { Cell space }(\mathrm{CS})(\mu \mathrm{m}) \\
\text { Individual cell size }(\mathrm{ICS})(\mu \mathrm{m})\end{array}$ \\
\hline Leaf dimension traits & $\begin{array}{l}\text { Leaf area }(\mathrm{LA})\left(\mathrm{mm}^{-2}\right) \\
\text { Leaf density }(\mathrm{LD})\left(\mathrm{mg} \mathrm{m}^{-3}\right) \\
\text { Total leaf area }(\mathrm{TLA})\left(\mathbf{m m}^{-2}\right) \\
\text { Costa length }(\mathrm{CL})(\mathbf{m m}) \\
\text { Costa width }(\mathrm{CW})(\mathbf{m m}) \\
\text { Costa cross sectional area }(\mathrm{CCA})\left(\mathrm{mm}^{-2}\right) \\
\text { Lamina thickness }(\mathrm{LT})(\mu \mathrm{m})\end{array}$ \\
\hline Leaf shape traits & $\begin{array}{l}\text { Perimeter }(\mathrm{P})(\mathrm{cm}) \\
\text { Perimeter2 /area }(\mathrm{TP} 2 / \mathrm{A})\left(\mathrm{cm}^{-3}\right) \\
\text { Total Perimeter2 /area }(\mathrm{TP} 2 / \mathrm{A})\left(\mathrm{cm}^{-3}\right) \\
\text { Length/width }(\mathrm{L} / \mathrm{W})(\mathrm{cm})\end{array}$ \\
\hline
\end{tabular}


Table 3.5 Summary table for belowground morphological trait measurements from $P$. juniperinum gametophytes to assess discernable characteristics and contributions to isoprene emission $(\mathrm{n}=45)$.

\begin{tabular}{|c|c|}
\hline $\begin{array}{l}\text { Rhizoidal network and } \\
\text { Stem structure }\end{array}$ & $\begin{array}{l}\text { Rhizoid length }(\mathrm{RL})(\mathrm{mm}) \\
\text { Root shoot ratio }(\mathrm{RSR})\left(\mathrm{mm}^{-2}\right) \\
\text { Stem area dry }(\mathrm{SAD})\left(\mathrm{mm}^{-2}\right) \\
\text { Total area dry stem }(\mathrm{TDSA})\left(\mathrm{mm}^{-2}\right) \\
\text { Total wet stem area }(\mathrm{TWSA12})\left(\mathrm{mm}^{-2}\right) \\
\text { Total wet stem area }(\mathrm{TWSA24})\left(\mathrm{mm}^{-2}\right) \\
\text { Wet stem area } 12 \mathrm{hr} \text {. }(\mathrm{WSA12})\left(\mathrm{mm}^{-2}\right) \\
\text { Wet stem area } 24 \mathrm{hr} \text {. (WSA24) }\left(\mathrm{mm}^{-2}\right) \\
\text { Water content in stem area } 12 \mathrm{hr}(\mathrm{SAWC12}) \\
\text { Water content in stem area } 24 \mathrm{hr}(\mathrm{SAWC24}) \\
\text { Stem dry diameter (SDD) }(\mathrm{mm}-2) \\
\text { Wet diameter of the stem } 12 \mathrm{hr} \text {. (WDS12) }\left(\mathrm{mm}^{-2}\right) \\
\text { Wet diameter of the stem } 24 \mathrm{hr} \text {. (WDS12) }\left(\mathrm{mm}^{-2}\right) \\
\text { Water content in stem diameter } 12 \mathrm{hr}(\mathrm{SDWC12}) \\
\text { Water content in stem diameter } 24 \mathrm{hr}(\mathrm{SDWC24})\end{array}$ \\
\hline
\end{tabular}


Figure 3.1 Illustration of $P$. juniperinum costa cross section with number of lamellae counts (LN) measurement at the widest part of the costa cross section. Each costa cross section was taken from five leaves with five replicate and at the widest part number of lamellae was counted using a Leica microscope (Leitz DME, Leica, Wetzlar, Germany) with a AxioCam 105 Color camera and Zen Blue software (version 1.1.2.0; Carl Zeiss Microscopy).

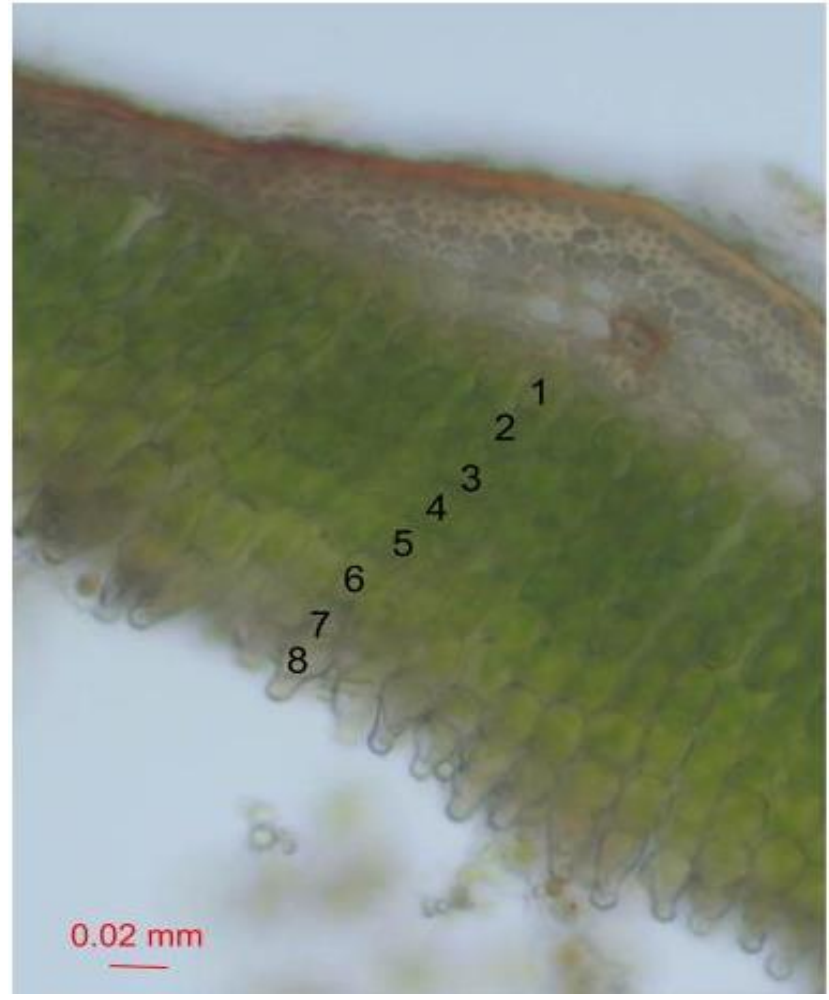


Figure 3.2 Illustration on $P$. juniperinum costa cross section with five lamellae height (CLH) measurement at the widest part of the costa cross section. This was accomplished by using a Leica microscope (Leitz DME, Leica, Wetzlar, Germany) with a AxioCam 105 Color camera and Zen Blue software (version 1.1.2.0; Carl Zeiss Microscopy).

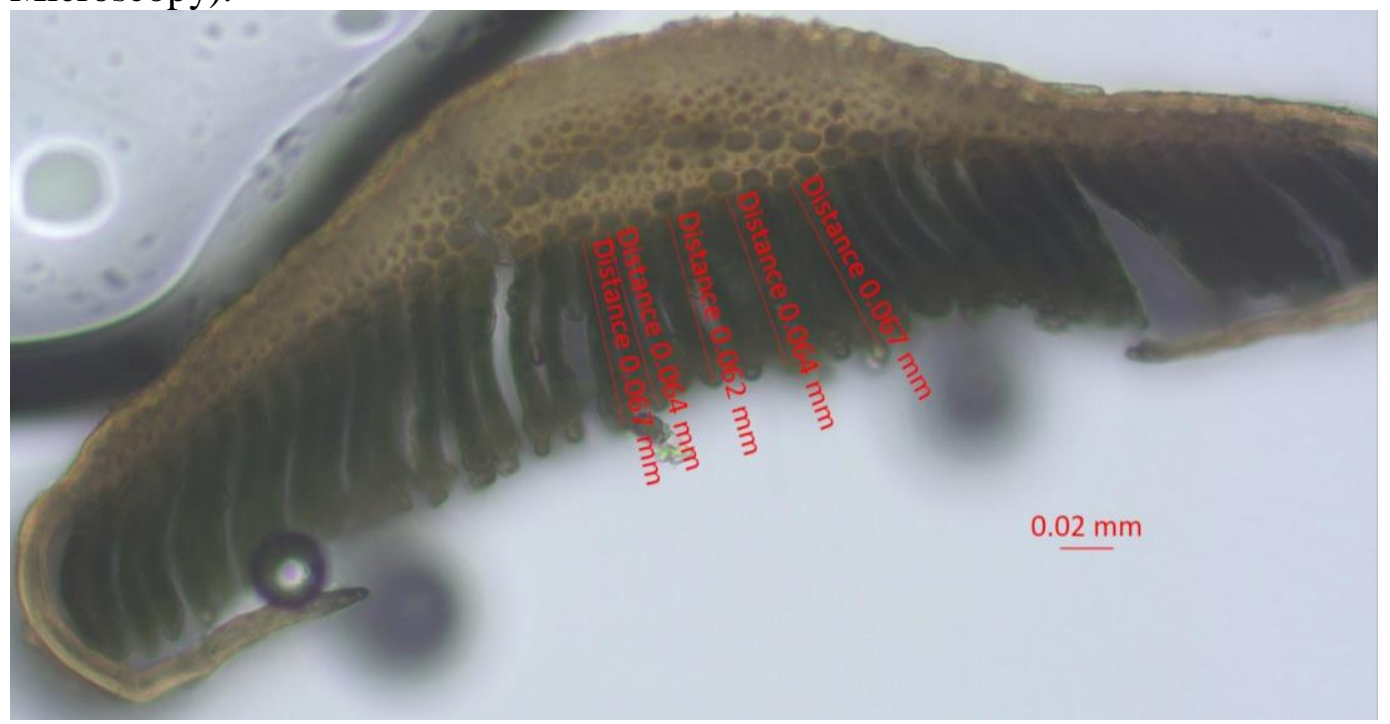


Figure 3.3 Illustration on $P$. juniperinum costa cross section of gametophyte stem after leaf removal. Stem area was measured at 12 hour water logged, following 24 hours water logged and dry state to approximate area and swelling of the stem. Water capacity assessment was estimated using a Leica microscope (Leitz DME, Leica, Wetzlar, Germany) with a AxioCam 105 Color camera and Zen Blue software (version 1.1.2.0; Carl Zeiss Microscopy).
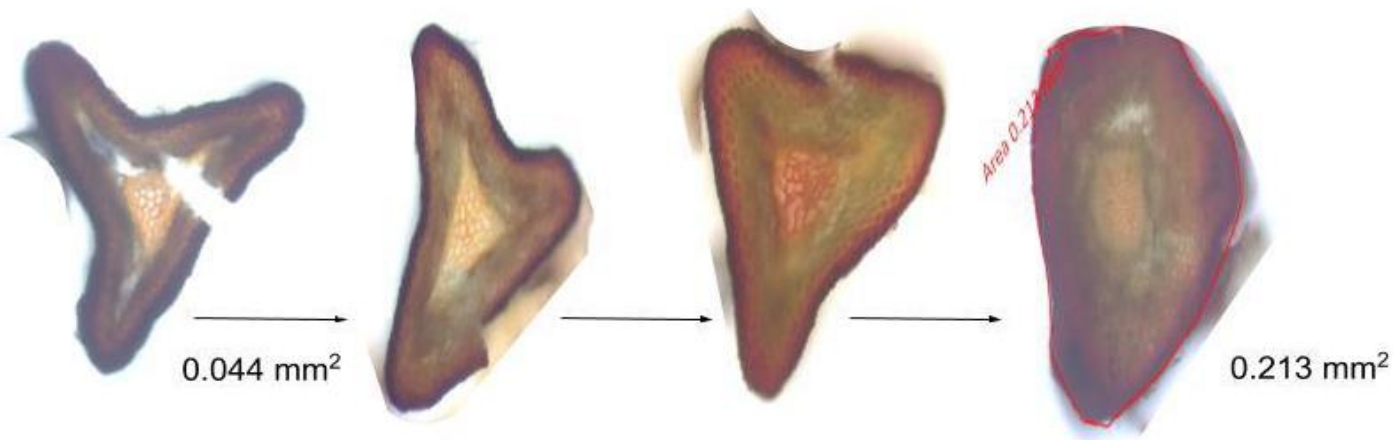
Figure 3.4 Setup for isoprene emission assessment for individual gametophyte emission using Dracast LED1000 Pro Daylight light panel, with light-emitting diode array (Photon Systems Instruments). Polytrichum species with rhizoids were pulled through a septa and inverted in glass vial. The rhizoid was then placed into a test tube filled with tap water.

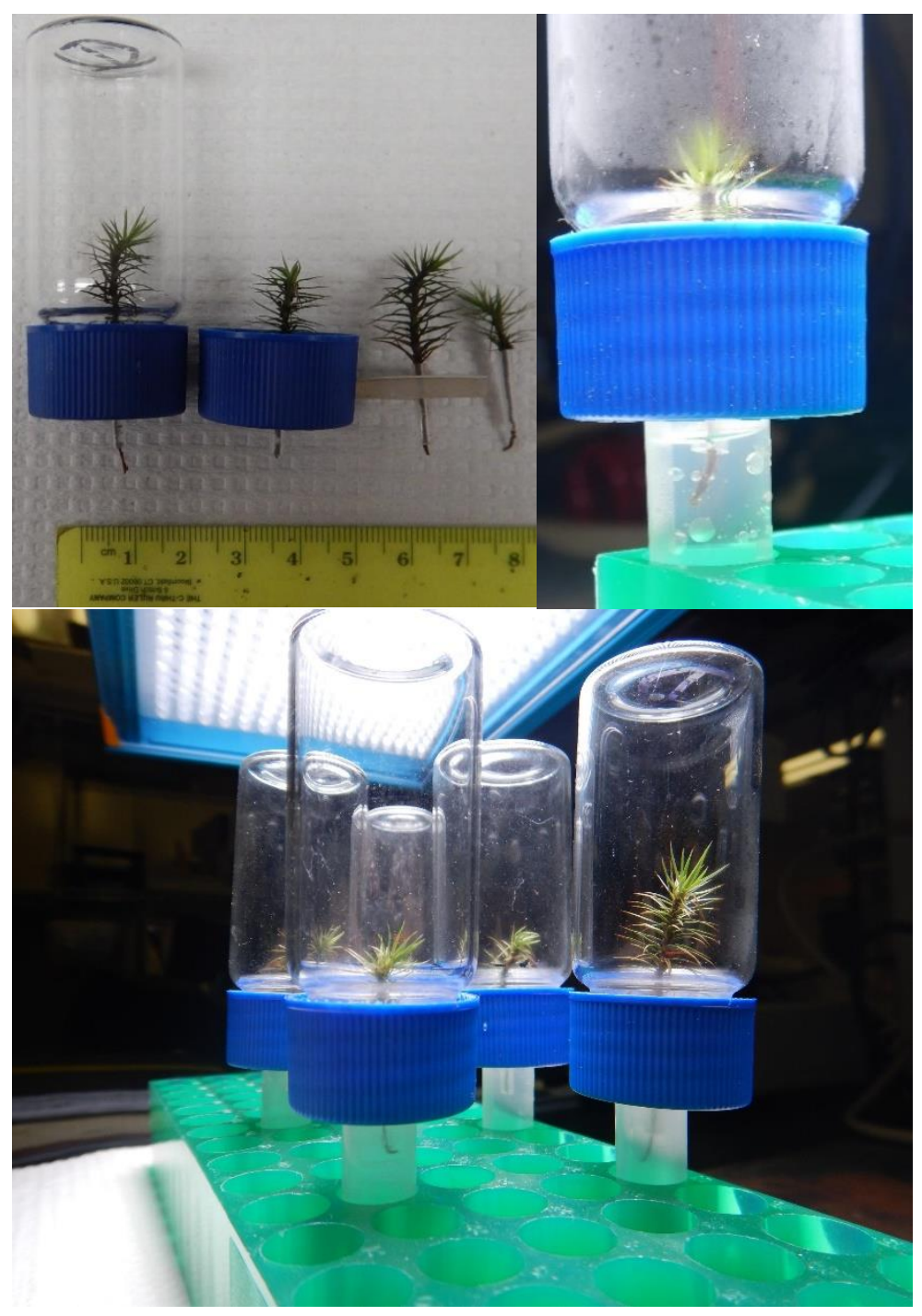


Figure 3.5 Logged isoprene emission $\left(\mathrm{nmol} \mathrm{m}^{-2} \mathrm{~s}^{-1}\right)$ versus above and belowground morphological variables in non-sexually expressing $P$. juniperinum gametophytes $(n=45)$. Above and belowground variables are plotted on the $\mathrm{x}$ axis. Tukey-Kramer HSD Multiple Comparisons Test shows areas of significant difference between logged isoprene emission vs. canopy traits: total leaves (TL), wet weight (WW), gametophyte width $(\mathrm{GW})$, leaf tip redness (LTR), vs. belowground traits: steam area dry (SAD), and wet stem area at 24 hours (WSA24). Error bars represent $\pm 1 \sigma$ (standard deviation). Letters show statistical significance between means. Means with the same letter are not significantly different. A* indicates significant difference, $* *$ indicates a highly significant difference, $* * *$ indicates high statistical significance, NS indicates no significance.

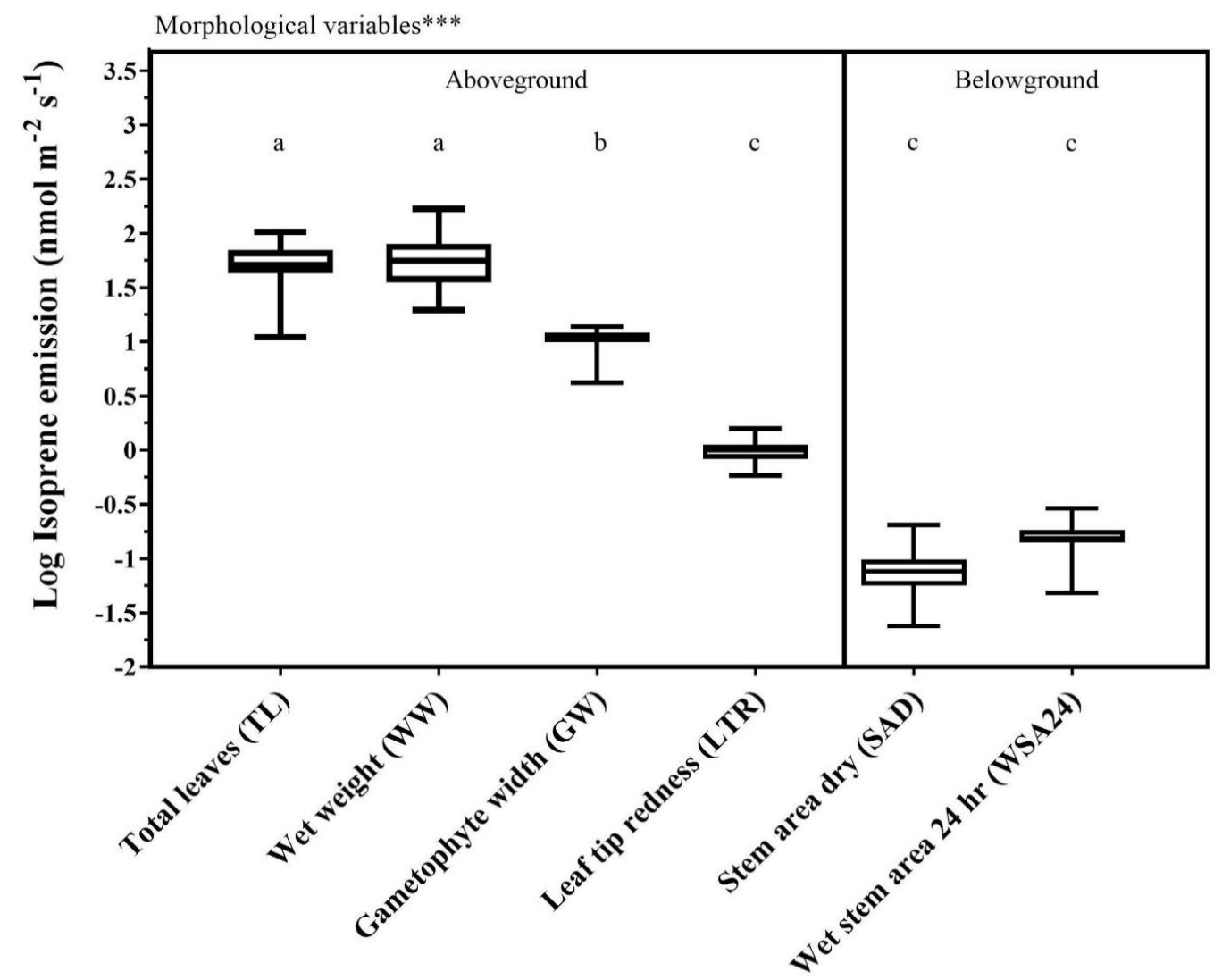


Figure 3.6 Isoprene emission $\left(\mathrm{nmol} \mathrm{m}^{-2} \mathrm{~s}^{-1}\right)$ best fit regression line versus stem area dry (SAD) $\mathrm{mm}^{2}$ in $P$. juniperinum gametophytes $(\mathrm{n}=45)$. Stem area dry $(\mathrm{SAD}) \mathrm{mm}^{2}$ is plotted on the $\mathrm{x}$ axis. Regression line is statistically significant. A * indicates significant difference, $* *$ indicates a highly significant difference, $* * *$ indicates high statistical significance, NS indicates no significance. Regression line equation shown below for isoprene emission and stem area dry (SAD).

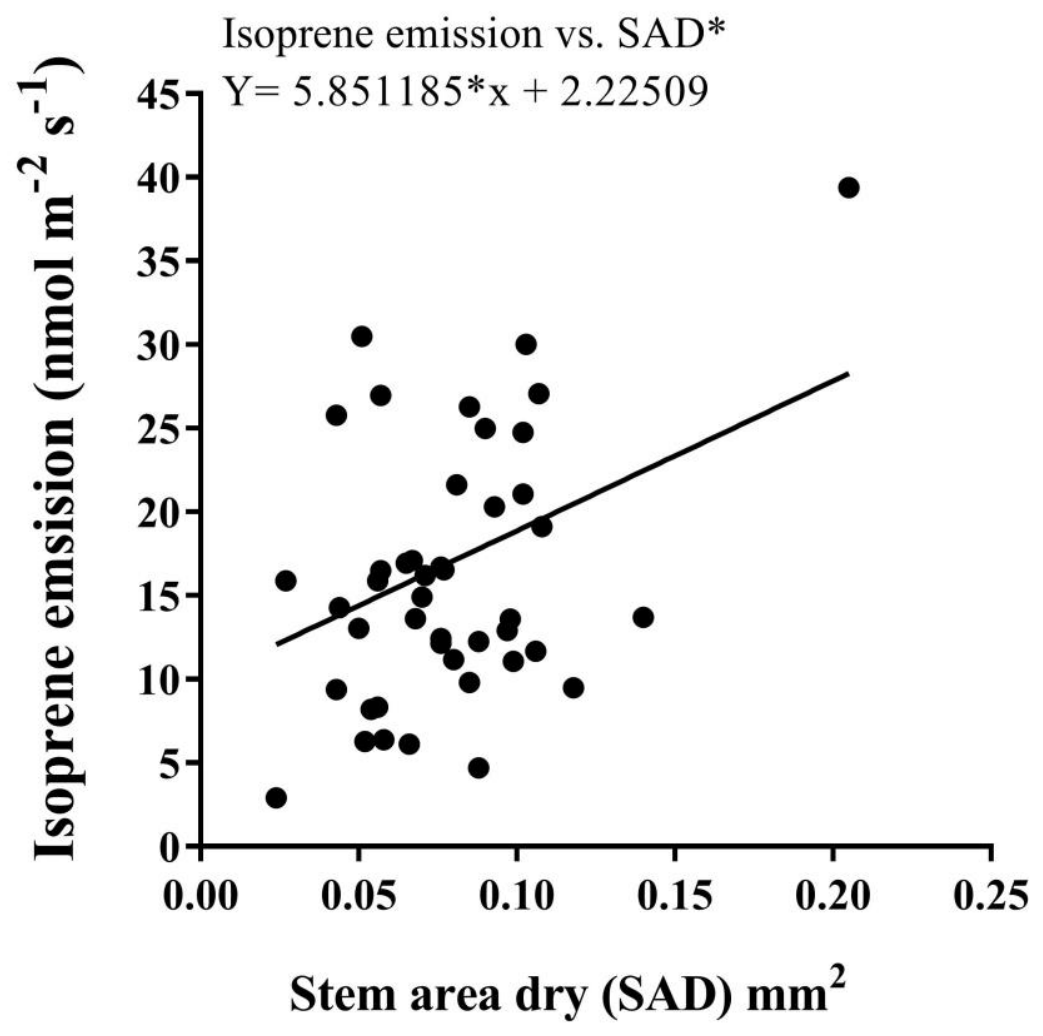


Figure 3.7 Isoprene emission $\left(\mathrm{nmol} \mathrm{m} \mathrm{m}^{-2} \mathrm{~s}^{-1}\right)$ versus plant sex in P. juniperinum gametophytes that were not expressing sex during the experiment $(n=300)$. Sex is plotted on the $\mathrm{x}$ - axis. Error bars represent $\pm 1 \sigma$ (standard deviation). Letters show statistical significance between means. Means with the same letter are not significantly different. A * indicates significant difference, $* *$ indicates a highly significant difference, $* * *$ indicates high statistical significance, NS indicates no significance.

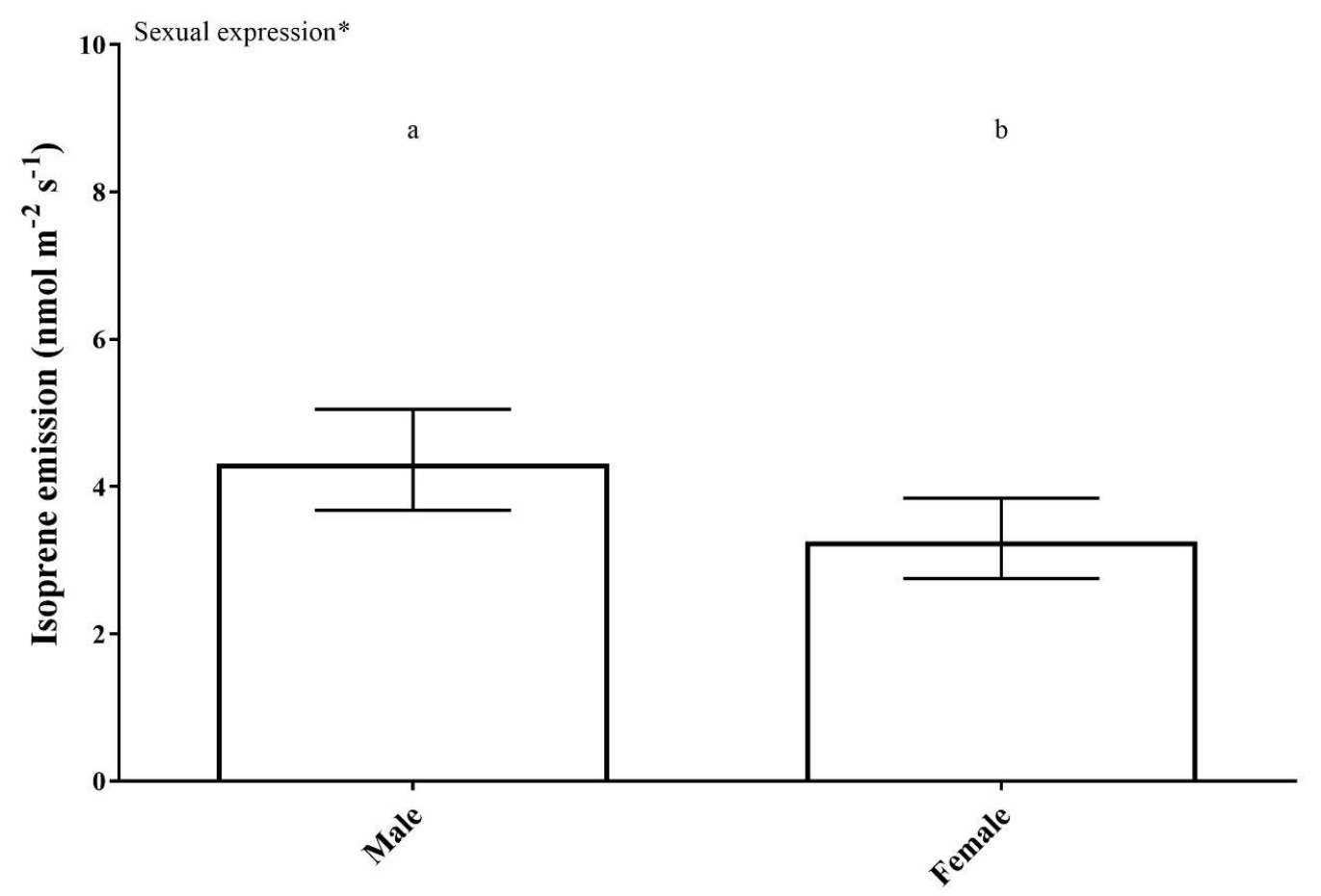


Figure 3.8 Isoprene emission ( $\mathrm{nmol} \mathrm{m}^{-2} \mathrm{~s}^{-1}$ ) versus species: Atrichum undulatum, Pogonatum urnigerum and Polytrichum juniperinum gametophytes $(\mathrm{n}=167)$. Species are plotted on the $\mathrm{x}$-axis. Error bars represent $\pm 1 \sigma$ (standard deviation). Letters show statistical significance between means. Means with the same letter are not significantly different. A* indicates significant difference, $* *$ indicates a highly significant difference, $* * *$ indicates high statistical significance, NS indicates no significance.

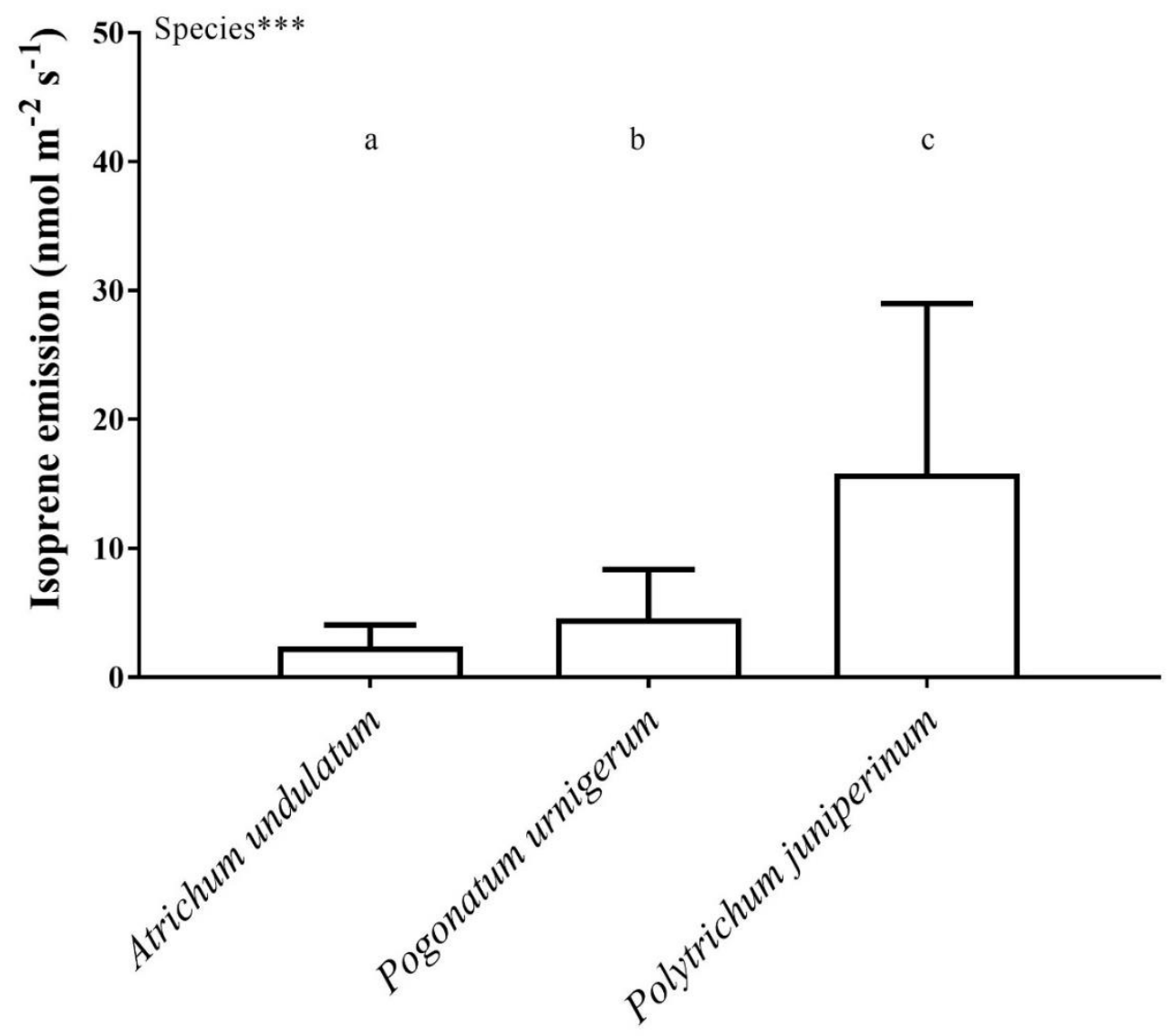


Figure 3.9 Logged isoprene emission $\left(\mathrm{nmol} \mathrm{m} \mathrm{s}^{-2} \mathrm{~s}^{-1}\right)$ versus sex between species of $A$. undulatum, $P$. urnigerum and $P$. juniperinum gametophytes $(\mathrm{n}=167)$. Species and sex are plotted on the $\mathrm{x}$ - axis. Tukey-Kramer HSD Multiple Comparisons Test shows areas of significant difference between isoprene emission $\left(\mathrm{nmol} \mathrm{m}^{-2} \mathrm{~s}^{-1}\right)$ vs. species and sex. Error bars represent $\pm 1 \sigma$ (standard deviation). Letters show statistical significance between means. Means with the same letter are not significantly different. A* indicates significant difference, $* *$ indicates a highly significant difference, $* * *$ indicates high statistical significance, NS indicates no significance.

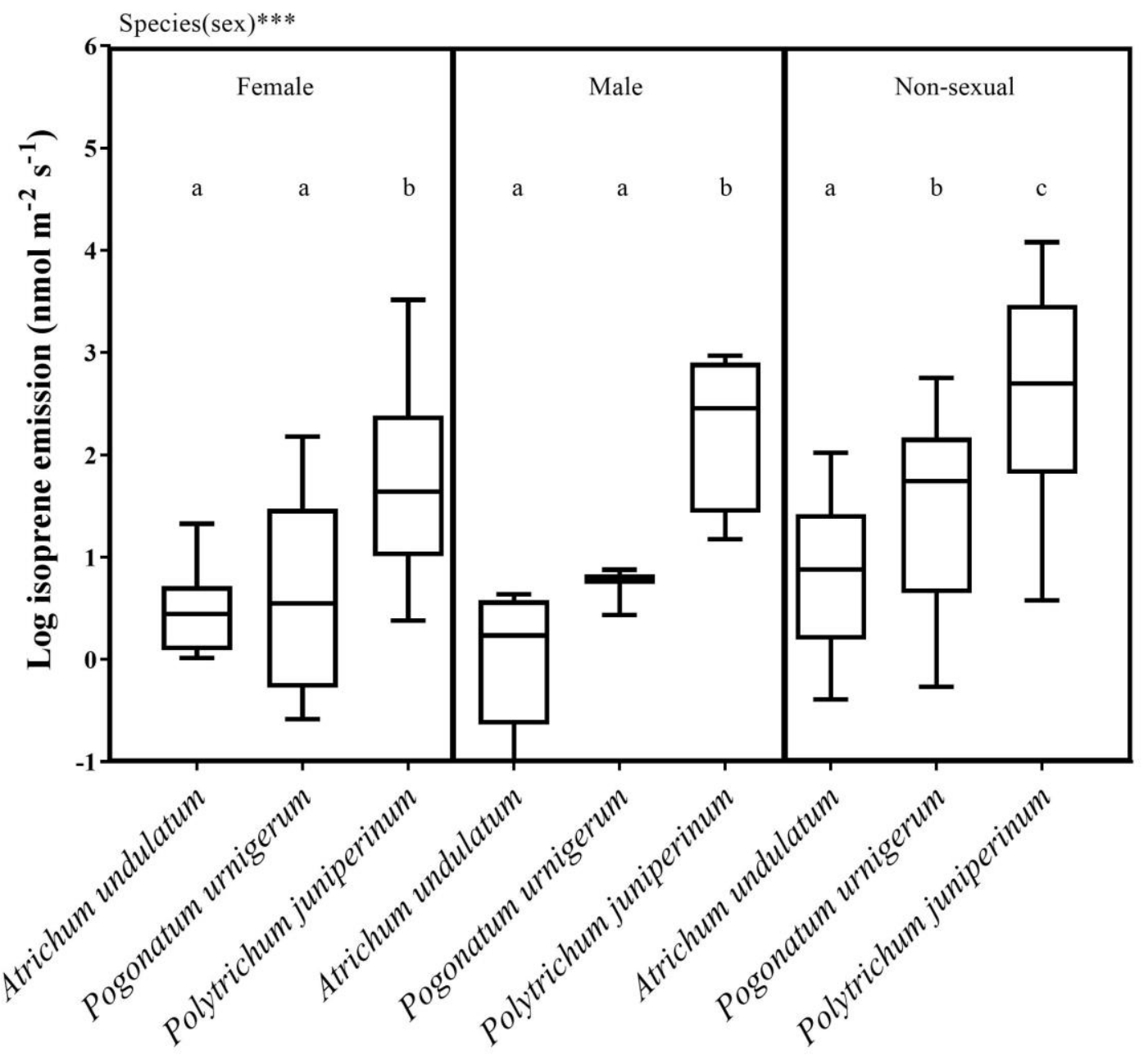


Figure 3.10 Isoprene emission $\left(\mathrm{nmol} \mathrm{m} \mathrm{m}^{-2} \mathrm{~s}^{-1}\right.$ ) versus sexes in Polytrichaceae gametophytes $(\mathrm{n}=167)$. Sexual expression, female, male and non-sexual expressions are plotted on the $\mathrm{x}$ - axis. Error bars represent $\pm 1 \sigma$ (standard deviation). Letters show statistical significance between means. Means with the same letter are not significantly different. A* indicates significant difference, ** indicates a highly significant difference, $* * *$ indicates high statistical significance, NS indicates no significance.

\section{Sexual expression**}

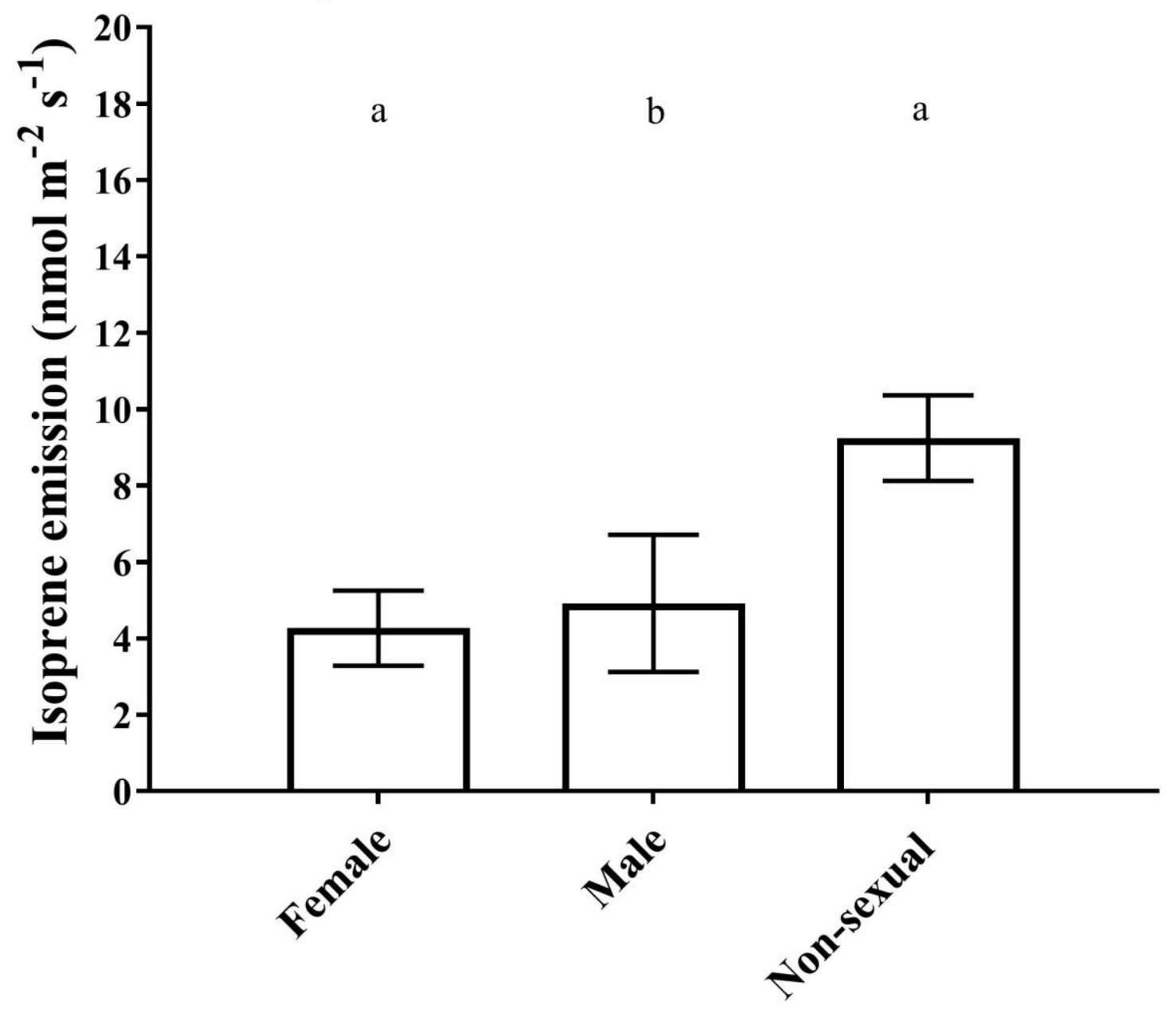


Figure 3.11 Isoprene emission ( $\mathrm{nmol} \mathrm{m} \mathrm{m}^{-2} \mathrm{~s}^{-1}$ ) versus site in A. undulatum gametophytes $(\mathrm{n}=70)$. Altitude is plotted on the $\mathrm{x}$ - axis. Tukey-Kramer HSD Multiple Comparisons Test shows areas of significant difference between isoprene emission $\left(\mathrm{nmol} \mathrm{m}^{-2} \mathrm{~s}^{-1}\right) \mathrm{vs}$. site. Error bars represent $\pm 1 \sigma$ (standard deviation). Letters show statistical significance between means. Means with the same letter are not significantly different. A * indicates significant difference, $* *$ indicates a highly significant difference, $* * *$ indicates high statistical significance, NS indicates no significance.

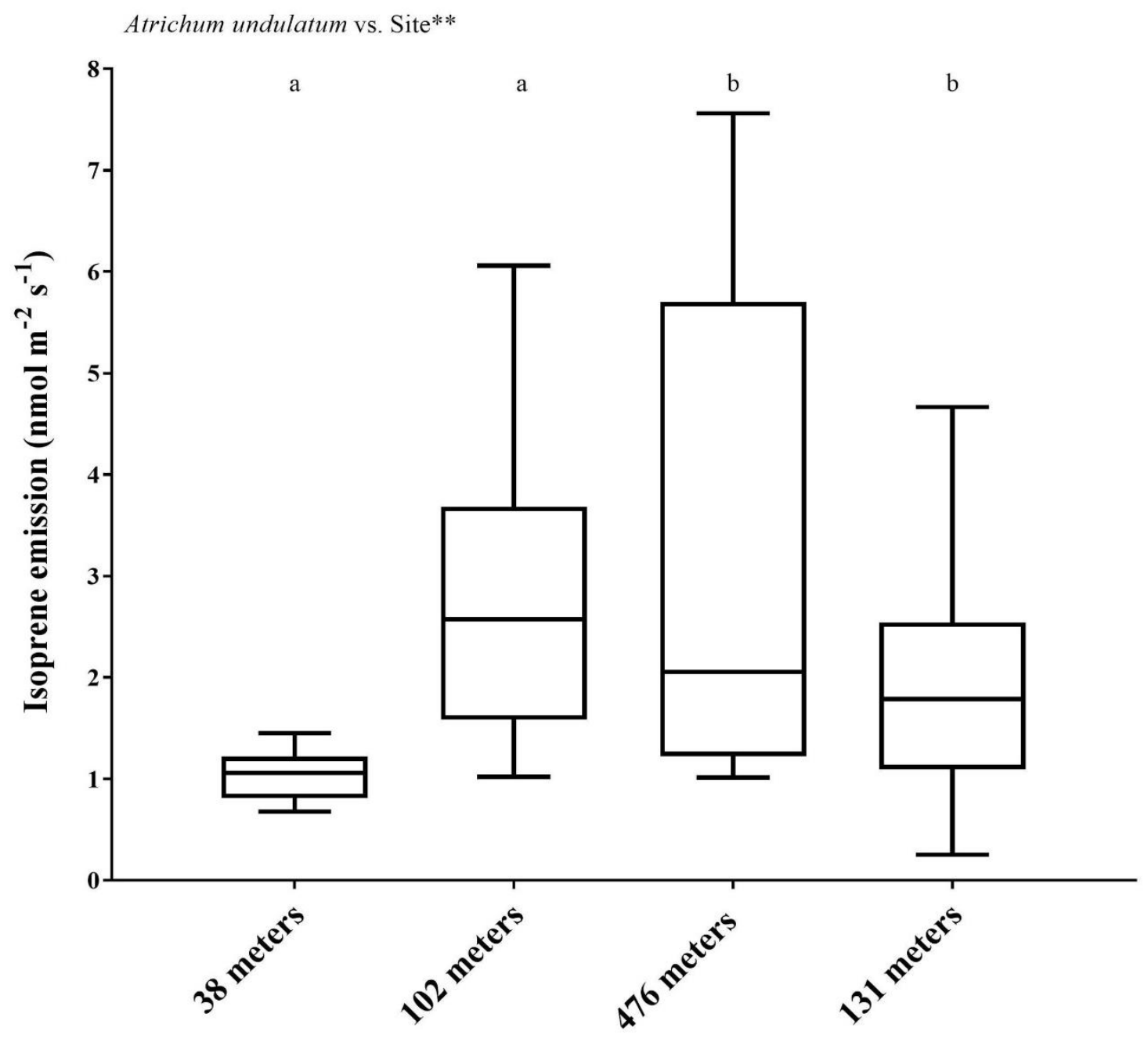


Figure 3.12 Isoprene emission (nmol m $\mathrm{m}^{-2} \mathrm{~s}^{-1}$ ) versus site in $P$. juniperinum gametophytes $(n=56)$. Altitude is plotted on the $\mathrm{x}$ - axis. Tukey-Kramer HSD Multiple Comparisons Test shows areas of significant difference between isoprene emission $\left(\mathrm{nmol} \mathrm{m}^{-2} \mathrm{~s}^{-1}\right) \mathrm{vs}$. site. Error bars represent $\pm 1 \sigma$ (standard deviation). Letters show statistical significance between means. Means with the same letter are not significantly different. A * indicates significant difference, $* *$ indicates a highly significant difference, $* * *$ indicates high statistical significance, NS indicates no significance.

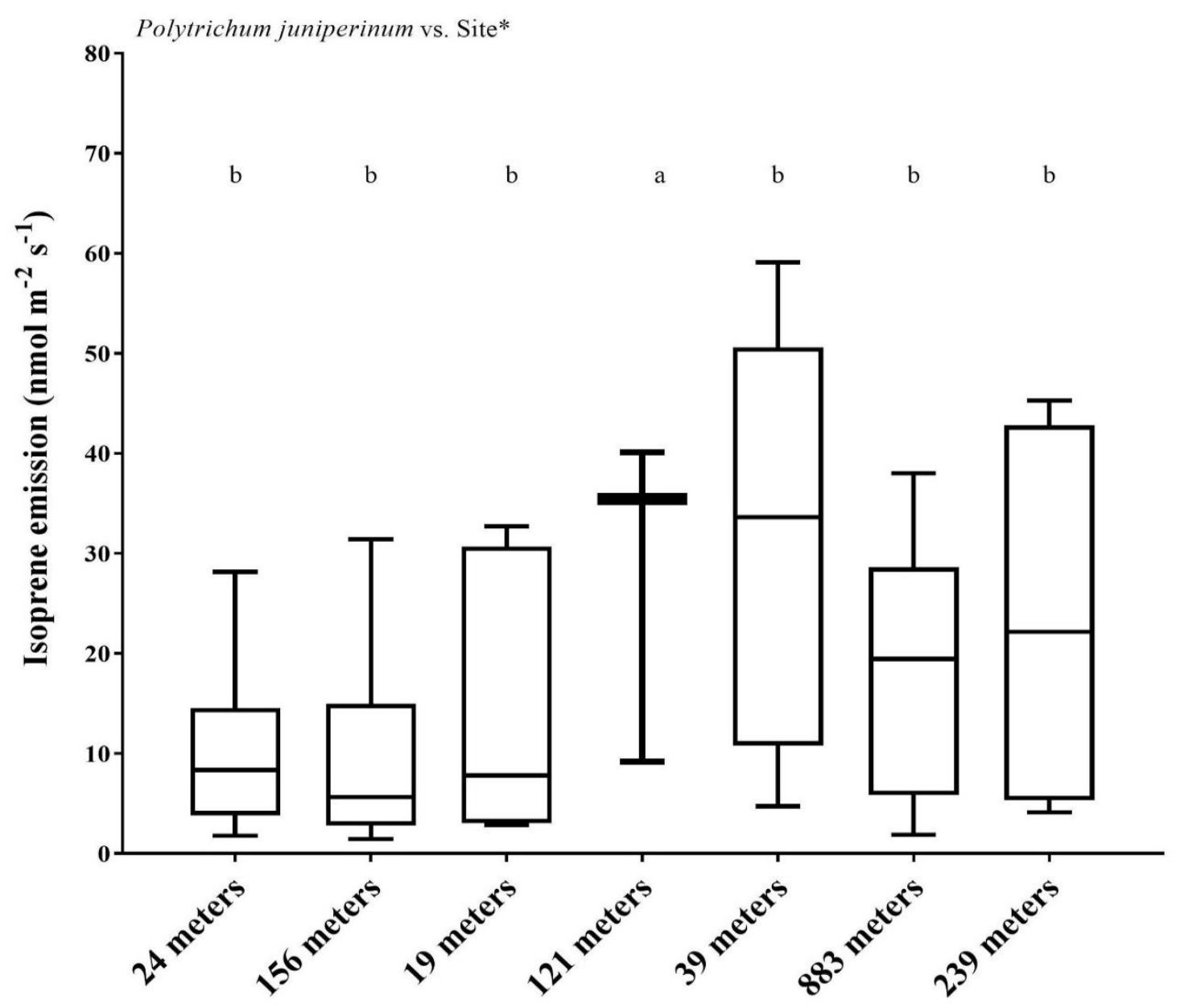


Figure 3.13 Isoprene emission (nmol m $\mathrm{m}^{-2} \mathrm{~s}^{-1}$ ) versus site in $P$. urnigerum gametophytes $(\mathrm{n}=41)$. Altitude is plotted on the $\mathrm{x}$ - axis. Tukey-Kramer HSD Multiple Comparisons Test shows areas of significant difference between isoprene emission $\left(\mathrm{nmol} \mathrm{m}^{-2} \mathrm{~s}^{-1}\right) \mathrm{vs}$. site. Error bars represent $\pm 1 \sigma$ (standard deviation). Letters show statistical significance between means. Means with the same letter are not significantly different. A * indicates significant difference, $* *$ indicates a highly significant difference, $* * *$ indicates high statistical significance, NS indicates no significance.

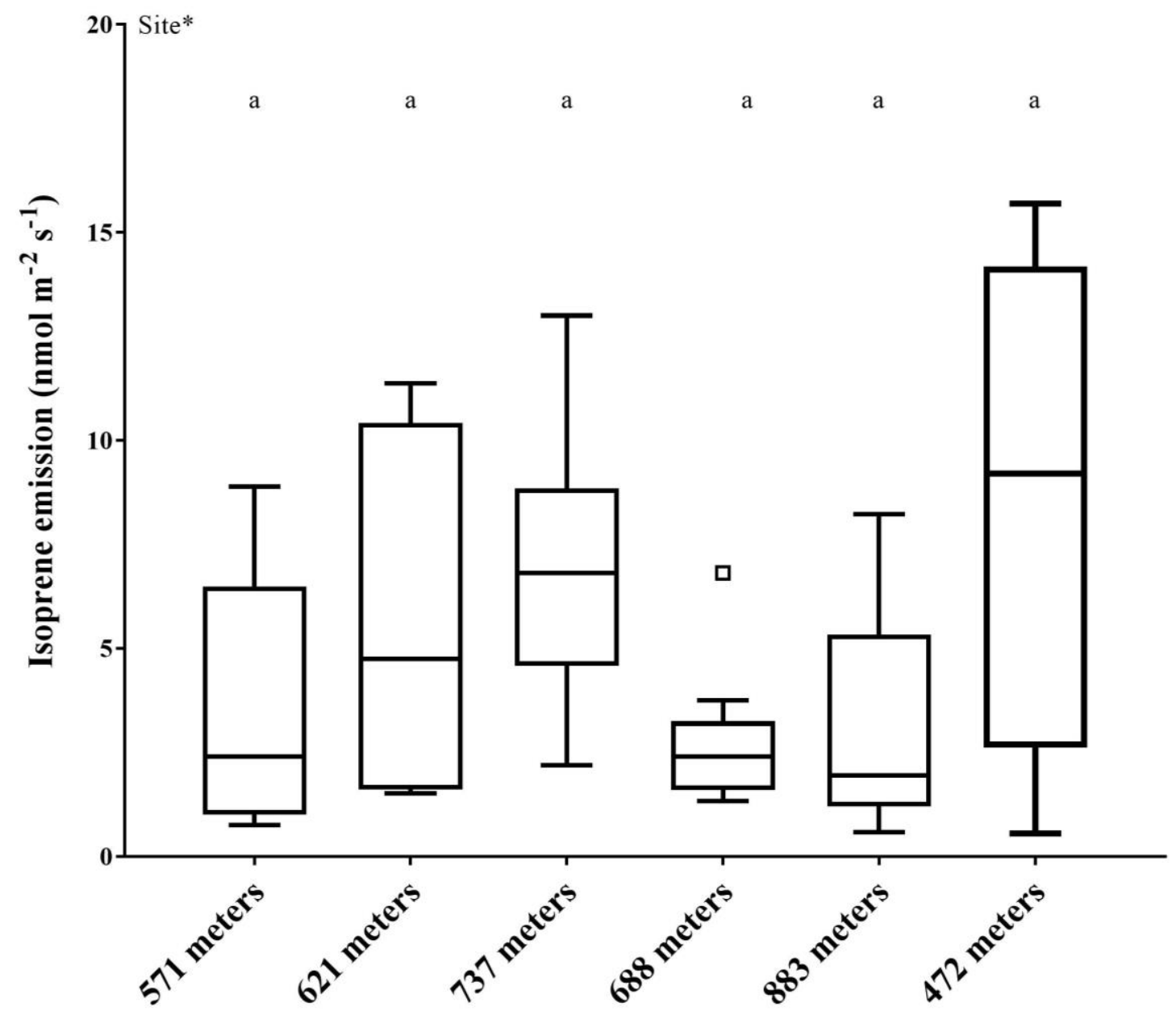




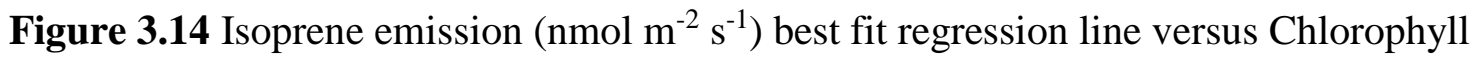
Fluorescence Ratio (CFR) in P. juniperinum gametophytes $(\mathrm{n}=45)$. CFR is plotted on the $\mathrm{X}$-axis. Regression line is statistically significant. A * indicates significant difference, ** indicates a highly significant difference, $* * *$ indicates high statistical significance, NS indicates no significance. Regression line equation shown below for isoprene emission and CFR.

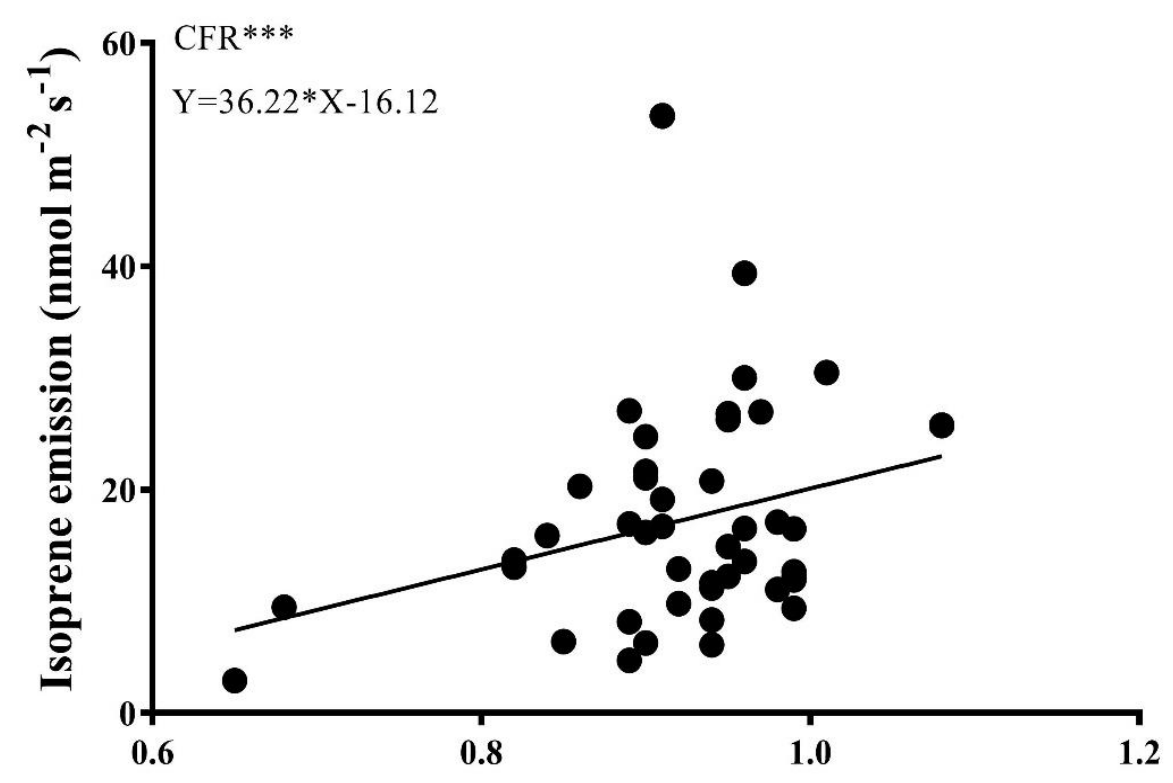

Chlorophyll fluorescence ratio (CFR) 
Figure 3.15 Logged isoprene emission $\left(\mathrm{nmol} \mathrm{m} \mathrm{m}^{-2} \mathrm{~s}^{-1}\right)$ best fit regression line versus Chlorophyll Fluorescence Ratio (CFR) in P. juniperinum gametophytes ( $\mathrm{n}=28)$. CFR is plotted on the x-axis. The nonlinear regression line is statistically significant in $A$. undulatum. The regression line in $P$. juniperinum is not statistically significant. A * indicates significant difference, $* *$ indicates a highly significant difference, $* * *$ indicates high statistical significance, NS indicates no significance. Regression line equation shown below for isoprene emission vs. CFR for A. undulatum.

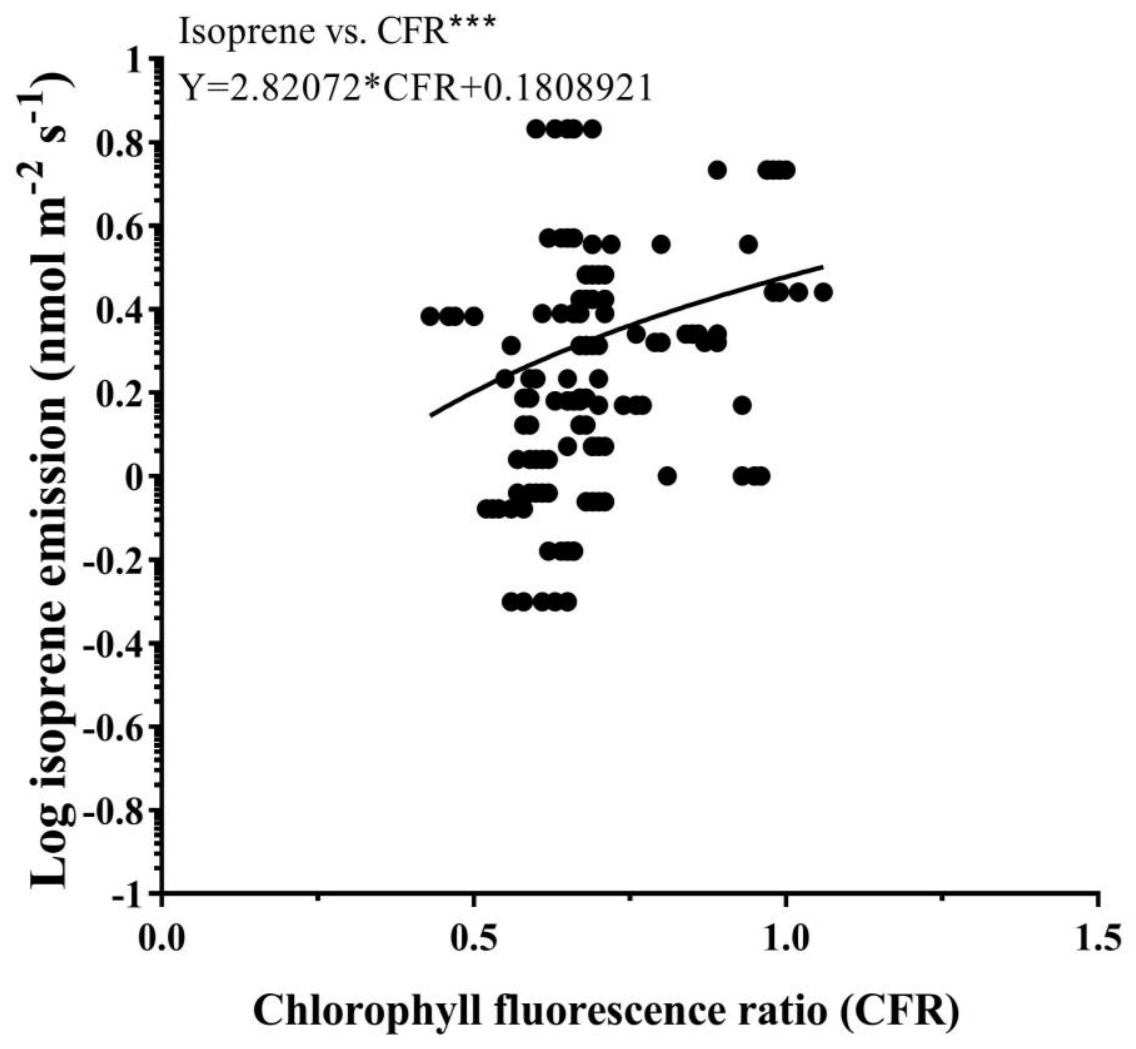


Figure 3.16 Chlorophyll Fluorescence Ratio (CFR) versus sex in P. juniperinum $(\mathrm{n}=25)$. Sex is plotted on the X-axis. Error bars represent $\pm 1 \sigma$ (standard deviation). Letters show statistical significance between means. Means with the same letter are not significantly different. A * indicates significant difference, ** indicates a highly significant difference, $* * *$ indicates high statistical significance, NS indicates no significance.

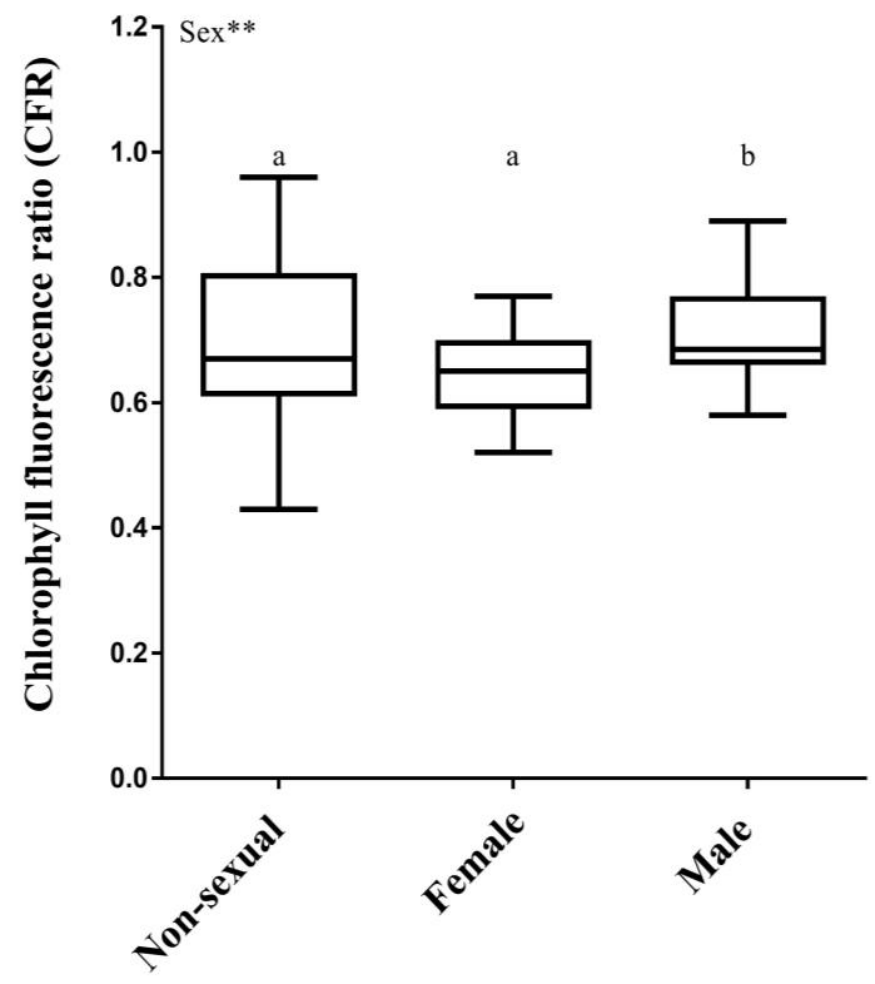


Figure 3.17 Relative Electron Transport Rate (RETR) ( $\mu$ mols $\mathrm{m}^{-2} \mathrm{~s}^{-1}$ ) versus sex on BCD media in $P$. juniperinum and A. undulatum gametophytes $(\mathrm{n}=28)$. Photosynthetic Photon Flux Density (PPFD) ( $\mu$ mols $\mathrm{m}^{-2} \mathrm{~s}^{-1}$ ) is plotted on the $\mathrm{x}$-axis. The regression line is statistically significant in male A. undulatum. The regression line in P. juniperinum is not statistically significant. A * indicates significant difference, $* *$ indicates a highly significant difference, $* * *$ indicates high statistical significance, NS indicates no significance. Regression line equation shown below for RETR vs. PPFD for $A$. undulatum.

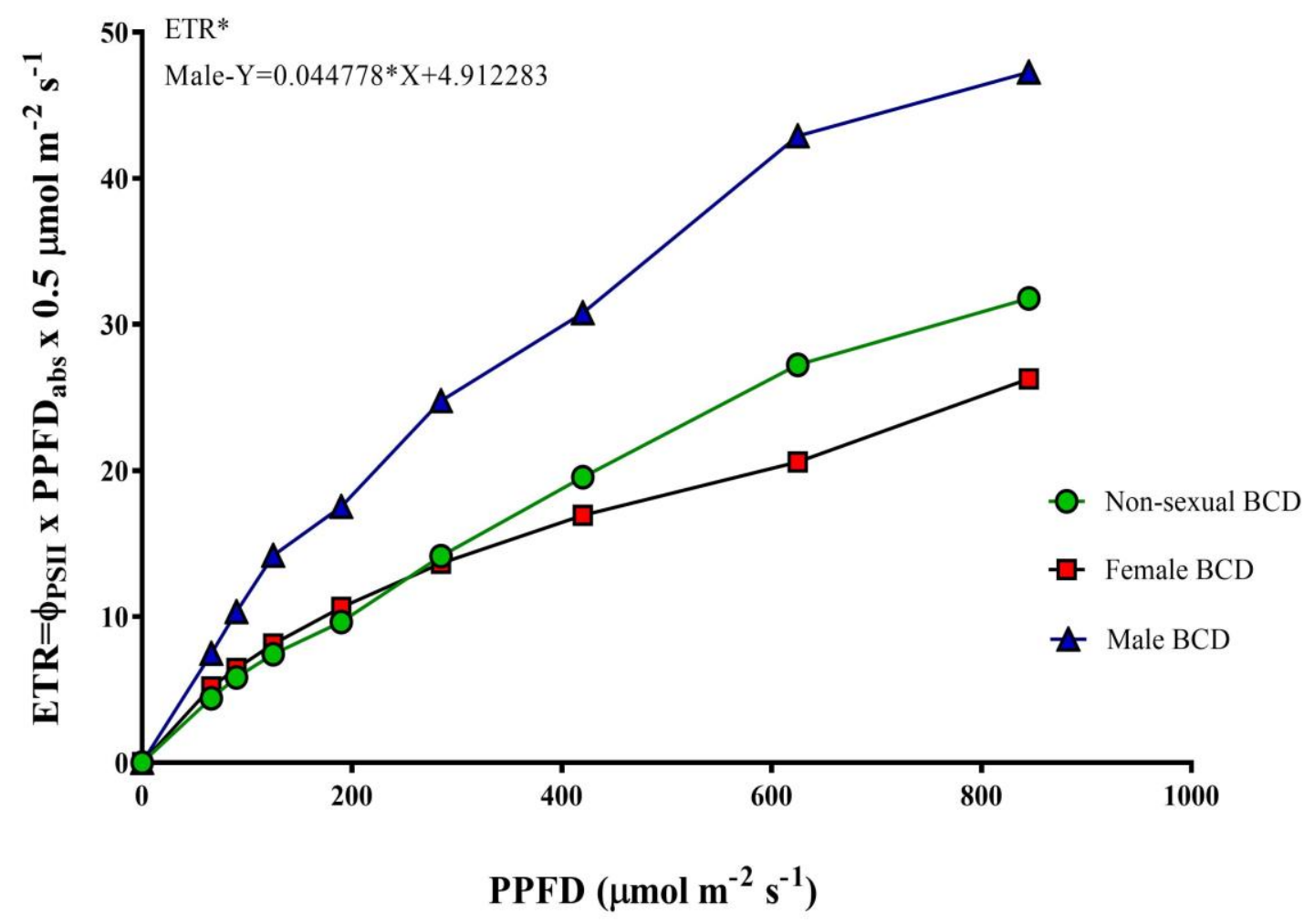




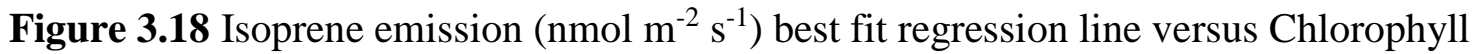
Fluorescence Ratio (CFR) in P. juniperinum gametophytes $(n=28)$. Chlorophyll

Fluorescence Ratio (CFR) is plotted on the $\mathrm{x}$-axis. The regression line in $P$. juniperinum is not statistically significant. The regression line in A. undulatum is statistically significant. A* indicates significant difference, $* *$ indicates a highly significant difference, $* * *$ indicates high statistical significance, NS indicates no significance. Regression line equation shown below for isoprene emission vs. CFR for A. undulatum.

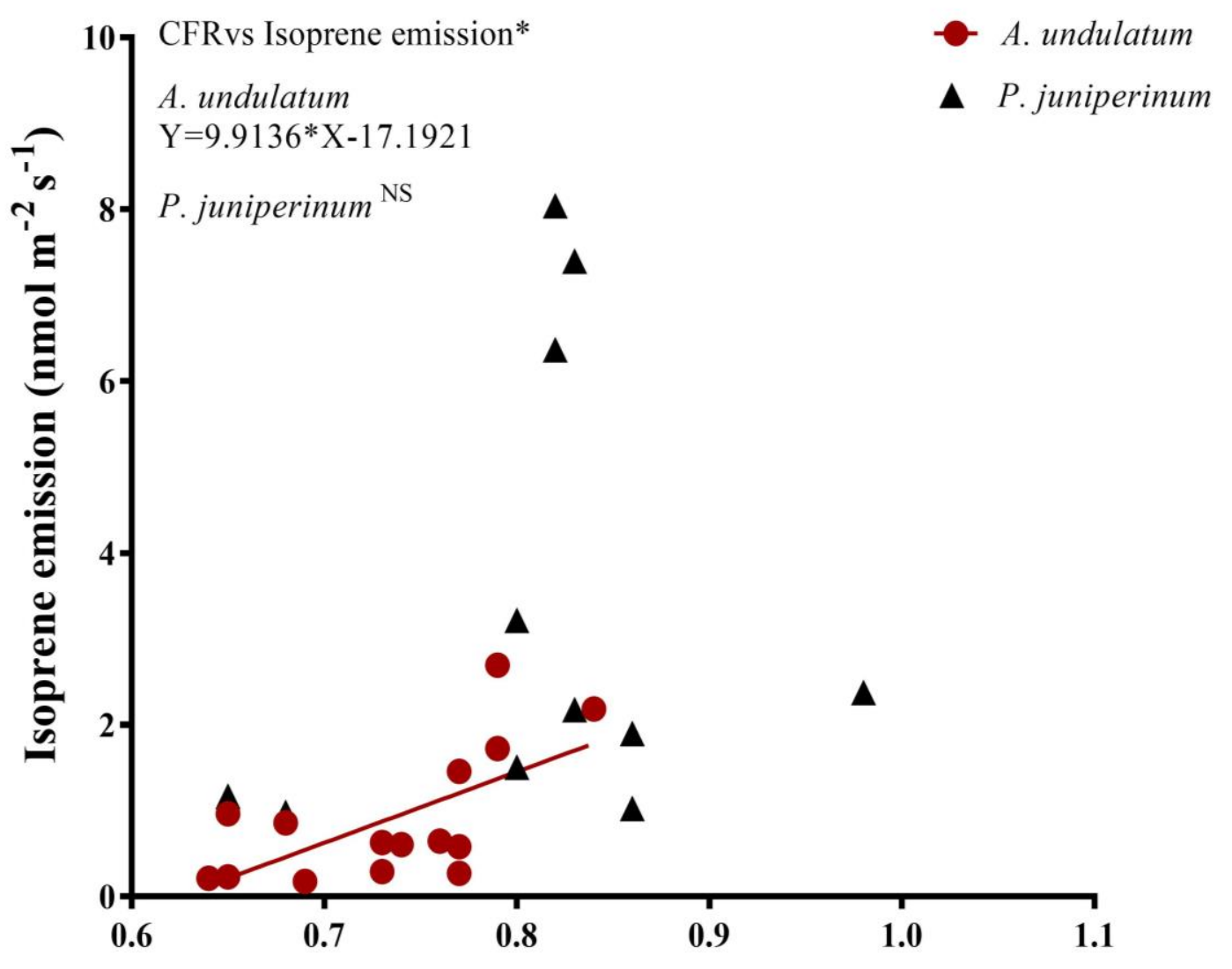

Chlorophyll fluorescence ratio (CFR) 
Figure 3.19 Chlorophyll Fluorescence Ratio (CFR) versus species: $P$. juniperinum and $A$. undulatum gametophytes $(\mathrm{n}=28)$. Species is plotted on the $\mathrm{x}$-axis. Error bars represent $\pm 1 \sigma$ (standard deviation). Letters show statistical significance between means. Means with the same letter are not significantly different. A * indicates significant difference, ** indicates a highly significant difference, $* * *$ indicates high statistical significance, NS indicates no significance.

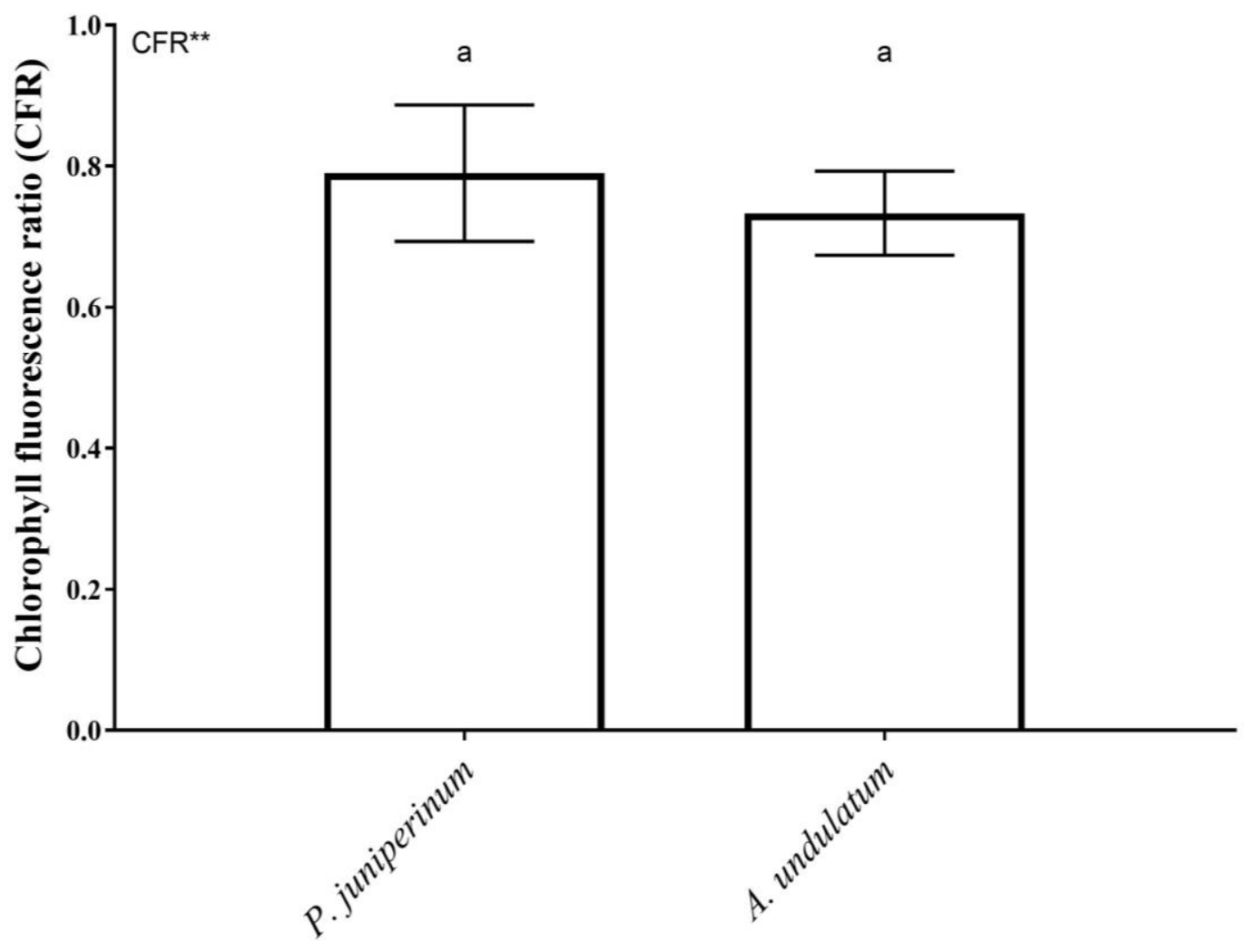


Figure 3.20 Relative Electron Transport Rate (RETR) $\left(\mu \mathrm{mols} \mathrm{m}^{-2} \mathrm{~s}^{-1}\right)$ versus Photosynthetic Photon Flux Density (PPFD) $\left(\mu \mathrm{mols} \mathrm{m}^{-2} \mathrm{~s}^{-1}\right)$ in $P$. juniperinum and $A$. undulatum gametophytes $(\mathrm{n}=28)$. PPFD is plotted on the $\mathrm{x}$-axis. The regression line for both species is statistically significant. Error bars represent $\pm 1 \sigma$ (standard deviation). A * indicates significant difference, $* *$ indicates a highly significant difference, $* * *$ indicates high statistical significance, NS indicates no significance. Regression line equation shown below for RETR vs. PPFD for $P$. juniperinum and A. undulatum.

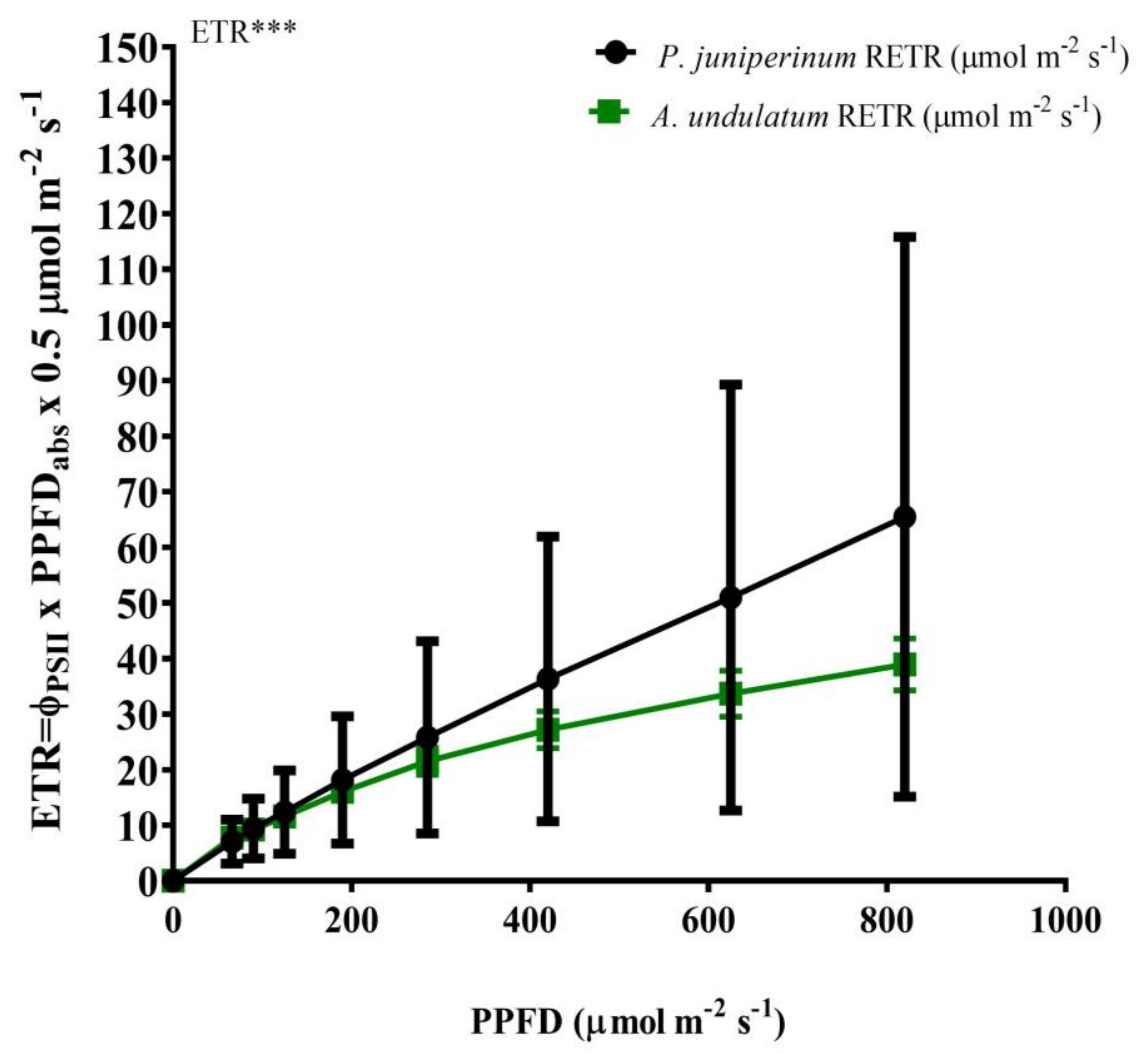


Figure 3.21 Relative Electron Transport Rate (RETR) ( $\mu$ mols $\mathrm{m}^{-2} \mathrm{~s}^{-1}$ ) versus sex in $P$. juniperinum and A. undulatum gametophytes $(\mathrm{n}=28)$. Sex is plotted on the $\mathrm{x}$-axis. Error bars represent $\pm 1 \sigma$ (standard deviation). Letters show statistical significance between means. Means with the same letter are not significantly different. A* indicates significant difference, $* *$ indicates a highly significant difference, *** indicates high statistical significance, NS indicates no significance.

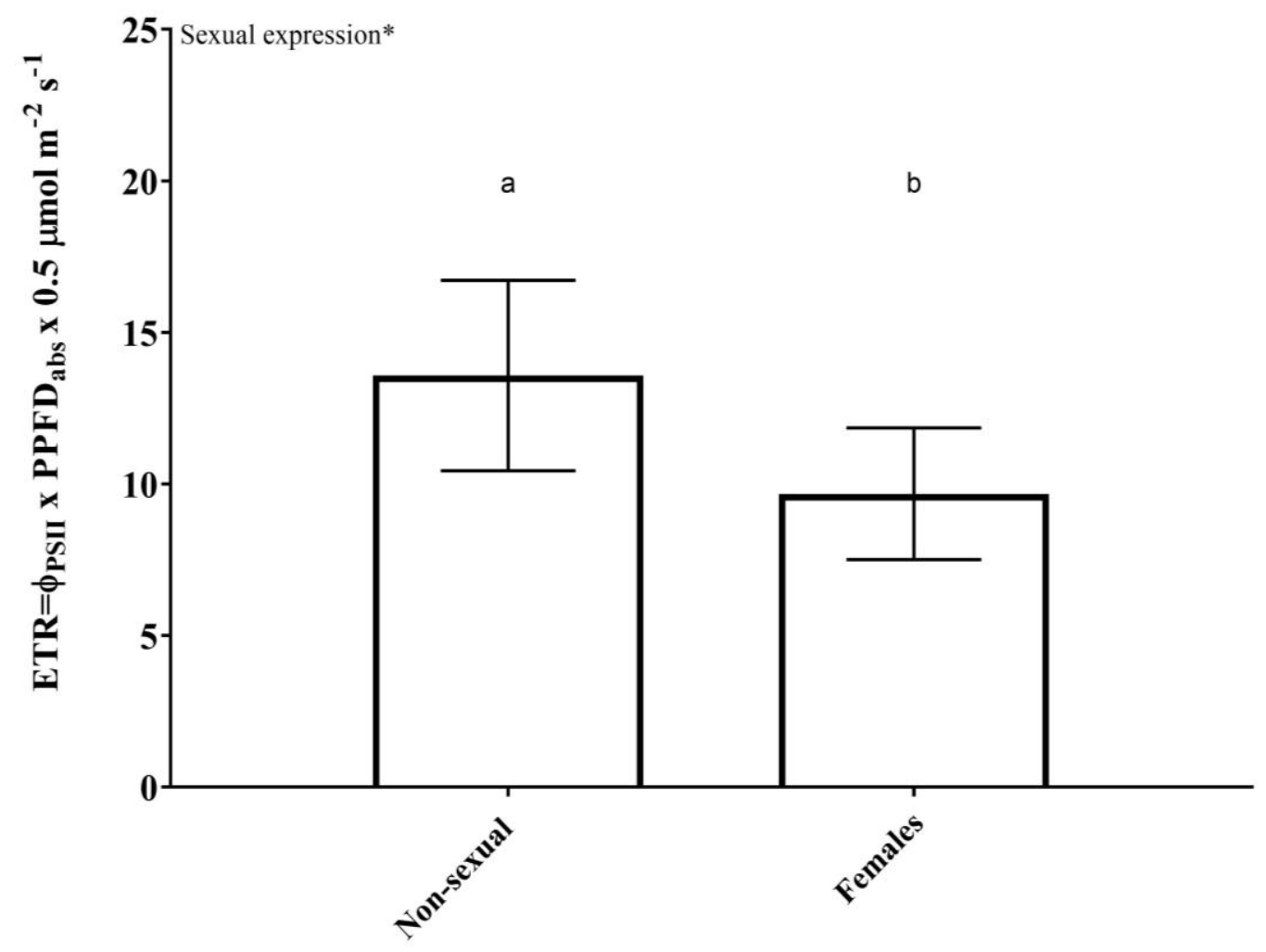




\title{
Chapter 4
}

\section{The effect of nitrogen addition on moss morphology, sexual reproduction, and isoprene production}

\begin{abstract}
Isoprene (2-methyl-1, 3-butadiene) accounts for approximately one third of all global BVOC emission and has been shown to protect plants from both abiotic and biotic stress with species and sex-specific preferences. As anthropomorphic nitrogen $(\mathrm{N})$ increases in altered ecosystems, understanding the influences of $\mathrm{N}$ on morphology, physiology and reproductive effort is important and has not been well-studied in bryophytes. In this study, we set up a four-year common garden experiment in the moss Polytrichum juniperinum to test the effects of nitrogen addition on plant morphology, sexual reproduction and isoprene emission. Morphological, sexual expression and physiological measures varied significantly across the six populations from which we collected plants. Nitrogen addition significantly affected gametophyte length, isoprene emission and chlorophyll fluorescence ratio (CFR). We are the first to report increased isoprene emission under nitrogen addition in $P$. juniperinum. The high variation in morphology and physiology makes mosses ideal study systems as they are highly adaptable to their environment. The role of isoprene emission in mosses has gone nearly unnoticed, BVOC in vegetation have been demonstrated to have both regional and global atmospheric chemistry and climate impacts, while estimating emission fluxes from mosses is poorly understood.
\end{abstract}


Keywords: Ammonium nitrate $\left(\mathrm{NH}_{4} \mathrm{NO}_{3}\right)$, bryophyte, isoprene emission, Polytrichum juniperinum, sexual reproduction 


\section{Introduction}

\section{Background nitrogen deposition}

Tracking nitrogen deposition patterns is important for understanding how anthropogenic sources of nitrogen affect both natural habitats and urban environments (Pujadas et al. 2000; Raciti et al. 2008; Kaushal et al. 2014; Jones et al. 2018; Chávez et al. 2018). The global deposition of anthropogenic $\mathrm{N}$ now surpasses those from natural sources, with a four-fold increase in the amount of $\mathrm{N}$ available to organisms in less than a century (Vitousek et al. 1997; Fields 2004; Luo et al. 2004; Bobbink et al. 2010; SchulteUebbing et al. 2018; Taboada et al. 2018; Calvo-Fernández et al. 2018). To quantify N deposition is a complex task, with a wide range of compounds in the gas phase, in aerosols, and in precipitation (Krusche et al. 2003; Miller et al. 2003; Mahowald et al. 2011; Guo et al. 2018; Zheng et al. 2018; Cook et al. 2018; Lu et al. 2018; Xu et al. 2018). It is now well established that the level of $\mathrm{N}$ introduced to the atmosphere is increasing due to human activities (Vitousek et al. 1997; Galloway 1998, 2008; Bobbink et al. 2010; Erisman et al. 2013; Mogollón et al. 2018), and the process of climate as drivers of nitrogen are difficult to predict (Hess et al. 2018). Nitrogen deposition models forecast that by the year 2100 nitrogen deposition will be the third largest threat to biodiversity with climate change remaining the leading continuing threat (Galloway et al. 2004; Gruber et al. 2008; Sala et al. 2010; Wankel et al. 2010; Erisman et al. 2013; Stevens et al. 2018). 
Anthropogenic bio-available $\mathrm{N}$ sources are driven by emission of nitrogen oxide species, such as nitrogen oxides: such as nitric oxide and nitrogen dioxide $(\mathrm{NOx}=\mathrm{NO}+\mathrm{NO} 2)$ and ammonia $(\mathrm{NH} 3)$, in the atmosphere (Crutzen 1970, 1971; Liang et al. 1998; Glarborg et al. 2018). The oxidized forms of $\mathrm{N}$, such as $\mathrm{N}_{2} \mathrm{O}$ and $\mathrm{NOx}$, are predominantly emitted as a byproduct of transport, industry and energy production which helps explain regional differences in $\mathrm{N}$ deposition, with transportation contributing $70 \%$ of the emissions of oxidized compounds (Patterson et al. 1994; Clapp et al. 2001; Carslaw 2005; Yuan et al. 2005; Hoekman et al. 2012; Chaichan et al. 2018; Souri et al. 2018; Teixeira et al. 2018). Once released to the atmosphere, $\mathrm{N}$ reactive compounds, such as NOx, oxidize to nitric acid (HNO3) in a relatively short period of time, while the oxidation to organic nitrates occurs in less than a day (Zhang et al. 2012). Nitric acid (HNO3) or nitrate (NO3-) is the dominant sink for reactive nitrogen oxides in the atmosphere (Fang et al. 2011). Nitric acid (HNO3) and nitrate (NO3-) are considered to be the principal compounds in nitrogen deposition (Phillips et al. 2006). In wet deposition, most of the nitrogen is in the form of nitrate (NO3-) and ammonium (NH4+). In dry deposition, nitric acid (HNO3), ammonia (NH3), and nitrogen dioxide (NO2) dominate (Poikolainen et al. 2009).

The largest source of nitrogen comes from fuel NOx from vehicles (Widory 2007). NOx contributes to the formation of ozone $\left(\mathrm{O}_{3}\right)$ and aerosol particulate matter and is thus an important factor affecting regional air quality and radiative balance due to smog production (Ehhalt et al. 2001). Since the lifetime of fixed nitrogen is short, most of the $\mathrm{N}$ deposition is near its source and is local in origin (Ollinger et al. 1993; Asman et al. 
1998; Munger et al. 1998; Aneja et al. 2001; Kirchner et al. 2005, 2014; Moomaw et al. 2002; Zhang et al. 2012; Redling et al. 2013; Xu et al. 2018). Nitrogen deposition in North America is damaging sensitive ecosystems, even with efforts to reduce nitrogen oxide emissions ( $\mathrm{Li}$ et al. 2006) and further steps are needed to reduce nitrogen deposition (Ellis et al. 2013). In the Pacific Northwest nitrogen deposition spans the range of $0.15 \mathrm{~kg} \mathrm{~N} \mathrm{ha}^{-1} \mathrm{yr}^{-1}$ to $39 \mathrm{~kg} \mathrm{~N} \mathrm{ha}^{-1} \mathrm{yr}^{-1}$ (Root et al. 2013). In and around urban areas, $\mathrm{N}$ deposition from anthropogenic sources can be many times the natural sources, significantly changing the behavior of the nitrogen cycle (Skeffington et al. 1988; Lovett 1994; Fenn et al. 1998, 2003; Kim et al. 2011; Pardo et al. 2011; Zhang et al. 2012; Benedict et al. 2018; Kharol et al. 2018).

An increasingly large body of evidence suggests that traits of plants adapted to nutrient-poor or nutrient-rich habitats may have feedback effects on a number of aboveground and belowground systems and communities (Aerts et al. 1989; Hobbie 1992; Nadelhoffer et al. 2000; Aber et al. 2003; Kou et al. 2018; Hou et al. 2018; Xia et al. 2018). Many biological and physiological processes, including photosynthesis, respiration, and carbon allocation due to increased nitrogen deposition have been used to analyze and detect environmental stress in plants (Darrall 1989; Townsend et al. 1996; Nellemann et al. 2001; Clark et al. 2008; Bobbink et al. 2010; Smithwick et al. 2013; Fusaro et al. 2017; Damgaard et al. 2017; Hess et al. 2018).

An increase in nitrogen in some cases can have a stabilizing effect on ecosystem development (Kristensen et al. 1998; Aerts et al. 1999; Neff et al. 2002; Dijkstra et al. 2004; Zechmeister et al. 2008; Kou et al. 2018; Ibáñez et al. 2018), but in most cases 
increased nitrogen deposition alters leaf and root composition (Xia et al. 2018), and alters growth responses of trees by increasing sensitivity to increased temperatures (Hess et al. 2018).

Even at low rates, $\mathrm{N}$ enrichment causes community shifts (Payne et al. 2017), affects greenhouse gas emissions (Song et al. 2017), causes key shifts in ecosystems such as widespread loss of species (Stevens et al. 2004; Maskell et al. 2010; Duprè et al. 2010) increase carbon sequestration (McKinley et al. 2008; de Vries et al. 2009; Liu et al. 2010), and promotes microbial competition in both subsoil and topsoil (Jones et al. 2018). Nitrogen increase can adversely affect seed productivity and flowering (Phoenix et al. 2012; Bogdziewicz et al. 2017; Wolf et al. 2017), increase competition and plant density among plant species, and influence decomposition and ecosystem nutrient turnover (Price et al. 1980; Steer et al. 1986; Muchow 1988; Vitousek et al. 1997; Cox et al. 2001; Vos et al. 2005; Kosola et al. 2018; Lemaire et al. 2018). There is also strong evidence to suggest that current rates of $\mathrm{N}$ deposition are altering many biogeochemical processes, which are influenced by climatic conditions (Southon et al. 2013; Neumann et al. 2018) and already cause reduction in soil respiration (Janssens et al. 2010), and alter photosynthetic capacity, foliar nutrient status and nitrogen metabolism (Mao et al. 2018).

\section{Nitrogen deposition and bryophytes}

The distribution pattern of mosses in urban centers can be related to the degree and extent of pollution (LeBlanc et al. 1971; Rao 1982). The major source of nitrogen input for mosses comes from atmospheric wet deposition as precipitation, throughfall and 
dry deposition of fixed $\mathrm{N}$; this allows for a correlation between the $\mathrm{N}$ content of moss tissue and local N deposition (Pitcairn et al. 1995; Solga et al. 2006; Wilson et al. 2009; Harmens et al. 2011; Kosonen et al. 2018). Mosses are readily available and can be used as an inexpensive tool to monitor nitrogen levels. While the $\mathrm{N}$ content in mosses provides no direct quantitative measurement of atmospheric deposition, the data obtained can give an indication of spatial patterns and temporal trends of $\mathrm{N}$ deposition from the atmosphere (Schröder et al. 2010, 2014; Kosonen et al. 2018). The use of moss nitrogen content and $\delta 15 \mathrm{~N}$ can be used to acquire nitrogen signal strength and origin (Pearce et al. 2003; Pitcairn et al. 2003; Turetsky 2003; Paulissen et al. 2004; Bragazza et al. 2005; Solga et al. 2005, 2006; Pesch et al. 2008; Arróniz-Crespo et al. 2008; Harmens et al. 2011; Varela et al. 2013; Schröder et al. 2010, 2014; Erisman et al. 2014; Meyer et al. 2015; Izquieta-Rojano et al. 2016; Song et al. 2016; Felix et al. 2016; Shi et al. 2017; Kosonen et al. 2018; Carballeira et al. 2018; Olmstead et al. 2018).

Cryptogamic covers, such as cyanobacteria, algae, lichens, bryophytes, fungi, and archaea fix approximately 50 million tons of nitrogen per year and take up approximately 14 billion tons of carbon dioxide per year (Elbert et al. 2012). Mosses can adjust their $\mathrm{N}$ assimilating regime in response to anthropogenic $\mathrm{N}$ deposition (Bakken et al. 1995; Granath et al. 2009; Wiedermann et al. 2009; Waite et al. 2010; Lee et al. 2018). As a result, mosses can be vulnerable to increased $\mathrm{N}$ uptake. NO, NO2 and $\mathrm{NH} 3$ is readily deposited on moist leaf surfaces, where it is reduced through nitrate reductase to nitrite (Cape et al. 2004). Mosses are known as competitive scavengers of $\mathrm{N}$ and are known to reduce $\mathrm{N}$ availability for higher plants (Svensson 1995). They play an important role in $\mathrm{N}$ 
cycling within the environment (Turetsky 2003) for both past and present atmospheric conditions shifting over time (Shetekauri et al. 2018; Xu et al. 2018; Olmstead et al. 2018).

High concentrations of nitrogen deposition has also been directly linked to negative effects on bryophyte communities leading to losses in moss cover and productivity (Pearce et al. 2003; Koranda et al. 2006; Arróniz-Crespo et al. 2008; Britton et al. 2018; Xing et al. 2019), losses in biodiversity (Alatalo et al. 2018), declines in nitrate reductase activity of plant tissue (Pearce et al. 2002; Gordon et al. 2001), and reduction in shoot length (Bell 1992, Salemaa et al. 2008). Without a vascular nutrient transport system and in the absence of roots, mosses are perennial primary producers that accumulate mineral cations and anionic nutrients through wet and dry deposition. High surface area to volume ratio in moss in addition to high cationic exchange capacity (Clymo et al. 1963; Little et al. 1974; Wells et al. 1990; Büscher et al. 1990; Turetsky et al. 1993) favor the accumulation of atmospherically available nutrients from which fixed $\mathrm{N}$ is obtained (Gerdol et al. 2002).

\section{Purpose of Study}

While the interaction between nitrogen deposition and mosses are well-studied in some respects, the effects of nitrogen deposition on volatile organic compounds (BVOCs), such as isoprene, is largely unknown in mosses. Only some plant species produce isoprene, and it has also been hypothesized that the isoprene-producing plants both protect themselves against ozone and, in $\mathrm{NO}_{\mathrm{x}}$-rich environments, increase the ozone 
stress on their non-isoprene-producing neighbors (Arneth et al. 2007). This suggests a physiological role of isoprene emission being more related to its putative function as an antioxidant (Holopainen 2013). In high $\mathrm{N}$ environments, where reactive $\mathrm{N}$ species such as $\mathrm{NO}_{\mathrm{X}}$ dominate near major roadways, plants are able to utilize the excess nitrogen and isoprene can oxidize in the presence of $\mathrm{NO}_{\mathrm{X}}$ creating organic nitrates (Tuazon et al. 1990; O'Brien et al. 1995).

We theorize that nitrogen will have a significant influence on bryophyte isoprene production, as a positive significant relationship has been found between isoprene emission rate and leaf nitrogen concentration in both sun and shade leaves of oak trees (Litvak et al. 1996). Understanding how nitrogen availability influences BVOC productivity and potentially their life history, including sexual reproduction, in mosses is key to understanding how these species are functioning, particularly in urban areas with high $\mathrm{N}$ input. Recently, sex-specific BVOC emissions have been shown to influence the reproductive success of $C$. purpureus (Rosenstiel et al. 2012), a cosmopolitan moss, suggesting a previously unrecognized role for these products in the moss sexual life cycle. Moss sex-specific isoprene/BVOC emissions are an important and poorly characterized piece of the chemical diversity that exists in these early land plants, and how gametangia expression changes with increased nitrogen availability creates a fundamental gap in our understanding of the chemical ecology of these ubiquitous plants. To test the effects of nitrogen on Polytrichum juniperinum populations, a common garden experiment was set up at Portland State University (PSU), which contained male-majority and female-majority intact moss patches from six populations. Ammonium nitrate was 
administered monthly for four years with treatments of $0 \mathrm{~kg} \mathrm{~N} \mathrm{ha}^{-1} \mathrm{yr}^{-1}, 10 \mathrm{~kg} \mathrm{~N} \mathrm{ha}^{-1} \mathrm{yr}^{-}$

${ }^{1}$, and $20 \mathrm{~kg} \mathrm{~N} \mathrm{ha}^{-1} \mathrm{yr}^{-1}$. We measured morphological, reproductive, and physiological traits, including isoprene emissions. Using our data, we are able to test the hypothesis that increased nitrogen will influence bryophyte 1) morphology, 2) reproduction, and 3) isoprene production.

\section{Materials and Methods}

\section{Study species}

Cosmopolitan, endohydric Polytrichum juniperinum mosses differ from typical bryophytes in that they have a network of underground rhizomes, and efficient internal water and carbohydrate conducting systems with apoplastic sugar loading (Thomas et al. 1990). They are able to translocate photoassimilates to sister shoots suggesting capacity for physiological integration between connected moss stems (Thomas et al. 1988; Eckstein et al. 1999). This family of mosses also stores starch in their rhizoids which act as sites for overwinter storage for carbohydrates (Skre et al. 1983). The family Polytrichaceae forms a monophyletic group (Hyvönen et al. 2004) and possesses the highest degree of specialization in being able to move photosynthate through conducting cells called leptoids, in both the haploid gametophyte and diploid sporophyte. The structure of leaves in Polytrichaceae is closest to the function of the leaves of vascular plants of all the mosses (Clayton- Greene et al. 1985; Potter et al. 1995), with thick cuticularized leaves that possess differentiated photosynthetic tissue anatomy. 
Polytrichum has a "high octane physiology" (Dani et al. 2014), and its highly complex anatomy facilitates high isoprene emission rates (Hanson et al. 1999). Polytrichum mosses possess many morphological, anatomical, and physiological properties that affect the capacity to accumulate nutrients on their surfaces and affect their uptake of nitrogen intracellularly (Zechmeister et al. 2003). P. juniperinum is equipped with a species-specific unique photosynthetic lamellae, a "proto phloem" like leptoid rich plasmodesmata, translocation of photoassimilates to sister gametophytes (shoots) through its rhizoidal system that allows for storage of starches not seen in other moss families (Thomas et al. 1988; Shotyk et al. 1998; Fernández et al. 2002; Limpens et al. 2003). It has been suggested that the inflexed achlorophyllous leaf margins enclosing the photosynthetic lamellae in $P$. juniperinum serve to increase the relative humidity and temperature of the air surrounding the lamellae, this adaptation can increase the effective growing season of the moss (Bazzaz et al. 1970; Bayfield et al. 1973; Krupa et al. 1977; Sveinbjörnsson et al. 1981). Polytrichum mosses have great desiccation tolerance that is a strategy for drought resistance and is enabled, at least in part, by its photosynthetic lamellae (Proctor et al. 2005, 2006). The negative effect of similarly increased lamellae temperature during summer months could be offset by its lower dark respiration rates (Herbst 1975), which could aid in attaining higher rate of new stem production, turf densities and higher rate of decomposition. The available reserve photosynthate present in the adult moss shoot could be transferred into new gametophytes via the extensive underground rhizoid system (Bowen et al. 1931; Wigglesworth et al. 1947; Collins et al. 1974; Trachtenberg et al. 1978; Schofield et al. 1981; Reinhart et al. 1981; Döbbeler et al. 
1987; Kodner et al. 2001; Groeneveld et al. 2007; Elumeeva et al. 2011; Tuba et al. 2011).

Since mosses experience strong limitation of photosynthesis because of the high resistance to $\mathrm{CO}_{2}$ diffusion through liquid water on the leaf surface and in the cell wall, the evolution of specialized lamellae cells are critical in this moss family to help reduce this resistance (Thomas et al. 1988; Barsig et al. 1998), providing larger and dry area for $\mathrm{CO}_{2}$ uptake (Proctor 2005; Marschall et al. 2004) and facilitate the absorption of $\mathrm{CO}_{2}$ by repelling water with cuticular waxes (Proctor 1979; Haas 1982; Neinhuis et al. 1995). The folding of leaves against the stem, followed by lateral closure appears to minimize water loss from the lamellae space and loss during the progression from wet to dry conditions (Bayfield 1973; Callaghan et al. 1978; Penny et al. 1982) and resembles stomatal closure in vascular plants (Thomas et al. 1996). Polytrichum populations that have been exposed to nitrogen have shown greater gametophyte height increase compared to rural sites, but at a cost of $36 \%$ less new shoot growth and $56 \%$ less old shoots with new growth (Bell et al. 1992). This suggests that in rural site with low nitrogen deposition, moss is able to utilize and benefit from extra nitrogen by growing upward toward light (Marschall et al. 2004). It is good to keep in mind that Polytrichum species incorporate about $23 \%$ photosynthetic assimilates to its new structural material aboveground, and $77 \%$ of assimilates are either respired or allocated belowground, but from this experiment did not link isoprene emission to allocation (Skre et al. 1983). Bryophytes are the closest living relatives to the first land plants, they are very suitable models for understanding the evolution of isoprene emission, and perhaps untangle the 
biological processes involved in BVOC/isoprene emission function and its implications from an evolutionary perspective.

\section{P. juniperinum moss collection method along a nitrogen gradient}

To establish a stable population of $P$. juniperinum we collected plants from six populations of $P$. juniperinum along a nitrogen gradient of low too high $\mathrm{N}$ in the winter of 2014 in Oregon. Each site was chosen to represent differing geographically isolated populations, environmental and altitudinal gradients. We established a common garden experiment at Portland State University Research greenhouse facility. $P$. juniperinum was collected from two sites near high traffic density, labeled as Site1 and Site 2; two populations from mid traffic density, labeled as Site 3 and Site 4; and two were collected from low traffic density areas, labeled as Site 5 and Site 6 (Table 4.1). We have also recorded environmental variables associated with each site (Table 4.2).

P. juniperinum was identified and specimens were placed in the Portland State University Herbarium (HPSU). Each population contained male, female and nonexpressing gametophytes (shoots). Plants were removed with all of the substrate down to the rock outcrop below the soil. This ensured the least disruption to the thick rhizoidal network holding the moss mats together as higher mortality have been reported when this species is disturbed by severing the rhizoidal network (Watson 1979). The moss mats were placed in $39.37 \mathrm{~cm}$ diameter pots, $50 \mathrm{~cm}$ deep holding 38 liters of substrate of 2:1 propagation grade sand and soil. Approximately 30 majority-male pots and 30 pots majority-female pots were planted from each site. Each $39.37 \mathrm{~cm}$ diameter pot in which 
the moss patch was placed contained approximately 1500 moss gametophytes, yielding 90,000 individual gametophytes. In addition, two set of control pots from each population and treatment containing only sand/soil mix pot was placed in between the rest of the pots. These were all randomly rotated every second week along with the 60 pots to ameliorate environmental conditions. Each pot was set 1.2 meters away from adjacent pots on all sides.

To obtain an idea of population differences, fifty random gametophytes from each pot were randomly collected and assessed for age category (Table 4.3). Polytrichum species possess morphological cues in their aboveground gametophyte, which can serve in identifying age characteristics and life history, and give a spectrum of age distribution observed to be initiated annually (Longton et al. 1967; Longton 1970, 1972, 1979; Collins 1976; Callaghan et al. 1978). All samples were cleaned of debris, such as other plant species, lichen and detritus, and all sporophytes were cut. Mosses were allowed to acclimate in a 'common garden' setting to reduce variation as a result of previous environmental conditions and maternal effects (Shaw 1986). Weeds were manually removed regularly, and pots were monitored on an ongoing basis.

\section{Sex determination from six populations of $P$. juniperinum}

To measure sex-specific characteristics, we assessed each population on a number of morphological and physiological characters. Annual growth increments can be observed to have regular variation in leaf length, where stem elongation continues throughout a season, but longer leaves are created during the middle of the growing 
season and are conspicuous (Hébant 1973). In male-majority pots, splash cups are visible discs on tops of the gametophytes, and new growth from the tip of the splash cups can be seen in early spring. In female-majority pots, after sporophyte production which develop for about a year after fertilization (Innes 1990), the gametophyte stem ceases to exist (Greene 1960; Sarafis 1971; Watson 1975; Callaghan et al. 1978), or shoots may innovate from below the perichaetium and continue to grow and produce sporophytes (Hedderson et al. 2008). All gametophytes may produce branches from shoot bases or on rhizoidal wicks (Wigglesworth 1947). Female P. juniperinum gametophytes therefore start new each time reproduction ensues, terminating with sporophyte maturation and spore release (Hughes 1962; Watson 1975; Hughes 1990).

We classified reproductive effort by counting sporophytes from females, gametophyte containing splash cups from males, and we counted non-sexually expressing gametophytes from each site and year. Non sexual gametophytes were counted and classified. Individual stems were chosen at random, gametophyte shoots from each sex were selected from each pot and marked with gold wire to follow sexual expression and morphological measurements (Watson 1975). We used gold-coated $0.31 \mathrm{~mm} 28$ gauge soft wire as it is chemically inert. Once banded baseline measurements were taken, the gold wire was placed $5 \mathrm{~mm}$ below the last leaf on the gametophyte. In female-majority pots, 6 females were randomly chosen, 2 males and 2 undifferentiated gametophytes were marked and measured with digital caliper. For male-majority pots, 6 males, 2 females and 2 undifferentiated gametophytes were marked and measured. Three measurements were 
taken from each gametophyte, the total height, lowest leaf to apex of shoot, and diameter of each shoot. Individual shoots were scored by age category (Callaghan et al. 1978).

Reproductive development followed an index described by Greene (1960). A total of 600 individual gametophytes were scored and studied. For male gametophytes, antheridia splash cups were counted, and for females, sporophytes were counted. When the study began, a majority of female stems had sporophytes. The sporophytes were collected in the late operculum intact stage of development (Greene 1960; Longton et al. 1967) and were cut, counted and stored once maturity was reached to avoid cross contamination among populations. Growth for males was measured from the base of the gametophyte 2-5 $\mathrm{mm}$ from the soil to the top of apex of the shoot, where usually antheridia resided. Females were measured from 3-5 $\mathrm{mm}$ from the soil surface to the top of the leafy apex of the shoot, not including sporophyte length. Vegetative stems were measured 3-5 $\mathrm{mm}$ from the soil surface to the top of the apex of the shoot. Growth of stems was followed from time of collection to termination of nitrogen addition experiment.

\section{Morphological data collection from six populations of $P$. juniperinum}

Morphological measurements were obtained from the populations before and after nitrogen addition. The collection involved intact in situ gametophyte measurements. Additionally, morphological characteristics were observed to ascertain population and leaf level differences between additions. We assessed gametophyte length (GL, mm), gametophyte width (GW, mm), gametophyte rhizoid length (GRL, mm), and 
gametophyte canopy area $\left(\mathrm{GCA}, \mathrm{m}^{2}\right)$ using a digital Fowler caliper (Lux Scientific Instrument Corp., Tucson, AZ, USA). Total bryophyte cover in each pot was assessed, and percent cover green shoots and percent cover brown shoots were estimated.

Each pot was photographed $\sim 60 \mathrm{~cm}$ above the canopy, and images were transferred to ArcMap GIS software (Version 10.4.1, ESRI Inc., ESRI, Los Angeles, USA). We estimated percent green and percent brown cover by using the Classification Tool in the Spatial Analyst package in ArcMap. We ran a Maximum Likelihood Classification (MLC), which is based on maximum likelihood probability theory. It assigns each pixel from a jpeg image to classes based on means and variances of the class signature, created precisely to look for specific pixel ratios (which is a technique that mathematically extracts factors from a set of variables (Shukla et al. 2017)). The jpeg was transformed into a multispectral image and was categorized and assigned into 50 classes. We ran unsupervised classification, where clusters were created from the statistical properties of the pixels. Pixels with similar properties were grouped to form individual clusters (ArcGis Desktop, 10.4.1, ESRI Inc., Los Angeles, USA).

In addition, sex-specific counts, live, brown shoots, and total number of shoots for each population and each pot were counted and monitored before and after the nitrogen experiment. All other morphological and anatomical observations were counted and recorded. Dead shoots were classified as no longer viable when the apex of the shoot was entirely brown (Potter et al. 1995). A detailed list can be found on summary of morphological and physiological measures (Table 4.4). 


\section{Ammonium nitrate (NH4NO3) addition method to six population of $P$. juniperinum}

P. juniperinum moss patches were allowed to acclimate for a six-month period and ammonium nitrate additions began in the winter of 2015. All six sites and sexspecific pots were randomly distributed between the additions so that 10 female-majority pots and 10 male-majority pots from the three nitrogen level gradient were distributed evenly across the three $\mathrm{N}$ treatment additions (Table 4.5). The nitrogen additions imposed were as follows: the $0 \mathrm{~kg} \mathrm{~N} \mathrm{ha}^{-1} \mathrm{yr}^{-1}$ group (control pots or No N) with a total of 20 pots, the $10 \mathrm{~kg} \mathrm{~N} \mathrm{ha}^{-1} \mathrm{yr}^{-1}$ group (Med N) with a total of 20 pots, and the $20 \mathrm{~kg} \mathrm{~N} \mathrm{ha}^{-1} \mathrm{yr}^{-1}$ group (High $\mathrm{N}$ ) with a total of 20 pots. Nitrogen in the form of granular ammonium nitrate was mixed with water to create an aqueous solution of ammonium nitrate $\mathrm{NH}_{4} \mathrm{NO}_{3}$ which was applied at the end of each month for four consecutive years starting in the winter of 2015 until winter of 2019.

Ammonium nitrate was measured out with analytical microbalance (AB104S/FACT, manufactured by Mettler Toledo Corporation, Tualatin, Oregon. The measured compound was placed in a $500 \mathrm{ml}$ Erlenmeyer flask and vortexed with $200 \mathrm{ml}$ of tap water until crystals dissolved completely. The $\mathrm{NH}_{4} \mathrm{NO}_{3}$ liquid was then transferred into a 1 Liter hand held pressure pump mister sprayer (Solo INC., Model 418, Newport News, VA). The same volume of water was added to the control pots at same frequency. The sprayer was held $20 \mathrm{~cm}$ above each pot and sprayed in clockwise circular motion beginning in the middle of the pot to the edge of the pot (Figure 4.1). Additional water was added to remove the fertilizer solution from the moss canopy and to minimize any potential damage to the plants as described in (Potter et al. 1995). 
The inside diameter of each pot was measured to $\mathrm{be}=41.91 \mathrm{~cm}$, with a radius of $20.995 \mathrm{~cm}$. We then calculated area of the pot, by $\mathrm{A}=\pi^{*} \mathrm{r} 2$, area of inside the pot equals $1379.48 \mathrm{~cm}^{2} 50.137948 \mathrm{~m}^{2}$ per pot. We then followed by taking 1 hectare converted to square meters, which equals to $10000 \mathrm{~m}^{2}$. We have then taken our inside pot radius of $20.995 \mathrm{~cm}$ and divided it by 1 hectare, yielding $0.0000137948=1.37948 * 10^{-5}$ hectares. We then took our desired addition of $20 \mathrm{~kg}$ (High N) and multiplied it by $1.37948^{-5}$ hectares. This yielded $0.000276 \mathrm{~kg} /$ pot, which we converted into grams as 0.276 grams per pot of $\mathrm{NH}_{4} \mathrm{NO}_{3}$ for equivalent of $20 \mathrm{~kg} \mathrm{~N} \mathrm{ha}^{-1} \mathrm{~m}^{-1}$. Each month 0.276 grams of $\mathrm{NH}_{4} \mathrm{NO}_{3}$ was sprayed into each pot in the High $\mathrm{N}$ addition, giving an annual $\mathrm{N}$ addition rate of $240 \mathrm{~kg} \mathrm{~N} \mathrm{ha}^{-1}$ year $^{-1}$. Next, we took our (Low N) of $10 \mathrm{~kg} \mathrm{~N}$ and multiplied it by $1.37948^{-5}$ hectares. This yielded us with $0.000138 \mathrm{~kg} /$ pot, which we converted into grams as 0.138 grams per pot of $\mathrm{NH}_{4} \mathrm{NO}_{3}$ for equivalent of $10 \mathrm{~kg} \mathrm{~N} \mathrm{ha}^{-1} \mathrm{~m}^{-1}$. Each month 0.138 grams of $\mathrm{NH}_{4} \mathrm{NO}_{3} 3$ was sprayed into each pot in the Low $\mathrm{N}$ addition, giving an annual $\mathrm{N}$ addition rate of $120 \mathrm{~kg} \mathrm{~N} \mathrm{ha}^{-1}$ year $^{-1}$.

\section{Physiological measurement of six populations of $P$. juniperinum}

All gametophytic leaf level isoprene emission samples were taken nondestructively by leaving $P$. juniperinum gametophyte intact. All six populations survived the transplant process. We collected isoprene emission data from moss canopy level from each intact population of $P$. juniperinum, because mechanical damage (burning, cutting, wind, rubbing) of a leaf, or nearby leaves, decreases isoprene emission (Loreto et al. 1993). Therefore, we sampled intact moss ramets for this experiment as this method with 
basal emission rate, as it gives a more spatially realistic profile of emission for sampling volatiles in an ecological context as it was more feasible to leave moss tissue intact for a multi-year experiment involving the addition of anthropogenic nitrogen $(\mathrm{N})$ addition when trying to correlate isoprene emission to morphological and physiological traits.

All sixty pots not including six control pots (two per $\mathrm{N}$ addition regime) were tested using static accumulation chambers, and samples were collected between 9 am and $10 \mathrm{am}$ to reduce diurnal variation. Measurements were taken after testing and utilizing a lab constructed $77 \mathrm{~mm} \times 77 \mathrm{~mm} \times 97 \mathrm{~mm}$ static chamber $\left(\right.$ Magenta ${ }^{\mathrm{TM}}$ vessel) made of polypropylene closure (Sigma-Aldrich Co., 2017) which, we have outfitted with thermocouple and Swagelok $®$ and a small fan for proper mixing of static air within the chamber. Magenta vessels ${ }^{\mathrm{TM}}$ were designed and inverted to best fit our experimental design. Leaf tissue was gently inserted into the magenta vessel when inverted, and carefully measured as to given an accurate representation of actual moss gametophytic canopy area (CA) under the magenta vessel (Figure 4.2). We have added a drilled hole to the side of the vessel equipped with a septa and Swagelok® to be able to take measurements from the side of the vessel. Measurement was taken by inserting a $2 \mathrm{ml}$ Pressure-Lok® Precision Analytical Syringes (VICI Precision Sampling Inc., Baton Rouge, LA, USA) after 10 minutes of incubation. Canopy moss temperature was measured with a shaded thermocouple (maintained at $30^{\circ} \mathrm{C}, \pm 3 \mathrm{C}$ ) in order to collect precise dynamic isoprene emission measurements.

An acclimation period was allowed before measurements were taken and temperatures were monitored with thermocouples and reported. Experiments were carried 
out under standard conditions $\left(30^{\circ} \mathrm{C}, 1,000 \mu \mathrm{mol} \mathrm{m} \mathrm{m}^{-2} \mathrm{~s}^{-1}\right.$ photosynthetic photon flux density at leaf level (PPFD), unless otherwise noted. Light was provided with a Dracast LED1000 Pro Daylight light panel, with light-emitting diode array (Photon Systems Instruments). Sexually expressing gametophytes patches were chosen, with no other debris and only photosynthetic active green tissue was sampled. Sampling order was randomized throughout the two trials in order to ensure that all sixty pots were sampled in a random matter. From each pot, four measurements were taken, each area consisting of about $16 \mathrm{~cm}^{2}$, resulting in four replicates per pot.

After 10 minutes, $1 \mathrm{~mL}$ of air was removed via Pressure-Lok® precision analytical syringe (VICI Precision Sampling Inc., Baton Rouge, LA, USA) and injected into a reduction gas detector (RGD2, Trace Analytical, Menlo Park, CA). Isoprene was separated on a stainless steel column (1.3 m long x $2 \mathrm{~mm}$ inner diameter i.d.). The column was packed with UNI 8 Beads 3S 60/80 6’ x 1/8”, 0.085 SS (Alicat Scientific, Inc; Tucson, AZ). Peak times and areas were recorded and transformed to ppm of isoprene. The GC-RGD2 was calibrated each day using a standard cylinder containing 71 $\mathrm{ppb}(\mathrm{v} / \mathrm{v})$ isoprene, references to a National Institute of Standard and Technology (NIST) Helium (HE) standard (SRM 1660a; 1ppm He in $\mathrm{N}_{2}$, Rochester, NY), (Praxair Inc., Specialty Gases, Portland, OR) with a ten point standard dilution of isoprene and He as a carrier gas. Blanks were run every four samples to ensure quality check and to look for contamination within the column. Isoprene gas was mixed with high purity helium using a mass flow controller calibrated to a flow rate of $21 \mathrm{ml} / \mathrm{min}$. (Alicat Scientific, Inc; Tucson, AZ). One $\mathrm{mL}$ of the calibration gas mixture was removed with a syringe from a 
mixing chamber and injected into the GC-RGD2 to create the calibration curve and obtain slope of the equation see (Equation 1.) Isoprene emission measurement was calculated as follows; using Peak Area Units (PAU) from the standard calibration curve $\mathrm{y}=\mathrm{mx}+\mathrm{b}$, at GC temperature of 298 Kelvin $(K)$, and Atmospheric Pressure (P) of 760 Torr.

$$
\begin{aligned}
= & \left(\frac{\mathrm{PAU}+20.69}{2.4703}\right) x\left(\frac{1 \mathrm{nmol} / \mathrm{L}}{\mathrm{ppb}}\right) x(.0005) x\left(\frac{\text { std } \mathrm{nl}}{\mathrm{nl}}\right) x\left(\frac{760 \mathrm{Torr}}{298 \mathrm{~K}}\right) x\left(\frac{378 \mathrm{~K}}{771.8 \mathrm{Torr}}\right) \\
& x\left(\frac{1 \mathrm{nmol}}{22.4 \mathrm{std} \mathrm{nl}}\right) x\left(\frac{\text { volume vial }(\mathrm{ml})}{.5 \mathrm{ml}}\right) x 1 \text { (factor for loop recovery) } \\
& x\left(\frac{1}{\text { area } / \mathrm{m} 2}\right)=\left(\text { nmol } \mathrm{m}^{2} * \mathrm{~S}^{-1}\right)
\end{aligned}
$$

Equation 1. Formula used to convert isoprene from calibration curve, $y=m x+b$, and PAU to isoprene $\left(\mathrm{nmol} \mathrm{m} \mathrm{m}^{-2} \mathrm{~s}^{-1}\right)$.

We obtained the volume mixing ratio of isoprene ( $\mathrm{ppb}$ ) we used Equation 1 to determine gametophyte emission flux. We determined the area of the gametophyte using a ruler. Peak identification was performed with the PEAK software (Stein 1999) that integrates raw peak area units and retention times. To identify isoprene, a custom calibration curve was created from isoprene standard (Sigma, Deisenhofen, Germany). For quantification, peak areas of isoprene were determined after baseline correction. Levels of background contamination were determined from blanks. Analytical quality was analyzed by using Standard Reference Material of isoprene (NIST SRM 1515, National Institute of Standards and Technology, Gaithersburg, USA).

Isoprene emission measures were achieved twice during the nitrogen addition, before $\mathrm{N}$ addition in 2015 and after $\mathrm{N}$ addition in 2016. We calculated that we can fit $~ 9$ 
magenta vessels ${ }^{\mathrm{TM}}$ into each $\sim 40 \mathrm{~cm}$ diameter container (Figure 4.3). The portable Gas Chromatograph with the Reduced Gas Detector (GC/RGD2) was utilized in multiple field sites at the time of this study, and monthly isoprene emission collection was not possible. Isoprene emission measures were taken in the winter of 2015 and in the summer of 2016, but due to seasonal differences it was not possible at this time to compare isoprene emission measures before and after nitrogen addition.

Canopy level isoprene emission was measured using a Magenta $^{\mathrm{TM}}$ vessel, but to establish area of moss under the vessel, we have used displacement by volume of moss tissue to calculate accurate headspace in the vessel from which isoprene measurement was taken. Where appropriate dry weight measurements were taken to assess initial moss selection. The volume displacement method was standardized by taking 10 point measurements of $16 \mathrm{~cm}^{2}$ moss with differing heights under the vessel and placing it into a cylinder to accrue water displacement. Moss ramets are highly varied in their structure, unlike vascular plants in which a flat area can easily be calculated. We felt given mosses 3D structure this method is better suited than what is currently used for vascular plant isoprene emission assessment.

Our second physiology measure was chlorophyll fluorescence ratio, as a nonintrusive tool in using it as a proxy to establish information on photosynthetic reactions in the chloroplast (Schreiber et al. 1987). The fluorescence-emission spectra read out two maxima in the $690 \mathrm{~nm}$ and the $735 \mathrm{~nm}$ region. The fluorescence ratio F690/F735 for green leaves is higher (values of 0.8 to 1.1 ) than in the yellow to red wavelength region (525 to $633 \mathrm{~nm}$ ) which only yields values for F690/F735 of 0.5 to 0.7 (Rinderle et al. 
1988). Chlorophyll fluorescence ratio (CFR) was measured with a chlorophyll content meter (OPTI-Sciences model CCM-300, Hudson, USA).

\section{Statistical Analyses}

We used repeated measures ANOVA to determine the effect of site, nitrogen treatment and pot majority-sex on gametophyte length and gametophyte width for two years after nitrogen treatment (2016 and 2017). We used repeated measures ANOVA to determine the effect of site, nitrogen treatment, and pot majority-sex on reproductive effort (sporophytes) for three years after nitrogen treatment (2016, 2017, and 2018). We used ANOVA to determine the effect of site on isoprene production before we applied the nitrogen treatments, and we used ANOVA to determine the effect of site, nitrogen treatment, and pot majority-sex on isoprene emission after the treatment was applied. We used a similar ANOVA to determine the effect of site, nitrogen treatment and pot majority-sex on CFR after the nitrogen treatments were applied. We transformed our data when necessary to meet the assumptions of ANOVA. We also used Tukey-Kramer HSD Multiple Comparison test (Ellison et al. 2004) to find sources of significant differences between sites and nitrogen additions. JMP Pro 14.1 (SAS Institute, Cary, North Carolina, USA) was used for all analyses.

\section{Results}

\section{Gametophyte length}


We found significant differences among sites in gametophyte length (GL) (RM ANOVA; DF=5,591; F= 15.97; $\mathrm{P}<0.0001 ;$ Figure 4.4). After nitrogen addition, mean gametophyte length was highest from our Site 4 with mean values of $1.823 \mathrm{~cm} \pm 0.046$ SEM ( $n=200)$. Our Site 5, had the smallest gametophyte length with mean values of $1.621 \mathrm{~cm} \pm 0.0371 \mathrm{SEM}(\mathrm{n}=200)$. We also found a significant site by time interaction where $11 \%$ of gametophyte length (GL) variation could be explained by time (RM ANOVA; $\mathrm{DF}=5,591 ; \mathrm{F}=45.71 ; \mathrm{P}<0.0001)$, with site differences becoming less pronounced, and sites resembling each other as the experiment progressed.

Gametophyte length (GL) was significant different among nitrogen addition treatments, explaining $21 \%$ of variation in gametophyte length (GL) (RM ANOVA; $\mathrm{DF}=2,591 ; \mathrm{F}=7.723 ; \mathrm{P}=0.0005)$. The longest gametophyte length (GL) was in the $20 \mathrm{~N}$ $\mathrm{kg} \mathrm{ha}^{-1} \mathrm{yr}^{-1}$ addition with mean values of $2.259 \mathrm{~cm} \pm 0.101 \mathrm{SEM}(\mathrm{n}=200)$, and lowest in the $0 \mathrm{~N} \mathrm{~kg} \mathrm{ha}^{-1} \mathrm{yr}^{-1}$ addition with mean values of $1.186 \mathrm{~cm} \pm 0.042 \mathrm{SEM}(\mathrm{n}=200)$. In the $10 \mathrm{~N} \mathrm{~kg} \mathrm{ha}^{-1} \mathrm{yr}^{-1}$ addition we saw intermediate mean values of $1.886 \mathrm{~cm} \pm 0.078 \mathrm{SEM}$ $(n=200)$. We also found a significant nitrogen treatment by time interaction (RM ANOVA; $\mathrm{DF}=2,591 ; \mathrm{F}=14.32 ; \mathrm{P}<0.0001)$, where we saw gametophyte length mean values closer to each other in all three treatments.

Gametophyte length (GL) differed significantly between the male- and femalemajority pots, with gametophyte length in female-majority pots longer than gametophyte length in male-majority pots (RM ANOVA; DF=1,591; $\mathrm{F}=19.65 ; \mathrm{P}<0.0001)$. We also found a significant difference for the interaction between nitrogen treatment and pot majority sex (RM ANOVA; DF=2,591; F=5.4261; $\mathrm{P}=0.0046$; Figure 4.5). Gametophyte 
length in female-majority pots was longest in the $20 \mathrm{~N} \mathrm{~kg} \mathrm{ha}^{-1} \mathrm{yr}^{-1}$ addition with mean values of $2.403 \mathrm{~cm} \pm 0.132 \mathrm{SEM}(\mathrm{n}=200)$, and lowest in the $0 \mathrm{~N} \mathrm{~kg} \mathrm{ha}^{-1} \mathrm{yr}^{-1}$ addition with mean values of $1.344 \mathrm{~cm} \pm 0.052 \mathrm{SEM}(\mathrm{n}=200)$. In the $10 \mathrm{~N} \mathrm{~kg} \mathrm{ha}^{-1} \mathrm{yr}^{-1}$ addition we saw intermediate mean values of $1.965 \mathrm{~cm} \pm 0.126 \mathrm{SEM}(\mathrm{n}=200)$. Gametophyte length in male-majority pots was longest in the $20 \mathrm{~N} \mathrm{~kg} \mathrm{ha}^{-1} \mathrm{yr}^{-1}$ addition with mean values of $2.065 \mathrm{~cm} \pm 0.162 \mathrm{SEM}(\mathrm{n}=200)$, and lowest in the $0 \mathrm{~N} \mathrm{~kg} \mathrm{ha}^{-1} \mathrm{yr}^{-1}$ addition with mean values of $1.175 \mathrm{~cm} \pm 0.0437 \mathrm{SEM}(\mathrm{n}=200)$. In the $10 \mathrm{~N} \mathrm{~kg} \mathrm{ha}^{-1} \mathrm{yr}^{-1}$ addition we saw intermediate mean values of $1.437 \mathrm{~cm} \pm 0.0404$ SEM $(n=200)$. The interaction between pot majority sex and time was not significant (RM ANOVA; $\mathrm{DF}=1,591 ; \mathrm{F}=2.75 ; \mathrm{P}=$ 0.09), as the differences in gametophyte length between male- and female-majority pots did not change during the course of the experiment.

\section{Gametophyte width}

We also found statistical significance in site differences for gametophyte width (GW) (RM ANOVA; DF=5,591; F= 13.8676; $\mathrm{P}<0.0001$; Figure 4.6). The widest gametophyte width $(\mathrm{GW})$ was found in Site 5 with mean values of $1.184 \mathrm{~cm} \pm 0.030$ SEM ( $n=200)$. Site 3 had the least wide gametophyte width $\mathrm{cm}(\mathrm{GW})$ with mean values of $1.083 \mathrm{~cm} \pm 0.010 \mathrm{SEM}(\mathrm{n}=200)$. We also found a significant site by time interactions (RM ANOVA; DF=5,591; F=22.27; $\mathrm{P}<0.0001$ ), with sites becoming significantly less different in gametophyte width as the experiment progressed.

Gametophyte width $(\mathrm{GW})$ was not significant between treatments (RM ANOVA; $\mathrm{DF}=2,591 ; \mathrm{F}=1.28 ; \mathrm{P}=0.28)$. Gametophyte width was also not significantly different 
between male- and female-majority pots (RM ANOVA; $\mathrm{DF}=1,591 ; \mathrm{F}=0.71 ; \mathrm{P}=0.40$ ).

However, for gametophyte width the interaction between nitrogen additions and pot majority sex was significant $(\mathrm{RM}$ ANOVA; $\mathrm{DF}=2,591 ; \mathrm{F}=32.5288 ; \mathrm{P}<0.0001$; Figure 4.7). Gametophyte width in majority female pots was widest in the $20 \mathrm{~N} \mathrm{~kg} \mathrm{ha}^{-1} \mathrm{yr}^{-1}$ addition with mean values of $2.403 \mathrm{~cm} \pm 0.139$ SEM $(n=200)$, and least wide in the $0 \mathrm{~N}$ $\mathrm{kg} \mathrm{ha}^{-1} \mathrm{yr}^{-1}$ addition with mean values of $1.343 \mathrm{~cm} \pm 0.056 \mathrm{SEM}(\mathrm{n}=200)$. In the $10 \mathrm{~N} \mathrm{~kg}$ $\mathrm{ha}^{-1} \mathrm{yr}^{-1}$ addition we saw intermediate mean values of $1.192 \mathrm{~cm} \pm 0.0232 \mathrm{SEM}(\mathrm{n}=200)$. Gametophyte width in male-majority pots was widest in the $10 \mathrm{~N} \mathrm{~kg} \mathrm{ha}^{-1} \mathrm{yr}^{-1}$ addition with mean value of $1.634 \mathrm{~cm} \pm 0.136 \mathrm{SEM}(\mathrm{n}=200)$, and least wide in the $0 \mathrm{~N} \mathrm{~kg} \mathrm{ha}^{-1} \mathrm{yr}^{-1}$ addition with mean values of $0.910 \mathrm{~cm} \pm 0.0253 \mathrm{SEM}(\mathrm{n}=200)$. In the $20 \mathrm{~N} \mathrm{~kg} \mathrm{ha}^{-1} \mathrm{yr}^{-1}$ addition we saw intermediate mean values of $1.192 \mathrm{~cm} \pm 0.0232 \operatorname{SEM}(\mathrm{n}=200)$.

We also found a significant interaction among pot majority sex, treatment and time (RM ANOVA; DF=2,591; F= 16.14; $\mathrm{P}<0.0001)$. Gametophyte width decreased in both male- and female-majority pots over the course of the nitrogen addition, because of moss rapid turnover rate. While gametophyte width in female-majority pots did not change over time, gametophyte width in male-majority pots changed during our nitrogen addition, and the widest mean values were found in the $20 \mathrm{~N} \mathrm{~kg} \mathrm{ha}^{-1} \mathrm{yr}^{-1}$ addition with mean value of $0.921 \pm 0.0191$ SEM $(n=200)$. Our least wide gametophyte width in male-majority pots remained in the $0 \mathrm{~N} \mathrm{~kg} \mathrm{ha}^{-1} \mathrm{yr}^{-1}$ addition, with mean values of 0.765 $\mathrm{cm} \pm 0.0143 \operatorname{SEM}(\mathrm{n}=200)$.

\section{Reproductive effort}


Female reproductive effort in terms of sporophyte count was statistically significant among sites (RM ANOVA; $\mathrm{DF}=5 ; \mathrm{F}=5,49 ; \mathrm{P}=0.0002$; Figure 4.8). The highest count of sporophytes was from Site 6 with 1848 sporophytes $(n=20)$, and we counted the lowest sporophytes in Site 3 with $945(n=20)$. Some sites increased sporophyte output between the years and treatment, while other sites remained stable across time.

We found that treatment did not significantly affect sporophyte count (RM ANOVA; $\mathrm{DF}=2,49 ; \mathrm{F}=2.6403 ; \mathrm{P}=0.08)$. Reproductive effort in sporophyte count was statistically significant between male-majority and female-majority pots, with plants in female-majority pots producing more sporophytes than plants in male-majority pots (RM ANOVA; $\mathrm{DF}=1,449 ; \mathrm{F}=13.4107 ; \mathrm{P}=0.0006)$. We did not find majority-sex by treatment interaction for sporophyte count (RM ANOVA; $\mathrm{DF}=2,49 ; \mathrm{F}=2.6559 ; \mathrm{P}=0.08)$. Lastly, we saw a significant time and majority-sex interaction (RM ANOVA; DF=2,48; $\mathrm{F}=4.1298 ; \mathrm{P}=0.0221)$. Sporophyte count was similar in both male-majority and femalemajority pots for the first two years of nitrogen addition, with very low count of sporophytes in male-majority pots. For our last year of nitrogen addition, sporophyte count was much higher in female-majority pots than male-majority pots.

\section{Isoprene emission before nitrogen addition}

Site-specific differences alone explained $22 \%$ variability of isoprene emission (ANOVA; DF=5; F=13.1835; $\mathrm{P}<0.0001$; Figure 4.9). Within each site, we saw even more variation in isoprene emission than between sites (Figure 4.10). Overall, we saw 
mean isoprene emission values of $6.787 \mathrm{nmol} \mathrm{m}^{-2} \mathrm{~s}^{-1} \pm 0.218 \mathrm{SEM}(\mathrm{n}=240)$. The highest isoprene emission was seen from Site 1 with a mean values of $10.337 \mathrm{nmol} \mathrm{m}-2 \mathrm{~s}-1 \pm$

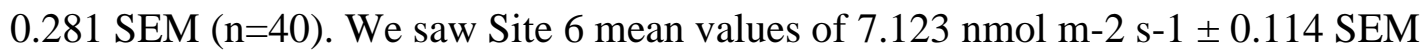
$(\mathrm{n}=40)$. Site 5 mean values of $7.118 \mathrm{nmol} \mathrm{m}-2 \mathrm{~s}-1 \pm 0.856 \mathrm{SEM}(\mathrm{n}=40)$. Site 3 mean values of $6.742 \mathrm{nmol} \mathrm{m-2} \mathrm{s-1 \pm 0.186} \mathrm{SEM} \mathrm{(n=40).} \mathrm{Site} 4$ mean values of $5.534 \mathrm{nmol} \mathrm{m}$ $2 \mathrm{~s}-1 \pm 0.081$ SEM $(\mathrm{n}=40)$. Lastly, Site 2 had the smallest isoprene emission with a mean values of $3.867 \mathrm{nmol} \mathrm{m}-2 \mathrm{~s}-1 \pm 0.134$ SEM $(\mathrm{n}=40)$.

We also saw sex-specific differences in isoprene emission with female-majority pots having a larger mean emission than male-majority pots (ANOVA; $\mathrm{DF}=1$; $\mathrm{F}=10.2925 ; \mathrm{P}<0.0015$; Figure 4.11). We saw that Site 1, Site 2, Site 4 and Site 6 femalemajority pots had higher isoprene emission values than male-majority pots. Only in Site 3, and Site 5, we saw male-majority pots having higher isoprene emission than female plots. In Site 1, we saw the highest isoprene emission from female-majority plots with mean values of $13.735 \mathrm{nmol} \mathrm{m}^{-2} \mathrm{~s}^{-1} \pm 0.472 \mathrm{SEM}(\mathrm{n}=40)$. Our lowest isoprene emission from majority-female plots was seen from Site 2 with mean values of $4.231 \mathrm{nmol} \mathrm{m}^{-2} \mathrm{~s}^{-}$ ${ }^{1} \pm 1.154 \operatorname{SEM}(\mathrm{n}=40)$. We saw the highest isoprene emission from male-majority pots from Site 1 with mean values of $6.932 \mathrm{nmol} \mathrm{m}^{-2} \mathrm{~s}^{-1} \pm 1.79 \mathrm{SEM}(\mathrm{n}=40)$, and the lowest isoprene emission from Site 2 with mean values of $3.508 \mathrm{nmol} \mathrm{m}^{-2} \mathrm{~s}^{-1} \pm 0.812 \mathrm{SEM}$ $(n=40)$.

\section{Isoprene emission after nitrogen addition}


We continued to see site-specific differences which explained $12 \%$ variability of isoprene emission between sites after nitrogen addition (ANOVA; $\mathrm{DF}=11 ; \mathrm{F}=7.3488 ; \mathrm{P}$ $<0.0001$; Figure 4.12; Figure 4.13). After nitrogen addition we saw isoprene emission mean values of $28.562 \mathrm{nmol} \mathrm{m}^{-2} \mathrm{~s}^{-1} \pm 0.710 \mathrm{SEM}(\mathrm{n}=240)$. Isoprene emission was highest for Site 1 with mean values of $38.801 \mathrm{nmol} \mathrm{m}^{-2} \mathrm{~s}^{-1} \pm 0.793 \mathrm{SEM}(\mathrm{n}=40)$. Site 2 mean values were $35.321 \mathrm{nmol} \mathrm{m}^{-2} \mathrm{~s}^{-1} \pm 0.894 \mathrm{SEM}(\mathrm{n}=40)$. Site 3 mean values were 24.678 $\mathrm{nmol} \mathrm{m} \mathrm{s}^{-2} \mathrm{~s}^{-1} \pm 0.679 \mathrm{SEM}(\mathrm{n}=40)$. Site 5 mean values were $27.298 \mathrm{nmol} \mathrm{m}^{-2} \mathrm{~s}^{-1} \pm 0.663$ $\operatorname{SEM}(\mathrm{n}=40)$. Site 6 mean values were $24.173 \mathrm{nmol} \mathrm{m}^{-2} \mathrm{~s}^{-1} \pm 0.521 \mathrm{SEM}(\mathrm{n}=40)$. Our lowest isoprene emission was seen from Site 4 with mean values of $21.093 \mathrm{nmol} \mathrm{m}^{-2} \mathrm{~s}^{-1} \pm$ $0.512 \operatorname{SEM}(\mathrm{n}=40)$.

We did not observe a statistically significant difference between male- and female-majority pots in isoprene emission after $\mathrm{N}$ addition ( $\mathrm{P}=0.89)$. We did however, observe a significant interaction between treatment and sexual expression in isoprene emission in the $10 \mathrm{~N} \mathrm{~kg} \mathrm{ha}^{-1} \mathrm{yr}^{-1} \mathrm{~N}$ treatment (ANOVA; DF=5; $\mathrm{F}=23.63 ; \mathrm{P}<0.0001$; Figure 4.14). Female and male isoprene emissions were highest in the $10 \mathrm{~N} \mathrm{~kg} \mathrm{ha}^{-1} \mathrm{yr}^{-1} \mathrm{~N}$ treatments. Male mean values were higher than female values $2.341 \pm 0.023 \mathrm{nmol} \mathrm{m}^{-2} \mathrm{~s}^{-1}$ $\operatorname{SEM}(\mathrm{n}=44)$. Female mean values were $2.214 \pm 0.181 \mathrm{nmol} \mathrm{m}^{-2} \mathrm{~s}^{-1} \mathrm{SEM}(\mathrm{n}=36)$. In the $20 \mathrm{~N} \mathrm{~kg} \mathrm{ha}^{-1} \mathrm{yr}^{-1}$ females values were similar to male values, female mean values were $1.514 \pm 0.035 \mathrm{nmol} \mathrm{m}^{-2} \mathrm{~s}^{-1} \mathrm{SEM}(\mathrm{n}=52)$, and male mean values were $1.560 \pm 0.105 \mathrm{nmol}$ $\mathrm{m}^{-2} \mathrm{~s}^{-1} \mathrm{SEM}(\mathrm{n}=32)$. Lastly, in the $0 \mathrm{~N} \mathrm{~kg} \mathrm{ha}^{-1} \mathrm{yr}^{-1}$ treatment female values were higher than male values, with female values of $1.625 \pm 0.141 \mathrm{nmol} \mathrm{m}^{-2} \mathrm{~s}^{-1} \mathrm{SEM}(\mathrm{n}=32)$, and male values of $1.389 \pm 0.015 \mathrm{nmol} \mathrm{m}^{-2} \mathrm{~s}^{-1} \mathrm{SEM}(\mathrm{n}=48)$. 
We also saw treatment specific differences which explained 32\% variation in isoprene emission (ANOVA; $\mathrm{DF}=2 ; \mathrm{F}=56.09 ; \mathrm{P}<0.0001$; Figure 4.15). Our $10 \mathrm{~kg} \mathrm{~N} \mathrm{ha}^{-1}$ $\mathrm{yr}^{-1}$ treatment had the highest isoprene emission with mean values of $2.284 \mathrm{nmol} \mathrm{m}^{-2} \mathrm{~s}^{-1} \pm$ $0.071 \mathrm{SEM}(\mathrm{n}=80)$. The $20 \mathrm{~kg} \mathrm{~N} \mathrm{ha}^{-1} \mathrm{yr}^{-1}$ treatment had mean values of $1.533 \mathrm{nmol} \mathrm{m}^{-2} \mathrm{~s}^{-}$ ${ }^{1} \pm 0.033$ SEM (n=84). Lastly, we saw our lowest isoprene emission with our $0 \mathrm{~kg} \mathrm{~N} \mathrm{ha}^{-1}$ $\mathrm{yr}^{-1}$ treatment with mean values of $1.484 \mathrm{nmol} \mathrm{m}^{-2} \mathrm{~s}^{-1} \pm 0.041 \mathrm{SEM}(\mathrm{n}=80)$.

\section{Physiological measurements}

We saw site-specific differences in CFR values (ANOVA; DF=5; F=8.1600; $\mathrm{P}$ $<0.0001$; Figure 4.16). Our highest CFR values were seen from Site 6, with mean values of $0.9222 \pm 0.006$ SEM $(n=484)$. Our lowest CFR values were found in Site 4 , with mean values of $0.85 \pm 0.0190$ SEM $(n=484)$.

Nitrogen additions significantly affected CFR (ANOVA; DF=2; F=3.8437; P <0.0228; Figure 4.17). Our $0 \mathrm{~kg} \mathrm{~N} \mathrm{ha}^{-1} \mathrm{yr}^{-1}$ addition, was significantly lower (0.998 \pm 0.0124 SEM; $\mathrm{n}=484)$ in CFR than our $20 \mathrm{~kg} \mathrm{~N} \mathrm{ha}^{-1} \mathrm{yr}^{-1}$ addition (1.007 $\pm 0.009 \mathrm{SEM}$; $\mathrm{n}=484)$. Our $10 \mathrm{~kg} \mathrm{~N} \mathrm{ha}^{-1} \mathrm{yr}^{-1}$ addition was not significantly different from either other addition. We did not find sex-specific differences in our CFR values $(\mathrm{P}=0.097)$.

\section{Discussion}

We collected moss samples from six locations around Portland Oregon, and we have established a large common garden experiment where we used Ammonium nitrate $\left(\mathrm{NH}_{4} \mathrm{NO}_{3}\right)$ to evaluate the effects of nitrogen addition on morphology, reproductive 
effort, and physiology in $P$. juniperinum. We used nitrogen values of $0 \mathrm{~kg} \mathrm{~N} \mathrm{ha}^{-1} \mathrm{yr}^{-1}, 10$ $\mathrm{kg} \mathrm{N} \mathrm{ha}^{-1} \mathrm{yr}^{-1}, 20 \mathrm{~kg} \mathrm{~N} \mathrm{ha}^{-1} \mathrm{yr}^{-1}$ as for the Pacific Northwest nitrogen deposition spans in this range of $0.15 \mathrm{~kg} \mathrm{~N} \mathrm{ha}^{-1} \mathrm{yr}^{-1}$ to $39 \mathrm{~kg} \mathrm{~N} \mathrm{ha}^{-1} \mathrm{yr}^{-1}$ (Root et al. 2013). We found significant effects of nitrogen addition and majority-sex of populations on gametophyte morphology. We also found significant effects of the nitrogen treatment on isoprene emissions and chlorophyll fluorescence ratio. We discuss our results below.

\section{Gametophyte morphology}

Gametophyte length (GL) and gametophyte width (GW) had high variation between sites (Figure 4.4; Figure 4.6). We saw the dynamics of moss communities going through cyclic changes as evidenced by rapid turnover of all moss populations. We found that both gametophyte length and gametophyte width were significantly affected by our six sites. However, for both morphological traits, the differences among sites diminished across time.

We saw gametophyte length (GL) affected by nitrogen addition (Figure 4.5), but not gametophyte width (GW) (Figure 4.7). We saw 21\% variation in gametophyte length be attributable to nitrogen addition (Figure 4.5). P. juniperinum could have used the added $\mathrm{N}$ to grow longer as it established optimal growth and the benefit of extra nitrogen was utilized either as respired carbon or allocated into belowground growth; as extensive rhizoidal system exist in this species (Wigglesworth 1947). In Polytrichum species, photosynthetic assimilates can be added to form new structural material belowground, or they can be respired or allocated to aboveground structures (Skre et al. 1983). Work from 
previous studies shows that nitrogen in Polytrichum ecosystems is retained in the soil and dead moss tissue (Bowden 1991). Further work will be required to assess belowground biomass to fully comprehend nitrogen treatment affects both aboveground and belowground where it could be utilized by rhizoids or stored in the soil.

Sex-specific resource allocation was evident. Gametophyte length (GL) was affected by sex, with majority-female pots having longer lengths than males (Figure 4.5), and this difference was significantly affected by the nitrogen treatments. The sex-specific difference was not found in the control treatment or in the high nitrogen treatment, but only in the $10 \mathrm{~kg} \mathrm{~N} \mathrm{ha}^{-1}$ year $^{-1}$ treatment.

We know that Polytrichum species have the very low caloric values, with very little energy fixed in tissue of the moss (Rastorfer 1976), suggesting that they spend all their acquired photosynthetic carbon on either allocation or respiration. Other studies have found that in Polytrichum species, variations in $\mathrm{N}$ addition of $20 \mathrm{vs} .10 \mathrm{~kg} \mathrm{~N} \mathrm{ha}^{-1}$ year $^{-1}$ did not affect growth (Van der Wal et al. 2005). While others, have shown that Polytrichum populations that have been exposed to nitrogen addition have greater height increase at a cost of $36 \%$ less new shoots (Bell et al. 1992), but we do not know if these new shoots were sexually expressing.

\section{Reproductive effort}

Nitrogen treatment had no significant effect on reproductive effect. However, reproductive effort in majority-female and majority-male pots was statistically different when it came to sporophyte reproduction, which was higher than male splash cup counts, 
as expected. Sporophyte count was highly variable among sites. Sporophytes production was most likely a result of inter-gametophyte self-fertilization (Stark et al. 2009; Koncz

et al. 2012). We saw that non-sexually expressing gametophytes outnumbered female and male gametophyte counts (Figure 4.8). In bryophytes, sex expression is reduced mainly because sporophyte maturation is resource-limited (Stark et al. 2009). Variation among populations in viability and germination capability of the spores refers to different levels of effective sexual reproduction. Populations with high viability and germination capability of spores indicate effective realized sexual reproduction (Longton 1988, Innes 1990). Denser populations as compared to sparser ones have a higher allocation to sexual reproduction (Wyatt and Derda 1997, Cronberg et al. 2006). We saw extremely dense populations produce more sporophytes than less dense populations.

\section{Physiology measurements}

In this study, nitrogen addition influenced isoprene emission in $P$. juniperinum populations. We are the first to report isoprene emission increasing under nitrogen addition in any moss species, and we are the first to report isoprene emission increasing under nitrogen addition in $P$. juniperinum. We found significant effects of the nitrogen treatment on isoprene emission in this species. Isoprene emission variation was statistically significant between sites and explained 30\% variation in winter of 2015 (Figure 4.9), and within sites (Figure 4.10). We also saw isoprene emission differences between the sexes before nitrogen addition, suggesting sex-specific resource allocation at this time of year, with female isoprene emission higher than male isoprene emission 
(Figure 4.11). After nitrogen addition, we continued to see site-specific differences in the summer of 2016 explaining 12\% variability between sites (Figure 4.12) and within sites (Figure 4.13). Isoprene emission rates vary among vascular plant species from near zero to over $50 \mathrm{nmol} \mathrm{m} \mathrm{m}^{-2}$ (Harley et al. 1999), and here we are the first to show large variation in isoprene emission from $P$. juniperinum under nitrogen addition.

In our experimental study, the medium level nitrogen treatment resulted in the highest isoprene emission level with almost twice the isoprene emission as the control treatment with no additional nitrogen, and significantly more than the high nitrogen treatment (Figure 4.14; Figure 4.15). The availability of nitrogen affects the concentration of secondary compounds such as isoprene in a predictable manner according to the carbon/ nutrient balance hypothesis (Bryant et al. 1983). If a plant is growing in nitrogen poor environments, the plant can use the carbon from photosynthesis for isoprene emission instead of growth allowing it to have increased secondary compounds (Bryant et al. 1983, Herms et al. 1992, Jones et al. 1999). A previous study assessing nitrogen in $P$. juniperinum population has found that belowground biomass of both live and dead tissue had higher nitrogen concentrations than aboveground tissue (Bowden 1991). This suggest that $P$. juniperinum under high nitrogen addition may not utilize all of available nitrogen. Nitrogen uptake response in mosses involves several steps (Heijmans et al. 2001, Xing et al. 2010). Initially, mosses can utilize nitrogen and benefit from nitrogen addition (Jauhiainen et al. 1994; Williams et al. 1997). In many moss populations, nitrogen is limiting (Bowden 1991; Bakken 1995; Eckstein et al. 1999, 2000; Aldous 2002; Ayres et al. 2006; Koranda et al. 2006; Arróniz-Crespo et al. 2008; Du et al. 2014; Juutinen et al. 
2015; Felix et al. 2016; Izquieta-Rojano et al. 2016; Becker et al. 2017; Kosonen et al. 2018), and thus additions of nitrogen result in increasing photosynthesis which can be used for additional growth, reproduction, or production of secondary compounds. The first phase of utilizing the nitrogen, when plants are limited in nitrogen, was seen in $P$. juniperinum in the difference between our control and our medium nitrogen addition, when isoprene emission increased significantly with nitrogen addition. This reflects similar findings in vascular plants, where nitrogen addition increases isoprene emission rate and photosynthesis (Harley et al. 1994).

Eventually, in the final phase of nitrogen uptake response in mosses, a maximum nitrogen content is reached and nitrogen leaches into the soil or fungal hyphae in the rhizome mat (Bowden 1991; Bragazza et al. 2005). Once maximum nitrogen content is reached, which we saw in our highest nitrogen addition, the added nitrogen may have been leached into the rhizoidal mat or soil reflecting the low isoprene emission we saw in our high nitrogen addition group. At this stage, the added nitrogen was potentially harmful as we saw these values were close to isoprene emission values from our no nitrogen, control pots. Nutrient translocation and retention from older tissue to young tissue is a key mechanism mosses use to avoid nutrient loss and nitrogen utilization peaks during highest growth (Clymo et al. 1982; Aerts et al. 1999). Under our highest nitrogen addition, carbon allocation could have been used for peak growth and additional nitrogen was not utilized resulting in lower isoprene emission, as all the resources were utilized in either above or belowground growth. The highest nitrogen addition we applied could have represented an environmental shift in available nitrogen to $P$. juniperinum, and this 
may have hindered the mosses ability to uptake this form of nitrogen and utilize it. We know that vascular plants can utilize many forms of nitrogen, and we could have seen a decrease in isoprene emission in our high nitrogen addition because of competition for carbon skeletons between the supply and demand of isoprenoid precursor dimethylallyl pyrophosphate (DMAPP) (Rosenstiel et al. 2004).

Mosses can also utilize different forms of nitrogen, and mosses access to nitrogen depends on direct bioavailable nitrogen coming from atmospheric deposition, internal nitrogen cycling by mineralization, and lastly species dependent nitrogen translocation (Aldous 2002; Bowden 1991). Future research should focus on determining the role of nitrogen from the demand side process including analyses of aboveground and belowground tissue concentrations, fungal biomass retention of nitrogen, and soil nitrogen content. Additional insights could be gained from work to understand what carbon allocation strategies $P$. juniperinum uses and what the consequences for ecosystem level carbon cycling under enhanced nitrogen deposition.

We also saw significant site-specific chlorophyll fluorescence ratio (Figure 4.16). Our highest CFR values were seen from forest Site 5, and Site 6, indicating reduced stress compared to the other sites. We found our highest CFR values in the highest nitrogen treatment (Figure 4.17), which we used as a as a proxy to establish information on photosynthetic reactions in the chloroplast (Schreiber et al. 1987). Stress in plants induces lower chlorophyll content, and lower rate of photosynthesis, because of degradation of chlorophyll content due to many factors, including excessive nitrogen 
addition (Rinderle et al. 1988). We did not see this pattern, as only healthy green gametophytes were sampled for chlorophyll content.

\section{Conclusion}

We have shown that moderate nitrogen addition significantly increases isoprene emission in moss populations. These results have important implication for understanding isoprene emissions from bryophyte communities as anthropogenic nitrogen levels increase. Our data also suggest that nitrogen male and female of $P$. juniperinum will respond differentially to nitrogen in terms of morphology, but this may not result in differential response in isoprene emission at the population level. Future work should focus on understanding the effect of additional community interactions, including the microbiome, on isoprene production in mosses across nitrogen gradients. 


\section{Tables and Figures}

Table 4.1 Summary table of Polytrichum juniperinum from six populations $(n=60)$.

\begin{tabular}{|l|l|l|l|l|l|}
\hline Site & Location & $\begin{array}{l}\text { Expected } \\
\text { Nitrogen } \\
\text { background }\end{array}$ & Latitude & Longitude & $\begin{array}{l}\text { Elevation } \\
\text { (meters) }\end{array}$ \\
\hline 1 & Highway & High N & $45^{\circ} 41^{\prime} 38.34^{\prime \prime N}$ & $122^{\circ} 52^{\prime} 14.23^{\prime \prime} \mathrm{W}$ & 15 \\
\hline 2 & Highway & High N & $45^{\circ} 38^{\prime} 7.45^{\prime \prime N}$ & $122^{\circ} 49^{\prime} 45.09^{\prime \prime} \mathrm{W}$ & 21 \\
\hline 3 & Intermediary & Medium N & $45^{\circ} 41^{\prime} 50.54^{\prime \prime N}$ & $122^{\circ} 52^{\prime} 40.83^{\prime \prime} \mathrm{W}$ & 145 \\
\hline 4 & Intermediary & Medium N & $45^{\circ} 46^{\prime} 58.78^{\prime \prime} \mathrm{N}$ & $123^{\circ} 22^{\prime} 14.14^{\prime \prime} \mathrm{W}$ & 315 \\
\hline 5 & Forest & Low N & $45^{\circ} 44^{\prime} 6.80^{\prime \prime N}$ & $122^{\circ} 59^{\prime} 30.62^{\prime \prime} \mathrm{W}$ & 412 \\
\hline 6 & Forest & Low N & $45^{\circ} 47^{\prime} 17^{\prime \prime N}$ & $122^{\circ} 56^{\prime} 16.00^{\prime \prime} \mathrm{W}$ & 241 \\
\hline
\end{tabular}


Table 4.2 Site characteristics of Polytrichum moss collected in the winter of 2015. Soil type, slope, depth to water table and available water in storage profile data was assessed from Soil Survey Staff, Natural Resources Conservation Service, United States Department of Agriculture. Web Soil Survey. Available online. Accessed (7/13/2018)https://websoilsurvey.sc.egov.usda.gov.

\begin{tabular}{|l|l|l|l|l|l|l|}
\hline Site & Location & Location & Soil type & Slope & $\begin{array}{l}\text { Depth to } \\
\text { water table } \\
(\mathrm{cm})\end{array}$ & $\begin{array}{l}\text { Available } \\
\text { water } \\
\text { storage in } \\
\text { profile } \\
\text { (mm) }\end{array}$ \\
\hline 1 & Highway & High N & $\begin{array}{l}\text { gravelly loam, } \\
\text { un-weathered } \\
\text { bedrock }\end{array}$ & $30-70 \%$ & $203+$ & Low (83) \\
\hline 2 & Highway & High N & $\begin{array}{l}\text { sandy loam, } \\
\text { gravelly loamy } \\
\text { sand }\end{array}$ & $40-60 \%$ & $91-183$ & $\begin{array}{l}\text { Moderate } \\
(216)\end{array}$ \\
\hline 3 & Intermediary & Medium N & $\begin{array}{l}\text { silt loam, } \\
\text { clay loam }\end{array}$ & $60-70 \%$ & $63-99$ & $\begin{array}{l}\text { Moderate } \\
(198)\end{array}$ \\
\hline 4 & Intermediary & Medium N & $\begin{array}{l}\text { silt loam, } \\
\text { clay loam, } \\
\text { weathered bedrock }\end{array}$ & $30-60 \%$ & $203+$ & $\begin{array}{l}\text { Moderate } \\
(216)\end{array}$ \\
\hline 5 & Forest & Low N & $\begin{array}{l}\text { silt loam, } \\
\text { clay loam }\end{array}$ & $12-20 \%$ & 163 & $\begin{array}{l}\text { Moderate } \\
(193)\end{array}$ \\
\hline 6 & Forest & Low N & silt loam & $15-30 \%$ & $64-252$ & $\begin{array}{l}\text { Moderate } \\
(191)\end{array}$ \\
\hline
\end{tabular}


Table 4.3 Age classification rubric of $P$. juniperinum populations.

\begin{tabular}{|l|l|}
\hline Age category & Classification \\
\hline Year 1 & $(0.0-2.0 \mathrm{~cm})(\mathrm{n}=50)$ \\
\hline Year 2 & $(2.0-4.0 \mathrm{~cm})(\mathrm{n}=50)$ \\
\hline Year 3 & $(4.0-6.0 \mathrm{~cm})(\mathrm{n}=50)$ \\
\hline Year 4 & $(6.0-8.0 \mathrm{~cm})(\mathrm{n}=50)$ \\
\hline Year 5 & $(8.0-10.0 \mathrm{~cm})(\mathrm{n}=50)$ \\
\hline Year 6 & $(10.0-12.0 \mathrm{~cm})(\mathrm{n}=50)$ \\
\hline Year 7 & $(12.0-14.0+\mathrm{cm})(\mathrm{n}=50)$ \\
\hline
\end{tabular}


Table 4.4 Summary of all morphological measurements taken from $P$. juniperinum populations.

\begin{tabular}{|c|c|c|c|}
\hline $\begin{array}{l}\text { 12/01/2015 } \\
\text { Before } N\end{array}$ & $\begin{array}{l}06 / 05 / 2016 \\
\text { After } \mathrm{N} \\
\end{array}$ & $\begin{array}{l}01 / 10 / 2017 \\
\text { After } N\end{array}$ & $\begin{array}{l}06 / 05 / 2018 \\
\text { After } N\end{array}$ \\
\hline $\begin{array}{l}\text { G. Length } \\
(\mathrm{mm})\end{array}$ & $\begin{array}{l}\text { G. Length } \\
(\mathrm{mm})\end{array}$ & $\begin{array}{l}\text { G. Length } \\
(\mathrm{mm})\end{array}$ & $\begin{array}{l}\text { G. Length } \\
(\mathrm{mm})\end{array}$ \\
\hline $\begin{array}{l}\text { G. Width } \\
(\mathrm{mm})\end{array}$ & $\begin{array}{l}\text { G. Width } \\
(\mathrm{mm})\end{array}$ & $\begin{array}{l}\text { G. Width } \\
(\mathrm{mm})\end{array}$ & $\begin{array}{l}\text { G. Width } \\
(\mathrm{mm})\end{array}$ \\
\hline $\begin{array}{l}\text { G. Canopy } \\
\text { area }(\mathrm{mm})\end{array}$ & $\begin{array}{l}\text { G. Canopy area } \\
(\mathrm{mm})\end{array}$ & $\begin{array}{l}\text { G. Canopy } \\
\text { area }(\mathrm{mm})\end{array}$ & $\begin{array}{l}\text { G. Canopy area } \\
(\mathrm{mm})\end{array}$ \\
\hline \multicolumn{4}{|l|}{$\begin{array}{l}\text { G. Rhizoid } \\
\text { length (mm) }\end{array}$} \\
\hline $\begin{array}{l}\text { Damage by } \\
\text { larvae }\end{array}$ & $\begin{array}{l}\text { Damage by } \\
\text { larvae }\end{array}$ & Damage by & $\begin{array}{l}\text { Damage by } \\
\text { larvae }\end{array}$ \\
\hline$\%$ cover green & $\%$ cover green & $\%$ cover green & $\%$ cover green \\
\hline $\begin{array}{l}\% \text { cover } \\
\text { brown }\end{array}$ & $\%$ cover brown & $\begin{array}{l}\% \text { cover } \\
\text { brown }\end{array}$ & $\%$ cover brown \\
\hline CFR & & CFR & \\
\hline CFR by sex & & CFR by sex & \\
\hline $\begin{array}{l}\text { Isoprene } \\
\text { emission } \\
\left(\mathrm{nmol} \mathrm{m}^{-2} \mathbf{s}^{-1}\right) \\
\end{array}$ & & 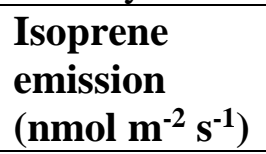 & \\
\hline $\begin{array}{l}\text { Canopy area } \\
\left(\mathrm{m}^{2}\right) \text { for } \\
\text { Isoprene }\end{array}$ & & $\begin{array}{l}\text { Canopy area } \\
\left(\mathrm{m}^{2}\right) \text { for } \\
\text { Isoprene }\end{array}$ & \\
\hline $\begin{array}{l}\text { Total } \\
\text { sporophyte } \\
\text { count }\end{array}$ & $\begin{array}{l}\text { Total } \\
\text { sporophyte } \\
\text { count }\end{array}$ & $\begin{array}{l}\text { Total } \\
\text { sporophyte } \\
\text { count }\end{array}$ & $\begin{array}{l}\text { Total } \\
\text { sporophyte } \\
\text { count }\end{array}$ \\
\hline $\begin{array}{l}\text { Last year } \\
\text { sporophyte } \\
\text { count }\end{array}$ & $\begin{array}{l}\text { Last year } \\
\text { sporophyte } \\
\text { count }\end{array}$ & $\begin{array}{l}\text { Last year } \\
\text { sporophyte } \\
\text { count }\end{array}$ & $\begin{array}{l}\text { Last year } \\
\text { sporophyte } \\
\text { count }\end{array}$ \\
\hline $\begin{array}{l}\text { New year } \\
\text { sporophyte } \\
\text { count }\end{array}$ & $\begin{array}{l}\text { New year } \\
\text { sporophyte } \\
\text { count }\end{array}$ & $\begin{array}{l}\text { New year } \\
\text { sporophyte } \\
\text { count }\end{array}$ & $\begin{array}{l}\text { New year } \\
\text { sporophyte } \\
\text { count }\end{array}$ \\
\hline $\begin{array}{l}\text { Total splash } \\
\text { cup count }\end{array}$ & $\begin{array}{l}\text { Total splash } \\
\text { cup count }\end{array}$ & $\begin{array}{l}\text { Total splash } \\
\text { cup count }\end{array}$ & $\begin{array}{l}\text { Total splash } \\
\text { cup count }\end{array}$ \\
\hline $\begin{array}{l}\text { Last year } \\
\text { splash cup }\end{array}$ & $\begin{array}{l}\text { Last year splash } \\
\text { cup }\end{array}$ & $\begin{array}{l}\text { Last year } \\
\text { splash cup }\end{array}$ & $\begin{array}{l}\text { Last year splash } \\
\text { cup }\end{array}$ \\
\hline $\begin{array}{l}\text { New year } \\
\text { splash cup }\end{array}$ & $\begin{array}{l}\text { New year } \\
\text { splash cup }\end{array}$ & $\begin{array}{l}\text { New year } \\
\text { splash cup }\end{array}$ & $\begin{array}{l}\text { New year } \\
\text { splash cup }\end{array}$ \\
\hline
\end{tabular}




\begin{tabular}{|l|l|l|l|}
\hline $\begin{array}{l}\text { Non-sexual } \\
\text { gametophytes }\end{array}$ & $\begin{array}{l}\text { Non-sexual } \\
\text { gametophytes }\end{array}$ & $\begin{array}{l}\text { G. Canopy } \\
\text { area }(\mathrm{mm})\end{array}$ & $\begin{array}{l}\text { Non-sexual } \\
\text { gametophytes }\end{array}$ \\
\hline $\begin{array}{l}\text { Total } \\
\text { gametophyte }\end{array}$ & $\begin{array}{l}\text { Total } \\
\text { gametophytes }\end{array}$ & $\begin{array}{l}\text { Total } \\
\text { gametophyte }\end{array}$ & $\begin{array}{l}\text { Total } \\
\text { gametophyte }\end{array}$ \\
\hline Age category & Age category & Age category & Age category \\
\hline & & $\begin{array}{l}\text { Pots with less } \\
\text { than 50 shoots }\end{array}$ & $\begin{array}{l}\text { Pots with less } \\
\text { than 50 shoots }\end{array}$ \\
\hline
\end{tabular}


Table 4.5 Experimental design set up showing three nitrogen additions. Within each block there are twelve pots. The three additions contain six control pots, two control pots in each addition and 20 pots in each addition.

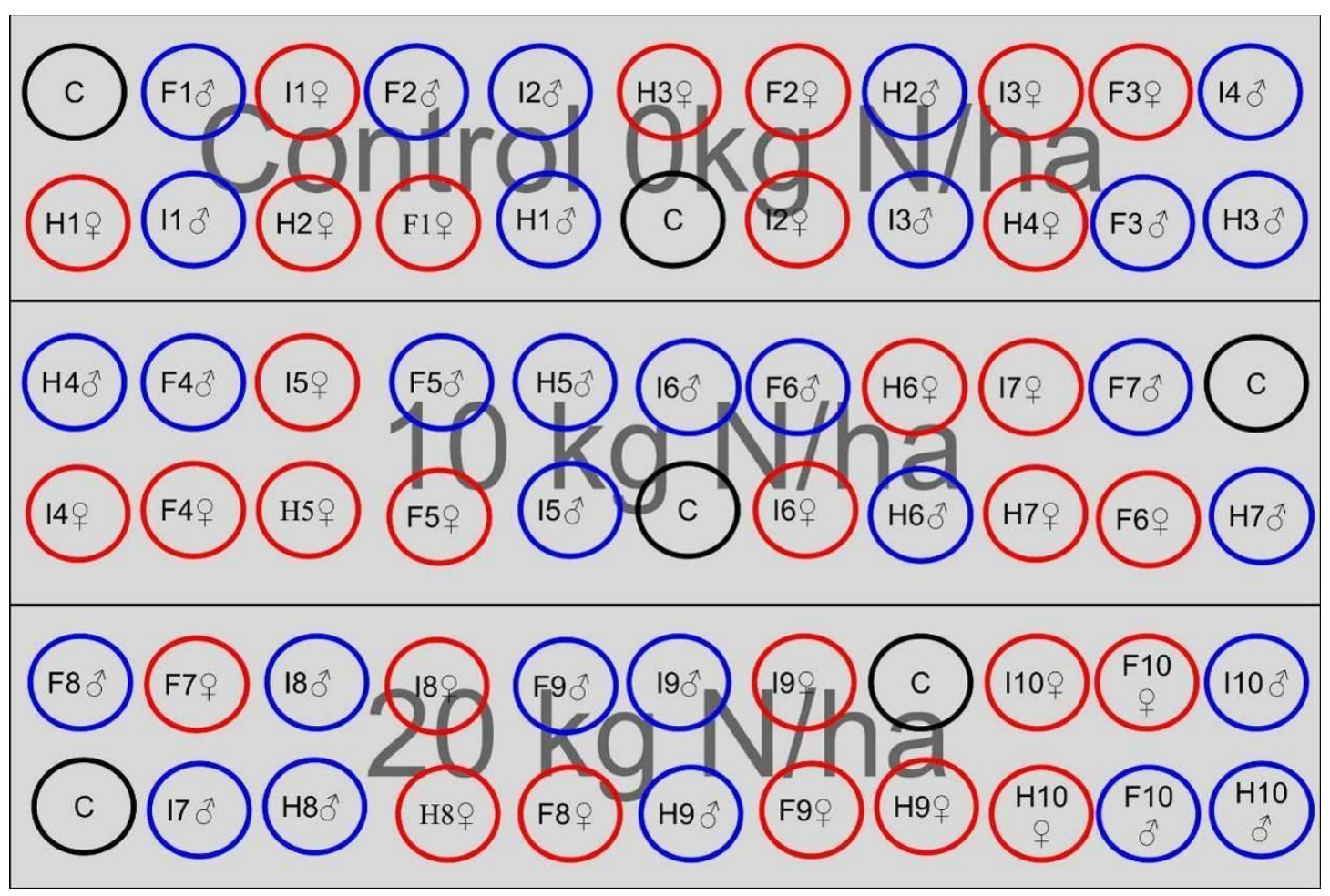


Figure 4.1 Ammonium nitrate addition to P. juniperinum moss via 1-Liter (L) hand held pump mister sprayer (Solo INC., Model 418, Newport News, VA).

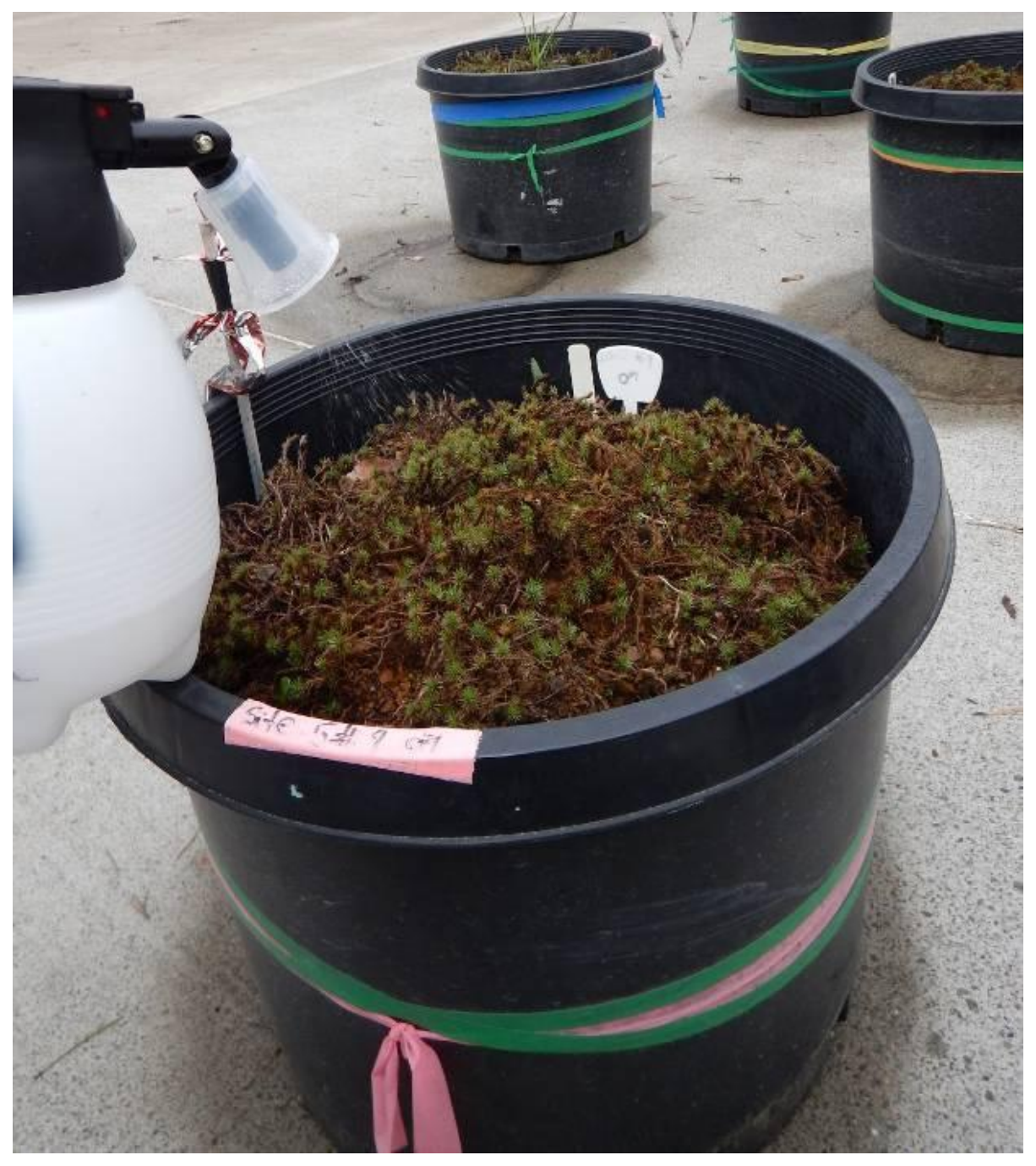


Figure 4.2 Small $77 \mathrm{~mm} \times 77 \mathrm{~mm} \times 97 \mathrm{~mm}$ static chamber (magenta jar) created for headspace analyses using (Magenta vessel ${ }^{\mathrm{TM}}$ ). Equipped with battery-operated fan to ensure equal mixing of air in the chamber and avoid settling.

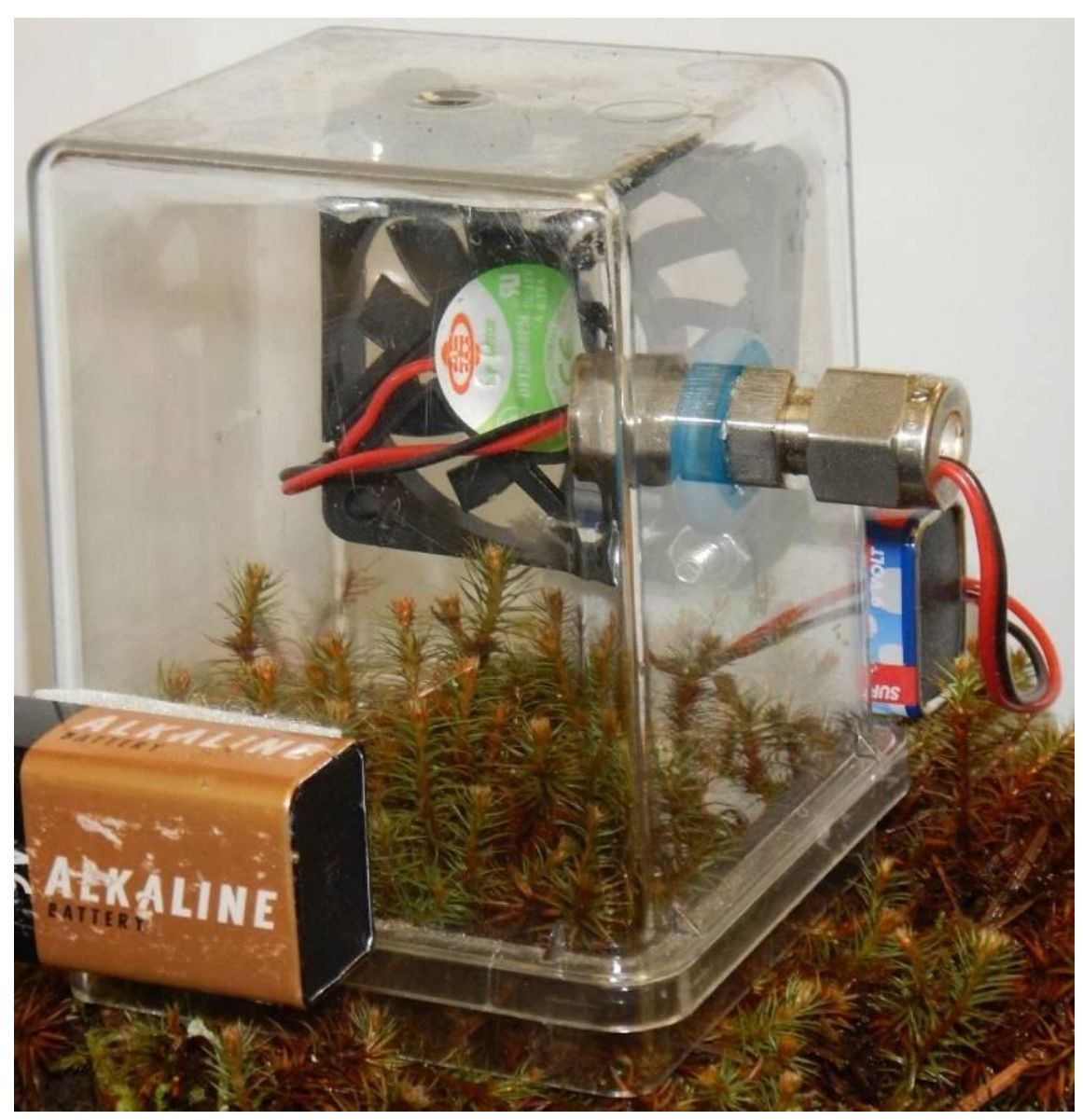


Figure 4.3 Magenta vessel ${ }^{\mathrm{TM}}$ used to collect isoprene emission data from $P$. juniperinum populations before and after nitrogen addition. Seen here inverted with Pressure-Lok® precision analytical syringe (VICI Precision Sampling Inc., Baton Rouge, LA, USA).

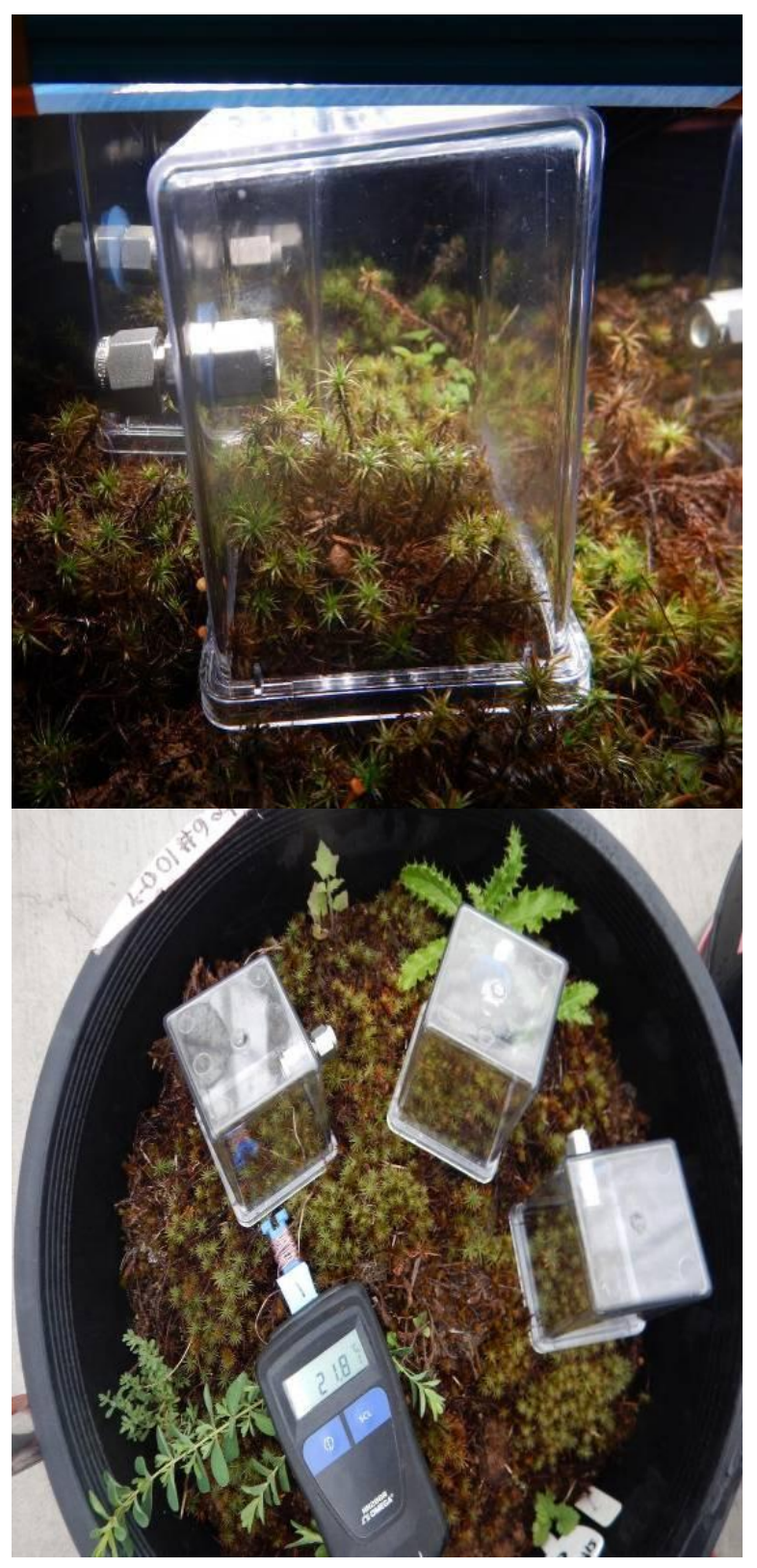


Figure 4.4 Gametophyte length (GL) cm versus sites (1-6) in P. juniperinum ( $\mathrm{n}=3596)$. Site is plotted on the X-axis. Tukey-Kramer HSD Multiple Comparisons Test shows areas of significant difference between gametophyte length and site. Error bars represent $\pm 1 \sigma$ (standard deviation). Letters show statistical significance between means. Means with the same letter are not significantly different. A * indicates significant difference, ** indicates a highly significant difference, $* * *$ indicates high statistical significance, NS indicates no significance.

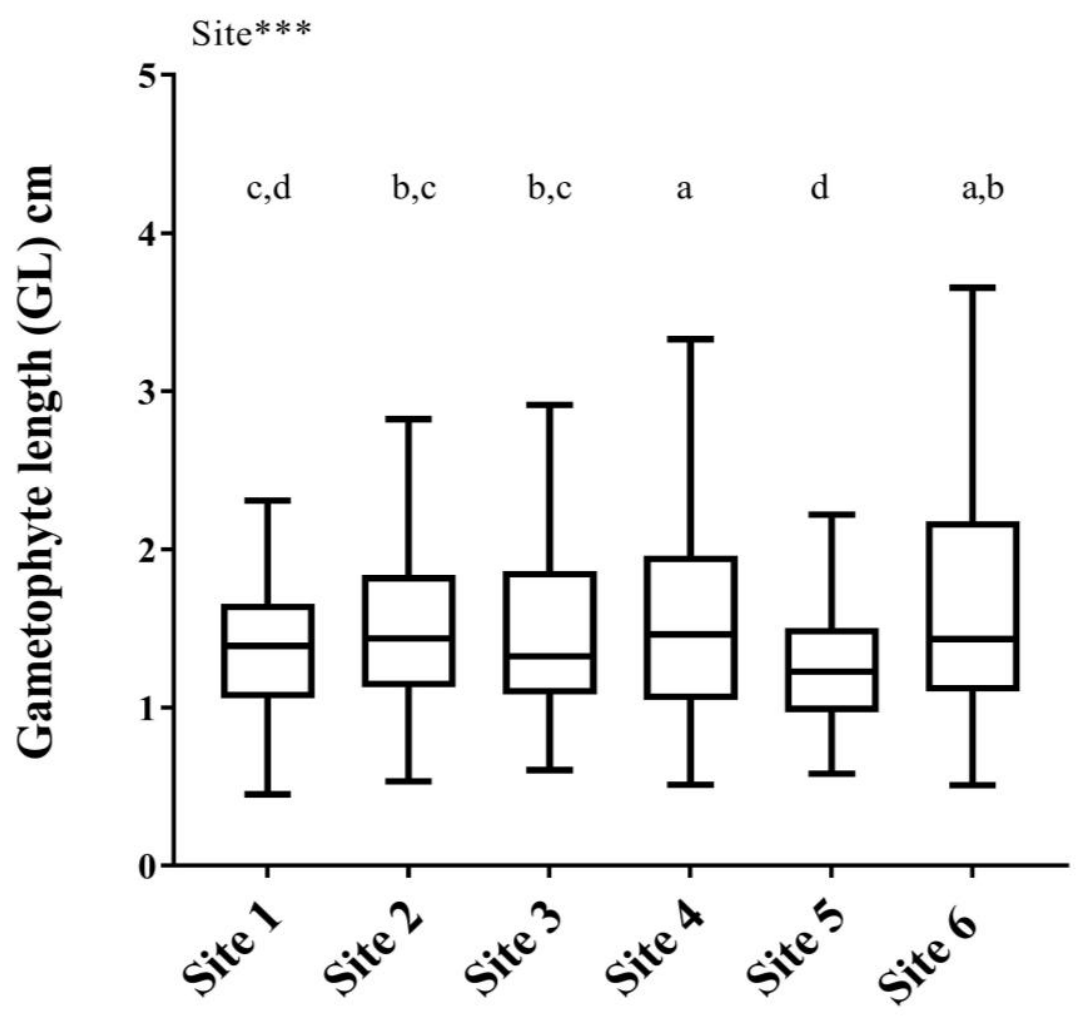


Figure 4.5 Gametophyte length (GL) cm versus sex and nitrogen treatment in $P$. juniperinum $(\mathrm{n}=3596)$. Nitrogen treatment is plotted on the $\mathrm{x}$-axis. Tukey-Kramer HSD Multiple Comparisons Test shows areas of significant difference between gametophyte length vs. nitrogen treatment and sex. Error bars represent $\pm 1 \sigma$ (standard deviation). Letters show statistical significance between means. Means with the same letter are not significantly different. A * indicates significant difference, ** indicates a highly significant difference, $* * *$ indicates high statistical significance, NS indicates no significance.

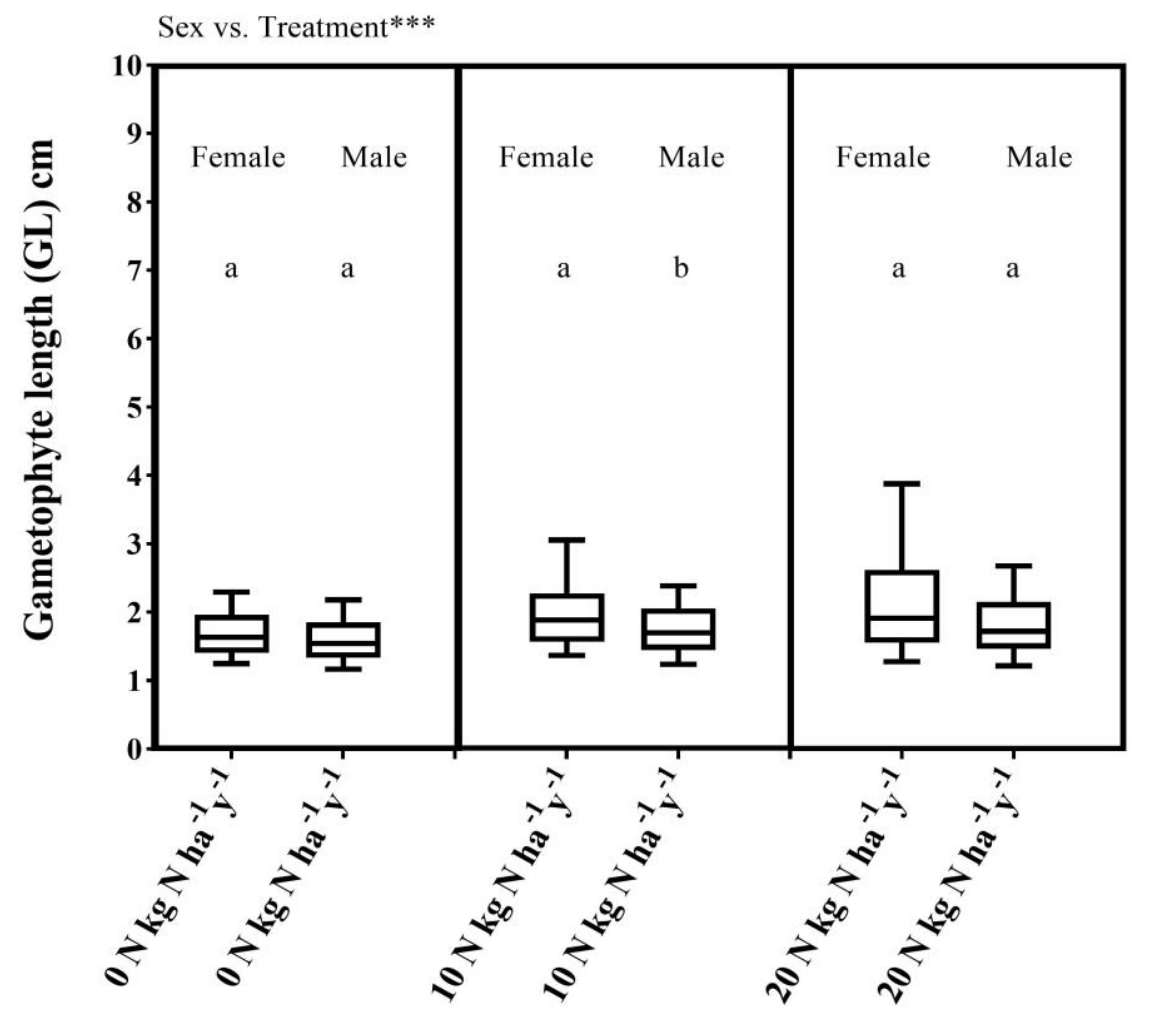


Figure 4.6 Gametophyte width (GW) cm versus sites (1-6) in P. juniperinum (n=3596). Site is plotted on the $\mathrm{x}$-axis. Tukey-Kramer HSD Multiple Comparisons Test shows areas of significant difference between avg. gametophyte width $\mathrm{cm}(\mathrm{GW})$ and site. Error bars represent $\pm 1 \sigma$ (standard deviation). Letters show statistical significance between means. Means with the same letter are not significantly different. A * indicates significant difference, $* *$ indicates a highly significant difference, $* * *$ indicates high statistical significance, NS indicates no significance.

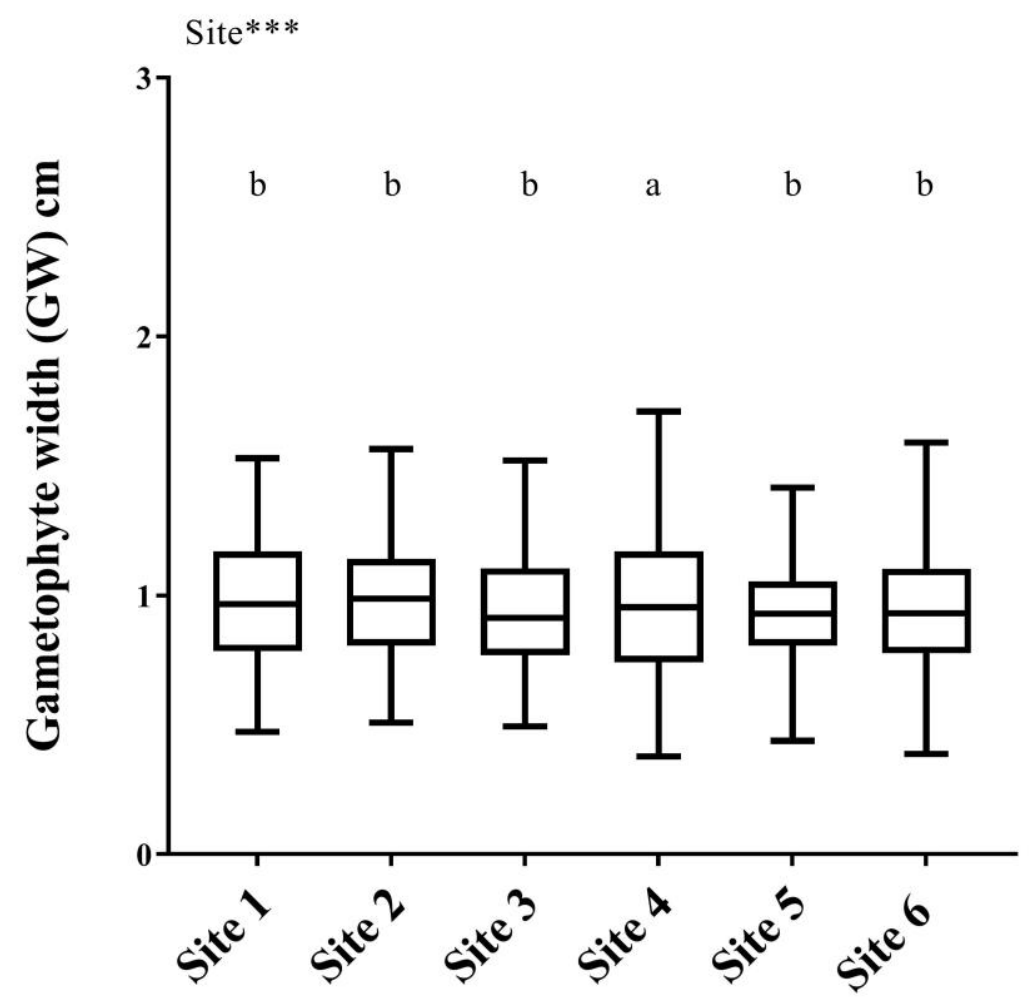


Figure 4.7 Gametophyte width $(\mathrm{GW}) \mathrm{cm}$ versus sex and nitrogen treatment in $P$. juniperinum $(\mathrm{n}=3596)$. Nitrogen treatment is plotted on the $\mathrm{x}$-axis. Tukey-Kramer HSD Multiple Comparisons Test shows areas of significant difference between gametophyte width vs. nitrogen treatment and sex. Error bars represent $\pm 1 \sigma$ (standard deviation). Letters show statistical significance between means. Means with the same letter are not significantly different. A * indicates significant difference, $* *$ indicates a highly significant difference, $* * *$ indicates high statistical significance, NS indicates no significance.

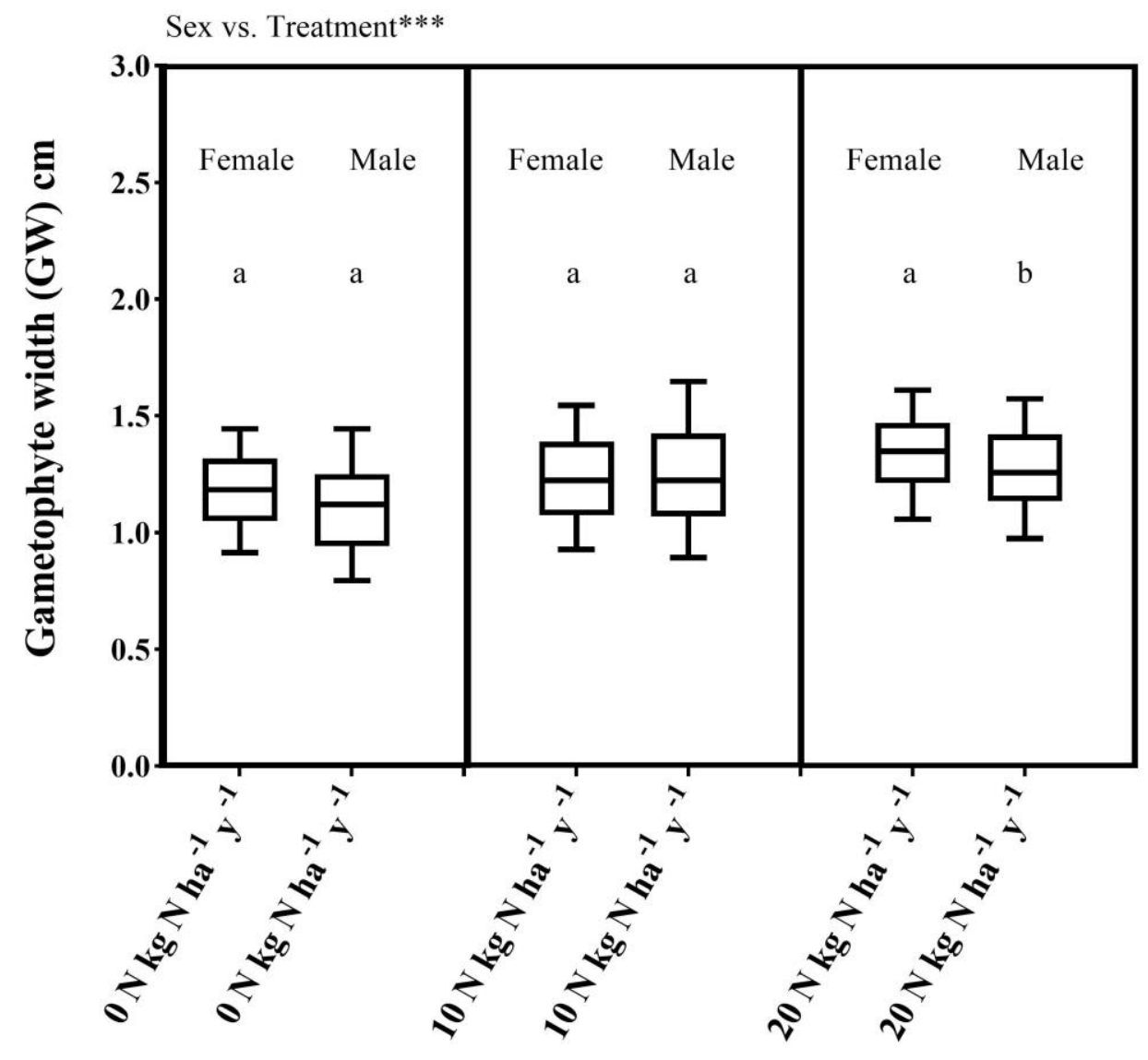


Figure 4.8 Reproductive effort versus sexual expression in P. juniperinum ( $\mathrm{n}=1440)$. Sexual expression is plotted on the X-axis. Tukey-Kramer HSD Multiple Comparisons Test shows areas of significant difference between total reproductive effort by sporophytes, splash cups, and non-sexual gametophytes. Error bars represent $\pm 1 \sigma$ (standard deviation). Letters show statistical significance between means. Means with the same letter are not significantly different. A * indicates significant difference, ** indicates a highly significant difference, $* * *$ indicates high statistical significance, NS indicates no significance.

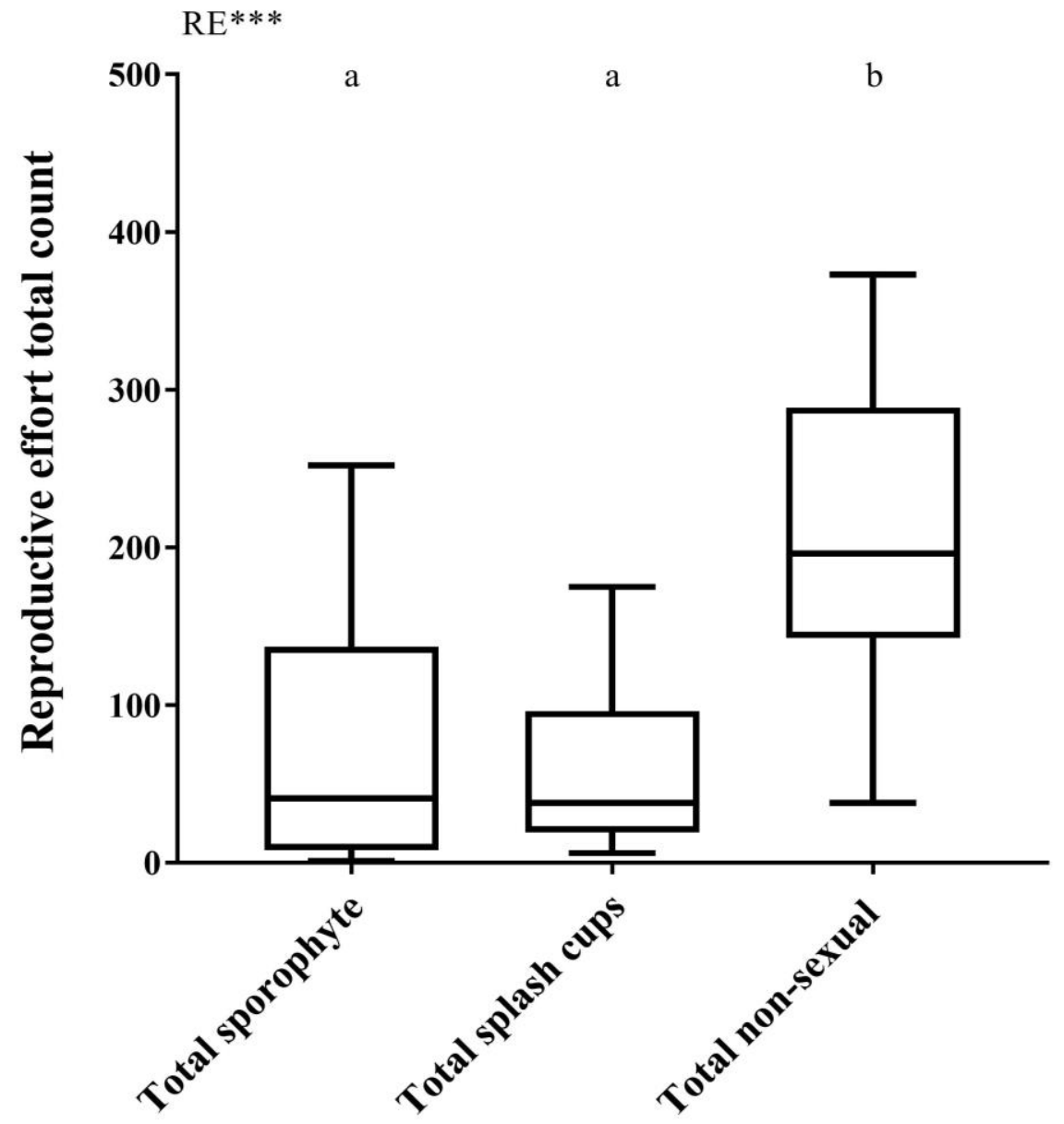


Figure 4.9 Isoprene emission $\left(\mathrm{nmol} \mathrm{m} \mathrm{m}^{-2} \mathrm{~s}^{-1}\right.$ ) in the winter of 2015 versus site-specific differences in $P$. juniperinum gametophytes $(\mathrm{n}=244)$. Site is plotted on the $\mathrm{x}$-axis. Tukey-Kramer HSD Multiple Comparisons Test shows areas of significant difference between avg. isoprene emission and site. Error bars represent $\pm 1 \sigma$ (standard deviation). Letters show statistical significance between means. Means with the same letter are not significantly different. A * indicates significant difference, $* *$ indicates a highly significant difference, $* * *$ indicates high statistical significance, NS indicates no significance.

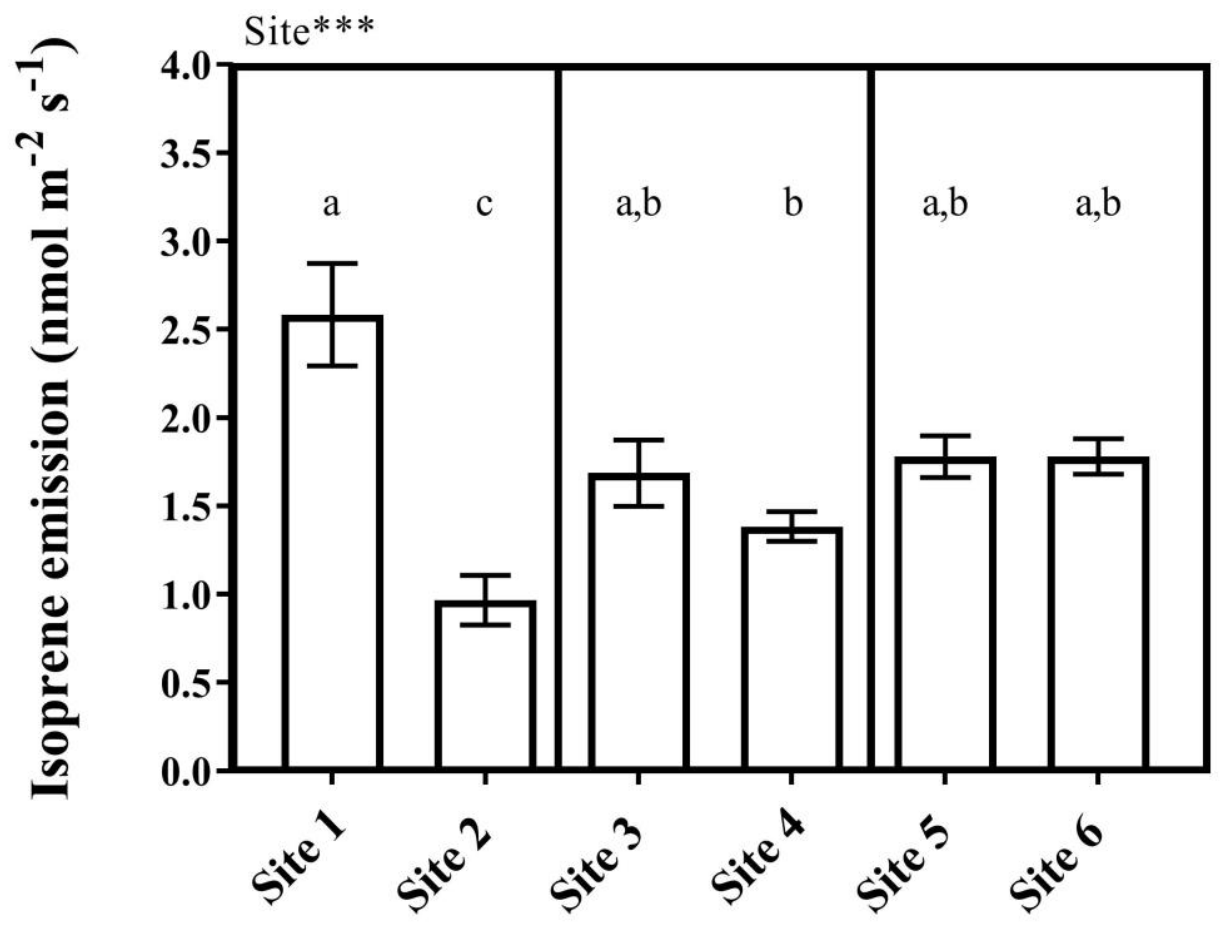




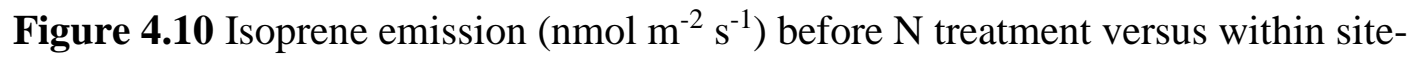
specific differences in $P$. juniperinum gametophytes $(n=244)$. Site is plotted on the $\mathrm{x}-$ axis. Error bars represent $\pm 1 \sigma$ (standard deviation). A * indicates significant difference, ** indicates a highly significant difference, $* * *$ indicates high statistical significance, NS indicates no significance.

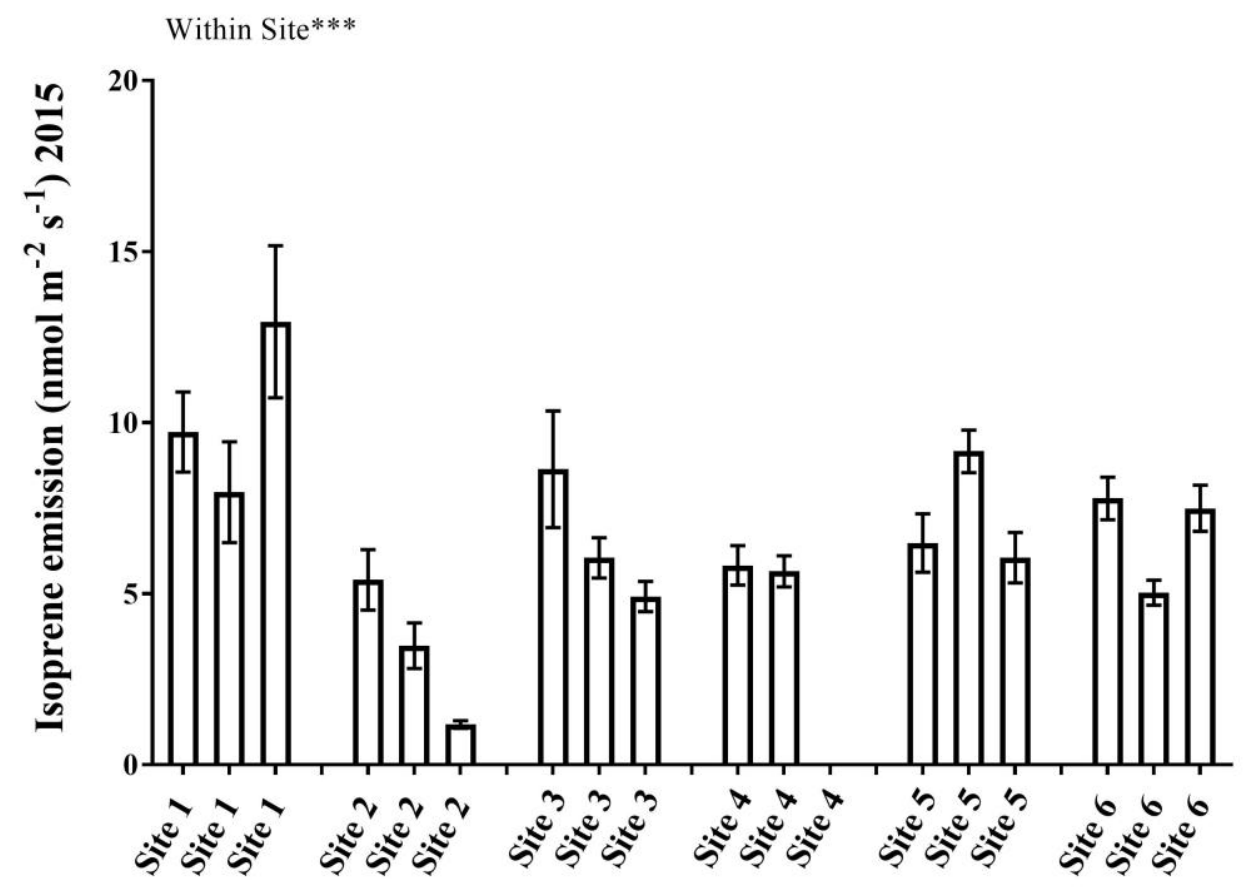


Figure 4.11 Isoprene emission $\left(\mathrm{nmol} \mathrm{m} \mathrm{m}^{-2} \mathrm{~s}^{-1}\right)$ before $\mathrm{N}$ treatment versus sex in $P$. juniperinum gametophytes $(\mathrm{n}=244)$. Sex is plotted on the $\mathrm{x}$-axis. Error bars represent $\pm 1 \sigma$ (standard deviation). Letters show statistical significance between means. Means with the same letter are not significantly different. A * indicates significant difference, ** indicates a highly significant difference, $* * *$ indicates high statistical significance, NS indicates no significance.

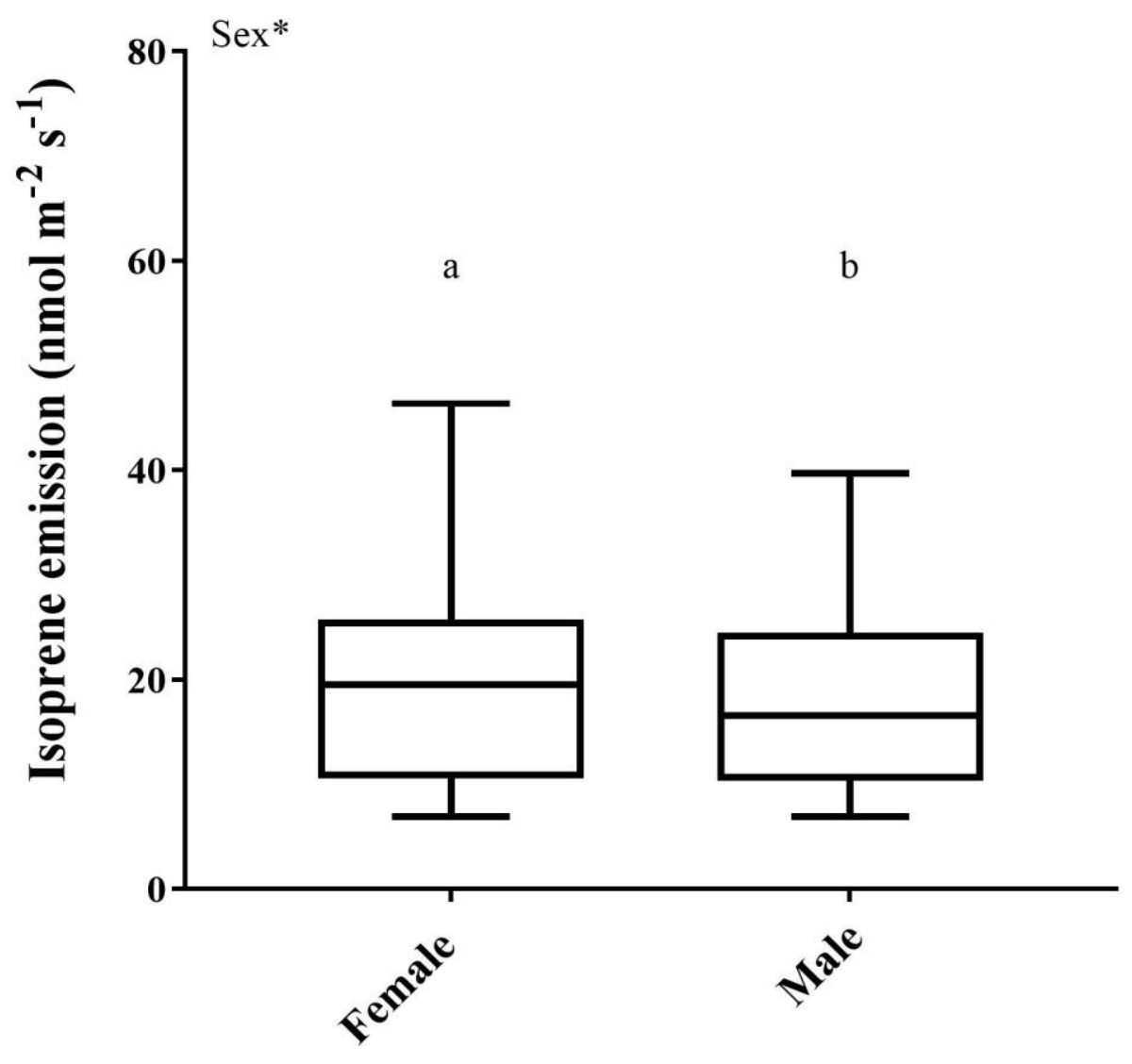


Figure 4.12 Isoprene emission $\left(\mathrm{nmol} \mathrm{m} \mathrm{m}^{-2} \mathrm{~s}^{-1}\right)$ after $\mathrm{N}$ treatment versus site-specific differences in $P$. juniperinum gametophytes $(n=244)$. Site is plotted on the $\mathrm{x}$-axis. TukeyKramer HSD Multiple Comparisons Test shows areas of significant difference between avg. isoprene emission and sites (1-6). Error bars represent $\pm 1 \sigma$ (standard deviation). Letters show statistical significance between means. Means with the same letter are not significantly different. A * indicates significant difference, $* *$ indicates a highly significant difference, $* * *$ indicates high statistical significance, NS indicates no significance.

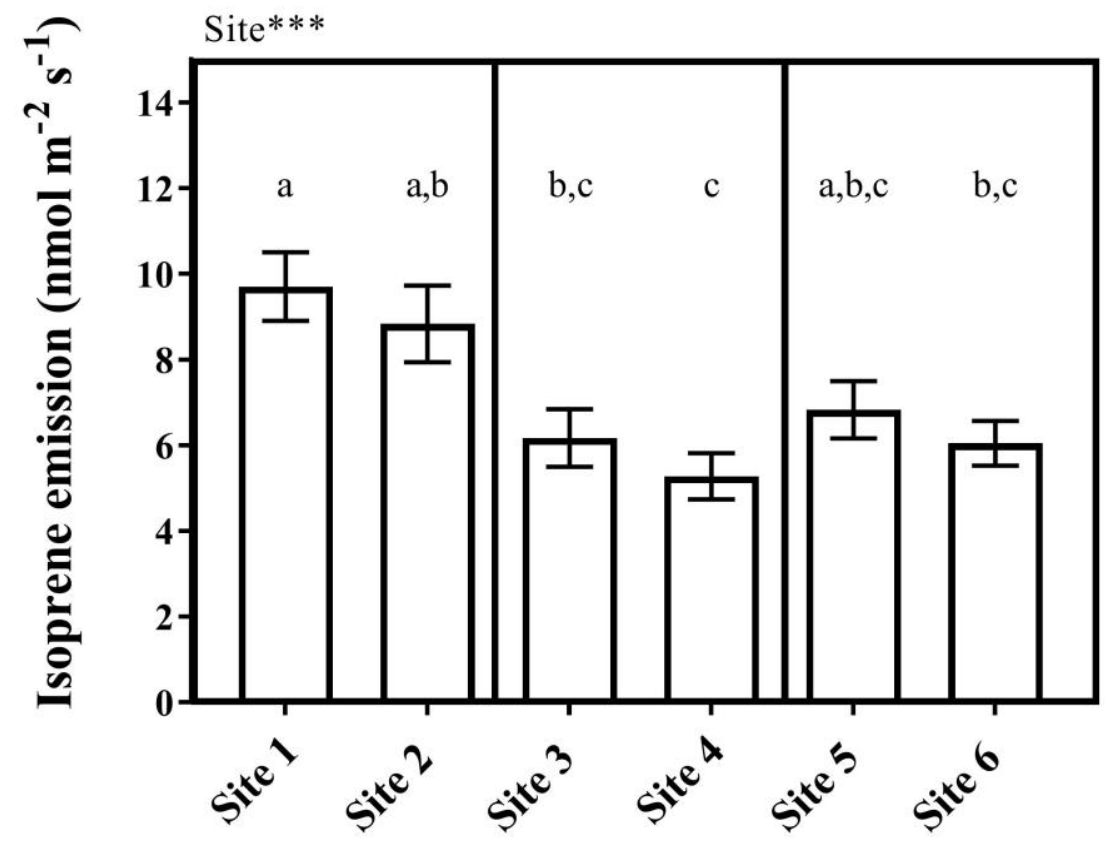


Figure 4.13 Isoprene emission $\left(\mathrm{nmol} \mathrm{m} \mathrm{m}^{-2} \mathrm{~s}^{-1}\right)$ after $\mathrm{N}$ treatment versus within site-specific differences in $P$. juniperinum gametophytes $(\mathrm{n}=244)$. Site is plotted on the $\mathrm{x}$-axis. Error bars represent $\pm 1 \sigma$ (standard deviation). A * indicates significant difference, $* *$ indicates a highly significant difference, $* * *$ indicates high statistical significance, NS indicates no significance.

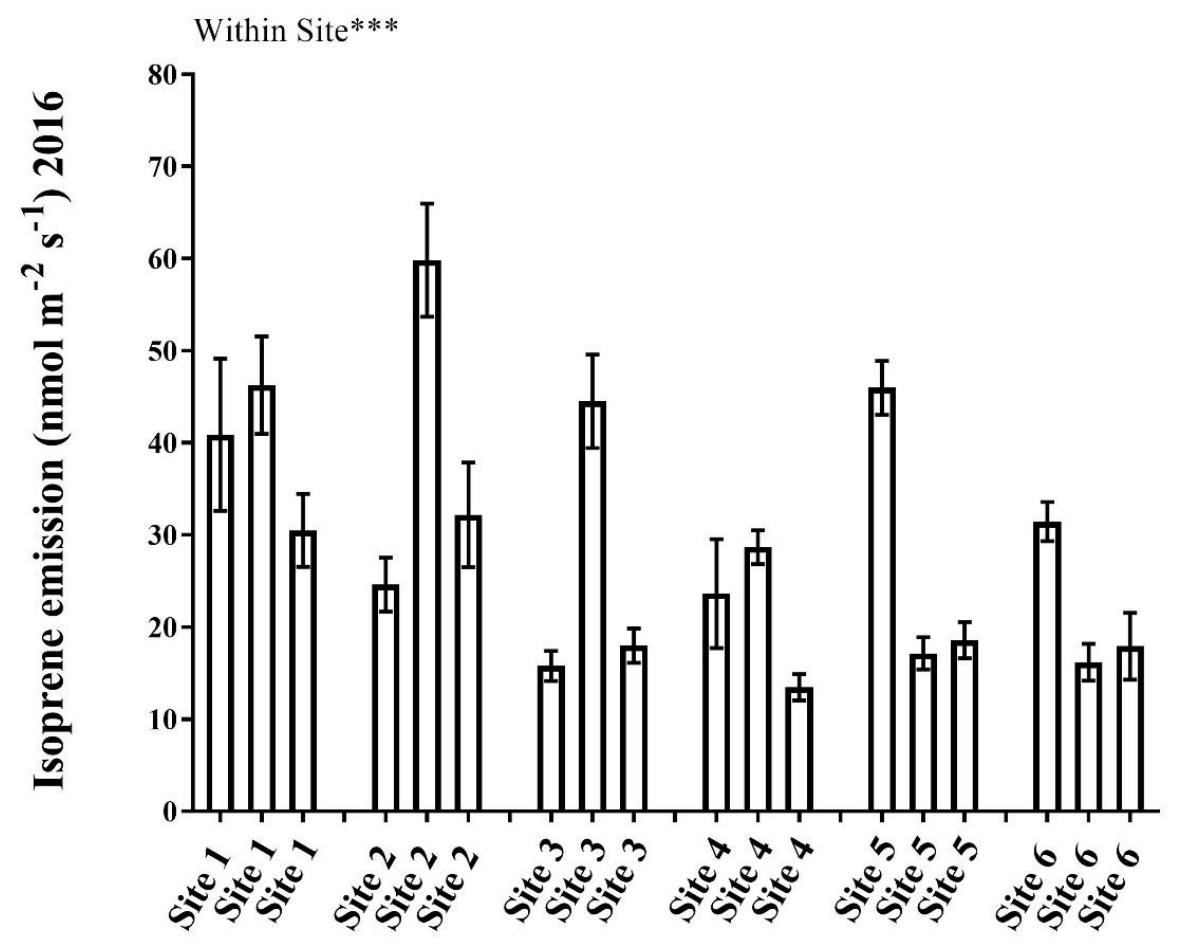


Figure 4.14 Isoprene emission $\left(\mathrm{nmol} \mathrm{m} \mathrm{m}^{-2} \mathrm{~s}^{-1}\right)$ after $\mathrm{N}$ treatment versus sex in $P$. juniperinum gametophytes $(\mathrm{n}=244)$. Treatment is plotted on the $\mathrm{x}$-axis. Tukey-Kramer HSD Multiple Comparisons Test shows areas of significant difference between avg. isoprene emission vs. nitrogen treatment. Error bars represent $\pm 1 \sigma$ (standard deviation). Letters show statistical significance between means. Means with the same letter are not significantly different. A * indicates significant difference, $* *$ indicates a highly significant difference, $* * *$ indicates high statistical significance, NS indicates no significance.

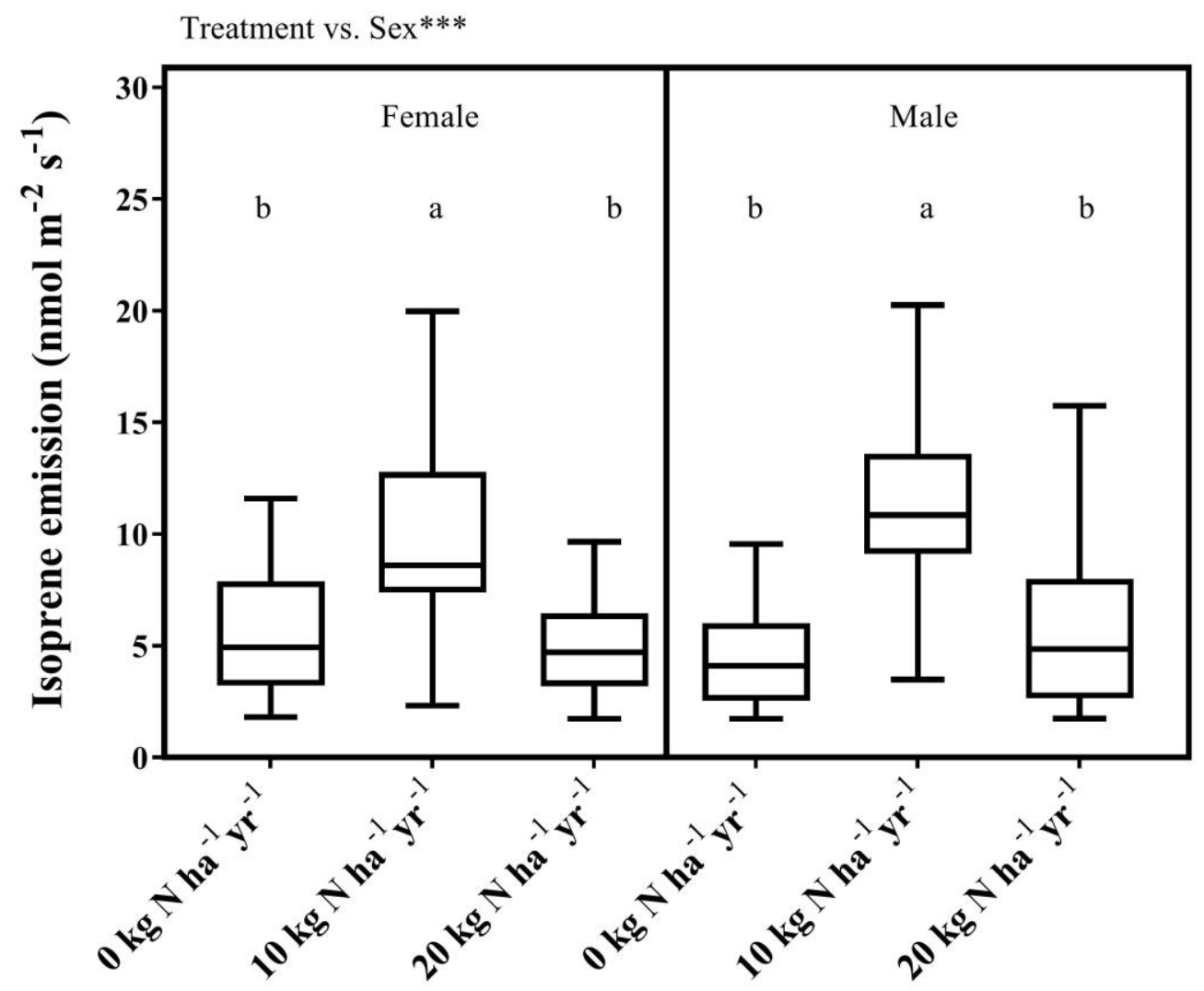


Figure 4.15 Isoprene emission $\left(\mathrm{nmol} \mathrm{m} \mathrm{m}^{-2} \mathrm{~s}^{-1}\right)$ versus nitrogen treatment in $P$. juniperinum gametophytes $(\mathrm{n}=244)$. Nitrogen addition is plotted on the $\mathrm{x}$-axis. Tukey-Kramer HSD Multiple Comparisons Test shows areas of significant difference between avg. isoprene emission vs. nitrogen treatment. Error bars represent $\pm 1 \sigma$ (standard deviation). Letters show statistical significance between means. Means with the same letter are not significantly different. A * indicates significant difference, ** indicates a highly significant difference, $* * *$ indicates high statistical significance, NS indicates no significance.

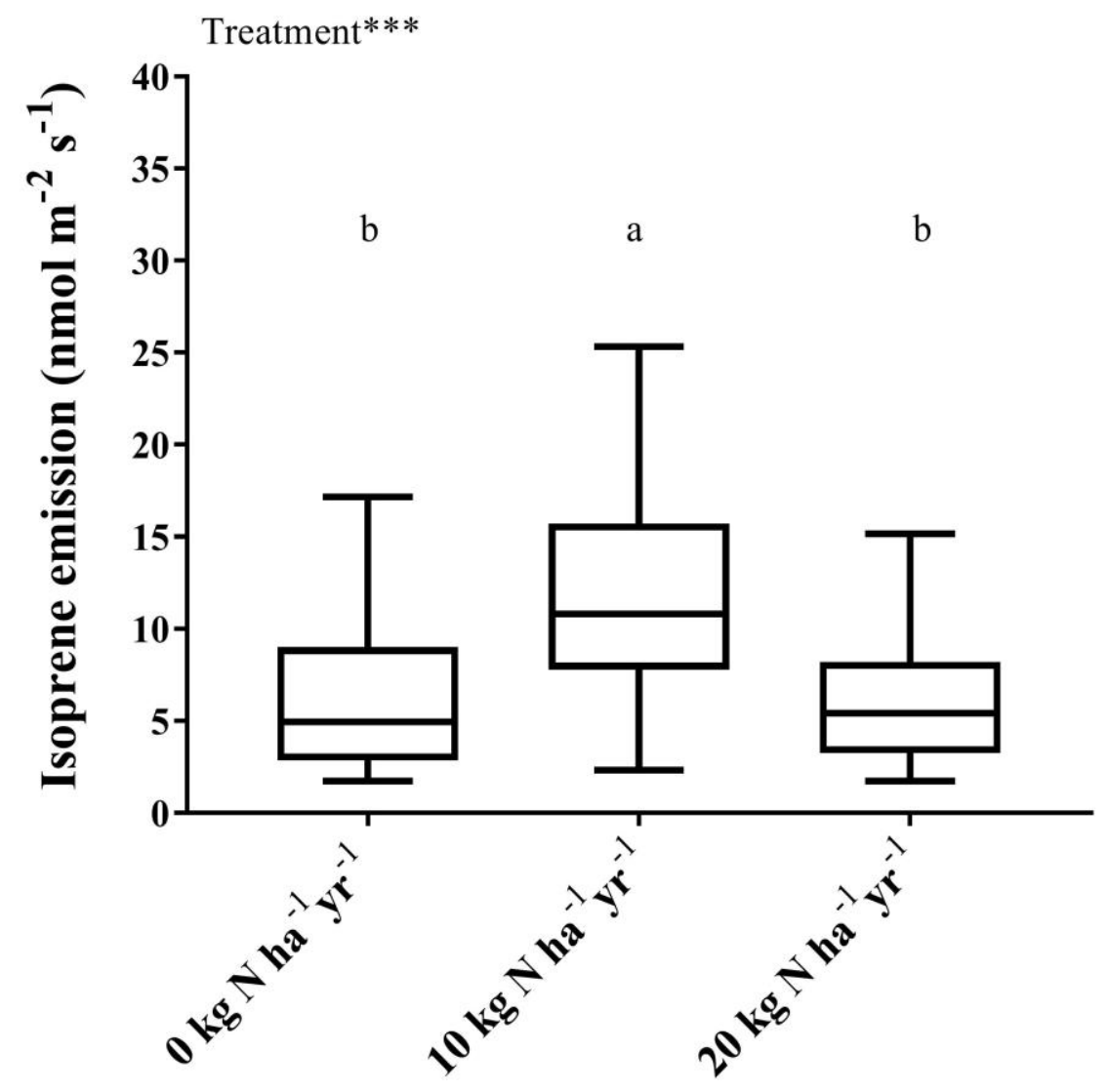


Figure 4.16 Chlorophyll Fluorescence Ratio (CFR) measures versus site in $P$. juniperinum gametophytes $(\mathrm{n}=244)$. Site is plotted on the $\mathrm{x}$-axis. Tukey-Kramer HSD Multiple Comparisons Test shows areas of significant difference between CFR vs. Site (1-6). Error bars represent $\pm 1 \sigma$ (standard deviation). Letters show statistical significance between means. Means with the same letter are not significantly different. A * indicates significant difference, $* *$ indicates a highly significant difference, $* * *$ indicates high statistical significance, NS indicates no significance.

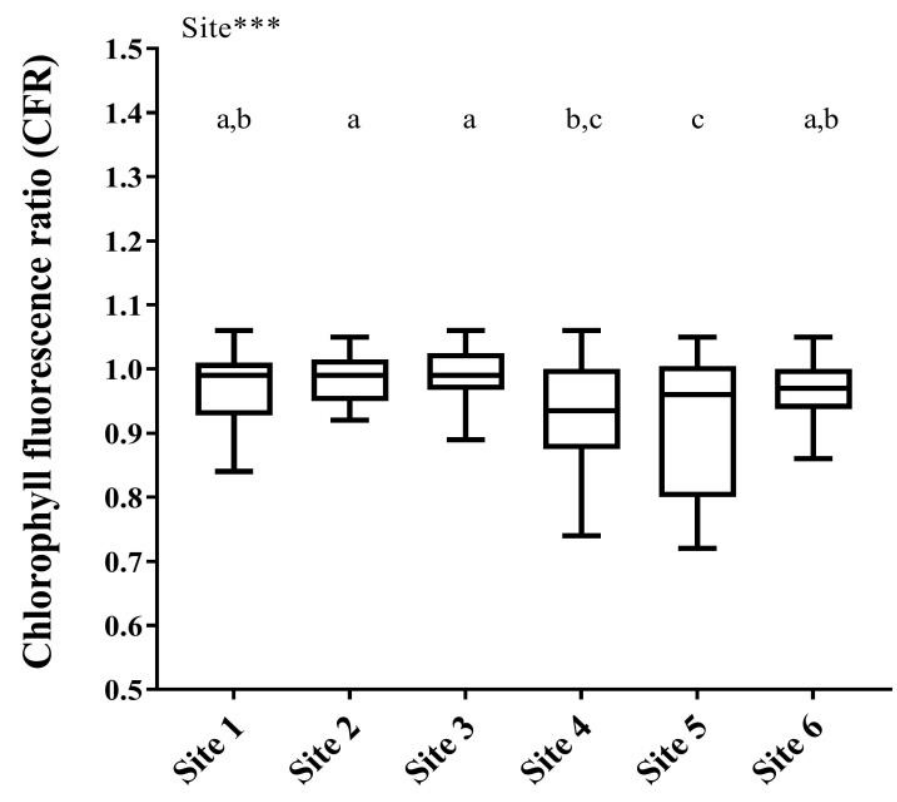


Figure 4.17 Chlorophyll Fluorescence Ratio (CFR) measures versus $\mathrm{N}$ treatment in $P$. juniperinum gametophytes $(\mathrm{n}=244)$. Nitrogen treatment is plotted on the $\mathrm{X}$-axis. TukeyKramer HSD Multiple Comparisons Test shows areas of significant difference between CFR vs. nitrogen treatment. Error bars represent $\pm 1 \sigma$ (standard deviation). Letters show statistical significance between means. Means with the same letter are not significantly different. A * indicates significant difference, ** indicates a highly significant difference, $* * *$ indicates high statistical significance, NS indicates no significance.

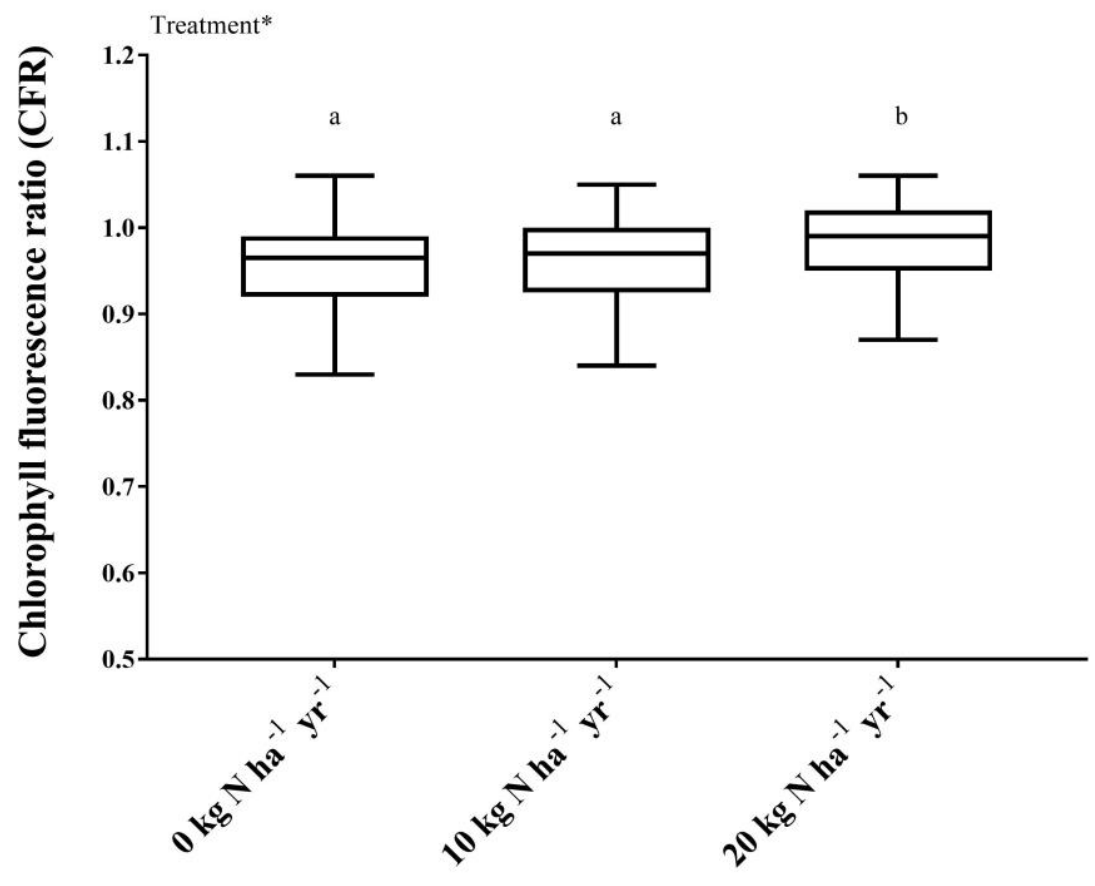




\section{Chapter 5}

\section{Conclusion}

We still do not understand the functional role of isoprene production and emission from vascular plants (Sharkey et al. 2017) or non-vascular plants. The ability to emit isoprene has been gained and lost multiple times during plant evolution (Sharkey et al. 2007, 2013; Fineschi et al. 2013; Monson et al. 2013; Dani et al. 2014; Loreto et al. 2015). Isoprene is the second most abundant BVOC in the atmosphere, and it represents one of the most important interactions between plants and the atmosphere (Monson et al. 1995; Sharkey et al. 1999; Niinemets et al. 2004; Peñuelas et al. 2010; Loreto et al. 2010; Guidolotti et al. 2019; Nagori et al. 2019; Li et al. 2019). Isoprene is the most abundant non-methane hydrocarbon in air near forests and has the greatest potential for transport from forest to urban areas (Khalil et al. 1992). In many ecosystems and even some urban areas, isoprene may dominate photochemical reactions in the atmospheric boundary layer (Chameides et al. 1988; Goldstein et al. 1998; Arneth et al. 2007; Park et al. 2011; Chang et al. 2014; Kota et al. 2015).

BVOC emission data are quite limited for non-vascular plants which do not possess structures such as stomatal pores, complex leaves, stems, or roots regulating water loss (Duckett et al. 2009; Ruszala et al. 2011; Chater et al. 2016). Since the signaling pathways for these emissions are present in both vascular plants and mosses (Cove et al. 2009), mosses make ideal systems to study the origin, diversification, and early function of isoprene emission. These often-overlooked early land plants might 
provide the crucial link to finally understand why plants in general produce and emit isoprene, partially because emission is more common in mosses than any other major land plant group (Hanson et al. 1999).

\section{Isoprene emission from Polytrichum juniperinum protonema}

In Chapter 2, we examined at what life stage mosses emit isoprene and at what cost. We have discovered that after spore germination, $P$. juniperinum is capable of isoprene emission in the protonema phase of its life cycle. We hypothesize that mosses are releasing isoprene as it is produced, and thus in their earliest life stages, as they do not possess guard cells or stomata in their gametophytic leaves (Woodward 1998; Raven 2002; Chater et al. 2011; Merced et al. 2013). Given mosses are rarely limited by nutrients (Bergamini et al. 2002), they must use direct uptake of dissolved nutrients from the atmosphere over their entire gametophytic leaf surface. Mosses gaseous exchange can be impacted by the slightest change in atmospheric humidity (Miyata et al. 1961). We suggest that mosses may always be in an opportunistic state, where emission and growth are tightly bound, and carbon gained from photosynthetic process is allocated to either growth or isoprene emission. Polytrichum species could lose water as reserves are deposited primarily within storage tissues in rhizoids, displacing water from the cells. With isoprene production, Polytrichum mosses could retain more of that water if through bioengineering the nearby atmospheric hydrological microenvironment.

We hypothesized that isoprene emission is fundamental to the emergence of life on land. The feedback mechanism that supplies BVOCs aerosols for cloud formation and 
precipitation helps to sustain the hydrological cycle in an ecosystem. Isoprene emission encourages cloud nuclei formation via isoprene/OH reduction to secondary organic aerosols (SOA), which in turn affects cloud droplet number (Claeys et al. 2004; Engelhart et al. 2011; Kerminen et al. 2012). Model simulations support this hypothesis, indicating that $100 \%$ of the observed changes in cloud properties can be attributed to isoprene secondary organic aerosols (SOA) (Pöschl et al. 2010). It is our suggestion that moss may employ a similar strategy throughout its lifecycle with an additional more direct water retention strategy when it reaches its adult gametophyte stage. Isoprene emission in both mature and protonemal moss is sensitive to both increased insolation and thermal stress. Both of these stress mechanisms have a direct effect on a plant's ability to maintain water levels, and both thermal and insolation changes can in theory be mitigated through isoprene emission leading to SOA water droplet nucleation particles.

The examination of isoprene (BVOCs) in the context of water strategies may shed significant light on the evolution of the earliest plants to colonize areal environments, with possible implications for our understanding of colonization strategies for all of Earth's plant life. Future work should address cost benefit analyses in isoprene emission and mosses as they are novel model system to test fundamental theories of ecological and ecosystem evolution. A better characterization of isoprene emissions from non-vascular plant species will be required, not just among the basal group of mosses, but also in later divergent species of mosses.

Additional work should distinguish genetic vs. environmental factors at work in the control of isoprene emission in mosses, and future work should focus on molecular 
work. A number of isoprene synthase enzymes have been characterized in vascular plants (Kuzma et al. 1993; Silver et al. 1991, 1995; Sharkey et al. 2005; Schnitzler et al. 2005). As of now, isoprene synthase enzyme has been characterized in only the heath star moss Campylopus introflexus (Lantz et al. 2015). This could pave the way for using mosses as a model system for understanding the evolution of isoprene in land plants that emit isoprene. It could also shed light of why not all plants emit isoprene and why there is such high variation in emission capability even within families that emit isoprene (Harley et al. 1999).

To further understand isoprene emission in protonema, the next step would be to suppress isoprene and assess the overall effect of mosses response to the loss of the ability to produce and emit isoprene. We have seen that protonema growth exhibited a negative correlation between isoprene emission and growth. It would be necessary to successfully suppress isoprene emission and evaluate growth. A study comparing isoprene emission and protonema mortality under various stress regimes would also be useful in elucidating the role of isoprene. A further step will be to utilize new methodology to suppress isoprene emission that will differ from vascular plant methods. No known literature exists on this subject, and it could provide useful and invaluable information to what is known in isoprene emission suppression in vascular plants (Niinemets et al. 1999; Sharkey et al. 2001; Grote et al, 2013).

\section{The role of isoprene emission in Polytrichaceae sexual systems}


In Chapter 3, we wanted to address the hypothesis that isoprene emission is related to the evolution of sexual systems in the mosses. Previous research in our lab has indicated that BVOCs can influence sexual strategies in mosses (Rosenstiel et al. 2012). Of particular interest to us was to understand how sex-specific isoprene emissions (both quantity and composition) change throughout the moss life cycle, and particularly during gametangia formation. We found that the highest isoprene emission was actually seen from non-sexually expressing gametophytes. Isoprene emission may confer benefits to species to negate the effects of selection pressure from loss of carbon and energy (Velikova et al. 2012).

These results suggest that the benefits associated with isoprene production may be too costly to maintain during periods of investment in reproductive structures. This would indicate that bulk isoprene emission does not play a role in sexual reproduction strategies other than to be shed and free up resources to invest in sexual organs. Bulk emission would seem to be involved in some non-sexual survival strategy. In Polytrichum mosses, male and female sexual organ formation does not occur synchronously (Watson 1974), and sexual reproduction is resource limited.

While sex has been investigated in these species independently from isoprene emission (Lloyd et al. 1977; Brown et al. 1990; Korpelainen et al. 1992, 1998; Rydgren et al. 2003; Stark et al. 2000, 2005, 2010), no one has invested in exploring isoprene emission and sexual expression in mosses. BVOCs taken together with sexual expression might explain some of the differences in sex and allocation of resources seen in Polytrichum species. Isoprene emission might suppress other chemical compounds that 
the moss emits, and since we categorized only one compound, it is necessary to run emission profiles for species within Polytrichaceae using analyses by gas chromatography-mass spectrometry (GC-MS). This could elucidate if a host of chemical compounds are suppressed while isoprene emission dominates. From non-isoprene emitting Ceratodon purpureus, we know that emission of over 281 chemical compounds are present, some that are analogous to floral volatiles (Rosenstiel et al. 2012). There is an interest in understanding if mosses that emit isoprene would have dissimilar chemical profiles and the evolutionary significance is between mosses that emit and mosses that do not emit isoprene. It is also evident, that large population of mosses contain non-sexually expressing gametophytes, of which there are no known chemical profiles. It seems that sex is costly in mosses (Stark et al. 2000), but not for isoprene emission in Polytrichaceae species.

\section{The effect of nitrogen addition on moss morphology, sexual reproduction, and isoprene production}

In Chapter 4, we tested the effects of nitrogen addition on moss morphology and physiology. In our experiment, we saw isoprene emission varied with season and site, and increased significantly with moderate increases in nitrogen. Also, treatment-specific differences were evident in morphology measurements. Polytrichum mosses are pioneer species and are highly adaptable across environments. In poor nitrogen conditions, low resource availability will limit growth of plants, and the allocated carbon could be used

for secondary compounds instead of growth (Bryant et al. 1983). There is a complicated 
and poorly understood interaction between isoprene emission and biomass accumulation in vascular plants (Hong et al. 2012), where trade-offs exist between carbon partitioning and biomass accumulation. Understanding the reasons for the increased isoprene emission we saw after nitrogen addition and the observed resource allocation will require a better understanding of the benefits of isoprene production versus growth. Studies are needed to examine the ontogenic patterns associated with isoprene emission in mosses. In vascular plants, the rates of emission are dependent on a host of environmental factors, and biotic interactions such as life stage, age, genotype, day length, temperature regimes, and water status (Harley et al. 1997; Hakola et al. 2003; Owen et al. 2002; Pio et al. 2005; Grabmer et al. 2006; Steinbrecher et al. 2009; Holopainen et al. 2010).

Future work in understanding the effect of nitrogen on isoprene emission in mosses should focus on allocation trade-offs as well as on biotic interactions. Further work could deconstruct the belowground morphological traits, such as rhizoidal biomass, nitrogen in soil and nitrogen within moss tissue both above and belowground to determine their effects on isoprene emissions. It has been shown that trait variation and inter-population differences must have a genetic basis and are associated with metabolic tradeoffs (Hedderson et al. 2009). Additionally, research has found that bacterial and fungal taxa are involved in degrading isoprene in vascular plant systems. Vascular plants emit isoprene that is deposited on their surfaces and in surrounding soil; microbial communities subsequently degrade isoprene on vascular plant leaves and in nearby soils (Rasmussen 1970; Cleveland et al. 1998; Fall et al. 2000; Gray et al 2005; Holopainen et al. 2013, 2017; El Khawand et al. 2016; Johnston et al. 2017; Crombie et al. 2019). 
Further work is required to assess if this holds true for non-vascular plants. Assessment must be made to estimate the number of bacterial and fungal taxa that can degrade isoprene in the soil or on the leaves of mosses. These interactions could regulate soil communities and affect chemical ecology both above and belowground. Isoprene emission and surface adsorption may play an additional role in water regulation by making the surface of the plants emitting isoprene and the surrounding soil much more hydrophilic than it otherwise would be. This would aid in amelioration of both water and heat stress through reducing the internal/external moisture gradient to zero while providing water for evaporation buffering against rapid thermal changes.

Another biotic interaction that might influence isoprene emission in mosses is herbivory. Isoprene has been shown to mediate plant-herbivore interaction in vascular plants (Laothawornkitkul et al. 2008). Whether isoprene emission deters or attracts herbivores in mosses is yet to be seen, as it has not been investigated before. In $P$. juniperinum, we have documented for the first time the destructive eating habits of the invasive generalist herbivore Noctua pronuba. Although mosses appear to have an extensive arsenal of chemical defenses, bryophyte herbivory by invertebrates is remarkably poorly characterized, creating a fundamental gap in our basic understanding of plant-animal interactions and the ecology of Earth's earliest terrestrial plants. In our preliminary data collection, we have found $N$. pronuba larvae fed on both grass and moss tissue, however survival rates were highest for $N$. pronuba larvae feeding on the grass Poа апnиa. Relative growth rate of the larvae was significantly influenced by food choice, and its attendant $\mathrm{C}: \mathrm{N}$ ratio. Despite our relatively poor understanding of the role 
of herbivory in bryophyte ecology, we found that mosses may be an important alternative food source for Noctua pronuba larvae, although strong moss species-specific effects may influence this plant-animal interaction. Allocation to resources such as isoprene may come at the expense of reproduction affecting optimal growth, fitness and chemical composition of other BVOCs within Polytrichum species. Future studies should focus on allocation of resources in ontogeny between different life stages and tissue type, above or belowground sources and sinks and nutrient demands between seasons and climates. In order to address isoprene emission and understand its multiple ecological functions and evolutionary implications, mosses provide the ideal study system and should be assessed as a model that may eventually be applied to both vascular and non-vascular plants.

Our research testing the effects of nitrogen addition on mosses is timely and imperative as we measured isoprene emission increases in moss plants with nitrogen addition. Further, we found that isoprene emissions increased strongly with temperature, and we saw species level variation, which could feed into functional type modeling. Isoprene emission is expected to increase at a global level because of increased climate warming (Feng et al. 2019; Guidolotti et al. 2019). Mosses must be accounted for in climate modeling, as they take up 350 million hectares on land in 175 countries (Harenda et al. 2018). One of the primary mosses to occupy these areas is Polytrichum species, a high isoprene emitter among mosses, and the focus of this research. We must consider what we know about general model predictions of global average temperatures increase by $2-9^{\circ} \mathrm{C}$ by the end of the $21^{\text {st }}$ century, and an increase in nitrogen from anthropogenic sources, which now surpass a 4-fold increase of nitrogen available to organisms 
(Christensen et al. 2007; Erwin 2009). Future work should focus on understanding how isoprene emission from mosses influences climate change.

Both temperature and nitrogen deposition will influence the carbon/nitrogen ratio of leaf tissue in mosses, and we must consider the species level response to these changes. As nitrogen deposition increases and global temperatures rise, an increase in higher percentage of photosynthetically fixed carbon may be utilized as isoprene from Polytrichum species altering the total ecosystem budget of carbon and nitrogen, which up to now has been largely overlooked. We do not understand how these changes will affect increased isoprene emission from mosses.

Carbon allocation could be used to supply primary processes such as growth either below or aboveground, translocation to growth of fungal or microbial populations, reproduction or as storage in the rhizoidal mat. If mosses are such great ecosystem engineers and they are translocating nutrients, recycling resources out of the atmosphere to include water and regulating flow of carbon and nitrogen, these mosses clonal integration provide several potential benefits to all ecosystems and as such this places them at the forefront of understanding why some plants emit isoprene and others do not.

Future work should focus on analyzing leaf tissue nitrogen, rhizoidal mat nitrogen content and soil nitrogen content as mosses can retain nitrogen anywhere from three to ten years in their biomass (Eckstein 2000; Du et al. 2014). This will be greatly affected by an increase in temperature and increase in nitrogen deposition at the species level, and a more thorough evaluation needs to be carried out. This would be especially important to assess as mosses are important elements in forest carbon and nitrogen cycling because 
they can utilize and access nitrogen from the atmosphere, their rhizoidal mat and soil. We conclude that some mosses will be at higher risk from global warming and nitrogen deposition at the species level. Mosses that emit isoprene might have an advantage and must be further investigated as the wider consequences of isoprene emission from mosses remain to be understood. This work highlights the importance of understanding how mosses shape local and global climate at a species level under enhanced temperature and nitrogen we can expect isoprene emission to increase from non-vascular plants. 


\section{References}

Aber, John D., et al. "Is nitrogen deposition altering the nitrogen status of northeastern forests?" AIBS Bulletin 53.4 (2003): 375-389.

Allison, Steven D., Matthew D. Wallenstein, and Mark A. Bradford. "Soil-carbon response to warming dependent on microbial physiology." Nature Geoscience 3.5 (2010): 336.

Alpert, Peter. "The discovery, scope, and puzzle of desiccation tolerance in plants." Plant Ecology 151.1 (2000): 5-17.

Alves, Eliane Gomes, et al. "Effects of light and temperature on isoprene emission at different leaf developmental stages of Eschweilera coriacea in central Amazon." Acta Amazonica 44.1 (2014): 9-18.

Andrew, N. R., Louise Rodgerson, and Michael Dunlop. "Variation in invertebratebryophyte community structure at different spatial scales along altitudinal gradients." Journal of Biogeography 30.5 (2003): 731-746.

Aneja, Viney P., et al. "Atmospheric nitrogen compounds II: emissions, transport, transformation, deposition and assessment." Atmospheric Environment 35.11 (2001): 1903-1911.

Arneth, Almut, et al. "CO2 inhibition of global terrestrial isoprene emissions: Potential implications for atmospheric chemistry." Geophysical Research Letters 34.18 (2007).

Arróniz-Crespo, María, et al. "Bryophyte physiological responses to, and recovery from, long-term nitrogen deposition and phosphorus fertilisation in acidic grassland." New Phytologist 180.4 (2008): 864-874.

Asakawa, Yoshinori. "Biologically active substances obtained from bryophytes." Journal of the Hattori Botanical Laboratory 50 (1981): p123-142.

Asakawa, Y. "Chemical constituents of the bryophytes." Progress in the chemistry of organic natural products. Springer, Vienna, 1995. 1-562.

Asakawa, Yoshinori. "Biologically active compounds from bryophytes." Pure and Applied Chemistry 79.4 (2007): 557-580.

Asakawa, Yoshinori. "Bryophytes: chemical diversity, synthesis and biotechnology. A review." Flavour and fragrance journal 26.5 (2011): 318-320. 
Ashworth, Kirsti, et al. "Global modeling of volatile organic compound emissions." Biology, controls and models of tree volatile organic compound emissions. Springer, Dordrecht, 2013. 451-487.

Asman, Willem AH, Mark A. Sutton, and Jan K. SchjØrring. "Ammonia: emission, atmospheric transport and deposition." The New Phytologist 139.1 (1998): 27-48.

Atkinson, Roger, and Janet Arey. "Atmospheric degradation of volatile organic compounds." Chemical reviews 103.12 (2003): 4605-4638.

Ayres, Edward, et al. "Direct uptake of soil nitrogen by mosses." Biology Letters 2.2 (2006): 286-288.

Baker, A. R., et al. "Distribution and sea-air fluxes of biogenic trace gases in the eastern Atlantic Ocean." Global Biogeochemical Cycles 14.3 (2000): 871-886.

Bakken, Solveig. "Effects of nitrogen supply and irradiance on growth and nitrogen status in the moss Dicranum majus from differently polluted areas." Journal of Bryology 18.4 (1995): 707-721.

Bala, Govindasamy, et al. "Combined climate and carbon-cycle effects of large-scale deforestation." Proceedings of the National Academy of Sciences 104.16 (2007): 6550-6555.

Balkan, Mehmet Ali. "Sex-specific fungal communities of the dioicous moss Ceratodon purpureus." (2016).

Bamberger, Ines, et al. "Isoprene emission and photosynthesis during heatwaves and drought in black locust." Biogeosciences 14.15 (2017): 3649-3667.

Barsig, Michael, Kathrin Schneider, and Carola Gehrke. "Effects of UV-B radiation on fine structure, carbohydrates, and pigments in Polytrichum commune." Bryologist (1998): 357-365.

Barton, Derek. Comprehensive natural products chemistry. Newnes, 1999.

Basile, Adriana, et al. "Antibacterial activity of pure flavonoids isolated from mosses." Phytochemistry 52.8 (1999): 1479-1482.

Bates, J. W. "The relationship between physiological vitality and age in shoot segments of Pleurozium schreberi (Brid.) Mitt." Journal of Bryology 10.3 (1979): 339-351.

Bauwens, Maite, et al. "Recent past (19792014) and future (20702099) isoprene fluxes 
over Europe simulated with the MEGANMOHYCAN model." Biogeosciences 15 (2018): 3673-3690.

Bayfield, Neil G. "Notes on water relations of Polytrichum commune Hedw." Journal of Bryology 7.4 (1973): 607-617.

Bazzaz, F. A., Dominick J. Paolillo Jr, and R. H. Jagels. "Photosynthesis and respiration of forest and alpine populations of Polytrichum juniperinum." Bryologist (1970): 579-585.

Becker Scarpitta, Antoine, et al. "Long-term community change: bryophytes are more responsive than vascular plants to nitrogen deposition and warming." Journal of Vegetation Science 28.6 (2017): 1220-1229.

Beer, Sven, et al. "Photosynthetic rates of Ulva (Chlorophyta) measured by pulse amplitude modulated (PAM) fluorometry." European Journal of Phycology 35.1 (2000): 69-74.

Behnke, Katja, et al. "Transgenic, non-isoprene emitting poplars don't like it hot." The Plant Journal 51.3 (2007): 485-499.

Behnke, Katja, et al. "RNAi-mediated suppression of isoprene biosynthesis in hybrid poplar impacts ozone tolerance." Tree physiology (2009): 009.

Behnke, Katja, et al. "Isoprene emission-free poplars-a chance to reduce the impact from poplar Plantations on the atmosphere." New Phytologist 194.1 (2012): 70-82.

Bell, S., T. W. Ashenden, and C. R. Rafarel. "Effects of rural roadside levels of nitrogen dioxide on Polytrichum formosum Hedw." Environmental pollution 76.1 (1992): 11-14.

Bell, Michelle L., Benjamin F. Hobbs, and Hugh Ellis. "The use of multi-criteria decision-making methods in the integrated assessment of climate change: implications for IA practitioners." Socio-Economic planning sciences 37.4 (2003): 289-316.

Bell, Michelle L., et al. "Climate change, ambient ozone, and health in 50 US cities." Climatic Change 82.1-2 (2007): 61-76.

Bell, Neil E., and Jaakko Hyvönen. "A phylogenetic circumscription of Polytrichastrum (Polytrichaceae): reassessment of sporophyte morphology supports molecular phylogeny." American journal of botany 97.4 (2010a): 566-578.

Bell, Neil E., and Jaakko Hyvönen. "Phylogeny of the moss class Polytrichopsida 
(Bryophyta): generic-level structure and incongruent gene trees." Molecular phylogenetics and evolution 55.2 (2010b): 381-398.

Benedict, Katherine B., et al. "Impact of Front Range sources on reactive nitrogen concentrations and deposition in Rocky Mountain National Park." PeerJ 6 (2018): 4759.

Biesenthal, T. A., et al. "A study of relationships between isoprene, its oxidation products, and ozone, in the Lower Fraser Valley, BC." Atmospheric Environment 31.14 (1997): 2049-2058.

Bilger, Wolfgang, Ulrich Schreiber, and Michael Bock. "Determination of the quantum efficiency of photosystem II and of non-photochemical quenching of chlorophyll fluorescence in the field." Oecologia 102.4 (1995): 425-432.

Bippus, Alexander C., Ignacio E. Escapa, and Alexandru MF Tomescu. "Wanted dead or alive (probably dead): Stem group Polytrichaceae." American journal of botany 105.8 (2018): 1243-1263.

Bisang, Irene, Johan Ehrlén, and Lars Hedenäs. "Mate limited reproductive success in two dioicous mosses." Oikos 104.2 (2004): 291-298.

Bisang, Irene, Johan Ehrlén, and Lars Hedenäs. "Reproductive effort and costs of reproduction do not explain female-biased sex ratios in the moss Pseudocalliergon trifarium (Amblystegiaceae)." American journal of botany 93.9 (2006): 1313-1319.

Bisang, Irene, Lars Hedenäs, and Nils Cronberg. "Can the meiotic sex ratio explain the sex ratio bias in adult populations in the dioicous moss Drepanocladus lycopodioides?." Journal of Bryology 39.2 (2017): 115-120

Bison, Josiane Valéria, et al. "Volatile organic compounds and nitric oxide as responses of a Brazilian tropical species to ozone: the emission profile of young and mature leaves." Environmental Science and Pollution Research 25.4 (2018): 3840-3848.

Bobbink, Roland, et al. "Global assessment of nitrogen deposition effects on terrestrial plant diversity: a synthesis." Ecological applications 20.1 (2010): 30-59.

Bogdziewicz, Michał, et al. "Effects of nitrogen deposition on reproduction in a masting tree: benefits of higher seed production are trumped by negative biotic interactions." Journal of Ecology 105.2 (2017): 310-320.

Bonan, Gordon B., et al. "Improving canopy processes in the Community Land Model 
version 4 (CLM4) using global flux fields empirically inferred from FLUXNET data." Journal of Geophysical Research: Biogeosciences 116.G2 (2011).

Bonsang, Bernard, Claude Polle, and Gérard Lambert. "Evidence for marine production of isoprene." Geophysical Research Letters 19.11 (1992): 1129-1132.

Bonsang, B., et al. "Isoprene emission from phytoplankton monocultures: the relationship with chlorophyll-a, cell volume and carbon content." Environmental Chemistry 7.6 (2010): 554-563.

Bowden, Richard D. "Inputs, outputs, and accumulation of nitrogen in an early successional moss (Polytrichum) ecosystem." Ecological Monographs 61.2 (1991): 207-223.

Bowen, Esther J. "Water conduction in Polytrichum commune." Annals of Botany 45.177 (1931): 175-200.

Bowker, Matthew A., et al. "Sex expression, skewed sex ratios, and microhabitat distribution in the dioecious desert moss Syntrichia caninervis (Pottiaceae)." American Journal of Botany 87.4 (2000): 517-526.

Bragazza, Luca, et al. "Atmospheric nitrogen deposition promotes carbon loss from peat bogs." Proceedings of the National Academy of Sciences 103.51 (2006): 1938619389.

Bragazza, Luca, et al. "Nitrogen concentration and $\delta 15 \mathrm{~N}$ signature of ombrotrophic Sphagnum mosses at different $\mathrm{N}$ deposition levels in Europe." Global Change Biology 11.1 (2005): 106-114.

Brodie, Harold J. "The splash-cup dispersal mechanism in plants." Canadian Journal of Botany 29.3 (1951): 224-234.

Brilli, Federico, et al. "Response of isoprene emission and carbon metabolism to drought in white poplar (Populus alba) saplings." New Phytologist 175.2 (2007): 244-254.

Brilli, Federico, et al. "Constitutive and herbivore-induced monoterpenes emitted by Populus $\times$ euroamericana leaves are key volatiles that orient Chrysomela populi beetles." Plant, cell \& environment 32.5 (2009): 542-552.

Broadgate, W. J., et al. "Isoprene and other non-methane hydrocarbons from seaweeds: a source of reactive hydrocarbons to the atmosphere." Marine Chemistry 88.1-2 (2004): 61-73.

Brown, Dennis H., and Jeffrey W. Bates. "Bryophytes and nutrient cycling." Botanical 
Journal of the Linnean Society 104.1-3 (1990): 129-147.

Bryant, John P., F. Stuart Chapin III, and David R. Klein. "Carbon/nutrient balance of boreal plants in relation to vertebrate herbivory." Oikos (1983): 357-368.

Budke, Jessica M., Bernard Goffinet, and Cynthia S. Jones. "The cuticle on the gametophyte calyptra matures before the sporophyte cuticle in the moss Funaria hygrometrica (Funariaceae)." American Journal of Botany 99.1 (2012): 14-22.

Budke, Jessica M., Bernard Goffinet, and Cynthia S. Jones. "Dehydration protection provided by a maternal cuticle improves offspring fitness in the moss Funaria hygrometrica." Annals of botany 111.5 (2013): 781-789.

Busby, J. R., and D. W. A. Whitfield. "Water potential, water content, and net assimilation of some boreal forest mosses." Canadian Journal of Botany 56.13 (1978): 1551-1558.

Burt, Austin. "Perspective: sex, recombination, and the efficacy of selection-was Weismann right?." Evolution 54.2 (2000): 337-351

Cai, Xuyi, and Robert J. Griffin. "Secondary aerosol formation from the oxidation of biogenic hydrocarbons by chlorine atoms." Journal of Geophysical Research: Atmospheres 111.D14 (2006).

Calfapietra, C., et al. "Role of Biogenic Volatile Organic Compounds (BVOC) emitted by urban trees on ozone concentration in cities: A review." Environmental pollution 183 (2013): 71-80.

Callaghan, T. V., N. J. Collins, and C. H. Callaghan. "Photosynthesis, growth and reproduction of Hylocomium splendens and Polytrichum commune in Swedish Lapland. Strategies of growth and population dynamics of tundra plants 4." Oikos (1978): 73-88.

Callaghan, T. V., et al. "Between-year variation in climate-related growth of circumarctic populations of the moss Hylocomium splendens." Functional Ecology 11.2 (1997): 157-165.

Calvo-Fernández, Javier, et al. "Time-and age-related effects of experimentally simulated nitrogen deposition on the functioning of montane heathland ecosystems." Science of the Total Environment 613 (2018): 149-159.

Cape, J. N., et al. "Organic nitrogen in precipitation across the United Kingdom." Water, Air, \& Soil Pollution: Focus 4.6 (2004): 25-35. 
Carballeira, C., et al. "Biomonitoring freshwater FISH farms by measuring nitrogen concentrations and the $\delta 15 \mathrm{~N}$ signal in living and devitalized moss transplants." Environmental Pollution (2018).

Carlton, A. G., Christine Wiedinmyer, and J. H. Kroll. "A review of Secondary Organic Aerosol (SOA) formation from isoprene." Atmospheric Chemistry and Physics 9.14 (2009): 4987-5005.

Carslaw, David C. "Evidence of an increasing NO2/NOx emissions ratio from road traffic emissions." Atmospheric Environment 39.26 (2005): 4793-4802.

Case, Andrea L., and Tia-Lynn Ashman. "Resources and pollinators contribute to population sex-ratio bias and pollen limitation in Fragaria virginiana (Rosaceae)." Oikos 118.8 (2009): 1250-1260.

Centritto, M., et al. "Profiles of isoprene emission and photosynthetic parameters in hybrid poplars exposed to free-air CO2 enrichment." Plant, Cell \& Environment 27.4 (2004): 403-412.

Centritto, Mauro, et al. "Different sensitivity of isoprene emission, respiration and photosynthesis to high growth temperature coupled with drought stress in black poplar (Populus nigra) saplings." Tree physiology 31.3 (2011): 275-286.

Chaban CI, Ripetskyj RT, Kordyum EL, Kit NA. High temperature alters the growth reaction of Pottia Protonemata. Adv Space Res. 1999; 23 (12): 2011-2016.

Chaichan, Miqdam T., and Qahtan A. Abass. "Study of NOx emissions of SI engine fueled with different kinds of hydrocarbon fuels and hydrogen." Al-Khwarizmi Engineering Journal 6.2 (2018): 11-20.

Chameides, W. L., et al. "The role of biogenic hydrocarbons in urban photochemical smog: Atlanta as a case study." Science 241.4872 (1988): 1473-1475

Chater, Caspar, et al. "Regulatory mechanism controlling stomatal behavior conserved across 400 million years of land plant evolution." Current Biology 21.12 (2011): 1025-1029.

Chávez, Abel, et al. "Understanding, Implementing, and Tracking Urban Metabolism Is Key to Urban Futures." The Urban Planet: Knowledge Towards Sustainable Cities (2018): 68.

Chen, Feng, et al. "Terpenoid secondary metabolites in bryophytes: chemical diversity, biosynthesis and biological functions." Critical Reviews in Plant Sciences (2018): $1-22$. 
Chidawanyika, Frank, et al. "Oviposition acceptance and larval development of Chilo partellus stemborers in drought-stressed wild and cultivated grasses of East Africa." Entomologia Experimentalis et Applicata 151.3 (2014): 209-217.

Chopra RN, Bhatla SC. Effect of physical factors on gametangical induction, fertilization and sporophyte development in the moss Bryum argenteum grow in vitro. New Phytol. 1981; 89: 439-447.

Christensen, J. H., and Coauthors. 'Regional climate projections”. Climate Change 2007: The Physical Science Basis. Contribution of WGI to the IPCC AR4, Solomon et al., Eds., Cambridge University Press, Cambridge, United Kingdom and New York, NY, USA, (2007) 847-940

Claeys, Magda, et al. "Formation of secondary organic aerosols through photooxidation of isoprene." Science 303.5661 (2004): 1173-1176.

Clapp, Lynette J., and Michael E. Jenkin. "Analyses of the relationship between ambient levels of $\mathrm{O} 3, \mathrm{NO} 2$ and $\mathrm{NO}$ as a function of NOx in the UK." Atmospheric Environment 35.36 (2001): 6391-6405.

Clark, Christopher M., and David Tilman. "Loss of plant species after chronic low-level nitrogen deposition to prairie grasslands." Nature 451.7179 (2008): 712.

Clayton-Greene, K. A., et al. "Surface wax, structure and function in leaves of Polytrichaceae." Journal of Bryology 13.4 (1985): 549-562.

Cleveland, Cory C., and J. B. Yavitt. "Microbial consumption of atmospheric isoprene in a temperate forest soil." Applied and Environmental Microbiology 64.1 (1998): $172-177$.

Clymo, R. S. "Ion exchange in Sphagnum and its relation to bog ecology." Annals of Botany 27.2 (1963): 309-324.

Clymo, R. S., and P. M. Hayward. "The ecology of Sphagnum." Bryophyte ecology. Springer, Dordrecht, 1982. 229-289.

Coe, Kirsten K., Jayne Belnap, and Jed P. Sparks. "Precipitation-driven carbon balance controls survivorship of desert biocrust mosses." Ecology 93.7 (2012): 16261636.

Cofer, Tristan M., Marie Engelberth, and Jurgen Engelberth. "Green leaf volatiles protect maize (Zea mays) seedlings against damage from cold stress." Plant, cell \& environment (2018). 
Collins, N. J. "Growth and Population Dynamics of the Moss Polytrichum Alpestre. in the Maritime Antarctic. Strategies of Growth and Population Dynamics of Tundra Plants 2". Oikos (1976): 389-401.

Collins, N. J., and W. C. Oechel. "The pattern of growth and translocation of photosynthate in a tundra moss, Polytrichum alpinum." Canadian Journal of Botany 52.2 (1974): 355-363.

Conard, Henry Shoemaker, and Paul L. Redfearn. How to know the mosses and liverworts: pictured-keys for determining many of the North American mosses and liverworts, with suggestions and aids for their study. WC Brown, 1956.

Convey, Peter, and RI Lewis Smith. "Investment in sexual reproduction by Antarctic mosses." Oikos (1993): 293-302.

Cook, Elizabeth M., et al. "Mixed method approach to assess atmospheric nitrogen deposition in arid and semi-arid ecosystems." Environmental Pollution 239 (2018): 617-630.

Cornell, S. E., et al. "Organic nitrogen deposition on land and coastal environments: a review of methods and data." Atmospheric Environment 37.16 (2003): 2173-2191.

Corradini, Pierre, and Bernard Clément. "Growth pattern and modular reiteration of a hardy coloniser Polytrichum commune Hedw." Plant Ecology 143.1 (1999): 6776.

Cove, D. J., et al. "Genetic and physiological studies of the effect of light on the development of the moss, Physcomitrella patens." Annual European Symposium on Photomorphogenesis. 1978.

Cove, David J., et al. "The moss Physcomitrella patens: a novel model system for plant development and genomic studies." Cold Spring Harbor Protocols 2009.2 (2009): pdb-emo115.

Cox, William J., and Debbie JR Cherney. "Row spacing, plant density, and nitrogen effects on corn silage." Agronomy Journal 93.3 (2001): 597-602.

Craney, Trevor A., and James G. Surles. "Model-dependent variance inflation factor cutoff values." Quality Engineering 14.3 (2002): 391-403.

Cremer, K. W. "Early stages of plant succession following the complete felling and burning of Eucalyptus regnans forest in the Florentine Valley, Tasmania." Australian Journal of Botany 13.2 (1965): 303-322. 
Crombie, Andrew T., et al. "Genetics and ecology of isoprene degradation." Aerobic Utilization of Hydrocarbons, Oils, and Lipids (2019): 557-571.

Cronberg, Nils, et al. "Clonal distribution, fertility and sex ratios of the moss Plagiomnium affine (Bland.) T. Kop. in forests of contrasting age." Journal of Bryology 25.3 (2003): 155-162.

Cronberg, Nils. "Colonization dynamics of the clonal moss Hylocomium splendens on islands in a Baltic land uplift area: reproduction, genet distribution and genetic variation." Journal of Ecology 90.6 (2002): 925-935.

Cronberg, Nils. "Genetic differentiation between populations of the moss Hylocomium splendens from low versus high elevation in the Scandinavian mountain range." Lindbergia (2004): 64-72.

Crum, Howard Alvin, Lewis Edward Anderson, and Lewis Anderson. Mosses of Eastern North America. Vol. 1. Columbia University Press, 1981.

Crutzen, Paul J. "Ozone production rates in an oxygen-hydrogen-nitrogen oxide atmosphere." Journal of Geophysical Research 76.30 (1971): 7311-7327.

Crutzen, Paul J. "The influence of nitrogen oxides on the atmospheric ozone content." Quarterly Journal of the Royal Meteorological Society 96.408 (1970): 320-325.

Curci, G., et al. "Modelling study of the impact of isoprene and terpene biogenic emissions on European ozone levels." Atmospheric Environment 43.7 (2009): 1444-1455.

Damgaard, Christian, Knud Erik Nielsen, and Morten Strandberg. "The effect of nitrogen deposition on the vegetation of wet heathlands." Plant Ecology 218.4 (2017): 373383.

Dani, KG Srikanta, and Francesco Loreto. "Trade-off between dimethyl sulfide and isoprene emissions from marine phytoplankton." Trends in plant science 22.5 (2017): 361-372.

Dani, KG Srikanta, et al. "Evolution of isoprene emission capacity in plants." Trends in plant science 19.7 (2014): 439-446.

Dani, KG Srikanta, et al. "Species-specific photorespiratory rate, drought tolerance and isoprene emission rate in plants." Plant signaling \& behavior 10.3 (2015): e990830. 
Dani, Srikanta, et al. "Increased ratio of electron transport to net assimilation rate supports elevated isoprenoid emission rate in eucalypts under drought." Plant physiology (2014): pp-114.

Darbah, Joseph NT, Thomas D. Sharkey, and David F. Karnosky. "Isoprene emission and carbon dioxide protect aspen leaves from heat stress." (2008).

Darrall, N. M. "The effect of air pollutants on physiological processes in plants." Plant, Cell \& Environment 12.1 (1989): 1-30.

de Carvalho Victoria, Filipe, Antonio Costa de Oliveira, and Jose Antonio Peters. "Establishment of the moss Polytrichum juniperinum Hedw. under axenic conditions." Bioscience journal 27.4 (2011): 673-676.

de Jong, Tom J., Heinjo J. During, and Avi Shmida. "Differences and similarities of sex ratios between dioecious angiosperms and dioicous bryophytes." Evolutionary Ecology Research 19.4 (2018): 365-386.

De Lucia, Evan, et al. "Climate change: resetting plant-insect interactions." Plant Physiology (2012): pp-112.

de Souza, Vinícius Fernandes, et al. "Alternative Carbon Sources for Isoprene Emission." Trends in plant science (2018).

De Vries, Wim, and Maximilian Posch. "Modelling the impact of nitrogen deposition, climate change and nutrient limitations on tree carbon sequestration in Europe for the period 1900-2050." Environmental Pollution 159.10 (2011): 2289-2299.

de Vries, Wim, et al. "The impact of nitrogen deposition on carbon sequestration by European forests and heathlands." Forest Ecology and Management 258.8 (2009): 1814-1823.

Delach, Aimee, and Robin Wall Kimmerer. "The effect of Polytrichum piliferum on seed germination and establishment on iron mine tailings in New York." The Bryologist 105.2 (2002): 249-255.

Delgado-Baquerizo, Manuel, et al. "Biocrust-forming mosses mitigate the impact of aridity on soil microbial communities in drylands: observational evidence from three continents." New Phytologist (2018).

Demmig-Adams, Barbara, Adam M. Gilmore, and W. W. Adams 3rd. "Carotenoids 3: in vivo function of carotenoids in higher plants." The FASEB Journal 10.4 (1996): 403-412. 
Depante, M., et al. "Potential influence of nutrient availability along a hillslope: Peatland gradient on aspen recovery following fire." Ecohydrology (2018): e1955.

Devika, R., and Justin Koilpillai. "An overview on plant secondary metabolites: Its medicinal importance." Journal of Pharmacy Research 5.2 (2012): 984-986.

Dicke, Marcel, and Ian T. Baldwin. "The evolutionary context for herbivore-induced plant volatiles: beyond the "cry for help'." Trends in plant science 15.3 (2010): 167-175.

Dijkstra, Feike A., et al. "Nitrogen deposition and plant species interact to influence soil carbon stabilization." Ecology Letters 7.12 (2004): 1192-1198.

Disch, Andrea, et al. "Distribution of the mevalonate and glyceraldehyde phosphate/pyruvate pathways for isoprenoid biosynthesis in unicellular algae and the cyanobacterium Synechocystis PCC 6714." Biochemical Journal 333.2 (1998): 381-388.

Döbbeler, Peter. "Ascomycetes growing on Polytrichum sexangulare." Arctic and alpine mycology II. Springer, Boston, MA, 1987. 87-107.

Doetterl, Sebastian, et al. "Links among warming, carbon and microbial dynamics mediated by soil mineral weathering." Nature Geoscience 11.8 (2018): 589.

Dreyer, Erwin, et al. "Temperature response of leaf photosynthetic capacity in seedlings from seven temperate tree species." Tree physiology 21.4 (2001): 223-232.

Du, Enzai, Xiuyuan Liu, and Jingyun Fang. "Effects of nitrogen additions on biomass, stoichiometry and nutrient pools of moss Rhytidium rugosum in a boreal forest in Northeast China." Environmental pollution 188 (2014): 166-171.

Duane, M., et al. "Isoprene and its degradation products as strong ozone precursors in Insubria, Northern Italy." Atmospheric Environment 36.24 (2002): 3867-3879.

Dudareva, Natalia, et al. "Plant volatiles: recent advances and future perspectives." Critical reviews in plant sciences 25.5 (2006): 417-440.

Duffy, J. Emmett, Casey M. Godwin, and Bradley J. Cardinale. "Biodiversity effects in the wild are common and as strong as key drivers of productivity." Nature 549.7671 (2017): 261.

Duncan, Bryan N., et al. "Temperature dependence of factors controlling isoprene emissions." Geophysical Research Letters 36.5 (2009). 
Duncan, Diana, and P. L. Dalton. "Recolonisation by bryophytes following fire." Journal of Bryology 12.1 (1982): 53-63.

Duprè, Cecilia, et al. "Changes in species richness and composition in European acidic grasslands over the past 70 years: the contribution of cumulative atmospheric nitrogen deposition." Global Change Biology 16.1 (2010): 344-357.

Eckstein, R. Lutz, and P. Staffan Karlsson. "Recycling of nitrogen among segments of Hylocomium splendens as compared with Polytrichum commune: implications for clonal integration in an ectohydric bryophyte." Oikos (1999): 87-96.

Eckstein, Rolf Lutz. "Nitrogen retention by Hylocomium splendens in a subarctic birch woodland." Journal of Ecology 88.3 (2000): 506-515.

Ehhalt, Dieter H., Franz Rohrer, and Andrea Wahner. "Sources and distribution of NO x in the upper troposphere at northern mid-latitudes." Journal of Geophysical Research: Atmospheres 97.D4 (1992): 3725-3738.

Ehrlén J, Bisang I, Hedenäs L. 2000. Costs of sporophyte production in the moss, Dicranum polysetum. Plant Ecology 149: 207-217.

Ekberg, Anna, Almut Arneth, and Thomas Holst. "Isoprene emission from Sphagnum species occupying different growth positions above the water table." Boreal environment research 16.1 (2011): 47-59.

Elbert, Wolfgang, et al. "Contribution of cryptogamic covers to the global cycles of carbon and nitrogen." Nature Geoscience 5.7 (2012): 459.

Ellis, R. A., et al. "Present and future nitrogen deposition to national parks in the United States: critical load exceedances." Atmospheric Chemistry and Physics 13.17 (2013): 9083-9095.

Ellison, G. N., and N. J. Gotelli. "A primer of ecological statistics." Sinauer, Sunderland, Massachusetts, USA (2004).

Elumeeva, Tatiana G., et al. "The importance of colony structure versus shoot morphology for the water balance of 22 subarctic bryophyte species." Journal of Vegetation Science 22.1 (2011): 152-164.

Engelberth, Juergen, et al. "Airborne signals prime plants against insect herbivore attack." Proceedings of the National Academy of Sciences 101.6 (2004): 1781-1785.

Engelhart, Gabriella J., et al. "Cloud condensation nuclei activity of isoprene secondary organic aerosol." Journal of Geophysical Research: Atmospheres 116.D2 (2011). 
Eppley, Sarah M., et al. "Limits to sexual reproduction in geothermal bryophytes." International Journal of Plant Sciences 172.7 (2011): 870-878.

Erisman, Jan Willem, et al. "Consequences of human modification of the global nitrogen cycle." Phil. Trans. R. Soc. B 368.1621 (2013): 20130116.

Erwin, Kevin L. "Wetlands and global climate change: the role of wetland restoration in a changing world." Wetlands Ecology and management 17.1 (2009): 71.

Erxleben, Anika, et al. "Metabolite profiling of the moss Physcomitrella patens reveals evolutionary conservation of osmoprotective substances." Plant cell reports 31.2 (2012): 427-436.

Fall, Ray, and Mary C. Wildermuth. "Isoprene synthase: from biochemical mechanism to emission algorithm." Journal of Geophysical Research: Atmospheres 103.D19 (1998): 25599-25609.

Fang, Chengwei, Russell K. Monson, and Ellis B. Cowling. "Isoprene emission, photosynthesis, and growth in sweetgum (Liquidambar styraciflua) seedlings exposed to short-and long-term drying cycles." Tree physiology 16.4 (1996): 441446.

Fang, Y. T., et al. "Anthropogenic imprints on nitrogen and oxygen isotopic composition of precipitation nitrate in a nitrogen-polluted city in southern China." Atmospheric Chemistry and Physics 11.3 (2011): 1313-1325.

Fares, Silvano, et al. "Influence of growth temperature and measuring temperature on isoprene emission, diffusive limitations of photosynthesis and respiration in hybrid poplars." Atmospheric Environment 45.1 (2011): 155-161.

Fattash, Isam, et al. "Evidence for the rapid expansion of microRNA-mediated regulation in early land plant evolution." BMC Plant Biology 7.1 (2007): 13.

Fehsenfeld, Fred, et al. "Emissions of volatile organic compounds from vegetation and the implications for atmospheric chemistry." Global Biogeochemical Cycles 6.4 (1992): 389-430.

Felix, J. David, et al. "Nitrogen content and isotopic composition of Spanish Moss (Tillandsia usneoides $L$.): reactive nitrogen variations and source implications across an urban coastal air shed." Environmental Processes 3.4 (2016): 711-722. 
Feng, Zhaozhong, et al. "Isoprene is more affected by climate drivers than monoterpenes: a meta-analytic review on plant isoprenoid emissions." Plant, cell \& environment (2019).

Fenn, Mark E., et al. "Ecological effects of nitrogen deposition in the western United States." AIBS Bulletin 53.4 (2003): 404-420.

Fenn, Mark E., et al. "Nitrogen excess in North American ecosystems: predisposing factors, ecosystem responses, and management strategies." Ecological Applications 8.3 (1998): 706-733.

Fernández, J. A., et al. "Biomonitoring of metal deposition in northern Spain by moss analyses." Science of the Total Environment 300.1 (2002): 115-127.

Ferrieri, Richard A., et al. "Use of carbon-11 in Populus shows that exogenous jasmonic acid increases biosynthesis of isoprene from recently fixed carbon." Plant, Cell \& Environment 28.5 (2005): 591-602.

Fields, Scott. "Global nitrogen: cycling out of control." Environmental Health Perspectives 112.10 (2004): A556.

Figueroa, Félix L., Rafael Conde-Alvarez, and Iván Gómez. "Relations between electron transport rates determined by pulse amplitude modulated chlorophyll fluorescence and oxygen evolution in macroalgae under different light conditions." Photosynthesis Research 75.3 (2003): 259-275.

Fini, Alessio, et al. "Isoprene responses and functions in plants challenged by environmental pressures associated to climate change." Frontiers in plant science 8 (2017): 1281.

Fiore, Arlene M., et al. "Evaluating the contribution of changes in isoprene emissions to surface ozone trends over the eastern United States." Journal of Geophysical Research: Atmospheres 110.D12 (2005).

Forcier, Lawrence K. "Reproductive strategies and the co-occurrence of climax tree species." Science 189.4205 (1975): 808-810.

Forrest, L. L. A phylogenetic analyses of Polytrichaceae (Musci). Diss. M. Sc. thesis, Department of Botany, University of Reading, 1995.

Foster, David R. "Vegetation development following fire in Picea mariana (black spruce)-Pleurozium forests of south-eastern Labrador, Canada." The Journal of Ecology (1985): 517-534. 
Fowler, David, et al. "Atmospheric composition change: ecosystems-atmosphere interactions." Atmospheric Environment 43.33 (2009): 5193-5267.

Franklin, Linda A., and Murray R. Badger. "A comparison of photosynthetic electron transport rates in macroalgae measured by pulse amplitude modulated chlorophyll fluorometry and mass spectrometry." Journal of Phycology 37.5 (2001): 756-767.

Fritz, Christian, et al. "Sphagnum mosses-masters of efficient N-uptake while avoiding intoxication." PloS one 9.1 (2014): e79991.

Fryer, Janet L. "Polytrichum juniperinum." Fire Effects Information System (FEIS),[Online] United States Department of Agriculture Forest Service, Rocky Mountain Research Station, Fire Sciences Laboratory, Missoula, MT. Website http://www. fs. fed. us/database/feis/(accessed 29 August 2018) (2008).

Fu, Peng, et al. "Constituents of the moss Polytrichum commune." Journal of natural products 72.7 (2009): 1335-1337.

Funk, Jennifer L., et al. "Diurnal variation in the basal emission rate of isoprene." Ecological Applications 13.1 (2003): 269-278.

Fusaro, L., E. Salvatori, and F. Manes. "Effects of nitrogen deposition, drought and their interaction, on functional and structural traits of Fraxinus ornus L. and Quercus ilex L." Plant Biosystems-An International Journal Dealing with all Aspects of Plant Biology 151.1 (2017): 174-189.

Galloway, James N. "The global nitrogen cycle: changes and consequences." Nitrogen, the Confer-NS. 1998. 15-24.

Galloway, James N., et al. "Nitrogen cycles: past, present, and future." Biogeochemistry 70.2 (2004): 153-226.

Galloway, James N., et al. "Transformation of the nitrogen cycle: recent trends, questions, and potential solutions." Science 320.5878 (2008): 889-892.

Gavazov, Konstantin, et al. "Vascular plant-mediated controls on atmospheric carbon assimilation and peat carbon decomposition under climate change." Global change biology (2018).

Genard-Zielinski, Anne-Cyrielle, et al. "Isoprene emissions from downy oak under water limitation during an entire growing season: what cost for growth?" PloS one 9.11 (2014): e112418. 
Gemmell, Alan Robertson. "Studies in the Bryophyta: I. The influence of sexual mechanism on varietal production and distribution of British musci." New Phytologist 49.1 (1950): 64-71.

Genard-Zielinski, Anne-Cyrielle, et al. "Seasonal variations of Quercus pubescens isoprene emissions from an in natura forest under drought stress and sensitivity to future climate change in the Mediterranean area." Biogeosciences 15.15 (2018): 4711-4730.

Genty, Bernard, Jean-Marie Briantais, and Neil R. Baker. "The relationship between the quantum yield of photosynthetic electron transport and quenching of chlorophyll fluorescence." Biochimica et Biophysica Acta (BBA)-General Subjects 990.1 (1989): 87-92.

Gerdol, Renato, et al. "Use of moss (Tortula muralis Hedw.) for monitoring organic and inorganic air pollution in urban and rural sites in Northern Italy." Atmospheric Environment 36.25 (2002): 4069-4075.

Gerken, T., et al. "Turbulent transport and chemistry of isoprene and monoterpenes within and above tropical forest canopies." AGU Fall Meeting Abstracts. 2016.

Geron, Chris, et al. "Temporal variability in basal isoprene emission factor." Tree Physiology 20.12 (2000): 799-805.

Geron, Chris, Peter Harley, and Alex Guenther. "Isoprene emission capacity for US tree species." Atmospheric Environment 35.19 (2001): 3341-3352.

Geron, Christopher D., Alex B. Guenther, and Thomas E. Pierce. "An improved model for estimating emissions of volatile organic compounds from forests in the eastern United States." Journal of Geophysical Research: Atmospheres 99.D6 (1994): 12773-12791.

Gerson, Uri. "Bryophytes and invertebrates." Bryophyte ecology. Springer, Dordrecht, 1982. 291-332.

Ghirardo, Andrea, et al. "Biogenic volatile organic compound and respiratory CO2 emissions after 13C-labeling: online tracing of $\mathrm{C}$ translocation dynamics in poplar plants." PLoS One 6.2 (2011): e17393.

Ghirardo, Andrea, et al. "Metabolic flux analyses of plastidic isoprenoid biosynthesis in poplar leaves emitting and nonemitting isoprene." Plant Physiology 165.1 (2014): 37-51. 
Glarborg, Peter, et al. "Modeling nitrogen chemistry in combustion." Progress in Energy and Combustion Science 67 (2018): 31-68.

Glime, Janice M. "Adaptive Strategies." (2017).

Goldan, Paul D., et al. "Hydrocarbon measurements in the southeastern United States: The rural oxidants in the southern environment (ROSE) program 1990." Journal of Geophysical Research: Atmospheres 100.D12 (1995): 25945-25963.

Goldstein, Allen H., et al. "Biogenic carbon and anthropogenic pollutants combine to form a cooling haze over the southeastern United States." Proceedings of the National Academy of Sciences 106.22 (2009): 8835-8840.

Goldstein, Allen H., et al. "Seasonal course of isoprene emissions from a midlatitude deciduous forest." Journal of Geophysical Research: Atmospheres 103.D23 (1998): 31045-31056.

González, Eduardo, et al. "Can indicator species predict restoration outcomes early in the monitoring process? A case study with peatlands." Ecological indicators 32 (2013): 232-238.

Gordon, C. W. J. M. W. S. J., J. M. Wynn, and Sarah Jane Woodin. "Impacts of increased nitrogen supply on high Arctic heath: the importance of bryophytes and phosphorus availability." New Phytologist 149.3 (2001): 461-471.

Gorham, Eville. "Northern peatlands: role in the carbon cycle and probable responses to climatic warming." Ecological applications 1.2 (1991): 182-195.

Gornall, Jemma L., et al. "Balancing positive and negative plant interactions: how mosses structure vascular plant communities." Oecologia 166.3 (2011): 769-782.

Grabmer, W., et al. "VOC emissions from Norway spruce (Picea abies L.[Karst]) twigs in the field-results of a dynamic enclosure study." Atmospheric Environment 40 (2006): 128-137.

Granath, Gustaf, et al. "Photosynthetic performance in Sphagnum transplanted along a latitudinal nitrogen deposition gradient." Oecologia 159.4 (2009): 705-715.

Gray, Christopher M., Detlev Helmig, and Noah Fierer. "Bacteria and fungi associated with isoprene consumption in soil." Elem Sci Anth 3 (2015).

Green, T. G. A., et al. "An assessment of the relationship between chlorophyll a fluorescence and $\mathrm{CO} 2$ gas exchange from field measurements on a moss and lichen." Planta 206.4 (1998): 611-618. 
Greene SW. The maturation cycle, or the stages of development of gametangia and capsules in mosses. Transactions of the British Bryological Society 3 1960: 736745 .

Grinspoon, Jennifer, William D. Bowman, and Ray Fall. "Delayed onset of isoprene emission in developing velvet bean (Mucuna sp.) leaves." Plant Physiology 97.1 (1991): 170-174

Groeneveld, Elisabeth VG, Ariane Masse, and Line Rochefort. "Polytrichum strictum as a nurse-plant in peatland restoration." Restoration Ecology 15.4 (2007): 709-719.

Gruber, Nicolas, and James N. Galloway. "An Earth-system perspective of the global nitrogen cycle." Nature 451.7176 (2008): 293.

$\mathrm{Gu}$, Baojing, et al. "Cleaning up nitrogen pollution may reduce future carbon sinks." Global Environmental Change 48 (2018): 56-66.

$\mathrm{Gu}$, Dasa, et al. "Airborne observations reveal elevational gradient in tropical forest isoprene emissions." Nature communications 8 (2017): 15541.

Guenther, A. B., et al. "The Model of Emissions of Gases and Aerosols from Nature version 2.1 (MEGAN2. 1): an extended and updated framework for modeling biogenic emissions." (2012).

Guenther, A., et al. "Estimates of global terrestrial isoprene emissions using MEGAN (Model of Emissions of Gases and Aerosols from Nature)." Atmospheric Chemistry and Physics 6.11 (2006): 3181-3210.

Guenther, Alex B., et al. "Isoprene and monoterpene emission rate variability: model evaluations and sensitivity analyses." Journal of Geophysical Research: Atmospheres 98.D7 (1993): 12609-12617.

Guenther, Alex B., Russell K. Monson, and Ray Fall. "Isoprene and monoterpene emission rate variability: observations with eucalyptus and emission rate algorithm development." Journal of Geophysical Research: Atmospheres 96.D6 (1991): 10799-10808.

Guenther, Alex, et al. "A global model of natural volatile organic compound emissions." Journal of Geophysical Research: Atmospheres 100.D5 (1995): 8873-8892.

Guenther, Alex, et al. "Isoprene fluxes measured by enclosure, relaxed eddy accumulation, surface layer gradient, mixed layer gradient, and mixed layer mass 
balance techniques." Journal of Geophysical Research: Atmospheres 101.D13 (1996): 18555-18567.

Guenther, Alex, Patrick Zimmerman, and Mary Wildermuth. "Natural volatile organic compound emission rate estimates for US woodland landscapes." Atmospheric Environment 28.6 (1994): 1197-1210.

Guenther, Alex. "The contribution of reactive carbon emissions from vegetation to the carbon balance of terrestrial ecosystems." Chemosphere 49.8 (2002): 837-844.

Guidolotti, Gabriele, et al. "Emission of constitutive isoprene, induced monoterpenes and other volatiles under high temperatures in Eucalyptus camaldulensis: a 13C labelling study." Plant, cell \& environment (2019).

Gundale, Michael J., Thomas H. Deluca, and Annika Nordin. "Bryophytes attenuate anthropogenic nitrogen inputs in boreal forests." Global Change Biology 17.8 (2011): 2743-2753.

Gunsch, Matthew J., et al. "Particle growth in an isoprene-rich forest: Influences of urban, wildfire, and biogenic air masses." Atmospheric Environment 178 (2018): 255-264.

Guo, Hao, et al. "Deposition of sulfur and nitrogen components in Louisiana in August, 2011." Science of the Total Environment 636 (2018): 124-133.

Haapanala, Sami, et al. "Measurements of hydrocarbon emissions from a boreal fen using the REA technique." Biogeosciences 3.1 (2006): 103-112.

Haas, Klaus. "Surface wax of Andreaea and Pogonatum species." Phytochemistry 21.3 (1982): 657-659.

Hackenberg, Dieter, et al. "Sporophyte formation and life cycle completion in moss requires heterotrimeric G-proteins." Plant Physiology (2016): pp-01088.

Haig, David. "Living together and living apart: the sexual lives of bryophytes." Phil. Trans. R. Soc. B 371.1706 (2016): 20150535.

Hakola, Hannele, et al. "Terpenoid and carbonyl emissions from Norway spruce in Finland during the growing season." Atmospheric Chemistry and Physics 17.5 (2017): 3357-3370.

Hallquist, Mattias, et al. "The formation, properties and impact of secondary organic aerosol: current and emerging issues." Atmospheric Chemistry and Physics 9.14 (2009): 5155-5236. 
Hanson, D. T., and Thomas D. Sharkey. "Rate of acclimation of the capacity for isoprene emission in response to light and temperature." Plant, Cell \& Environment 24.9 (2001): 937-946.

Hanson, David T., and Steven K. Rice, eds. Photosynthesis in bryophytes and early land plants. New York: Springer, 2014.

Hanson, David T., et al. "Evolutionary significance of isoprene emission from mosses." American Journal of Botany 86.5 (1999): 634-639.

Harborne, Jeffrey B. Introduction to ecological biochemistry. Academic press, 2014.

Harenda, Kamila M., et al. "The role of peatlands and their carbon storage function in the context of climate change." Interdisciplinary Approaches for Sustainable

Development Goals. Springer, Cham, 2018. 169-187

Harley, P., A. Guenther, and P. Zimmerman. "Effects of light, temperature and canopy position on net photosynthesis and isoprene emission from sweetgum (Liquidambar styraciflua) leaves." Tree Physiology 16.1-2 (1996): 25-32.

Harley, P., A. Guenther, and P. Zimmerman. "Environmental controls over isoprene emission in deciduous oak canopies." Tree Physiology 17.11 (1997): 705-714.

Harley, Peter C., et al. "Isoprene emission from velvet bean leaves (interactions among nitrogen availability, growth photon flux density, and leaf development)." Plant Physiology 105.1 (1994): 279-285.

Harley, Peter C., et al. "Isoprene emission from velvet bean leaves (interactions among nitrogen availability, growth photon flux density, and leaf development)." Plant Physiology 105.1 (1994): 279-285.

Harley, Peter C., Russell K. Monson, and Manuel T. Lerdau. "Ecological and evolutionary aspects of isoprene emission from plants." Oecologia 118.2 (1999): 109-123.

Harmens, Harry, et al. "Nitrogen concentrations in mosses indicate the spatial distribution of atmospheric nitrogen deposition in Europe." Environmental Pollution 159.10 (2011): 2852-2860.

Harper, JL, and J. White. "The demography of plants." Annual review of ecology and systematics 5.1 (1974): 419-463. 
Harrison, Sandy P., et al. "Volatile isoprenoid emissions from plastid to planet." New Phytologist 197.1 (2013): 49-57.

Hartley, Karri. "Plants on the edge: How will Antarctic mosses respond to Global Environmental Change?" (2014).

Hayward, Sean, et al. "Online analyses of volatile organic compound emissions from Sitka spruce (Picea sitchensis)." Tree Physiology 24.7 (2004): 721-728.

Heald, Colette L., et al. "Response of isoprene emission to ambient CO2 changes and implications for global budgets." Global Change Biology 15.5 (2009): 1127-1140.

Hébant, Charles. "Studies on the development of the conducting tissue-system in the gametophytes of some polytrichales-1-Misecellaneous notes on apical segmentation, growth of gametophytes, and diversity in histo-anatomical structures." Journal of the Hattori Botanical Laboratory 37 (1973): 211-227.

Heckathorn, Scott A., et al. "The small, methionine-rich chloroplast heat-shock protein protects photosystem II electron transport during heat stress." Plant Physiology 116.1 (1998): 439-444.

Hedderson, Terry A., and R. E. Longton. "Local adaptation in moss life histories: population-level variation and a reciprocal transplant experiment." Journal of Bryology 30.1 (2008): 1-11.

Heijmans, Monique MPD, et al. "Effects of elevated carbon dioxide and increased nitrogen deposition on bog vegetation in the Netherlands." Journal of ecology 89.2 (2001): 268-279.

Heikkinen RK, Marmion M, Luoto M (2012) Does the interpolation accuracy of species distribution models come at the expense of transferability? Ecography 35: 276288. doi: 10.1111/j.1600-0587.2011.06999.x

Heimann, Martin, and Markus Reichstein. "Terrestrial ecosystem carbon dynamics and climate feedbacks." Nature 451.7176 (2008): 289.

Heino, Jani, et al. "Searching for biodiversity indicators in running waters: do bryophytes, macroinvertebrates, and fish show congruent diversity patterns?" Biodiversity \& Conservation 14.2 (2005): 415-428.

Hellén, H., et al. "C 2-C 10 hydrocarbon emissions from a boreal wetland and forest floor." Biogeosciences 3.2 (2006): 167-174. 
Herbst, Lesley Ann. Comparative ecology of Polytrichum commune Hedw. and Polytrichum juniperinum Hedw. University of Wisconsin-Madison, 1975.

Hess, Carsten, et al. "Anthropogenic nitrogen deposition alters growth responses of European beech (Fagus sylvativa L.) to climate change." Environmental Pollution 233 (2018): 92-98.

Hett, Joan M., and Orie L. Loucks. "Sugar maple (Acer saccharum Marsh.) seedling mortality." The Journal of Ecology (1971): 507-520.

Hinshiri, H. M., and M. C. F. Proctor. "The effect of desiccation on subsequent assimilation and respiration of the bryophytes Anomodon viticulosus and Porella platyphylla." New Phytologist 70.3 (1971): 527-538.

Hobbie, Sarah E. "Effects of plant species on nutrient cycling." Trends in ecology \& evolution 7.10 (1992): 336-339.

Hoekman, S. Kent, and Curtis Robbins. "Review of the effects of biodiesel on NOx emissions." Fuel Processing Technology 96 (2012): 237-249.

Hoffmann, Thorsten, et al. "Formation of organic aerosols from the oxidation of biogenic hydrocarbons." Journal of Atmospheric Chemistry 26.2 (1997): 189-222.

Holopainen, J. K., M. Kivimäenpää, and S. A. Nizkorodov. "Plant-derived secondary organic material in the air and ecosystems." Trends in plant science 22.9 (2017): 744-753.

Holopainen, Jarmo K. "Loss of isoprene-emitting capacity: deleterious for trees?." Tree Physiology 33.6 (2013): 559-561.

Holopainen, Jarmo K., and Jonathan Gershenzon. "Multiple stress factors and the emission of plant VOCs." Trends in plant science 15.3 (2010): 176-184.

Holopainen, Jarmo K., Anne-Marja Nerg, and James D. Blande. "Multitrophic signalling in polluted atmospheres." Biology, controls and models of tree volatile organic compound emissions. Springer, Dordrecht, (2013). 285-314.

Hong, S-Y., A. S. Zurbriggen, and A. Melis. "Isoprene hydrocarbons production upon heterologous transformation of Saccharomyces cerevisiae." Journal of applied microbiology 113.1 (2012): 52-65

Hossaert-McKey, Martine, et al. "Floral scents: their roles in nursery pollination mutualisms." Chemoecology 20.2 (2010): 75-88. 
Hou, Shuang-Li, et al. "Quantifying the indirect effects of nitrogen deposition on grassland litter chemical traits." Biogeochemistry 139.3 (2018): 261-273.

Hughes, J. G. "Seasonal growth and development of sporophytes in wild populations of Pogonatum and Polytrichum species." Journal of Bryology 16.1 (1990): 97-108.

Hughes, J. G. "The effects of Day-kength on the development of the sporophyte of the Polytrichum aloides HEDW. and P. piliferum HEDW." New Phytologist 61.3 (1962): 266-273.

Hyvönen, Jaakko, et al. "Phylogeny of the Polytrichales (Bryophyta) based on simultaneous analyses of molecular and morphological data." Molecular phylogenetics and evolution 31.3 (2004): 915-928.

Ibáñez, Inés, et al. "Anthropogenic nitrogen deposition ameliorates the decline in tree growth caused by a drier climate." Ecology 99.2 (2018): 411-420.

Innes, David J. "Microgeographic genetic variation in the haploid and diploid stages of the moss Polytrichum juniperinum Hedw." Heredity 64.3 (1990): 331.

Ishimatsu, Atsushi, et al. "Biosynthesis of isoprene units in the C34 botryococcene molecule produced by Botryococcus braunii strain Bot-22." Procedia Environmental Sciences 15 (2012): 56-65.

Izquieta-Rojano, S., et al. "Pleurochaete squarrosa (Brid.) Lindb. as an alternative moss species for biomonitoring surveys of heavy metal, nitrogen deposition and $\delta 15 \mathrm{~N}$ signatures in a Mediterranean area." Ecological indicators 60 (2016): 1221-1228.

Jakub, Buda, et al. "Tardigrades and oribatid mites in bryophytes from geothermally active lava fields (Krafla, Iceland) and the description of Pilatobius islandicus sp. nov.(Eutardigrada)." Polish Polar Research (2018).

Jambert, Corinne, et al. "Observations of biogenic isoprene emissions and atmospheric chemistry components at the Savé super site in Benin, West Africa, during the DACCIWA field campaign." EGU General Assembly Conference Abstracts. Vol. 19. 2017.

Janson, Robert, and Claes De Serves. "Isoprene emissions from boreal wetlands in Scandinavia." Journal of Geophysical Research: Atmospheres 103.D19 (1998): 25513-25517.

Janson, Robert, Claes De Serves, and Rodrigo Romero. "Emission of isoprene and carbonyl compounds from a boreal forest and wetland in Sweden." Agricultural and Forest Meteorology 98 (1999): 671-681. 
Janssens, I. A., et al. "Reduction of forest soil respiration in response to nitrogen deposition." Nature geoscience 3.5 (2010): 315.

Jassey, Vincent EJ, et al. "Above-and belowground linkages in Sphagnum peatland: climate warming affects plant-microbial interactions." Global Change Biology 19.3 (2013): 811-823.

Jauhiainen, Jyrki, Harri Vasander, and Jouko Silvola. "Response of Sphagnum fuscum to N deposition and increased CO2." Journal of Bryology 18.1 (1994): 83-96.

Jiang, Xiaoyan, et al. "Isoprene emission response to drought and the impact on global atmospheric chemistry." Atmospheric Environment 183 (2018): 69-83.

Jiang, Xiaoyan, et al. "Projected future changes in vegetation in western North America in the twenty-first century." Journal of Climate 26.11 (2013): 3671-3687.

Jones, Clive G., John H. Lawton, and Moshe Shachak. "Organisms as ecosystem engineers." Ecosystem management. Springer, New York, NY, 1994. 130-147.

Jones, Benjamin L., Leanne C. Cullen-Unsworth, and Richard KF Unsworth. "Tracking nitrogen source using $\delta 15 \mathrm{~N}$ reveals human and agricultural drivers of seagrass degradation across the British Isles." Frontiers in plant Science 9 (2018): 133.

Jones, D. L., et al. "Microbial competition for nitrogen and carbon is as intense in the subsoil as in the topsoil." Soil Biology and Biochemistry 117 (2018): 72-82.

Jonsson, Bengt Gunnar. "The bryophyte diaspore bank and its role after small-scale disturbance in a boreal forest." Journal of vegetation Science 4.6 (1993): 819-826.

Juutinen, Sari, et al. "Responses of the mosses Sphagnum capillifolium and Polytrichum strictum to nitrogen deposition in a bog: growth, ground cover, and $\mathrm{CO} 2$ exchange." Botany 94.2 (2015): 127-138.

Kanakidou, Maria, Stelios Myriokefalitakis, and Kostas Tsigaridis. "Aerosols in atmospheric chemistry and biogeochemical cycles of nutrients." Environmental Research Letters (2018).

Kandi, Sabitha, et al. "Biomedical significance of terpenes: an insight." Biomedicine 3.1 (2015): 8-10.

Karl, T., et al. "High concentrations of reactive biogenic VOCs at a high altitude site in late autumn." Geophysical Research Letters 28.3 (2001): 507-510. 
Kaushal, Sujay S., William H. McDowell, and Wilfred M. Wollheim. "Tracking evolution of urban biogeochemical cycles: past, present, and future." Biogeochemistry 121.1 (2014): 1-21.

Kegge, Wouter, and Ronald Pierik. "Biogenic volatile organic compounds and plant competition." Trends in plant science 15.3 (2010): 126-132.

Kesselmeier, John, and Michael Staudt. "Biogenic volatile organic compounds (VOC): an overview on emission, physiology and ecology." Journal of atmospheric chemistry 33.1 (1999): 23-88.

Keuper, Frida, et al. "A Race for Space? How Sphagnum fuscum stabilizes vegetation composition during long-term climate manipulations." Global Change Biology 17.6 (2011): 2162-2171.

Khalil, M. A. K., and R. A. Rasmussen. "Forest hydrocarbon emissions: relationships between fluxes and ambient concentrations." Journal of the Air \& Waste Management Association 42.6 (1992): 810-813.

Kharol, S. K., et al. "Dry deposition of reactive nitrogen from satellite observations of ammonia and nitrogen dioxide over North America." Geophysical Research Letters 45.2 (2018): 1157-1166.

Khedive, Ehsan, et al. "In situ emission of BVOCs by three urban woody species." Urban Forestry \& Urban Greening 21 (2017): 153-157.

Kim, Tae-Wook, et al. "Increasing $\mathrm{N}$ abundance in the northwestern Pacific Ocean due to atmospheric nitrogen deposition." Science (2011): 1206583.

Kim, Yongwon, et al. "Carbon exchange rates in Polytrichum juniperinum moss of burned black spruce forest in interior Alaska." Polar Science 8.2 (2014): 146-155.

Kirchner, Manfred, et al. "Elevated NH3 and NO2 air concentrations and nitrogen deposition rates in the vicinity of a highway in Southern Bavaria." Atmospheric Environment 39.25 (2005): 4531-4542.

Kirchner, Manfred, et al. "Nitrogen deposition along differently exposed slopes in the Bavarian Alps." Science of the Total Environment 470 (2014): 895-906.

Kodner, Robin B., and Linda E. Graham. "High-temperature, acid-hydrolyzed remains of Polytrichum (Musci, Polytrichaceae) resemble enigmatic Silurian-Devonian tubular microfossils." American Journal of Botany 88.3 (2001): 462-466. 
Koncz, Peter Bertalan. Allocation to Sexual and Asexual Reproduction Along Environmental Gradients of the Moss Polytrichum Juniperinum in the Low Arctic (Torngat Mountains National Park, Labrador, Canada). Diss. Memorial University of Newfoundland, 2012.

Koranda, M., et al. "Physiological responses of bryophytes Thuidium tamariscinum and Hylocomium splendens to increased nitrogen deposition." Annals of Botany 99.1 (2006): 161-169.

Korpelainen, Helena, et al. "The first sex-specific molecular marker discovered in the moss Pseudocalliergon trifarium." Journal of Heredity 99.6 (2008): 581-587.

Korpelainen, Helena. "Labile sex expression in plants." Biological Reviews 73.2 (1998): 157-180.

Korpelainen, Helena. "Patterns of resource allocation in male and female plants of Rumex acetosa and $R$. acetosella." Oecologia 89.1 (1992): 133-139.

Korsu, Kai. "Response of benthic invertebrates to disturbance from stream restoration: the importance of bryophytes." Hydrobiologia 523.1-3 (2004): 37-45.

Kosola, Kevin R. "Field Testing for Improved Nitrogen Use Efficiency of Corn-From Whole-Plant Physiology to Agroecosystem Scales." Engineering Nitrogen Utilization in Crop Plants. Springer, Cham, 2018. 161-172.

Kosonen, Zaida, et al. "Nitrogen concentration in moss compared with $\mathrm{N}$ load in precipitation and with total $\mathrm{N}$ deposition in Switzerland." Environmental Pollution 239 (2018): 169-178.

Kou, Liang, et al. "Nitrogen deposition increases root production and turnover but slows root decomposition in Pinus elliottii Plantations." New Phytologist 218.4 (2018): 1450-1461.

Kristensen, Hanne L., and Kaj Henriksen. "Soil nitrogen transformations along a successional gradient from Calluna heathland to Quercus forest at intermediate atmospheric nitrogen deposition." Applied Soil Ecology 8.1-3 (1998): 95-109.

Krupa, J. "The interdependence between transpiration intensity and the anatomical structure of moss leaves." Acta Societatis Botanicorum Poloniae 46.1 (1977): 5768 .

Krupa, Jan. "Anatomical structure of moss leaves and their photosynthetic activity." Acta Societatis Botanicorum Poloniae 53.1 (1984): 43-51. 
Krusche, A. V., et al. "Acid rain and nitrogen deposition in a sub-tropical watershed (Piracicaba): ecosystem consequences." Environmental Pollution 121.3 (2003): 389-399.

Kuhn, U., et al. "Isoprene and monoterpene emissions of Amazonian tree species during the wet season: Direct and indirect investigations on controlling environmental functions." Journal of Geophysical Research: Atmospheres 107.D20 (2002).

Kuhn, U., et al. "Isoprene and monoterpene fluxes from Central Amazonian rainforest inferred from tower-based and airborne measurements, and implications on the atmospheric chemistry and the local carbon budget." Atmospheric Chemistry and Physics 7.11 (2007): 2855-2879.

Kuhn, U., et al. "Seasonal differences in isoprene and light-dependent monoterpene emission by Amazonian tree species." Global Change Biology 10.5 (2004): 663682.

Kuhn, U., et al. "Strong correlation between isoprene emission and gross photosynthetic capacity during leaf phenology of the tropical tree species Hymenaea courbaril with fundamental changes in volatile organic compounds emission composition during early leaf development." Plant, Cell \& Environment 27.12 (2004): 14691485 .

Kuzma, Jennifer, and Ray Fall. "Leaf isoprene emission rate is dependent on leaf development and the level of isoprene synthase." Plant Physiology 101.2 (1993): 435-440.

Lambers, Hans. "Rising CO 2, secondary plant metabolism, plant-herbivore interactions and litter decomposition." CO2 and biosphere. Springer, Dordrecht, 1993. 263271.

Lang, Daniel, et al. "The Physcomitrella patens chromosome-scale assembly reveals moss genome structure and evolution." The Plant Journal 93.3 (2018): 515-533.

Laothawornkitkul, Jullada, et al. "Isoprene emissions influence herbivore feeding decisions." Plant, Cell \& Environment 31.10 (2008): 1410-1415.

Larmola, Tuula, et al. "The role of Sphagnum mosses in the methane cycling of a boreal mire." Ecology 91.8 (2010): 2356-2365.

Lee, J. A., et al. "22. Effects of ozone and atmospheric nitrogen deposition on bryophytes." Bryology for the Twenty-first Century (2018). 
Lehning, A., et al. "Isoprene synthase activity and its relation to isoprene emission in Quercus robur L. leaves." Plant, Cell \& Environment 22.5 (1999): 495-504.

Lelieveld, J. O. S., Paul J. Crutzen, and Frank J. Dentener. "Changing concentration, lifetime and climate forcing of atmospheric methane." Tellus B 50.2 (1998): 128150.

Lemaire, Gilles, and François Gastal. "Crop responses to nitrogen." Encyclopedia of Sustainability Science and Technology (2018): 1-27.

Lerdau, M., and M. Keller. "Controls on isoprene emission from trees in a subtropical dry forest." Plant, Cell \& Environment 20.5 (1997): 569-578.

Lerdau, Manuel, Alex Guenther, and Russ Monson. "Plant production and emission of volatile organic compounds." Bioscience 47.6 (1997): 373-383.

$\mathrm{Li}, \mathrm{Yi}$, et al. "Increasing importance of deposition of reduced nitrogen in the United States." Proceedings of the National Academy of Sciences (2016): 201525736.

Liang, Jinyou, et al. "Seasonal budgets of reactive nitrogen species and ozone over the United States, and export fluxes to the global atmosphere." Journal of Geophysical Research: Atmospheres 103.D11 (1998): 13435-13450.

Lichtenthaler, Hartmut K. "Biosynthesis, accumulation and emission of carotenoids, $\alpha$ tocopherol, plastoquinone, and isoprene in leaves under high photosynthetic irradiance." Photosynthesis Research 92.2 (2007): 163-179.

Ligrone, R., J. G. Duckett, and K. S. Renzaglia. "Conducting tissues and phyletic relationships of bryophytes." Philosophical Transactions of the Royal Society of London B: Biological Sciences 355.1398 (2000): 795-813.

Lim, Ho-Jin, Annmarie G. Carlton, and Barbara J. Turpin. "Isoprene forms secondary organic aerosol through cloud processing: Model simulations." Environmental Science \& technology 39.12 (2005): 4441-4446.

Limpens, Juul, and Frank Berendse. "How litter quality affects mass loss and N loss from decomposing Sphagnum." Oikos 103.3 (2003): 537-547.

Little, P., and M. H. Martin. "Biological monitoring of heavy metal pollution." Environmental Pollution (1970) 6.1 (1974): 1-19.

Litvak, M. E., et al. "The response of isoprene emission rate and photosynthetic rate to photon flux and nitrogen supply in aspen and white oak trees." Plant, Cell \& Environment 19.5 (1996): 549-559. 
Liu, Lingli, and Tara L. Greaver. "A global perspective on belowground carbon dynamics under nitrogen enrichment." Ecology Letters 13.7 (2010): 819-828.

Liu, Shibiao, et al. "Spore germination and protonemal development of Dolichomitriopsis diversiformis." Brazilian Archives of Biology and Technology 59 (2016).

Lloyd, David G., and C. J. Webb. "Secondary sex characters in plants." The botanical review 43.2 (1977): 177-216.

Lloyd, Kelvin M., et al. "Vegetation change after artificial disturbance in an alpine Chionochloa pallens grassland in New Zealand." New Zealand Journal of Ecology (2003): 31-36.

Logan, Barry A., Russell K. Monson, and Mark J. Potosnak. "Biochemistry and physiology of foliar isoprene production." Trends in plant science 5.11 (2000): 477-481.

Lohmann, Ulrike, and Johann Feichter. "Global indirect aerosol effects: a review." Atmospheric Chemistry and Physics 5.3 (2005): 715-737.

Loivamäki, Maaria, et al. "Isoprene interferes with the attraction of bodyguards by herbaceous plants." Proceedings of the National Academy of Sciences (2008).

Lombard, Jonathan, and David Moreira. "Origins and early evolution of the mevalonate pathway of isoprenoid biosynthesis in the three domains of life." Molecular biology and evolution 28.1 (2010): 87-99.

Longstaff, Ben J., et al. "An in situ study of photosynthetic oxygen exchange and electron transport rate in the marine macroalga Ulva lactuca (Chlorophyta)." Photosynthesis Research 74.3 (2002): 281-293.

Longton RE, Greene SW. 1967. The growth and reproduction of Polytrichum alpestre Hoppe on South Georgia. Philosophical Transactions of the Royal Society of London, Series B. 252: 295-322.

Longton RE, Schuster RM. Reproductive biology. In: Schuster RM, ed. New manual of bryology. Nichinan: Hattori Botanical Laboratory, (1983) 386-462.

Longton RE. Studies on growth, reproduction and population ecology in the bipolar moss Polytrichum alpestre Hoppe. Bryologist 82: (1979): 325-367. 
Longton RE. Sexual reproduction in bryophytes in relation to physical factors of the environment. In: Chopra RN, Bhatla SC, eds. Bryophyte development: physiology and biochemistry. Boca Raton, Florida: CRC Press, (1990) 139-166.

Longton, R. E. "Growth and productivity of the moss Polytrichum alpestre Hoppe in Antarctic regions." Holdgate, MW Antarctic ecology (1970).

Longton, RE. Reproduction of Antarctic mosses in the genera Polytrichum and Psilopilum with particular reference to temperature. British Antarctic Survey Bulletin 27: (1972): 51-96.

Longton, Royce E. "The role of bryophytes and lichens in polar ecosystems." Special Publication-British Ecological Society 13 (1997): 69-96.

Loreto, F., and T. D. Sharkey. "Isoprene emission by plants is affected by transmissible wound signals." Plant, Cell \& Environment 16.5 (1993): 563-570.

Loreto, Francesco, and Jörg-Peter Schnitzler. "Abiotic stresses and induced BVOCs." Trends in plant science 15.3 (2010): 154-166.

Loreto, Francesco, and Silvano Fares. "Is ozone flux inside leaves only a damage indicator? Clues from volatile isoprenoid studies." Plant Physiology 143.3 (2007b): 1096-1100.

Loreto, Francesco, and Thomas D. Sharkey. "A gas-exchange study of photosynthesis and isoprene emission in Quercus rubra L." Planta 182.4 (1990): 523-531.

Loreto, Francesco, and Violeta Velikova. "Isoprene produced by leaves protects the photosynthetic apparatus against ozone damage, quenches ozone products, and reduces lipid peroxidation of cellular membranes." Plant Physiology 127.4 (2001): 1781-1787.

Loreto, Francesco, et al. "13C labeling reveals chloroplastic and extrachloroplastic pools of dimethylallyl pyrophosphate and their contribution to isoprene formation." Plant Physiology 135.4 (2004): 1903-1907.

Loreto, Francesco, et al. "A hypothesis on the evolution of isoprenoid emission by oaks based on the correlation between emission type and Quercus taxonomy." Oecologia 115.3 (1998): 302-305.

Loreto, Francesco, et al. "Ozone quenching properties of isoprene and its antioxidant role in leaves." Plant Physiology 126.3 (2001): 993-1000. 
Loreto, Francesco, et al. "The relationship between isoprene emission rate and dark respiration rate in white poplar (Populus alba L.) leaves." Plant, Cell \& Environment 30.5 (2007a): 662-669.

Loreto, Francesco, Francesca Bagnoli, and Silvia Fineschi. "One species, many terpenes: matching chemical and biological diversity." Trends in plant science 14.8 (2009): 416-420.

Loreto, Francesco, et al. "Plant volatiles and the environment." Plant, cell \& environment 37.8 (2014): 1905-1908.

Lovett, Gary M. "Atmospheric deposition of nutrients and pollutants in North America: an ecological perspective." Ecological applications 4.4 (1994): 629-650.

Lu, Xiankai, et al. "Plant acclimation to long-term high nitrogen deposition in an N-rich tropical forest." Proceedings of the National Academy of Sciences 115.20 (2018): 5187-5192.

Luo, Yiqi, et al. "Progressive nitrogen limitation of ecosystem responses to rising atmospheric carbon dioxide." AIBS Bulletin 54.8 (2004): 731-739.

Machteld, Biersma Elisabeth, et al. "Genetic insights on the origins and age of the contemporary Antarctic flora." Book of Abstracts. 2017.

Maciel-Silva, Adaíses S., et al. "Altitude affects the reproductive performance in monoicous and dioicous bryophytes: examples from a Brazilian Atlantic rainforest." AoB plants 2012 (2012).

Magel, E., et al. "Photosynthesis and substrate supply for isoprene biosynthesis in poplar leaves." Atmospheric Environment 40 (2006): 138-151.

Magombo, Zacharia LK. "The phylogeny of basal peristomate mosses: evidence from cpDNA, and implications for peristome evolution." Systematic Botany (2003): 24-38.

Mahowald, Natalie. "Aerosol indirect effect on biogeochemical cycles and climate." Science 334.6057 (2011): 794-796.

Mäki, Mari, et al. "Interannual and seasonal dynamics of volatile organic compound fluxes from the boreal forest floor." Frontiers in plant science 10 (2019).

Makkonen, R., et al. "BVOC-aerosol-climate interactions in the global aerosol-climate model ECHAM5. 5-HAM2." Atmospheric Chemistry and Physics 12.21 (2012): 10077-10096. 
Mao, Qinggong, et al. "Effects of simulated N deposition on foliar nutrient status, $\mathrm{N}$ metabolism and photosynthetic capacity of three dominant understory plant species in a mature tropical forest." Science of the Total Environment 610 (2018): 555-562.

Maraist, Caitlin Ann. "Effect of Microbes on the Growth and Physiology of the Dioecious Moss, Ceratodon purpureus." (2018).

Marmulla, Robert, and Jens Harder. "Microbial monoterpene transformations - a review." Frontiers in microbiology 5 (2014): 346.

Marschall, Mariann, and Michael CF Proctor. "Are bryophytes shade plants? Photosynthetic light responses and proportions of chlorophyll a, chlorophyll $\mathrm{b}$ and total carotenoids." Annals of Botany 94.4 (2004): 593-603.

Maskell, Lindsay C., et al. "Nitrogen deposition causes widespread loss of species richness in British habitats." Global Change Biology 16.2 (2010): 671-679.

Maslov, M. N., et al. "Biological Activity of Soils in Mountain Tundra Ecosystems under Postpyrogenic Restoration." Eurasian Soil Science 51.6 (2018): 692-700.

Matsunaga, Sou N., et al. "Determination and potential importance of diterpene (kaur-16ene) emitted from dominant coniferous trees in Japan." Chemosphere 87.8 (2012): 886-893.

Mau, Rebecca L., et al. "Warming induced changes in soil carbon and nitrogen influence priming responses in four ecosystems." Applied Soil Ecology 124 (2018): 110116.

McDaniel, Stuart F., John H. Willis, and A. Jonathan Shaw. "A linkage map reveals a complex basis for segregation distortion in an interpopulation cross in the moss Ceratodon purpureus." Genetics 176.4 (2007): 2489-2500.

McGenity, Terry J., Andrew T. Crombie, and J. Colin Murrell. "Microbial cycling of isoprene, the most abundantly produced biological volatile organic compound on Earth." The ISME journal (2018): 1.

McKinley, Duncan C., and John M. Blair. "Woody plant encroachment by Juniperus virginiana in a mesic native grassland promotes rapid carbon and nitrogen accrual." Ecosystems 11.3 (2008): 454-468.

McLetchie DN. Sex-specific germination response in the liverwort Sphaerocarpos texanus (Sphaerocarpaceae), The Bryologist, 2001, vol. 104 (pg. 69-71) 
Melis, Anastasios. "Carbon partitioning in photosynthesis." Current opinion in chemical biology 17.3 (2013): 453-456.

Merced, Amelia, and Karen S. Renzaglia. "Moss stomata in highly elaborated Oedipodium (Oedipodiaceae) and highly reduced Ephemerum (Pottiaceae) sporophytes are remarkably similar." American Journal of Botany 100.12 (2013): 2318-2327.

Meskhidze, Nicholas, et al. "Quantifying environmental stress-induced emissions of algal isoprene and monoterpenes using laboratory measurements." Biogeosciences 12.3 (2015): 637-651.

Meyer, Michaela, et al. "Relevance of canopy drip for the accumulation of nitrogen in moss used as biomonitors for atmospheric nitrogen deposition in Europe." Science of the Total Environment 538 (2015): 600-610.

Milne, Peter J., et al. "Measurement of vertical distribution of isoprene in surface seawater, its chemical fate, and its emission from several phytoplankton monocultures." Marine Chemistry 48.3-4 (1995): 237-244.

Mishler, Brent D. "Reproductive ecology of bryophytes." Plant reproductive ecology: patterns and strategies (1988): 285-306.

Mishler, Brent D. "The biology of bryophytes—bryophytes aren't just small tracheophytes." (2001): 2129-2131.

Mishler, Brent D. "Three centuries of paradigm changes in biological classification: Is the end in sight?" Taxon 58.1 (2009): 61-67.

Miyata, Itsuo, and Takahide Hosokawa. "Seasonal variations of the photosynthetic efficiency and chlorophyll content of epiphytic mosses." Ecology 42.4 (1961): 766-775.

Mogollón, J. M., et al. "Assessing future reactive nitrogen inputs into global croplands based on the shared socioeconomic pathways." Environmental Research Letters 13.4 (2018): 044008.

Monson, R. K., et al. "Environmental and developmental controls over the seasonal pattern of isoprene emission from aspen leaves." Oecologia 99.3-4 (1994): 260270.

Monson, Russell K., and Ray Fall. "Isoprene emission from aspen leaves: influence of environment and relation to photosynthesis and photorespiration." Plant Physiology 90.1 (1989): 267-274. 
Monson, Russell K., et al. "Modeling the isoprene emission rate from leaves." New Phytologist 195.3 (2012): 541-559.

Monson, Russell K., et al. "Relationships among isoprene emission rate, photosynthesis, and isoprene synthase activity as influenced by temperature." Plant Physiology 98.3 (1992): 1175-1180.

Monson, Russell K., et al. "Relationships among isoprene emission rate, photosynthesis, and isoprene synthase activity as influenced by temperature." Plant Physiology 98.3 (1992): 1175-1180.

Monson, Russell K., et al. "Why only some plants emit isoprene." Plant, Cell \& Environment 36.3 (2013): 503-516.

Mooney, Harold A., Peter M. Vitousek, and Pamela A. Matson. "Exchange of materials between terrestrial ecosystems and the atmosphere." Science 238.4829 (1987): 926-932.

Moore, D. D. "Diversity and unity in the nuclear hormone receptors: a terpenoid receptor superfamily." The New Biologist 2.1 (1990): 100-105.

Moore, R. M., D. E. Oram, and S. A. Penkett. "Production of isoprene by marine phytoplankton cultures." Geophysical Research Letters 21.23 (1994): 2507-2510.

Morfopoulos, Catherine, et al. "A model of plant isoprene emission based on available reducing power captures responses to atmospheric CO2." New Phytologist 203.1 (2014): 125-139.

Morrison, R. T.; Boyd, R. N. Organic Chemistry, 6th ed.; Prentice Hall: Englewood Cliffs, NJ, 2002; p 277.

Mozafar, Ahmad. Plant vitamins. CRC Press, 2018.

Muchow, R. C. "Effect of nitrogen supply on the comparative productivity of maize and sorghum in a semi-arid tropical environment I. Leaf growth and leaf nitrogen." Field Crops Research 18.1 (1988): 1-16.

Müller, J-F., et al. "Global isoprene emissions estimated using MEGAN, ECMWF analyses and a detailed canopy environment model." Atmospheric Chemistry and Physics 8.5 (2008): 1329-1341.

Müller, Stefanie J., et al. "Can mosses serve as model organisms for forest research?" Annals of forest Science 73.1 (2016): 135-146. 
Munger, J. William, et al. "Regional budgets for nitrogen oxides from continental sources: Variations of rates for oxidation and deposition with season and distance from source regions." Journal of Geophysical Research: Atmospheres 103.D7 (1998): 8355-8368.

Nadelhoffer, Knute J. "The potential effects of nitrogen deposition on fine-root production in forest ecosystems." New Phytologist 147.1 (2000): 131-139.

Nakamura, Toshihiko. "Effect of bryophytes on survival of conifer seedlings in subalpine forests of central Japan." Ecological Research 7.2 (1992): 155-162.

Neff, Jason C., et al. "Variable effects of nitrogen additions on the stability and turnover of soil carbon." Nature 419.6910 (2002): 915.

Nehlsen, Willa."Control of gametophore bud initiation in Polytrichum juniperinum." Santa Cruz, CA: University of California. 142 p. Dissertation. (1979): 0051-0051.

Neinhuis, C., and R. Jetter. "Ultrastructure and chemistryofepicuticular wax crystals in Polytrichales sporophytes." Journal of Bryology 18.3 (1995): 399-406.

Nellemann, Christian, and Mette Goul Thomsen. "Long-term changes in forest growth: potential effects of nitrogen deposition and acidification." Water, Air, and Soil Pollution 128.3-4 (2001): 197-205.

Neumann, Daniel, et al. "Importance of high resolution nitrogen deposition data for biogeochemical modeling in the western Baltic Sea and the contribution of the shipping sector." Ocean Sci. Discuss (2018): 1-31.

Newton, Angela E., et al. "Evolution of the major moss lineages: phylogenetic analyses based on multiple gene sequences and morphology." Bryologist (2000): 187-211.

$\mathrm{Ng}$, N. L., et al. "Secondary organic aerosol (SOA) formation from reaction of isoprene with nitrate radicals (NO 3)." Atmospheric Chemistry and Physics 8.14 (2008): 4117-4140.

Nickrent, Daniel L., et al. "Multigene phylogeny of land plants with special reference to bryophytes and the earliest land plants." Molecular Biology and Evolution 17.12 (2000): 1885-1895.

Niinemets, Ülo, and Zhihong Sun. "How light, temperature, and measurement and growth [CO2] interactively control isoprene emission in hybrid aspen." Journal of experimental Botany 66.3 (2014): 841-851. 
Niinemets, Ülo, et al. "A model of isoprene emission based on energetic requirements for isoprene synthesis and leaf photosynthetic properties for Liquidambar and Quercus." Plant, Cell \& Environment 22.11 (1999): 1319-1335.

Niinemets, Ülo, et al. "The emission factor of volatile isoprenoids: stress, acclimation, and developmental responses." Biogeosciences 7.7 (2010): 2203-2223.

Niinemets, Ülo, Francesco Loreto, and Markus Reichstein. "Physiological and physicochemical controls on foliar volatile organic compound emissions." Trends in plant science 9.4 (2004): 180-186.

Niinemets, Ülo, Zhihong Sun, and Eero Talts. "Controls of the quantum yield and saturation light of isoprene emission in different-aged aspen leaves." Plant, Cell \& Environment 38.12 (2015): 2707-2720.

Niinemets, Ülo. "What Are Plant-Released Biogenic Volatiles and How They Participate in Landscape-to Global-Level Processes?" Ecosystem Services from Forest Landscapes. Springer, Cham, 2018. 29-56.

Niklas, Karl J., and Ulrich Kutschera. "The evolution of the land plant life cycle." New Phytologist 185.1 (2010): 27-41.

Nishihama R, Ishizaki K, Hosaka M, Matsuda Y, Kubota A, Kohchi T. Phytochromemediated regulation of cell division and growth during regeneration and sporeling development in the liverwort Marchantia polymorpha. J Plant Res. 2015; 128: 407-421.

Nogues, Isabel, et al. "Leaf gas exchange and isoprene emission in poplar in response to long-term experimental night-time warming and summer drought in a foreststeppe ecosystem." Environmental and Experimental Botany (2018).

O'Brien, J. M., et al. "Measurements of alkyl and multifunctional organic nitrates at a rural site in Ontario." Journal of Geophysical Research: Atmospheres 100.D11 (1995): 22795-22804.

Oishi, Yoshitaka. "Urban heat island effects on moss gardens in Kyoto, Japan." Landscape and Ecological Engineering (2018): 1-8.

Ojiodu, C. C., and E. E. Elemike. "Temporal variability of heavy metal content in the atmosphere of Ketu-mile 12 area of Lagos-State, southwestern-Nigeria using moss plant Polytrichum juniperinum as bioindicator." Science World Journal 13.2 (2018): 12-16. 
Oliver, Melvin J., J. E. F. F. Velten, and Brent D. Mishler. "Desiccation tolerance in bryophytes: a reflection of the primitive strategy for plant survival in dehydrating habitats?" Integrative and Comparative Biology 45.5 (2005): 788-799.

Oliver, Melvin J., Jeff Velten, and Andrew J. Wood. "Bryophytes as experimental models for the study of environmental stress tolerance: Tortula ruralis and desiccationtolerance in mosses." Plant Ecology 151.1 (2000): 73-84.

Ollinger, Scott V., et al. "A spatial model of atmospheric deposition for the northeastern US." Ecological applications 3.3 (1993): 459-472.

Olmstead, Emily, and Julian Aherne. "Are tissue concentrations of Hylocomium splendens a good predictor of nitrogen deposition?." Atmospheric Pollution Research (2018).

Owen, S. M., et al. "Light dependency of VOC emissions from selected Mediterranean plant species." Atmospheric Environment 36.19 (2002): 3147-3159.

Owen, Susan M., and Josep Peñuelas. "Opportunistic emissions of volatile isoprenoids." Trends in plant science 10.9 (2005): 420-426.

Pakarinen, Pekka, and Kimmo Tolonen. "Nutrient contents of Sphagnum mosses in relation to bog water chemistry in northern Finland." Lindbergia (1977): 27-33.

Palmer, Paul I., and Stephanie L. Shaw. "Quantifying global marine isoprene fluxes using MODIS chlorophyll observations." Geophysical Research Letters 32.9 (2005).

Paolillo, D. J., Jn. 1969. The plastids of Polytrichum II. The sporogenous cells. Cytologia 34: 133-144.

Pardo, Linda H., et al. "Effects of nitrogen deposition and empirical nitrogen critical loads for ecoregions of the United States." Ecological applications 21.8 (2011): 3049-3082.

Patiño, Jairo, et al. "Climate threat on the Macaronesian endemic bryophyte flora." Scientific reports 6. (2016): 29156.

Patterson, M. A., et al. "Modeling the effects of fuel injection characteristics on diesel engine soot and NOx emissions." SAE transactions (1994): 836-852.

Paulissen, Maurice PCP, et al. "Differential effects of nitrate and ammonium on three fen bryophyte species in relation to pollutant nitrogen input." New Phytologist 164.3 (2004): 451-458. 
Payne, Richard J., et al. "Nitrogen deposition and plant biodiversity: past, present, and future." Frontiers in Ecology and the Environment 15.8 (2017): 431-436.

Pearce, I. S. K., Sarah Jane Woodin, and R. Van der Wal. "Physiological and growth responses of the montane bryophyte Racomitrium lanuginosum to atmospheric nitrogen deposition." New Phytologist 160.1 (2003): 145-155.

Pegoraro E, Rey ANA, Abrell L, Haren J, Lin G. Drought effect on isoprene production and consumption in Biosphere 2 tropical rainforest. Glob Change Biol. 2006; $12: 456-69$.

Penny, M. G., and N. G. Bayfield. "Photosynthesis in desiccated shoots of Polytrichum." New Phytologist 91.4 (1982): 637-645.

Peñuelas, J., and J. Llusià. "The complexity of factors driving volatile organic compound emissions by plants." Biologia Plantarum 44.4 (2001): 481-487.

Peñuelas, Josep, and Iolanda Filella. "Phenology feedbacks on climate change." Science 324.5929 (2009): 887-888.

Peñuelas, Josep, and Joan Llusià. "BVOCs: plant defense against climate warming?" Trends in plant science 8.3 (2003): 105-109.

Peñuelas, Josep, and Michael Staudt. "BVOCs and global change." Trends in plant science 15.3 (2010): 133-144.

Pesch, Roland, et al. "Monitoring nitrogen accumulation in mosses in central European forests." Environmental Pollution 155.3 (2008): 528-536.

Petron, G., et al. "Seasonal temperature variations influence isoprene emission." Geophysical Research Letters 28.9 (2001): 1707-1710.

Phillips, Sharon B., et al. "Modelling and analyses of the atmospheric nitrogen deposition in North Carolina." International journal of global environmental issues 6.2-3 (2006): 231-252.

Phoenix, Gareth K., et al. "Impacts of atmospheric nitrogen deposition: responses of multiple plant and soil parameters across contrasting ecosystems in long-term field experiments." Global Change Biology 18.4 (2012): 1197-1215.

Pier, P. A., and C. McDuffie Jr. "Seasonal isoprene emission rates and model comparisons using whole-tree emissions from white oak." Journal of Geophysical Research: Atmospheres 102.D20 (1997): 23963-23971. 
Piesik, D., et al. "Volatile organic compounds released by R umex confertus following H ypera rumicis herbivory and weevil responses to volatiles." Journal of applied entomology 140.4 (2016): 308-316.

Pike, Rachel C., and Paul J. Young. "How plants can influence tropospheric chemistry: the role of isoprene emissions from the biosphere." Weather 64.12 (2009): 332336.

Pio, C. A., et al. "Diurnal and seasonal emissions of volatile organic compounds from cork oak (Quercus suber) trees." Atmospheric Environment 39.10 (2005): 18171827.

Pitcairn, C. E. R., D. Fowler, and J. Grace. "Deposition of fixed atmospheric nitrogen and foliar nitrogen content of bryophytes and Calluna vulgaris (L.) Hull."

Environmental Pollution 88.2 (1995): 193-205.

Pitcairn, C. E. R., et al. "Bioindicators of enhanced nitrogen deposition." Environmental Pollution 126.3 (2003): 353-361.

Pöhlker, Christopher, et al. "Biogenic potassium salt particles as seeds for secondary organic aerosol in the Amazon." Science 337.6098 (2012): 1075-1078.

Poikolainen, J., et al. "Long-term changes in nitrogen deposition in Finland (1990-2006) monitored using the moss Hylocomium splendens." Environmental Pollution 157.11 (2009): 3091-3097.

Pokhilko, Alexandra, et al. "Mathematical modelling of the diurnal regulation of the MEP pathway in Arabidopsis." New Phytologist 206.3 (2015): 1075-1085.

Pold, Grace, et al. "Changes in substrate availability drive carbon cycle response to chronic warming." Soil Biology and Biochemistry 110 (2017): 68-78.

Pongratz, J., et al. "Effects of anthropogenic land cover change on the carbon cycle of the last millennium." Global Biogeochemical Cycles 23.4 (2009).

Porembski, Stefan, and Wilhelm Barthlott. "Granitic and gneissic outcrops (inselbergs) as centers of diversity for desiccation-tolerant vascular plants." Plant Ecology 151.1 (2000): 19-28.

Portillo-Estrada, Miguel, et al. "Contribution of volatile organic compound fluxes to the ecosystem carbon budget of a poplar short-rotation Plantation." GCB Bioenergy 10.6 (2018): 405-414. 
Potter, Jac A., et al. "Growth responses of Polytrichum commune and Hylocomium splendens to simulated environmental change in the sub-arctic." New Phytologist 131.4 (1995): 533-541.

Pratt, Kerri A., et al. "Organosulfates in cloud water above the Ozarks' isoprene source region." Atmospheric Environment 77 (2013): 231-238.

Price, Peter W., et al. "Interactions among three trophic levels: influence of plants on interactions between insect herbivores and natural enemies." Annual review of Ecology and Systematics 11.1 (1980): 41-65.

Proctor, M. C. F. "Surface wax on the leaves of some mosses." Journal of Bryology 10.4 (1979): 531-538.

Proctor, M. C. F. "The physiological basis of bryophyte production." Botanical Journal of the Linnean Society 104.1-3 (1990): 61-77.

Proctor, Michael CF, and Valerie C. Pence. "Vegetative tissues: bryophytes, vascular resurrection plants and vegetative propagules." Desiccation and survival in plants: Drying without dying (2002): 207-237.

Proctor, M. C. F. "Why do Polytrichaceae have lamellae?." Journal of Bryology 27.3 (2005): 221-229.

Proctor, Michael CF, Roberto Ligrone, and Jeffrey G. Duckett. "Desiccation tolerance in the moss Polytrichum formosum: physiological and fine-structural changes during desiccation and recovery." Annals of botany 99.1 (2006): 75-93.

Proctor, M. C. F. "Water analyses from some Irish bogs and fens, with thoughts on'the Schoenus problem'." Biology and Environment: Proceedings of the Royal Irish Academy. Royal Irish Academy, 2008.

Proctor, Michael CF, and Jeffrey W. Bates. "Chlorophyll-fluorescence measurements in bryophytes: evidence for three main types of light-curve response." Journal of Bryology 40.1 (2018): 1-11.

Pujadas, M., et al. "Passive remote sensing of nitrogen dioxide as a tool for tracking air pollution in urban areas: the Madrid urban plume, a case of study." Atmospheric Environment 34.19 (2000): 3041-3056.

Quesada, Benjamin, et al. "Potential strong contribution of future anthropogenic land-use and land-cover change to the terrestrial carbon cycle." Environmental Research Letters 13.6 (2018): 064023. 
Raciti, Steve Michael, P. M. Groffman, and T. J. Fahey. "Nitrogen retention in urban lawns and forests." Ecological applications 18.7 (2008): 1615-1626.

Raghoebarsing, Ashna A., et al. "Methanotrophic symbionts provide carbon for photosynthesis in peat bogs." Nature 436.7054 (2005): 1153.

Raguso, Robert A. "Wake up and smell the roses: the ecology and evolution of floral scent." Annual review of ecology, evolution, and systematics 39 (2008): 549-569.

Rao, Dhruva N. "Responses of bryophytes to air pollution." Bryophyte ecology. Springer, Dordrecht, 1982. 445-471.

Rap, A., et al. "Enhanced global primary production by biogenic aerosol via diffuse radiation fertilization." Nature GeoScience (2018): 1.

Rapparini, Francesca, Rita Baraldi, and Osvaldo Facini. "Seasonal variation of monoterpene emission from Malus domestica and Prunus avium." Phytochemistry 57.5 (2001): 681-687.

Rasmussen, Reinhold A. "Isoprene: identified as a forest-type emission to the atmosphere." Environmental Science \& Technology 4.8 (1970): 667-671.

Rasulov, Bahtijor, et al. "Evidence that light, carbon dioxide, and oxygen dependencies of leaf isoprene emission are driven by energy status in hybrid aspen." Plant Physiology151.1 (2009): 448-460.

Rasulov, Bahtijor, et al. "Temperature response of isoprene emission in vivo reflects a combined effect of substrate limitations and isoprene synthase activity: a kinetic analyses." Plant Physiology (2010): pp-110.

Rasulov, Bahtijor, et al. "Competition between isoprene emission and pigment synthesis during leaf development in aspen." Plant, Cell \& Environment 37.3 (2014): 724741.

Rasulov, Bahtijor, et al. "Acclimation of isoprene emission and photosynthesis to growth temperature in hybrid aspen: resolving structural and physiological controls." Plant, Cell \& Environment 38.4 (2015): 751-766.

Rasulov, Bahtijor, et al. "Evidence That Isoprene Emission Is Not Limited by Cytosolic Metabolites. Exogenous Malate Does Not Invert the Reverse Sensitivity of Isoprene Emission to High [CO2]." Plant Physiology 176.2 (2018): 1573-1586. 
Raven, John A. "Selection pressures on stomatal evolution." New Phytologist 153.3 (2002): 371-386.

Raven, John A., and Dianne Edwards. "Photosynthesis in early land plants: adapting to the terrestrial environment." Photosynthesis in bryophytes and early land plants. Springer, Dordrecht, 2014. 29-58.

Reichstein, Markus, et al. "Climate extremes and the carbon cycle." Nature 500.7462 (2013): 287.

Reinhart, David A., and Robert J. Thomas. "Sucrose uptake and transport in conducting cells of Polytrichum commune." Bryologist (1981): 59-64.

Renault, Hugues, et al. "A phenol-enriched cuticle is ancestral to lignin evolution in land plants." Nature communications 8 (2017): 14713.

Rensing, Stefan A. "Great moments in evolution: the conquest of land by plants." Current opinion in plant biology 42 (2018a): 49-54.

Rensing, Stefan A. "Plant evolution: phylogenetic relationships between the earliest land plants." Current Biology 28.5 (2018b): R210-R213.

Rensing, Stefan A., et al. "The Physcomitrella genome reveals evolutionary insights into the conquest of land by plants." Science (2007).

Renzaglia, Karen Sue, et al. "Vegetative and reproductive innovations of early land plants: implications for a unified phylogeny." Philosophical Transactions of the Royal Society B: Biological Sciences 355.1398 (2000): 769.

Renzaglia KS, Schuette S, Duff RJ, Ligrone R, Shaw AJ, Mishler BD, Duckett JG. 2007. Bryophyte phylogeny: advancing the molecular and morphological frontiers. The Bryologist 110: 179-213.

Reski, Ralf. "Physcomitrella and Arabidopsis: the David and Goliath of reverse genetics." Trends in plant science 3.6 (1998): 209-210.

Reski, Ralf, Hansol Bae, and Henrik Toft Simonsen. "Physcomitrella patens, a versatile synthetic biology chassis." Plant Cell Reports (2018a): 1-9.

Reski, Ralf. "Quantitative moss cell biology." Current opinion in plant biology 46 (2018b): 39-47. 
Rice, Steven K., David Collins, and Ann M. Anderson. "Functional significance of variation in bryophyte canopy structure." American Journal of Botany 88.9 (2001): 1568-1576.

Richter, D. D., K. P. O’Neill, and E. S. Kasischke. "Stimulation of soil respiration in burned black spruce (Picea mariana L.) forest ecosystems: a hypothesis." Fire, Climate Change, and Carbon Cycling in the North American Boreal Forest. Springer-Verlag, New York (2000):164-178.

Riebeek, Holli. "The Carbon Cycle: Feature Articles." National Aeronautics and Space Administration (NASA), NASA Earth Observatory. (2011). Web. 02 Aug. 2018. https://earthobservatory.nasa.gov/Features/CarbonCycle/page1.php

Rinderle, Ursula, and Hartmut K. Lichtenthaler. "The chlorophyll fluorescence ratio F690/F735 as a possible stress indicator." Applications of Chlorophyll Fluorescene in Photosynthesis Research, Stress Physiology, Hydrobiology and Remote Sensing. Springer, Dordrecht, 1988. 189-196.

Rinnan, Riikka, et al. "Emission of non-methane volatile organic compounds (VOCs) from boreal peatland microcosms - effects of ozone exposure." Atmospheric Environment 39.5 (2005): 921-930.

Rinne, H. J. I., et al. "Isoprene and monoterpene fluxes measured above Amazonian rainforest and their dependence on light and temperature." Atmospheric Environment 36.14 (2002): 2421-2426.

Roberts, Alison W., Eric M. Roberts, and Candace H. Haigler. "Moss cell walls: structure and biosynthesis." Frontiers in plant Science 3 (2012): 166.

Robertson, G. W., et al. "Changes in the chemical composition of volatiles released by the flowers and fruits of the red raspberry (Rubus idaeus) cultivar Glen Prosen." Phytochemistry 38.5 (1995): 1175-1179.

Robinson, Sharon A., et al. "Desiccation tolerance of three moss species from continental Antarctica." Functional plant biology 27.5 (2000): 379-388.

Root, Heather T., et al. "A simple tool for estimating throughfall nitrogen deposition in forests of western North America using lichens." Forest Ecology and Management 306 (2013): 1-8.

Root, Heather T., et al. "Epiphytic macrolichen indication of air quality and climate in interior forested mountains of the Pacific Northwest, USA." Ecological Indicators 53 (2015): 95-105. 
Rosenstiel, Todd N., et al. "Increased CO 2 uncouples growth from isoprene emission in an agriforest ecosystem." Nature 421.6920 (2003): 256.

Rosenstiel, T. N., et al. "Induction of poplar leaf nitrate reductase: a test of extrachloroplastic control of isoprene emission rate." Plant Biology 6.1 (2004): $12-21$.

Rosenstiel, Todd N., et al. "Sex-specific volatile compounds influence microarthropodmediated fertilization of moss." Nature 489.7416 (2012): 431.

Rossi, Lorenzo, et al. "Overexpression of Populus $\times$ canescens isoprene synthase gene in Camelina sativa leads to alterations in its growth and metabolism." Journal of Plant Physiology 215 (2017): 122-131.

Royles, Jessica, and Howard Griffiths. "Invited review: climate change impacts in polar regions: lessons from Antarctic moss bank archives." Global Change Biology 21.3 (2015): 1041-1057.

Ruiz-Molina, Natalia, Miguel Ángel Villalobos-López, and Mario Arias-Zabala. "Protonema suspension cultures of the medicinal moss Polytrichum juniperinum." In Vitro Cellular \& Developmental Biology-Plant 52.4 (2016): 419-426.

Rundel, Philip W., Donald T. Gordon, and David J. Parsons. "Montane and subalpine vegetation of the Sierra Nevada and Cascade ranges [California]." (1977).

Ryan, Annette C., et al. "Isoprene emission protects photosynthesis but reduces plant productivity during drought in transgenic tobacco (Nicotiana tabacum) plants." New Phytologist 201.1 (2014): 205-216.

Rydgren, K., and R. H. Økland. "Sex distribution and sporophyte frequency in a population of the clonal moss Hylocomium splendens." Journal of Bryology 24.3 (2002a): 207-214.

Rydgren, Knut, and Rune H. Økland. "Ultimate costs of sporophyte production in the clonal moss Hylocomium splendens." Ecology 83.6 (2002b): 1573-1579.

Rydgren, Knut, and Rune H. Økland. "Short-term costs of sexual reproduction in the clonal moss Hylocomium splendens." The Bryologist 106.2 (2003): 212-220.

Rydgren, Knut, Rune Halvorsen, and Nils Cronberg. "Infrequent sporophyte production maintains a female-biased sex ratio in the unisexual clonal moss Hylocomium splendens." Journal of Ecology 98.5 (2010): 1224-1231. 
Ryo, Masashi, et al. "Light-regulated PAS-containing histidine kinases delay gametophore formation in the moss Physcomitrella patens." Journal of experimental Botany (2018).

Ryömä, Riitta, and Sanna Laaka-Lindberg. "Bryophyte recolonization on burnt soil and logs." Scandinavian Journal of Forest Research 20.S6 (2005): 5-16

Sabovljeviæ, Marko, Milorad Vujièiæ, and Aneta Sabovljeviæ. "Plant growth regulators in bryophytes." Botanica serbica 38.1 (2014): p99-107.

Sala, Osvaldo E., et al. "Global biodiversity scenarios for the year 2100." Science 287.5459 (2000): 1770-1774.

Sanadze, G. A., and A. N. Kalandaze. "Light and temperature curves of the evolution of C5H8." Fiziol. Rast 13 (1966): 458-461.

Sanadze, G. A. "Light-dependent excretion of molecular isoprene." Prog Photosynth Res 2 (1969): 701-707.

Sanadze, G. A. "Biogenic isoprene (a review)." Russian Journal of Plant Physiology 51.6 (2004): 729-741.

Sanadze, G. A. "Photobiosynthesis of isoprene as an example of leaf excretory function in the light of contemporary thermodynamics." Russian Journal of Plant Physiology 57.1 (2010): 1-6.

Sanadze, G. A., A. A. Davituliani, and S. Sh Pkhachiashvili. "Biological role for synthesis and release of isoprene by photosynthesizing cells in view of the entropy phenomenon." Russian journal of Plant Physiology 63.2 (2016): 204-209.

Sanadze, G. A. "Biogenic isoprene emission as expression of dissipativity, a fundamental cell property." Russian Journal of Plant Physiology 64.2 (2017): 133-140.

Sarafis, V. "A biological account of Polytrichum commune." New Zealand Journal of Botany 9.4 (1971): 711-724.

Sarukhan, Jose, and Madhav Gadgil. "Studies on Plant Demography: Ranunculus Repens L., R. Bulbosus L. and R. Acris L.: III. A Mathematical Model Incorporating Multiple Modes of Reproduction." The Journal of Ecology (1974): 921-936.

Sasaki, Kanako, Kazuaki Ohara, and Kazufumi Yazaki. "Gene expression and characterization of isoprene synthase from Populus alba." Febs Letters 579.11 (2005): 2514-2518. 
Saxena, Pallavi, and Chirashree Ghosh. "Establishing Correlation Between Abiotic Stress and Isoprene Emission of Selected Plant Species." Emerging Issues in Ecology and Environmental Science. Springer, Cham, 2019. 43-65.

Schaefer, H. Martin, Veronika Schaefer, and Douglas J. Levey. "How plant-animal interactions signal new insights in communication." Trends in Ecology \& Evolution 19.11 (2004): 577-584.

Schaefer, H. Martin, and Graeme D. Ruxton. "Fatal attraction: carnivorous plants roll out the red carpet to lure insects." Biology Letters 4.2 (2008): 153-155.

Schnitzler, J-P, et al. "Characterization of an isoprene synthase from leaves of Quercus petraea (Mattuschka) Liebl." Botanica Acta 109.3 (1996): 216-221.

Schnitzler, J-P., Andrea Lehning, and R. Steinbrecher. "Seasonal pattern of isoprene synthase activity in Quercus robur leaves and its significance for modeling isoprene emission rates." Botanica Acta 110.3 (1997): 240-243.

Schnitzler, J-P., et al. "Biochemical properties of isoprene synthase in poplar (Populus $\times$ canescens)." Planta 222.5 (2005): 777-786.

Schofield, W. B. "Ecological significance of morphological characters in the moss gametophyte." Bryologist (1981): 149-165.

Scholefield, P. A., et al. "Impact of rising CO2 on emissions of volatile organic compounds: isoprene emission from Phragmites australis growing at elevated CO2 in a natural carbon dioxide spring." Plant, Cell \& Environment 27.4 (2004): 393-401.

Schreiber, U., and W. Bilger. "Rapid assessment of stress effects on plant leaves by chlorophyll fluorescence measurements." Plant response to stress. Springer, Berlin, Heidelberg, 1987. 27-53.

Schröder, Winfried, et al. "First Europe-wide correlation analyses identifying factors best explaining the total nitrogen concentration in mosses." Atmospheric Environment 44.29 (2010): 3485-3491.

Schulte-Uebbing, Lena, and Wim de Vries. "Global-scale impacts of nitrogen deposition on tree carbon sequestration in tropical, temperate, and boreal forests: A metaanalyses." Global Change Biology 24.2 (2018): e416-e431. 
Scotter, George Wilby. "Effects of forest fires on the winter range of barren-ground caribou in northern Saskatchewan." Can. Wildl. Manage. Bull. Series 1 (1964): 111.

Sedia, Ekaterina G., and Joan G. Ehrenfeld. "Lichens and mosses promote alternate stable plant communities in the New Jersey Pinelands." Oikos 100.3 (2003): 447-458.

Seinfeld, John H., and Spyros N. Pandis. Atmospheric Chemistry and Physics: from air pollution to climate change. John Wiley \& Sons, 2012.

Shafigullina, N. R., and E. N. Karzhavkina. "Productivity of Polytrichum juniperinum Hedw. in forest ecosystem of Tatarstan." IOP Conference Series: Earth and Environmental Science. Vol. 107. No. 1. IOP Publishing, 2018

Sharkey, T. D., F. Loreto, and C. F. Delwiche. "High carbon dioxide and sun/shade effects on isoprene emission from oak and aspen tree leaves." Plant, Cell \& Environment 14.3 (1991): 333-338.

Sharkey, Thomas D., and Francesco Loreto. "Water stress, temperature, and light effects on the capacity for isoprene emission and photosynthesis of kudzu leaves." Oecologia 95.3 (1993): 328-333.

Sharkey, Thomas D., and Eric L. Singsaas. "Why plants emit isoprene." Nature 374.6525 (1995): 769.

Sharkey, Thomas D., et al. "Field measurements of isoprene emission from trees in response to temperature and light." Tree Physiology 16.7 (1996): 649-654.

Sharkey, Thomas D., et al. "Weather effects on isoprene emission capacity and applications in emissions algorithms." Ecological applications 9.4 (1999): 11321137.

Sharkey, Thomas D., and Sansun Yeh. "Isoprene emission from plants." Annual review of plant biology 52.1 (2001): 407-436.

Sharkey, Thomas D., et al. "Evolution of the isoprene biosynthetic pathway in kudzu." Plant Physiology 137.2 (2005a): 700-712

Sharkey, Thomas D. "Effects of moderate heat stress on photosynthesis: importance of thylakoid reactions, rubisco deactivation, reactive oxygen species, and thermotolerance provided by isoprene." Plant, Cell \& Environment 28.3 (2005b): 269-277. 
Sharkey, Thomas D., Amy E. Wiberley, and Autumn R. Donohue. "Isoprene emission from plants: why and how." Annals of Botany 101.1 (2007): 5-18.

Sharkey, Thomas D. "Is it useful to ask why plants emit isoprene?." Plant, Cell \& Environment 36.3 (2013): 517-520.

Sharkey, Thomas D., and Russell K. Monson. "The future of isoprene emission from leaves, canopies and landscapes." Plant, Cell \& Environment 37.8 (2014): 17271740 .

Sharkey, Thomas D., and Russell K. Monson. "Isoprene research-60 years later, the biology is still enigmatic." Plant, Cell \& Environment 40.9 (2017): 1671-1678.

Shaw, Jonathan. "The relevance of ecology to species concepts in bryophytes." Bryologist (1985): 199-206.

Shaw, Jonathan. "A new approach to the experimental propagation of bryophytes." Taxon (1986): 671-675.

Shaw, A. Jonathan, and James F. Gaughan. "Control of sex ratios in haploid populations of the moss, Ceratodon purpureus." American Journal of Botany 80.5 (1993): 584-591.

Shaw, A. Jonathan. "The genetic structure of sporophytic and gametophytic populations of the moss, Funaria hygrometrica Hedw." Evolution 45.5 (1991a): 1260-1274.

Shaw, A. Jonathan. "Ecological genetics of serpentine tolerance in the moss, Funaria flavicans: Variation within and among haploid sib families." American Journal of Botany 78.11 (1991b): 1487-1493.

Shaw, Jonathan, and Samuel C. Beer. "Life history variation in gametophyte populations of the moss Ceratodon purpureus (Ditrichaceae)." American Journal of Botany 86.4 (1999): 512-521.

Shaw, A. Jonathan, and Bernard Goffinet, eds. Bryophyte biology. Cambridge University Press, 2000.

Shaw, Stephanie L., Sallie W. Chisholm, and Ronald G. Prinn. "Isoprene production by Prochlorococcus, a marine cyanobacterium, and other phytoplankton." Marine Chemistry 80.4 (2003): 227-245.

Sheil, Douglas. "Forests, atmospheric water and an uncertain future: the new biology of the global water cycle." Forest Ecosystems 5.1 (2018): 19. 
Sheil, Douglas. "How plants water our planet: advances and imperatives." Trends in plant science 19.4 (2014): 209-211.

Shetekauri, Shamil, et al. "Biomonitoring Air Pollution Using Moss in Georgia." Polish Journal of Environmental Studies 27.5 (2018): 2259-2266.

Shi, Xian-Meng, et al. "Epiphytic bryophytes as bio-indicators of atmospheric nitrogen deposition in a subtropical montane cloud forest: response patterns, mechanism, and critical load." Environmental Pollution 229 (2017): 932-941.

Shortlidge, Erin E., Todd N. Rosenstiel, and Sarah M. Eppley. "Tolerance to environmental desiccation in moss sperm." New Phytologist 194.3 (2012): 741750 .

Shortlidge, Erin Elizabeth. "Testing the Ecological and Physiological Factors Influencing Reproductive Success in Mosses." (2014).

Shortlidge, Erin E., et al. "Passive warming reduces stress and shifts reproductive effort in the Antarctic moss, Polytrichastrum alpinum." Annals of Botany 119.1 (2016): 27-38.

Shotyk, William, et al. "History of atmospheric lead deposition since 12,370 14C yr BP from a peat bog, Jura Mountains, Switzerland." Science 281.5383 (1998): 16351640 .

Shukla, Arvind K., et al. "Spatial Distribution and Management Zones for Sulphur and Micronutrients in Shiwalik Himalayan Region of India." Land Degradation \& Development 28.3 (2017): 959-969.

Silva ASM, Cavalcanti PK, Simabukuro EA. Effects of light and nutrients on different germination phases of the Cosmopolitan moss Bryum argenteum Hedw. (Bryaceae). Braz Arch Biol Technol. 2010; 53 (4): 763-769.

Silva-e-Costa, Juliana da Costa, et al. "Spore germination, early development and some notes on the effects of in vitro culture medium on Frullania ericoides (Nees) Mont. (Frullaniaceae, Marchantiophyta)." Acta Botanica Brasilica AHEAD (2017): 0-0.

Sims, R. A., and J. M. Stewart. "Aerial biomass distribution in an undisturbed and disturbed subarctic bog." Canadian Journal of Botany 59.5 (1981): 782-786.

Singh, Abhishek, Navnita Srivastava, and Suresh Kumar Dubey. "Molecular characterization and kinetics of isoprene degrading bacteria." Bioresource technology (2019). 
Singsaas, Eric L., et al. "Isoprene increases thermotolerance of isoprene-emitting species." Plant Physiology 115.4 (1997): 1413-1420.

Singsaas, E. L., and T. D. Sharkey. "The regulation of isoprene emission responses to rapid leaf temperature fluctuations." Plant, Cell \& Environment 21.11 (1998): $1181-1188$.

Sinha, V., et al. "Air-sea fluxes of methanol, acetone, acetaldehyde, isoprene and DMS from a Norwegian fjord following a phytoplankton bloom in a mesocosm experiment." Atmospheric Chemistry and Physics 7.3 (2007): 739-755.

Sjögren, Erik. Moss vegetation in deciduous woods on the island of Bornholm (Denmark). 1970.

Skeffington, R. A., and Emma J. Wilson. "Excess nitrogen deposition: issues for consideration." Environmental Pollution 54.3-4 (1988): 159-184.

Skre, O., W. C. Oechel, and P. M. Miller. "Moss leaf water content and solar radiation at the moss surface in a mature black spruce forest in central Alaska." Canadian Journal of Forest Research 13.5 (1983): 860-868.

Slate, Mandy L., Todd N. Rosenstiel, and Sarah M. Eppley. "Sex-specific morphological and physiological differences in the moss Ceratodon purpureus (Dicranales)." Annals of Botany 120.5 (2017): 845-854

Smith, G. L. "Continental drift and the distribution of Polytrichaceae." Hattori Bot Lab J (1972).

Smith, John Maynard, and John Maynard-Smith. The evolution of sex. No. 574.1 S5. Cambridge: Cambridge University Press, 1978.

Smithwick, Erica AH, et al. "Root stress and nitrogen deposition: consequences and research priorities." New Phytologist 197.3 (2013): 712-719.

Snedecor, George W., and Witiiam G. Cochran. "Statistical methods, 8thEdn." Ames: Iowa State Univ. Press Iowa (1989).

Sohlberg, E. H., and L. C. Bliss. "Responses of Ranunculus sabinei and Papaver radicatum to removal of the moss layer in a high-arctic meadow." Canadian Journal of Botany 65.6 (1987): 1224-1228.

Soler, Catherine, et al. "Geographic variation of floral scent in a highly specialized pollination mutualism." Phytochemistry72.1 (2011): 74-81. 
Solga, A., et al. "Nitrogen content, $15 \mathrm{~N}$ natural abundance and biomass of the two pleurocarpous mosses Pleurozium schreberi (Brid.) Mitt. and Scleropodium purum (Hedw.) Limpr. in relation to atmospheric nitrogen deposition." Environmental Pollution 134.3 (2005): 465-473.

Solga, A., and J-P. Frahm. "Nitrogen accumulation by six pleurocarpous moss species and their suitability for monitoring nitrogen deposition." Journal of Bryology 28.1 (2006): 46-52.

Song, Liang, et al. "Organic nitrogen uptake is a significant contributor to nitrogen economy of subtropical epiphytic bryophytes." Scientific reports 6 (2016): 30408.

Song, Lei, et al. "Effects of three years of simulated nitrogen deposition on soil nitrogen dynamics and greenhouse gas emissions in a Korean pine Plantation of northeast China." Science of the Total Environment 609 (2017): 1303-1311.

Souri, Amir H., et al. "First Top-Down Estimates of Anthropogenic NOx Emissions Using High-Resolution Airborne Remote Sensing Observations." Journal of Geophysical Research: Atmospheres 123.6 (2018): 3269-3284.

Southon, Georgina E., et al. "Nitrogen deposition reduces plant diversity and alters ecosystem functioning: field-scale evidence from a nationwide survey of UK heathlands." PLoS one 8.4 (2013): e59031.

Stark, Lloyd R., Brent D. Mishler, and D. Nicholas McLetchie. "The cost of realized sexual reproduction: assessing patterns of reproductive allocation and sporophyte abortion in a desert moss." American Journal of Botany 87.11 (2000): 1599-1608.

Stark, Lloyd, Nicholas McLetchie, and Brent Mishler. "Sex expression and sex dimorphism in sporophytic populations of the desert moss Syntrichia caninervis." Plant ecology 157.2 (2001): 183-196.

Stark LR. Phenology and its repercussions on the reproductive ecology of mosses, The Bryologist, 2002, vol. 105 (pg. 204-218)

Stark, Lloyd R., D. Nicholas McLetchie, and Brent D. Mishler. "Sex expression, plant size, and spatial segregation of the sexes across a stress gradient in the desert moss Syntrichia caninervis." The Bryologist 108.2 (2005): 183-193.

Stark, Lloyd R., John C. Brinda, and D. Nicholas McLetchie. "An experimental demonstration of the cost of sex and a potential resource limitation on reproduction in the moss Pterygoneurum (Pottiaceae)." American Journal of Botany 96.9 (2009): 1712-1721. 
Stark, Lloyd R., D. Nicholas McLetchie, and Sarah M. Eppley. "Sex ratios and the shy male hypothesis in the moss Bryum argenteum (Bryaceae)." The Bryologist 113.4 (2010): 788-797.

Steer, B. T., et al. "Effects of nitrogen supply and population density on plant development and yield components of irrigated sunflower (Helianthus annuus L.)." Field Crops Research 13 (1986): 99-115.

Steinbrecher, Rainer, et al. "Intra-and inter-annual variability of VOC emissions from natural and semi-natural vegetation in Europe and neighbouring countries." Atmospheric Environment 43.7 (2009): 1380-1391.

Stenøien, Hans Kristen, and Sigurd M. Såstad. "Genetic variability in bryophytes: does mating system really matter?" Journal of Bryology 23.4 (2001): 313-318.

Stenøien, Hans K. "Adaptive basis of codon usage in the haploid moss Physcomitrella patens." Heredity 94.1 (2005): 87.

Stevens, Carly J., et al. "Impact of nitrogen deposition on the species richness of grasslands." Science 303.5665 (2004): 1876-1879.

Stevens, Carly J., Thomas I. David, and Jonathan Storkey. "Atmospheric nitrogen deposition in terrestrial ecosystems: Its impact on plant communities and consequences across trophic levels." Functional Ecology (2018).

Stotzky, Guenther, Susan Schenck, and George C. Papavizas. "Volatile organic compounds and microorganisms." CRC critical reviews in microbiology 4.4 (1976): 333-382.

Stuber, Stephanie. "The world of mosses." Arnoldia 71.1 (2013): 26-35.

Sveinbjörnsson, Bjartmar, and Walter C. Oechel. "Controls on CO 2 Exchange in Two Polytrichum Moss Species. 1. Field Studies on the Tundra near Barrow, Alaska." Oikos (1981): 114-128.

Svensson, Brita M. "Competition between Sphagnum fuscum and Drosera rotundifolia: a case of ecosystem engineering." Oikos (1995): 205-212.

Taboada, Angela, et al. "Plant and vegetation functional responses to cumulative high nitrogen deposition in rear-edge heathlands." Science of the Total Environment 637 (2018): 980-990.

Tegen, Ina, and Kerstin Schepanski. "Climate feedback on aerosol emission and atmospheric concentrations." Current Climate Change Reports 4.1 (2018): 1-10. 
Teixeira, C. V., A. B. Caldeira, and M. J. Colaço. "analyses of NOx emissions and specific fuel consumption of a diesel engine operating with diesel/biodiesel blends." RETERM-Thermal Engineering 12.1 (2018): 11-16.

Terry, G. M., et al. "Exposure to isoprene promotes flowering in plants." Journal of experimental Botany 46.10 (1995): 1629-1631.

Tharammal, Thejna, et al. "Potential roles of CO 2 fertilization, nitrogen deposition, climate change, and land use and land cover change on the global terrestrial carbon uptake in the twenty-first century." Climate Dynamics (2018): 1-14.

Thomas, Robert J., Edwin M. Schiele, and Daniel C. Scheirer. "Translocation in Polytrichum commune (Bryophyta) I. Conduction and allocation of photoassimilates." American Journal of Botany 75.2 (1988): 275-281.

Thomas, Robert J., Edwin M. Schiele, and Douglas T. Damberg. "Translocation in Polytrichum commune (Bryophyta). II. Clonal integration." American Journal of Botany 77.12 (1990): 1569-1573.

Thomas, Robert J., et al. "Photosynthetic function of leaf lamellae in Polytrichum commune." Bryologist (1996): 6-11.

Tiiva, Päivi, et al. "Isoprene emission from a subarctic peatland under enhanced UV-B radiation." New Phytologist 176.2 (2007a): 346-355.

Tiiva, Päivi, et al. "Isoprene emissions from boreal peatland microcosms; effects of elevated ozone concentration in an open field experiment." Atmospheric Environment 41.18 (2007b): 3819-3828.

Tiiva, Päivi, et al. "Contribution of vegetation and water table on isoprene emission from boreal peatland microcosms." Atmospheric Environment 43.34 (2009): 54695475.

Tingey, David T., et al. "The influence of light and temperature on isoprene emission rates from live oak." Physiologia Plantarum 47.2 (1979): 112-118.

Townsend, A. R., et al. "Spatial and temporal patterns in terrestrial carbon storage due to deposition of fossil fuel nitrogen." Ecological applications 6.3 (1996): 806-814.

Trachtenberg, S., and E. Zamski. "Conduction of ionic solutes and assimilates in the leptom of Polytrichum juniperinum Willd." Journal of Experimental Botany (1978): 719-727. 
Trapp, Susan C., and Rodney B. Croteau. "Genomic organization of plant terpene synthases and molecular evolutionary implications." Genetics 158.2 (2001): 811832.

Trowbridge, Amy M., and Paul C. Stoy. "BVOC-mediated plant-herbivore interactions." Biology, controls and models of tree volatile organic compound emissions. Springer, Dordrecht, 2013. 21-46.

Tuazon, Ernesto C., and Roger Atkinson. "A product study of the gas-phase reaction of isoprene with the $\mathrm{OH}$ radical in the presence of NOx." International Journal of Chemical Kinetics 22.12 (1990): 1221-1236.

Tuba, Zoltan, Zsolt Csintalan, and Michael CF Proctor. "Photosynthetic responses of a moss, Tortula ruralis, ssp. ruralis, and the lichens Cladonia convoluta and $C$. furcata to water deficit and short periods of desiccation, and their ecophysiological significance: a baseline study at present-day $\mathrm{CO} 2$ concentration." New Phytologist 133.2 (1996):353-361.

Tuba, Zoltán, Nancy G. Slack, and Lloyd R. Stark, eds. Bryophyte ecology and climate change. Cambridge University Press, 2011.

Turetsky, Merritt R. "The role of bryophytes in carbon and nitrogen cycling." The Bryologist 106.3 (2003): 395-409.

Turetsky, Merritt R., et al. "The resilience and functional role of moss in boreal and arctic ecosystems." New Phytologist 196.1 (2012): 49-67.

Unda, Faride, et al. "Altering carbon allocation in hybrid poplar (Populus albax grandidentata) impacts cell wall growth and development." Plant biotechnology journal 15.7 (2017): 865-878.

Unger, N., et al. "Photosynthesis-dependent isoprene emission from leaf to planet in a global carbon-chemistry-climate model." Atmospheric Chemistry and Physics 13.20 (2013): 10243-10269.

Unsicker, Sybille B., Grit Kunert, and Jonathan Gershenzon. "Protective perfumes: the role of vegetative volatiles in plant defense against herbivores." Current opinion in plant biology 12.4 (2009): 479-485.

Ussiri, David AN, and Rattan Lal. "Introduction to Global Carbon Cycling: An Overview of the Global Carbon Cycle." Carbon Sequestration for Climate Change Mitigation and Adaptation. Springer, Cham, 2017. 61-76. 
Vamosi, J. C., S. P. Otto, and Spencer CH Barrett. "Phylogenetic analysis of the ecological correlates of dioecy in angiosperms." Journal of evolutionary biology 16.5 (2003): 1006-1018.

Van der Velde, Marco. Genetic structure of the moss genus Polytrichum. Rijksuniversiteit Groningen, 2000.

Van der Velde, M., et al. "The reproductive biology of Polytrichum formosum: clonal structure and paternity revealed by microsatellites." Molecular ecology 10.10 (2001): 2423-2434.

Van Der Velde, Marco, and R. Bijlsma. "Phylogeography of five Polytrichum species within Europe." Biological Journal of the Linnean Society 78.2 (2003): 203-213.

Van der Wal, Rene, Imogen SK Pearce, and Rob W. Brooker. "Mosses and the struggle for light in a nitrogen-polluted world." Oecologia 142.2 (2005): 159-168.

Van Ginkel, C. G., H. G. J. Welten, and J. A. M. De Bont. "Oxidation of gaseous and volatile hydrocarbons by selected alkene-utilizing bacteria." Applied and environmental microbiology 53.12 (1987): 2903-2907.

Van Jaarsveld, E. R. N. S. T. "Cultivation of South African and Namibian cliff-dwelling succulents with pendent growth forms." Cactus and Succulent Journal 78.6 (2006): 268-283.

Van Meeningen, Ylva, et al. "Isoprenoid emission response to changing light conditions of English oak, European beech and Norway spruce." Biogeosciences 14.18 (2017): 4045.

Vanderpoorten, Alain, and Patrick Engels. "The effects of environmental variation on bryophytes at a regional scale." Ecography 25.5 (2002): 513-522.

Varela, Z., et al. "On the use of epigaeic mosses to biomonitor atmospheric deposition of nitrogen." Archives of environmental contamination and toxicology 64.4 (2013): $562-572$.

Velikova, Violeta, Aglika Edreva, and Francesco Loreto. "Endogenous isoprene protects Phragmites australis leaves against singlet oxygen." Physiologia Plantarum 122.2 (2004): 219-225.

Velikova, V., and F. Loreto. "On the relationship between isoprene emission and thermotolerance in Phragmites australis leaves exposed to high temperatures and during the recovery from a heat stress." Plant, Cell \& Environment 28.3 (2005): 318-327. 
Velikova, Violeta, Silvano Fares, and Francesco Loreto. "Isoprene and nitric oxide reduce damages in leaves exposed to oxidative stress." Plant, Cell \& Environment 31.12 (2008): 1882-1894.

Velikova, Violeta, et al. "Increased thermostability of thylakoid membranes in isopreneemitting leaves probed with three biophysical techniques." Plant Physiology (2011): pp-111.

Velikova, Violeta, Thomas D. Sharkey, and Francesco Loreto. "Stabilization of thylakoid membranes in isoprene-emitting plants reduces formation of reactive oxygen species." Plant Signaling \& Behavior 7.1 (2012): 139-141.

Velikova, Violeta, et al. "Genetic manipulation of isoprene emissions in poplar plants remodels the chloroplast proteome." Journal of Proteome Research 13.4 (2014): 2005-2018.

Velikova, Violeta, et al. "Physiological significance of isoprenoids and phenylpropanoids in drought response of Arundinoideae species with contrasting habitats and metabolism." Plant, Cell \& Environment 39.10 (2016): 2185-2197.

Vickers, Claudia E., et al. "A unified mechanism of action for volatile isoprenoids in plant abiotic stress." Nature chemical biology 5.5 (2009): 283.

Vickers, Claudia E., et al. "Isoprene synthesis protects transgenic tobacco plants from oxidative stress." Plant, Cell \& Environment 32.5 (2009): 520-531.

Vickers, Claudia E., et al. "Genetic structure and regulation of isoprene synthase in Poplar (Populus spp.)." Plant molecular biology 73.4-5 (2010): 547-558.

Vitousek, Peter M., et al. "Human alteration of the global nitrogen cycle: sources and consequences." Ecological applications 7.3 (1997): 737-750.

Vos, J., P. E. L. Van Der Putten, and C. J. Birch. "Effect of nitrogen supply on leaf appearance, leaf growth, leaf nitrogen economy and photosynthetic capacity in maize (Zea mays L.)." Field Crops Research 93.1 (2005): 64-73.

Wagner, Sebastian, et al. "Altitudinal changes in temperature responses of net photosynthesis and dark respiration in tropical bryophytes." Annals of Botany 111.3 (2012): 455-465.

Waite, Mashuri, and Lawren Sack. "How does moss photosynthesis relate to leaf and canopy structure? Trait relationships for 10 Hawaiian species of contrasting light habitats." New Phytologist 185.1 (2010): 156-172. 
Walker, Marilyn D., et al. "Plant community responses to experimental warming across the tundra biome." Proceedings of the National Academy of Sciences 103.5 (2006): 1342-1346.

Wang CY, Liu J, Xiao HG, Du DL. Response of leaf functional traits of Cerasus yedoensis (Mats.) Yü li to serious insect attack. Pol. J. Environ. Stud. 2016; 25: 333-339.

Wang, Xiaoqin, and Yikun He. "Tissue culturing and harvesting of protonemata from the moss Physcomitrella patens." Bio-protocol 5.15 (2015): e1556.

Ward, Max. "Callus tissues from the mosses Polytrichum and Atrichum." Science 132.3437 (1960): 1401-1402.

Warren, Charles R., Mark A. Adams, and ZuLiang Chen. "Is photosynthesis related to concentrations of nitrogen and Rubisco in leaves of Australian native plants?." Functional Plant Biology 27.5 (2000): 407-416.

Waters, Elizabeth R., Garrett J. Lee, and Elizabeth Vierling. "Evolution, structure and function of the small heat shock proteins in plants." Journal of Experimental Botany 47.3 (1996): 325-338.

Watson, M. A. "Age structure and mortality within a group of closely related mosses." Ecology 60.5 (1979): 988-997.

Watson, Maxine A. "Chemically mediated interactions among juvenile mosses as possible determinants of their community structure." Journal of Chemical Ecology 7.2 (1981): 367-376.

Weber, M. G., and K. van Cleve. "Nitrogen transformations in feather moss and forest floor layers of interior Alaska black spruce ecosystems." Canadian Journal of Forest Research14.2 (1984): 278-290.

Wei, Dandan, et al. "Environmental and biological controls on seasonal patterns of isoprene above a rain forest in central Amazonia." Agricultural and Forest Meteorology 256 (2018): 391-406

Wells, J. M., and D. H. Brown. "Ionic control of intracellular and extracellular Cd uptake by the moss Rhytidiadelphus squarrosus (Hedw.) Warnst." New Phytologist 116.3 (1990): 541-553.

Wiberley, Amy E., et al. "Development of the capacity for isoprene emission in kudzu." Plant, Cell \& Environment 28.7 (2005): 898-905 
Widory, David. "Nitrogen isotopes: Tracers of origin and processes affecting PM10 in the atmosphere of Paris." Atmospheric Environment 41.11 (2007): 2382-2390.

Wiedermann, Magdalena M., et al. "Ecophysiological adjustment of two Sphagnum species in response to anthropogenic nitrogen deposition." New Phytologist 181.1 (2009): 208-217.

Wigglesworth, G. "Reproduction in Polytrichum commune L. and the significance of the rhizoid system." Transactions of the British Bryological Society 1.1 (1947): 4-13.

Wildermuth, Mary C., and Ray Fall. "Light-dependent isoprene emission (characterization of a thylakoid-bound isoprene synthase in Salix discolor chloroplasts)." Plant Physiology 112.1 (1996): 171-182.

Wilkinson, C. E., M. D. Hocking, and T. E. Reimchen. "Uptake of salmon-derived nitrogen by mosses and liverworts in coastal British Columbia." Oikos 108.1 (2005): 85-98.

Williams, B. L., and D. J. Silcock. "Nutrient and microbial changes in the peat profile beneath Sphagnum magellanicum in response to additions of ammonium nitrate." Journal of Applied Ecology (1997): 961-970.

Wilson, Daniel, W. D. Stock, and Terry Hedderson. "Historical nitrogen content of bryophyte tissue as an indicator of increased nitrogen deposition in the Cape Metropolitan Area, South Africa." Environmental Pollution 157.3 (2009): 938945.

Wilson, James, et al. "Bio-production of gaseous alkenes: ethylene, isoprene, isobutene." Biotechnology for Biofuels 11.1 (2018): 234.

Wilson, Pamela J., and Jim Provan. "Effect of habitat fragmentation on levels and patterns of genetic diversity in natural populations of the peat moss Polytrichum commune." Proceedings of the Royal Society of London B: Biological Sciences 270.1517 (2003): 881-886.

Wolf, Amelia A., Erika S. Zavaleta, and Paul C. Selmants. "Flowering phenology shifts in response to biodiversity loss." Proceedings of the National Academy of Sciences (2017): 201608357.

Wood, Andrew J., Melvin J. Oliver, and David J. Cove. "Bryophytes as model systems." The Bryologist 103.1 (2000): 128-133. 
Woodward, F. I. "Do plants really need stomata?." Journal of Experimental Botany (1998): 471-480.

Xia, Mengxue, Alan F. Talhelm, and Kurt S. Pregitzer. "Long-term simulated atmospheric nitrogen deposition alters leaf and fine root decomposition." Ecosystems 21.1 (2018): 1-14.

Xiao HG, Wang CY, Liu J, Wang L, Du D L. Insights into the differences in leaf functional traits of heterophyllous Syringa oblata under different light intensities. J. For. Res. 2015; 26: 613-621.

Xing, Yangping, et al. "The fate of $15 \mathrm{~N}$-nitrate in a northern peatland impacted by long term experimental nitrogen, phosphorus and potassium fertilization." Biogeochemistry 103.1-3 (2011): 281-296.

Xiong, Dongliang, et al. "Leaf density explains variation in leaf mass per area in rice between cultivars and nitrogen treatments." Annals of Botany 117.6 (2016): 963971.

$\mathrm{Xu}$, Wen, et al. "Atmospheric nitrogen deposition in the Yangtze River basin: spatial pattern and source attribution." Environmental Pollution 232 (2018): 546-555.

$\mathrm{Yu}$, Haofei, et al. "Airborne measurements of isoprene and monoterpene emissions from southeastern US forests." Science of the Total Environment 595 (2017): 149-158.

Yuan, W., et al. "Spray, ignition, and combustion modeling of biodiesel fuels for investigating NOx emissions." Transactions of the ASAE 48.3 (2005): 933-939.

Yumol, Lauren. "Response of Polytrichum strictum Plants to Regional Warming of the Antarctic Peninsula Using Geochemistry of Peat and Modern and Fossil Plants." (2016).

Zar, Jerrold H. Biostatistical analyses: Pearson new international edition. Pearson Higher Ed, 2013.

Zechmeister, Harald G., et al. "Total nitrogen content and $\delta 15 \mathrm{~N}$ sigNatures in moss tissue: indicative value for nitrogen deposition patterns and source allocation on a nationwide scale." Environmental Science \& technology 42.23 (2008): 86618667.

Zhang, Lin, et al. "Nitrogen deposition to the United States: distribution, sources, and processes." (2012). 
Zhang, Yang, et al. "Role of isoprene in secondary organic aerosol formation on a regional scale." Journal of Geophysical Research: Atmospheres 112.D20 (2007).

Zhao, D. F., et al. "Environmental conditions regulate the impact of plants on cloud formation." Nature communications 8 (2017): 14067.

Zhao, Wenqian, et al. "Development of a method for protonema proliferation of peat moss (Sphagnum squarrosum) through regeneration analyses." New Phytologist (2018).

Zheng, Shuai, et al. "Effect of nitrogen and acid deposition on soil respiration in a temperate forest in China." Geoderma 329 (2018): 82-90.

Zheng, Yiqi, et al. "Drought impacts on photosynthesis, isoprene emission and atmospheric formaldehyde in a mid-latitude forest." Atmospheric Environment 167 (2017): 190-201.

Ziemann, Paul J., and Roger Atkinson. "Kinetics, products, and mechanisms of secondary organic aerosol formation." Chemical Society Reviews 41.19 (2012): 6582-6605.

Zimmerman, Patrick R., et al. "Estimates on the production of $\mathrm{CO}$ and $\mathrm{H} 2$ from the oxidation of hydrocarbon emissions from vegetation." Geophysical Research Letters 5.8 (1978): 679-682.

Zimmerman, Patrick R. "Testing of hydrocarbon emissions from vegetation, leaf litter and aquatic surfaces, and development of a methodology for compiling biogenic emission inventories." (1979).

Zimmerman, Jess K. "Ecological correlates of labile sex expression in the orchid Catasetum viridiflavum." Ecology 72.2 (1991): 597-608.

Zotz, Gerhard, and Herbert Kahler. "A moss "canopy"-Small-scale differences in microclimate and physiological traits in Tortula ruralis." Flora-Morphology, Distribution, Functional Ecology of Plants 202.8 (2007): 661-666

Zouhair, Rachid, et al. "RAPD markers for genetic differentiation of species within Polytrichum (Polytrichaceae, Musci): a preliminary survey." Taxon (2000): 217229. 